\title{
Architecture of Memory
}

\author{
By \\ Zohra Akbari \\ Bachelor of Architectural Science, Ryerson University, Toronto, 2012 \\ A thesis \\ presented to Ryerson University \\ in partial fulfillment of the \\ requirements for the degree of \\ Master of Architecture \\ in the Program of \\ Architecture \\ Toronto, Ontario, Canada, 2017 \\ (C) Zohra Akbari 2017
}





\section{Author's Declaration}

I hereby declare that I am the sole author of this thesis. This is a true copy of the thesis, including any required final revisions, as accepted by my examiners.

I authorize Ryerson University to lend this thesis to other institutions or individuals for the purpose of scholarly research.

I further authorize Ryerson University to reproduce this thesis by photocopying or by other means, in total or in part, at the request of other institutions or individuals for the purpose of scholarly research.

I understand that my thesis may be made electronically available to the public. 
Architecture of Memory

Zohra Akbari

Master of Architecture

Ryerson University, 2017

\section{Abstract}

Buildings and city forms are restructured and reused through time in response to evolving contexts, with each successive change leaving traces of the past that accumulate as layers. Collective knowledge and memory are strongly tied to these artifacts, which provide the depth and continuity necessary for the affirmation of identity.

Dramatic changes in the contemporary city have prompted a reconsideration of the way architecture adapts, and highlights the need for a creative approach to change and advancement. A successful approach would meaningfully engage the past and memory to record and transmit vital aspects of culture and history while simultaneously using them to inform future actions.

The palimpsest as an evolving record provides a productive framework for this kind of transformation, and uncovers the tangible and intangible layers of a site to protect and project the future layers. 


\section{Acknowledgements}

The completion of this work is indebted to the following:

Dr. June Komisar (thesis supervisor)

whose support, guidance, and commitment played an instrumental part in the completion of this thesis. This thesis was very much a process of discovery, and I am forever grateful for instilling the confidence that allowed me to explore and make this my own.

Scott Sørli (second reader) and Dr. Leila Farah (program representative), for their invaluable and constructive suggestions at various stages.

My MArch cohort,

for their enthusiasm and good laughs.

My family,

for their unfailing support and continuous encouragement.

And finally, Calvin Fung,

for the countless conversations and continuous dedication to push the boundaries of this thesis. 


\section{Table of Contents}

Author's Declaration

Abstract $\quad$ v

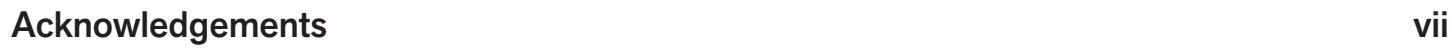

Table of Contents viii

List of Figures $\quad$ x

List of Appendices $\quad$ xxV

$\begin{array}{lr}\text { 1. Introduction } & 1\end{array}$

$\begin{array}{ll}\text { The Contemporary City } & 4\end{array}$

$\begin{array}{lr}\text { 2. Memory } & 7\end{array}$

Collective Memory/ Memory and Society

$\begin{array}{lr}\text { Memory and Images } & 9\end{array}$

$\begin{array}{lr}\text { Memory and the City } & 9\end{array}$

$\begin{array}{ll}\text { Memory and Places } & 10\end{array}$

Memory and Transformation $\quad 11$

$\begin{array}{lr}\text { 3. Palimpsest } & 13\end{array}$

$\begin{array}{ll}\text { Palimpsest and Memory } & 14\end{array}$

$\begin{array}{ll}\text { Palimpsest Metaphor } & 15\end{array}$

$\begin{array}{ll}\text { Palimpsest in Urbanism and Landscape } & 16\end{array}$

$\begin{array}{ll}\text { Medieval Times } & 17\end{array}$

$\begin{array}{ll}\text { Palimpsest in Architecture } & 19\end{array}$

$\begin{array}{lr}\text { Precedents } & 20\end{array}$ 
4. Design Research

Site 1.0

Book 1.0

Book 2.0

Creative Demolition

Superposition/ Superimposition

Bisecting Planes

Overlapping Planes

Transparency

40

Conclusions

41

5. Lieux de Memoire in Architecture

Site 2.0 Layers

Site Conclusions 66

LDM Explorations 71

6. Design Project

Program

Conclusions

7. Future Layers

Appendices

Bibliography 


\section{List of Figures}

Figure 1.1 St Mark's Basilica campanile collapse, 1902

Source: https://s-media-cache-ak0.pinimg.com/originals/c1/89/fa/c189fa46ba00285bcdfe46d857

07cc3b.jpg

Figure 1.2 St Mark's Basilica campanile, modern-day

Source: by author, October 2016

Figure 1.3 New York skyline pre 9/11, 1976

Source: https://qph.ec.quoracdn.net/main-qimg-0945f292db80dfb5212274fdf47eb4c3-c

Figure 1.4 New York skyline 9th anniversary of 9/11, 2010

source: https://media.npr.org/assets/img/2014/09/10/14024923_h11872161_wide-d2a24ba726 ee3fcb76cff895b6cb65db7dca5dcc.jpg?s=1400

Figure 1.5 Naiku Shrine reconstruction effort, Ise, Japan

Source: http://68.media.tumblr.com/18ca9a35a31e4f3f39ca9e9cc25f0515/tumblr_ nvr4ryHph61rOqg4mo1_1280.jpg

Figure 1.6 Naiku Shrine, most recently reconstructed in 2013

Source: http://storage0.dms.mpinteractiv.ro/media/401/321/5109/15579943/7/naiku-04.jpg

Figure 1.7 Photograph at Jarvis St and Dundas St. looking south illustrating the demolition of both eastern corners and a new development on the south-west corner Source: by author, February 2017

Figure 2.1 Illustrated Invisible City 'Zaira', Karina Puente Frantzen Source: http://images.adsttc.com/media/images/56a7/ee58/e58e/cebb/6800/002d/large_jpg/ ZAIRA.jpg?1453846078

Figure 3.1 Archimedes palimpsest containing mathematical text circa 1000 (copied from original text from 287-212 B.C) layered with Christian liturgical text circa 1200

Source: http://i2.wp.com/designandtime2016.co.uk/wp-content/uploads/2016/05/Panel-7a.jpg

Figure 3.2 Lucca Amphitheatre aerial at Piazza dell'Anfiteatro, modern day

Source: https://romanfootprints.files.wordpress.com/2016/03/44-lucca-amphitheatre-remains.jpg 
Figure 3.3 Amphitheatre of Arles drawing, Arles, France, 18th century

Source: https://upload.wikimedia.org/wikipedia/commons/0/08/ArlesGuibert.JPG

Figure 3.4 Cannaregio project, Peter Eisenman

Source: from http://images.adsttc.com/media/images/5237/cc9f/e8e4/4eee/a100/018a/

newsletter/The_Cannaregio_project_(1978).jpg?1379388568

Figure 3.5 Former power station prior to CaixaForum addition

Source: http://www.arcspace.com/CropUp/380x290/media/52566/5caixa.jpg

Figure 3.6 CaixaForum view from the abutting piazza

Source: https://static.dezeen.com/uploads/2008/05/squ0078587-421.jpg

Figure 3.7 Corkin Gallery looking towards main gallery area and the surfaced masonry walls

Source: https://s3.amazonaws.com/files.collageplatform.com.prod/image_cache/supersized_ big/557f2eb507a72cf448626700/0f114b7539273f629bbada149991eea1.jpeg

Figure 3.8 Corkin Gallery new steel base at existing timber columns

Source: by author, May 2017

Figure 3.9 SESC Pompeia view of large lounge and arterial pond

Source: https://s-media-cache-ak0.pinimg.com/736x/67/d4/cd/67d4cd174bc2a639ab45204642

382d74.jpg

Figure 3.10 SESC Pompeia view of complex looking towards sports complex towers

Source: http://www.infoartsp.com.br/imgs/8502b682ea.jpg

Figure 3.11 Castelvecchio Museum view towards the space for the Cangrande statue from the courtyard, the 12th century Roman commune wall on the left and former 18th century Napoleonic barracks on the right

Source: by author, October 2016

Figure 3.12 Castelvecchio Museum space for the Cangrande statue

Source: by author, October 2016

Figure 3.13 Kolumba Museum view at modern day 'excavation area' layered with new winding passage Source http://images.adsttc.com/media/images/55f8/0533/d4f7/b715/c900/00f6/slideshow/25custom.jpg?1442317613

Figure 3.14 Pinacoteca view of bridge crossing

Source: http://img.estadao.com.br/thumbs/620/resources/jpg/8/8/1438192199188.jpg

Figure 3.15 Corkin Gallery view from second level bridge overlooking masonry walls

Source: by author, May 2017

Figure 3.16 Castelvecchio Museum Cangrande space as seen from commune wall 
Figure 3.17 Kolumba Museum perforated brick

Source: http://1.bp.blogspot.com/-6JWRfuei1W4/T5Okvloqicl/AAAAAAAARL8/xufwbXzOif4/

s1600/Kolumba_Peter_Zumthor_Photographer_Michiel_van_Raaij_3_S\%2Bcopy.jpg

Figure 3.18 Kolumba Museum outdoor courtyard

Source: http://iloboyou.com/wp-content/uploads/2015/01/Kolumba_K\%C3\%B6ln_-_Innenhof_ 2.jpg

Figure 3.19 Pinacoteca new glass ceiling above courtyards

Source: http://www.galeriadaarquitetura.com.br/lmg/projeto/SF1/3010/pinacoteca-de-sao-paulo 1017.jpg

Figure 3.20 SESC Pompeia view at lounge entrance

Source: https://c1.staticflickr.com/4/3845/14535979289_03df6d3939_b.jpg

Figure 3.21 Kolumba Museum exterior view close-up

Source: https://s-media-cache-ak0.pinimg.com/originals/f5/5f/26/f55f267bbe22f1 b94526b5f0fc6 38d67.jpg

Figure 3.22 CaixaForum's aerial view of hipped roof-scape

Source: https://www.iconeye.com/images/2014/04/caixa1.jpg

Figure 3.23 SESC Pompeia concrete water tower

Source: http://linabobarditogether.com/wp-content/uploads/2012/12/07_SESC_marcelo_ ferraz.png

Figure 3.24 SESC Pompeia concrete reading pods next to large lounge

Source: https://c2.staticflickr.com/4/3090/2507282834_b9ac20fba5_b.jpg

Figure 4.1 Book 1.0 design exploration

Source: by author

Figure 4.2 Book 2.0 design exploration

Source: by author

Figure 4.3 Bisecting Planes design exploration

Source: by author

Figure 4.4 Overlapping planes design exploration

Source: by author

Figure 5.1 Site 2.0 Location Map, 2016 
Figure 5.2 St. Andrew's Hall, 1907

Source: http://www.billgladstone.ca/wp-content/uploads/2012/08/StAndrews-Police-Station1.jpg

Figure 5.3 St Andrew's Hall West elevation, 1908

Source: City of Toronto Archives, Fonds 200, Series 2277, Item 136

Figure 5.4 St Andrew's Hall ground floor plan, 1908

Source: City of Toronto Archives, Fonds 200, Series 2277, Item 138

Figure 5.5 St. Andrews Market Annex Building, 1921

Source: City of Toronto archives, Fonds 1244, Item 299

Figure 5.6 St. Andrew's West Annex Building West elevation, 1908

Source: City of Toronto archives, Fonds 200, Series 2277, Item 139

Figure 5.7 St. Andrew's Market Annex Building ground floor plan, 1908

Source: City of Toronto archives, Fonds 200, Series 2277, Item 140

Figure 5.8 St. Andrew's Playground swing set, 1914

Source: City of Toronto Archives, Series 372, s0372_ss0052_it0196

Figure 5.9 St. Andrew's playground map, 1924

Source: City of Toronto Archives, Fonds 200, Series 724, Item 125B

Figure 5.10 St. Andrew's Playground maypole dancing, 1914

Source: City of Toronto Archives, Series 372, s0372_ss0052_it0424F

Figure 5.11 St. Andrew's Market demolition, 1932

Source: City of Toronto Archives, Fonds 200, Series 372, Subseries 1, Item 1075

Figure 5.12 Waterworks building inside machine shop, water maintenance machine, 1932

Source: City of Toronto Archives, Fonds 1266, Item 28204

Figure 5.13 Waterworks Building - sheet \# 2 First Floor Plan, 1932

Source: Diamond Schmitt Architects

Figure 5.14 Waterworks, 1936

Source: City of Toronto Archives, Fonds 200, Series 372, Subseries 1, Item 1412

Figure 5.15 Waterworks Program Diagram, 1932

Source: by author

Figure 5.16 St. Andrew's Playground looking north-west, 1974

Source: City of Toronto Archives, Fonds 200, Series 1465, File 755, Item 14

Figure 5.17 Waterworks at Brant Street looking north-west 
Source: by author, May 2017

Figure 5.19 Waterworks at Richmond and Brant Street looking south-west, 2012

Source: Calvin Fung

Figure 5.20 Waterworks at Richmond and Maud Street, 2012

Source: Calvin Fung

Figure 5.21 Waterworks 511 entrance

60

Source: by author, May 2017

Figure 5.22 Waterworks 511 entrance

60

Source: by author, May 2017

Figure 5.23 Waterworks 511 entrance

60

Source: by author, May 2017

Figure 5.24 Waterworks courtyard looking north-east, from left to right: 1-storey garage storage buildings, south hall building, garage building

Source: by author, May 2017

Figure 5.25 Waterworks view of courtyard looking north-west, from left to right: storage garages, south hall building, garage building, Richmond driveway, pattern storage building, 1-storey garage storage building/ Eva's Phoenix building

Source: by author, May 2017

Figure 5.26 Waterworks south hall loading area looking west towards Maud Street

62

Source: by author, May 2017

Figure 5.27 Waterworks south hall looking east towards Camden Street

Source: by author, May 2017

Figure 5.28 Waterworks wooden block flooring in the south hall

Source: http://waterworkstoronto.com/dev/wp-content/uploads/2015/12/waterworks-about_6.jpg

Figure 5.29 Photography of existing boilers at the Pit

Source: by author, January 2017

Figure 5.30 Waterworks rear facade at St. Andrew's Park looking north-west

Source: by author, May 2017

Figure 5.31St. Andrew's Park looking north-east, from left to right: off-leash dog area, children's playground, shaded seating area

Source: by author, May 2017 
Figure 5.32 St. Andrew's Park St Andrew's Park looking north, from left to right: children's playground, shaded seating area

Source: by author, May 2017

Figure 5.33Waterworks parking lot west of St. Andrew's Park

Source: by author, May 2017

Figure 5.34 Waterworks MyMarket at the rear parking lot, 2009

Source: Taylor, 2010, p. 44 by Sandy Kemsley

Figure 5.35 Waterworks photograph of Eva's Phoenix at Brant Street

Source: by author, May 2017

Figure 5.36 Waterworks Eva's Phoenix at central atrium space

Source: http://www.architecturalrecord.com/ext/resources/Issues/2017/February/building-typestudies/1702-Renovation-Restoration-Adaptation-LGA-Architectural-Partners-Toronto-Eva-Phoenix01.jpg

Figure 5.37 Proposed future development at 520 Richmond Street

Source: http://www.insidercondos.com/images/20104/Richmond-and-Augusta-Condo/Richmondand-Augusta-Condo-Rendering-2.jpg

Figure 5.38 Proposed future development at 51 Camden Street

Source: https://cdn.torontolife.com/wp-content/uploads/2015/08/ace-hotel-3.jpg

Figure 5.39 Proposed future development addition from Richmond Street

Source: http://media.blogto.com/uploads/2016/12/06/2016126-waterworks2.

jpg $\mathrm{h}=2500 \& \mathrm{cmd}=$ resize\&quality $=70 \& \mathrm{w}=1400$

Figure 5.40 Waterworks proposed development ground floor plan

Source: http://urbantoronto.ca/sites/default/files/imagecache/display-default/images/

articles/2016/11/23858/23858-82999.png

Figure 5.41 Proposed development program diagram

Source: http://media.blogto.com/uploads/2016/12/06/2016126-waterworks2.

jpg $\mathrm{h}=2500 \& \mathrm{cmd}=$ resize\&quality $=70 \& \mathrm{w}=1400$

Figure 5.42 1850- 1860 West Market Square tracing

Source: City of Toronto Archives, Fleming Ridout \& Schreiber, 1857, Series 88, Item 13; ERA

Architects, 2016, p. 5; modified by author

Figure 5.43 1850- 1860 West Market massing

Source: by author

Figure 5.44 1880- 1832 St. Andrew's Market \& Hall tracing

Source: City of Toronto Archives, Goads Fire Insurance Plan 1880, West of University Avenue, Plate 2;

ERA Architects, 2016, p. 5; modified by author 
Source: by author

Figure 5.46 1893- 1932 St. Andrew's Market Annex Building tracing

Source: City of Toronto Archives, Goads Fire Insurance Plan 1899, Central City, Plate; ERA Architects, 2016, p. 5; modified by author

Figure 5.47 1850-1893 massing overlay

Source: by author

Figure 5.48 1910- 1932 tracing

Source: City of Toronto Archives, Goads Fire Insurance Plan 1903, Central City, Plate; ERA Architects, 2016, p. 5; modified by author

Figure 5.49 1850- 1910 massing overlay

Source: by author

Figure 5.50 1932- present Waterworks building tracing

Source: City of Toronto Archives, Series 12, Aerial Photographs of the Metropolitan Toronto Area, 1947

Figure 5.51 1850- 1932 massing overlay

Source: by author

Figure 5.52 1850- 1932 massing overlay (large)

Source: by author

Figure 5.53 Matrix showing overlays of built form, (highest degree of overlay indicated in box)

Source: by author

Figure 5.54 Overlap of all programs since 1850

Source: by author

Figure 5.55 Collage 1

Source: by author

Figure 5.56 Collage 2

Source: by author

Figure 5.57 Collage 3

80

Source: by author

Figure 6.1 Proposed site plan

Source: by author

Figure 6.2 Proposed ground floor plan 
Figure 6.3 Proposed second floor

Source: by author

Figure 6.4 Section AA transparency

Source: by author

Figure 6.5 Section AA existing

Source: by author

Figure 6.6 Section AA proposed

Source: by author

Figure 6.7 Section BB transparency

Source: by author

Figure 6.8 Section BB existing

Source: by author

Figure 6.9 Section BB proposed

Source: by author

Figure 6.10 Section CC transparency

Source: by author

Figure 6.11 Section CC existing

Source: by author

Figure 6.12 Section CC proposed

Source: by author

Figure 6.13 Section DD transparency

Source: by author

Figure 6.14 Section DD existing

Source: by author

Figure 6.15 Section DD proposed

Source: by author

Figure 6.16 Proposed aerial view

Source: by author

Figure 6.17 Proposed view at St. Andrew's Park looking north

Source: by author

Figure 6.18 Proposed view at St. Andrew's Park entrance

Source: by author 
Figure 6.19 Proposed view at St. Andrew's Park entrance

Source: by author

Figure 6.20 Proposed Park Lobby looking North

Source: by author

Figure 6.21 Proposed Recreation space at track level looking West

Source: by author

Figure 6.22 Proposed Market looking East

Source: by author

Figure 6.23 Proposed bridges at Boiler Pit

Source: by author

Figure 6.24 Proposed chimney skylight at Boiler Pit

Source: by author

Figure 6.25 Proposed view at Central Square from theatre balcony looking north-east

Source: by author

Figure 6.26 Proposed view at central square looking west towards theatre

Source: by author

Figure 6.27 Proposed view inside theatre looking east towards central square

Source: by author

Figure 6.28 Proposed view of skylight balcony

Source: by author

Figure 6.29 Proposed view at central square's Richmond entrance looking south

Source: by author

Figure 6.30 Proposed view of new windows at Eva's Phoenix wall, east of the central square looking

Source: by author

Figure 6.31 Proposed view of Richmond Street entrance looking south-east

Source: by author

Figure 6.32 Proposed Richmond Street entrance revealed beams

Source: by author

Figure 8.1 Book 1.0 process images

Source: by author 
Figure 8.2 Book 1.0

Source: by author

Figure 8.3 Book 2.0 process images

Source: by author

Figure 8.4 Book 2.0

Source: by author

Figure 8.5 St. Andrew's Market West Elevation, 1908

Source: City of Toronto Archives, Fonds 200, Series 2277, Item 136

Figure 8.6 St. Andrew's Market North Elevation, 1908

Source: City of Toronto Archives, Fonds 200, Series 2277, Item 135

Figure 8.7 St. Andrew's Market Ground Floor Plan, 1908

Source: City of Toronto Archives, Fonds 200, Series 2277, Item 138

Figure 8.8 St. Andrew's Market Second Floor Plan, 1908

Source: City of Toronto Archives, Fonds 200, Series 2277, Item 137

Figure 8.9 St Andrew's Market Annex Building West Elevation, 1908

Source: City of Toronto Archives, Fonds 200, Series 2277, Item 139

Figure 8.10 St Andrew's Market Annex Building Ground Floor Plan, 1908

Source: City of Toronto Archives, Fonds 200, Series 2277, Item 140

Figure 8.11 St. Andrews Market Annex Building, 1931

Source: City of Toronto Archives, Fonds 1266, Item 26017

Figure 8.12 St. Andrews Market Annex Building, 1931

Source: City of Toronto Archives, Fonds 1266, Item 26018

Figure 8.13 St. Andrew's playground map, 1924

Source: City of Toronto Archives, Fonds 200, Series 724, Item 125B

Figure 8.14 St. Andrew's Playground swing set, 1913

Source: City of Toronto Archives, Fonds 200, Series 372, Subseries 52, Item 196

Figure 8.15 St. Andrew's Playground volleyball, 1914

Source: City of Toronto Archives, Fonds 200, Series 372, Subseries 52, Item 361

Figure 8.16 St. Andrew's Playground basketball, 1914

Source: City of Toronto Archives, Fonds 200, Series 372, Subseries 52, Item 422

Figure 8.17 St. Andrew's Playground basketball, 1914

Source: City of Toronto Archives, Fonds 200, Series 372, Subseries 52, Item 423 
Source: City of Toronto Archives, Fonds 200, Series 372, Subseries 52, Item 424

Figure 8.19 St. Andrew's Playground children, 1914

Source: City of Toronto Archives, Fonds 200, Series 372, Subseries 52, Item 425

Figure 8.20 St. Andrew's Playground exercises, 1914

Source: City of Toronto Archives, Fonds 200, Series 372, Subseries 52, Item 426

Figure 8.21 St. Andrew's Playground exercises, 1914

Source: City of Toronto Archives, Fonds 200, Series 372, Subseries 52, Item 427

Figure 8.22 St. Andrew's Playground games, 1914

Source: City of Toronto Archives, Fonds 200, Series 372, Subseries 52, Item 428

Figure 8.23 St. Andrew's Playground Maypole dancing, 1914

Source: City of Toronto Archives, Fonds 200, Series 372, Subseries 52, Item 429

Figure 8.24 St. Andrew's Playground Maypole dancing, 1914

Source: City of Toronto Archives, Fonds 200, Series 372, Subseries 52, Item 430

Figure 8.25 St. Andrew's Playground Maypole dancing, 1914

Source: City of Toronto Archives, Fonds 200, Series 372, Subseries 52, Item 431)

Figure 8.26 St. Andrew's Playground folk dancing, 1914

Source: City of Toronto Archives, Fonds 200, Series 372, Subseries 52, Item 432

Figure 8.27 St. Andrew's Playground team, 1914

Source: City of Toronto Archives, Fonds 200, Series 372, Subseries 52, Item 433

Figure 8.28 Playground in St. Andrew's Park looking west, 1991

Source: City of Toronto Archives, Fonds 200, Series 1465, File 682, Item 16

Figure 8.29 Playground in St. Andrew's Park, 1991

(Source: City of Toronto Archives, Fonds 200, Series 1465, File 682, Item 15

Figure 8.30 St. Andrew's Park looking north-west, 1991

Source: City of Toronto Archives, Fonds 200, Series 1465, File 682, Item 13

Figure 8.31 St. Andrew's Park looking north-west, 1991

Source: Cit y of Toronto Archives, Fonds 200, Series 1465, File 682, Item 14

Figure 8.32 Waterworks Building - sheet \# 1 Basement and Foundation Plan, 1932, J.J. Woolnough

Source: Diamond Schmitt Architects

Figure 8.33 Waterworks Building - sheet \# 2 First Floor Plan, 1932, J.J. Woolnough

Source: Diamond Schmitt Architects 
Figure 8.36 Waterworks Building - sheet \# 5 Richmond Street Elevations, Brant Street Elevation,

Sections DD to JJ, 1932, J.J. Woolnough

Source: Diamond Schmitt Architects

Figure 8.37 Waterworks Building - sheet \# 6 North Elevation of Garage, South Elevation of Courtyard,

Sections KK to MM, Section OO, 1932, J.J. Woolnough

Source: Diamond Schmitt Architects

Figure 8.38 Waterworks Building - sheet \# 7 South Elevation, Maud Street Elevation, Gates Details,

1932, J.J. Woolnough

Source: Diamond Schmitt Architects

Figure 8.39 Waterworks Building - sheet \# 8 Office Building Basement, First, Second, and Third Floor

Plans, 1932, J.J. Woolnough

Source: Diamond Schmitt Architects

Figure 8.40 Waterworks Building - sheet \# 9 Office Building North, South and West Elevations,

Sections AA to CC, Stair Detail, Vestibule Detail, 1932, J.J. Woolnough

Source: Diamond Schmitt Architects

Figure 8.41 Waterworks Building - sheet \# 10 Office Building Detail at Front Entrance, 1932,

J.J. Woolnough

Source: Diamond Schmitt Architects

Figure 8.42 Waterworks Building - sheet \# 11 Detail at Pattern Storage Entrance/ Driveway Entrance,

Details of steel rolling doors/ partitions and shower/ toilet partitions, 1932, J.J. Woolnough

Source: Diamond Schmitt Architects

Figure 8.43 Waterworks Building - sheet \# 12 Water Services and Drainage Plan, 1932, J.J. Woolnough

Source: Diamond Schmitt Architects

Figure 8.44 Waterworks Building - sheet \# 70 Basement and Foundation Heating Plan, 1932,

J.J. Woolnough

Source: Diamond Schmitt Architects

Figure 8.45 Waterworks Building - sheet \# 71 First Floor Heating Plan, 1932, J.J. Woolnough

Source: Diamond Schmitt Architects

Figure 8.46 Waterworks Building - sheet \# 72 Second Floor Heating Plan, 1932, J.J. Woolnough

Source: Diamond Schmitt Architects 
Source: Diamond Schmitt Architects

Figure 8.48 Waterworks Building - sheet \# 78 Third Floor and Roof Electrical Plan, 1932,

J.J. Woolnough

Source Diamond Schmitt Architects

Figure 8.49 St. Andrew's Market demolition, 1932

161

Source: City of Toronto Archives, Fonds 200, Series 372, Subseries 1, Item 1076

Figure 8.50 St. Andrew's Market demolition, 1932

161

Source: City of Toronto Archives, Fonds 200, Series 372, Subseries 1, Item 1077

Figure 8.51 Waterworks construction, 1932

Source: City of Toronto Archives, Fonds 200, Series 372, Subseries 1, Item 1112

Figure 8.52 Waterworks construction, 1932

Source: City of Toronto Archives, Fonds 200, Series 372, Subseries 1, Item 1111

Figure 8.53 Waterworks construction, 1932

Source: City of Toronto Archives, Fonds 200, Series 372, Subseries 1, Item 1115

Figure 8.54 Waterworks construction, 1932

161

Source: City of Toronto Archives, Fonds 200, Series 372, Subseries 1, Item 1116

Figure 8.55 Waterworks construction, 1932

Source: City of Toronto Archives, Fonds 200, Series 372, Subseries 1, Item 1117

Figure 8.56 Waterworks construction, 1932

Source: City of Toronto Archives, Fonds 200, Series 372, Subseries 1, Item 1118)

Figure 8.57 Waterworks construction, south-east corner, 1932

Source: ERA Architects, 2016, p. i \& City of Toronto Archives

Figure 8.58 Waterworks construction, south-west corner, 1932

Source: ERA Architects, 2016, p. 11 \& City of Toronto Archives

Figure 8.59 Waterworks construction, north-west corner, 1932

Source: ERA Architects, 2016, p. 11 \& City of Toronto Archives

Figure 8.60 Waterworks construction, north-east corner, 1932

Source: ERA Architects, 2016, p. 11 \& City of Toronto Archives

Figure 8.61 Waterworks Building - south-west corner, 1932

Source: City of Toronto Archives, Fonds 1266, Item 28205

Figure 8.62 Waterworks building - looking down driveway
Source: City of Toronto Archives, Fonds 1266, Item 28206 
Figure 8.63 Waterworks building - looking west from Richmond Street West, 195-

Source: City of Toronto Archives, Fonds 200, Series 372, Subseries 100, Item 737

Figure 8.64 Waterworks building - looking north from Adelaide Street West, 195-

Source: City of Toronto Archives, Fonds 200, Series 372, Subseries 100, Item 738

Figure 8.65 Waterworks building - looking south from corner of Richmond Street West and Maud

Street, between 1975 and 1983

(Source: City of Toronto Archives, Fonds 200, Series 1465, File 752, Item 3)

Figure 8.66 Waterworks Richmond Street elevation close-up

Source: by author, May 2017

Figure 8.67 Waterworks St. Andrew's Park elevation close-up

Source: by author, May 2017

Figure 8.68 Waterworks St. Maud Street driveway gate

Source: by author, May 2017

Figure 8.69 Waterworks view of courtyard from Richmond street driveway

Source: by author, May 2017

Figure 8.69 Waterworks view of courtyard from Richmond street driveway

Source: by author, May 2017

Figure 8.70 Waterworks south hall north facade close-up

Source: by author, May 2017

Figure 8.71 Waterworks Maud Street driveway

Source: by author, May 2017

Figure 8.72 Waterworks south hall looking east

Source: by author, May 2017

Figure 8.73 Waterworks south hall looking west

Source: by author, May 2017

Figure 8.74 Waterworks south hall looking east

Source: by author, May 2017

Figure 8.75 Waterworks south hall latticework bracing close-up

Source: by author, May 2017

Figure 8.76 Waterworks south hall looking south-east

Source: by author, May 2017

Figure 8.77 Waterworks south hall looking south-west 
Figure 8.79 St. Andrew's Park sheltered seating area

Source: by author, May 2017

Figure 8.80 St. Andrew's Park looking south-west

Source: by author, May 2017

Figure 8.81 St. Andrew's Park off-leash dog area

Source: by author, May 2017

Figure 8.82 St. Andrew's Park children's play equipment

Source: by author, May 2017

Figure 8.83 Waterworks office building rooftop playground

Source: by author, May 2017

Figure 8.84 Process sketches

Source: by author

Figure 8.85 Early process model

Source: by author

Figure 8.86 Early process model

Source: by author

Figure 8.87 Overlap of all forms all buildings on the site using string

Source: by author

Figure 8.88 Sectional model of axial connection (red indicates new), scale 1:200

Source: by author

Figure 8.89 Sectional model of St. Andrew's Park entrance and lobby area, scale 1:50

Source: by author 


\section{List of Appendices}

Appendix A

Site 1.0 Book Explorations

Appendix B

St. Andrew's Market \& Annex Drawing Set (1908) \& Archival Photographs

Appendix C

St Andrew's Playground map (1908) \& Archival Photographs

Appendix D

Waterworks Drawing Set (1932) \& Archival Photographs

Appendix E

Waterworks \& St. Andrew's Park Photographs (2017)

Appendix F

170

Site 2.0 Design Project Process Work, Models 

Architecture of Memory 



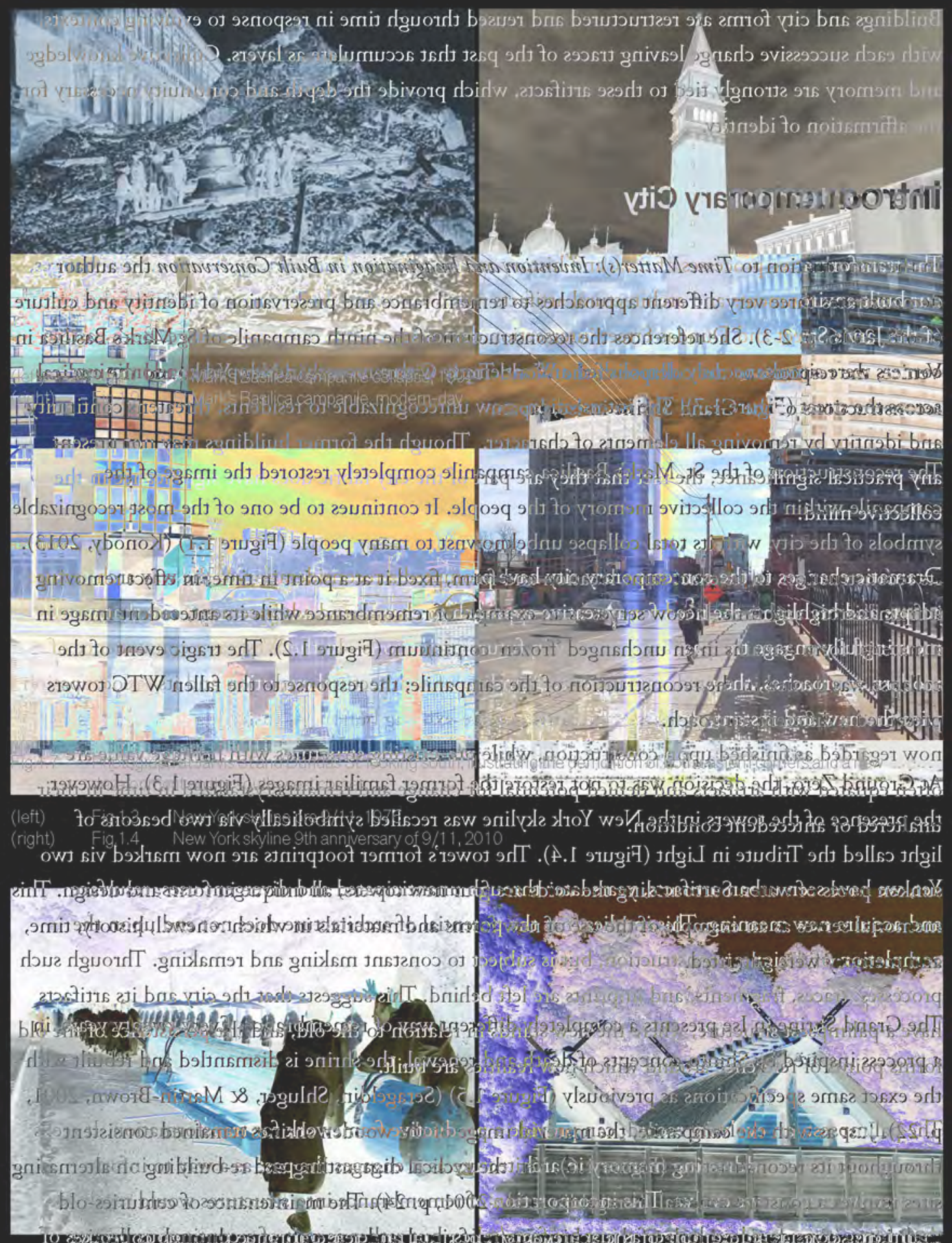

(left) Fig. 1.5 Naiku Shrine reconstruction effort, Ise, Japar
(1)

(left) Fig.1.6 Naiku Shrine, most recently reconstructed in 2013

Isymath: 


\section{Introduction}

In the introduction to Time Matter(s): Invention and Imagination in Built Conservation the author demonstrates three very different approaches to remembrance and preservation of identity and culture (Goffi, 2016, p. 2-3). She references the reconstruction of the ninth campanile of St Mark's Basilica in Venice, the response to the collapse of the World Trade Centre towers in New York, and the cyclical reconstructions of the Grand Shrine in Ise, Japan.

The reconstruction of the St. Mark's Basilica campanile completely restored the image of the campanile within the collective memory of the people. It continues to be one of the most recognizable symbols of the city, with its total collapse unbeknownst to many people (Figure 1.1) (Konody, 2013). Its reconstruction, in its exact same location and form, fixed it at a point in time, in effect removing it from history and time. It now serves as an example of remembrance while its antecedent image in a material form remains in an unchanged 'frozen' continuum (Figure 1.2). The tragic event of the collapse was denied in the reconstruction of the campanile; the response to the fallen WTC towers presented a different approach.

At Ground Zero, the decision was to not restore the former familiar images (Figure 1.3). However, the presence of the towers in the New York skyline was recalled symbolically via two beacons of light called the Tribute in Light (Figure 1.4). The tower's former footprints are now marked via two sunken pools of water. Surrounding the voids are four new towers, all unique in form and design. This memorial serves as an example of the use of new forms and materials in which renewal, history, time, and memory were admitted.

The Grand Shrine in Ise presents a completely different way of remembrance. Every twenty years, in a process inspired by Shinto concepts of death and renewal, the shrine is dismantled and rebuilt with the exact same specifications as previously (Figure 1.5) (Serageldin, Shluger, \& Martin-Brown, 2001, p. 22). Just as with the campanile, the material image of the wooden shrines remained consistent throughout its reconstruction (Figure 1.6). Yet, the cyclical dismantling and re-building on alternating sites implies a constant renewal (Serageldin et al., 2001, p. 24). The maintenance of centuries-old traditions serves as an example of the achievement of ritual and remembrance through collective effort. 

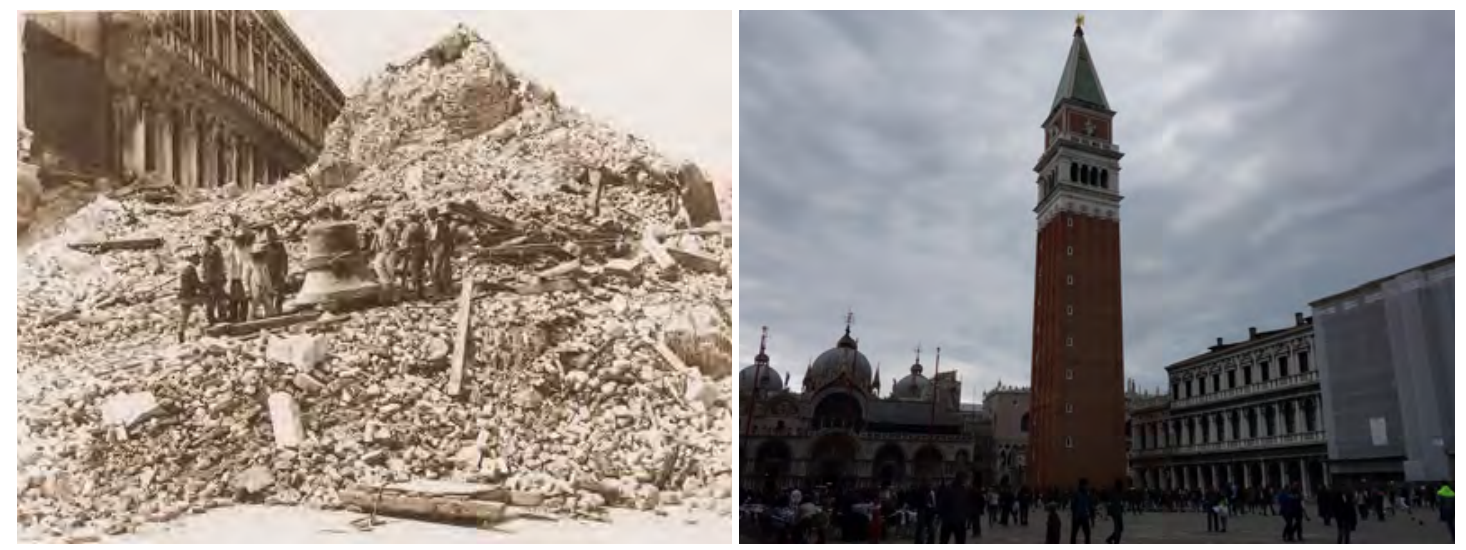

(left) Fig.1.1 St Mark's Basilica campanile collapse, 1902

(right) Fig.1.2 St Mark's Basilica campanile, modern-day
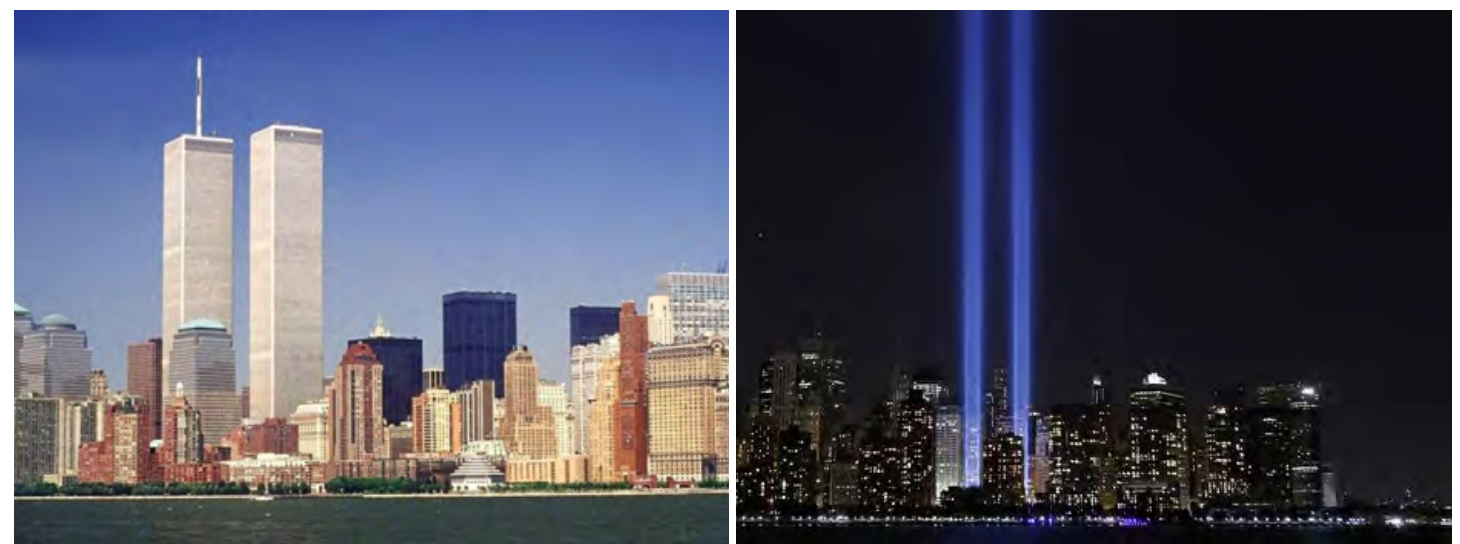

(left) Fig.1.3 New York skyline pre 9/11,1976

(right) Fig.1.4 New York skyline 9th anniversary of 9/11,2010
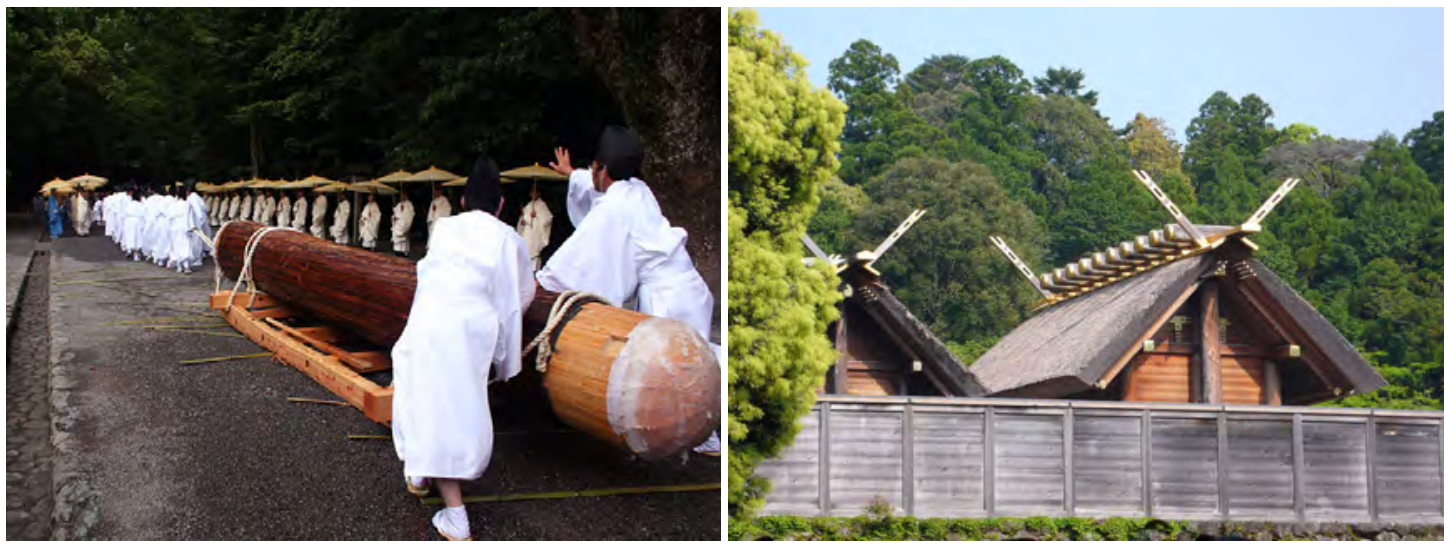

(left) Fig.1.5 Naiku Shrine reconstruction effort, Ise, Japan

(left) Fig.1.6 Naiku Shrine, most recently reconstructed in 2013 
Buildings and city forms are restructured and reused through time in response to evolving contexts, with each successive change leaving traces of the past that accumulate as layers. Collective knowledge and memory are strongly tied to these artifacts, which provide the depth and continuity necessary for the affirmation of identity.

\section{The Contemporary City}

The transformative processes of time and history are powerful and unyielding. As the world changes, our built environments and architectural artifacts must too evolve. In Toronto, the transformation of the Jarvis Street and Dundas Street intersection demonstrates an unsettling change. Both eastern corners were simultaneously demolished and sat empty with a recently developed condominium across the street (Figure 1.7). The intersection, now unrecognizable to residents, threatens continuity and identity by removing all elements of character. Though the former buildings may not present any practical significance, the fact that they are part of the city fabric does have significance in the collective mind.

Dramatic changes to the contemporary city have prompted a reconsideration of the way architecture adapts and highlights the need for a creative approach to change and advancement, one that would meaningfully engage the past and memory in future projections. In the West, as a consequence of modern approaches, the predominant understanding of architectural evolution and its preoccupation with the new and instant, dismisses the canvas of pre-existing buildings. Instead, architecture is now regarded as finished upon construction, while pre-existing structures with heritage value are often equated with artifacts and denied potential for change and remain crystallized in time in their unaltered or antecedent condition.

Yet, we have seen urban artifacts, years later through unanticipated and divergent uses, resurface and acquire new meaning. This implies that the potential of architecture does not end upon the completion of design or construction, but is subject to constant making and remaking. Through such processes, traces, fragments, and imprints are left behind. This suggests that the city and its artifacts have a palimpsest structure, where the new stands in relation to the old, and the persistence of the old forms points of reference around which new realities are built.

The palimpsest, an evolving record, can provide a productive framework for transformation. It seeks new approaches to addressing memory in architecture as it engages the past as a way to inform prospective steps as we evolve. This incorporation of remembrance into structures would result in their being considered no longer as just artifacts/relics, but rather as part of a continuous process of renewal. 


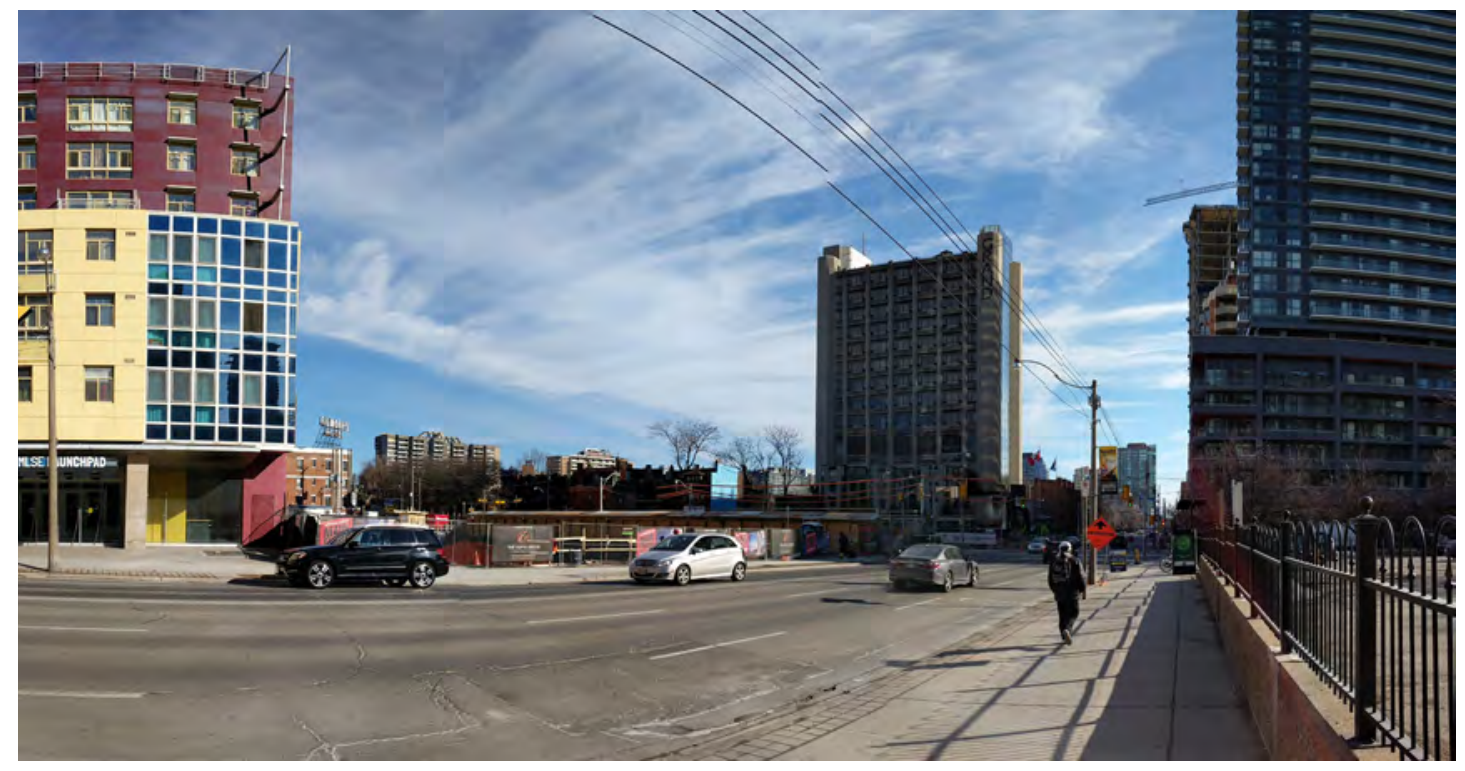

Fig.1.7 Photograph at Jarvis St and Dundas St. looking south, illustrating the demolition of both eastern corners and a new development on the south-west corner 



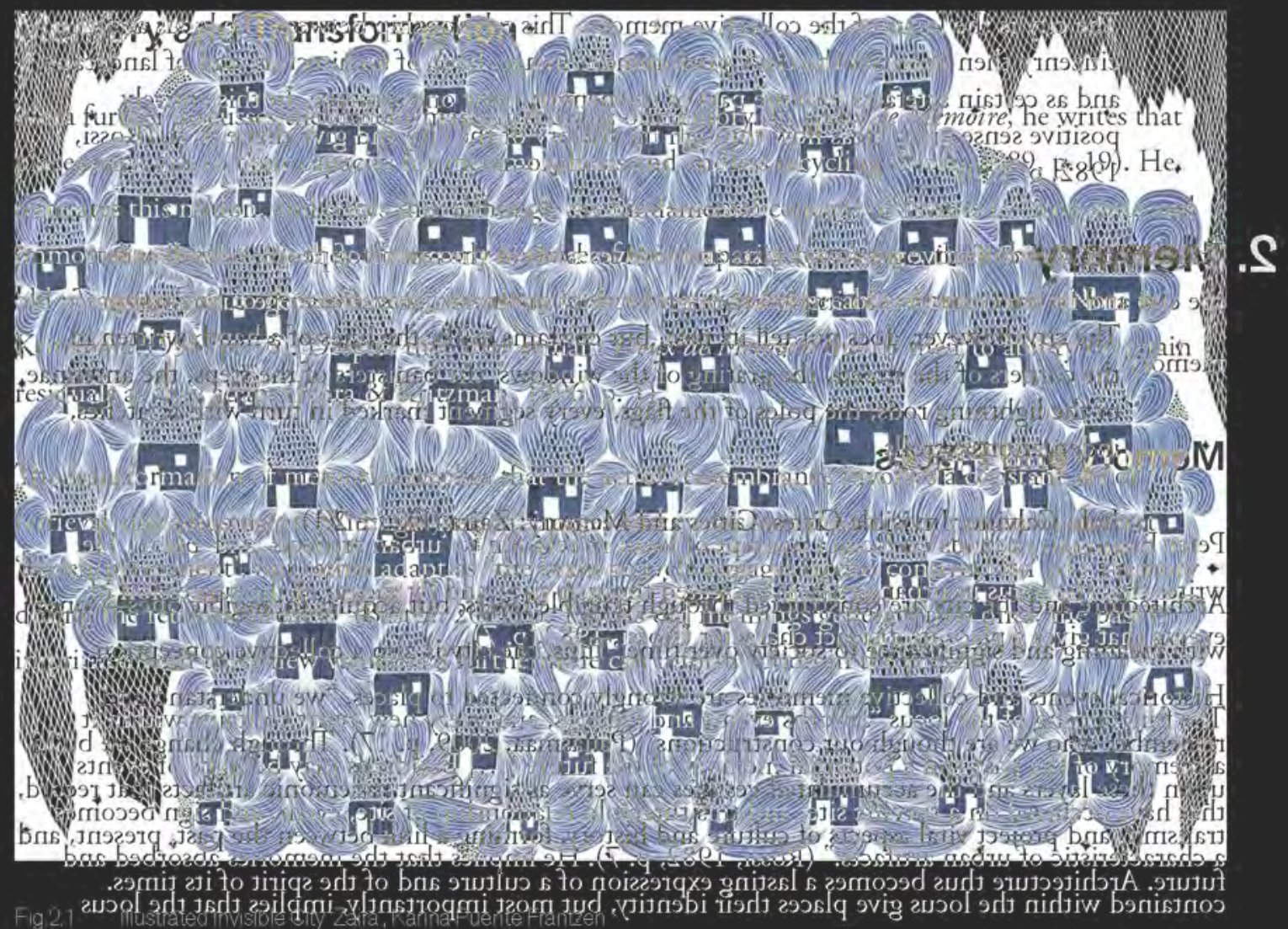

\section{Memory and Images}

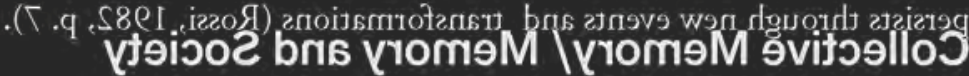

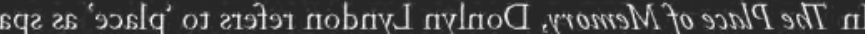

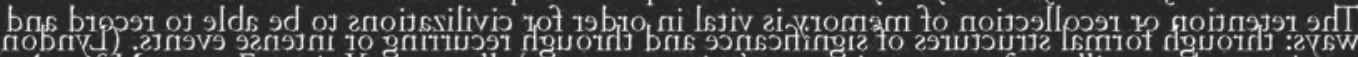

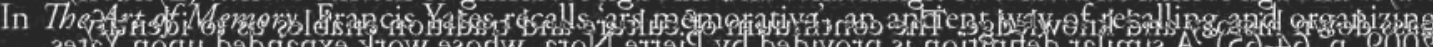
2935 Y noqu b9brifg

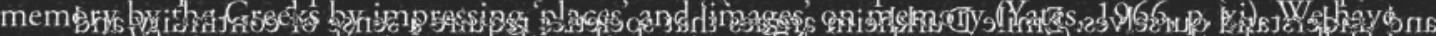

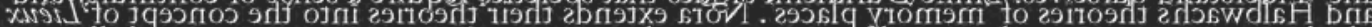

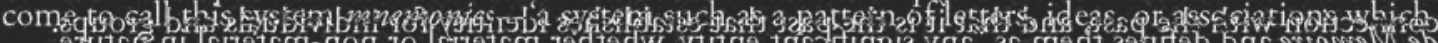

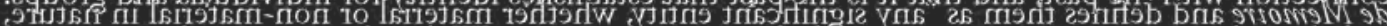

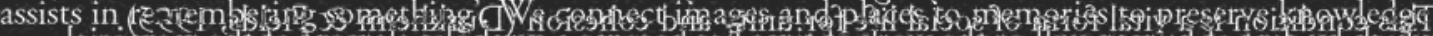

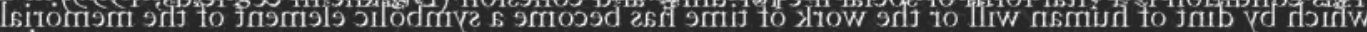
and culture.

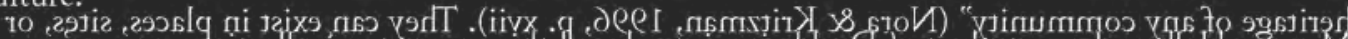
.

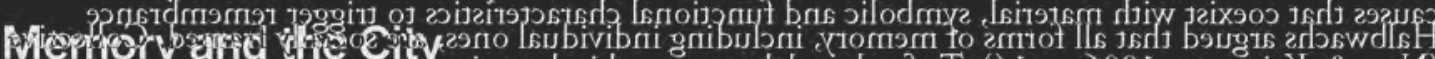

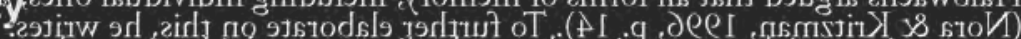

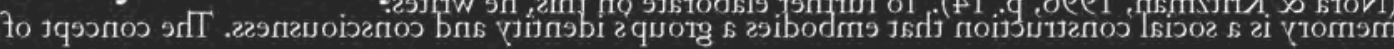

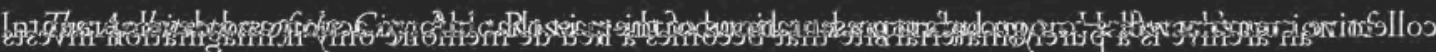

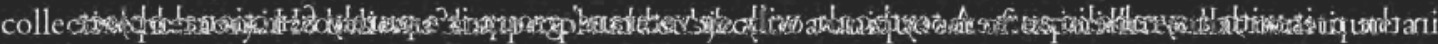

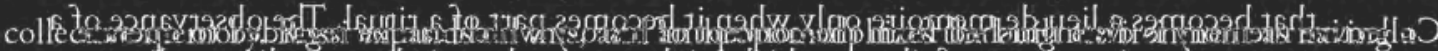

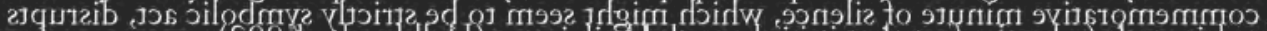

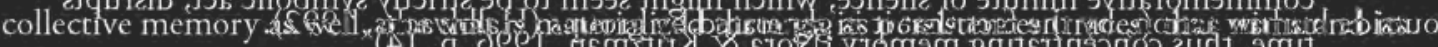
transformations.

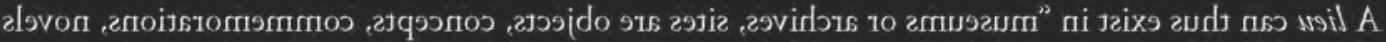

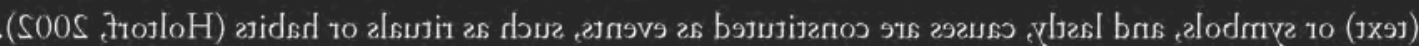




\section{Memory}

The city, however, does not tell its past, but contains it like the lines of a hand, written in the corners of the streets, the grating of the windows, the banisters of the steps, the antennae of the lightning rods, the poles of the flags, every segment marked in turn with scratches, indentations, scrolls.

Italo Calvino, Invisible Cities, Cities and Memory: Zaira (Figure 2.1)

Architecture and the city are constructed through tangible layers, but acquire intangible ones - ones with meaning and significance to society over time. Thus, the city is also a collective conception. Historical events and collective memories are strongly connected to places, "we understand and remember who we are though our constructions" (Pallasmaa, 2009, p. 17). Through change we build upon these layers and the accumulated vestiges can serve as significant mnemonic artifacts that record, transmit, and project vital aspects of culture and history, forming a link between the past, present, and future. Architecture thus becomes a lasting expression of a culture and of the spirit of its times.

\section{Collective Memory/ Memory and Society}

The retention or recollection of memory is vital in order for civilizations to be able to record and pass down history and knowledge. The continuum of culture and tradition enables us to identify and understand ourselves. Emile Durkheim argues that societies require a sense of continuity and connection with the past, and that it is the past that establishes identity for individuals and groups. This condition is a vital form of social life for unity and cohesion (Durkheim \& Fields, 1995).

Maurice Halbwachs, a student of Durkheim, introduced this concept as 'collective memory'. Halbwachs argued that all forms of memory, including individual ones, are socially framed. Collective memory is a social construction that embodies a group's identity and consciousness. The concept of collective memory refers to a group's representations of the past that inform action and development in the present, thus collective memory is not only shared but can transform across time and place. Collective memory is distinguished from the concept of history which can be regarded to operate outside human action, by the fact that it is generated by groups (Halbwachs, 1992). 


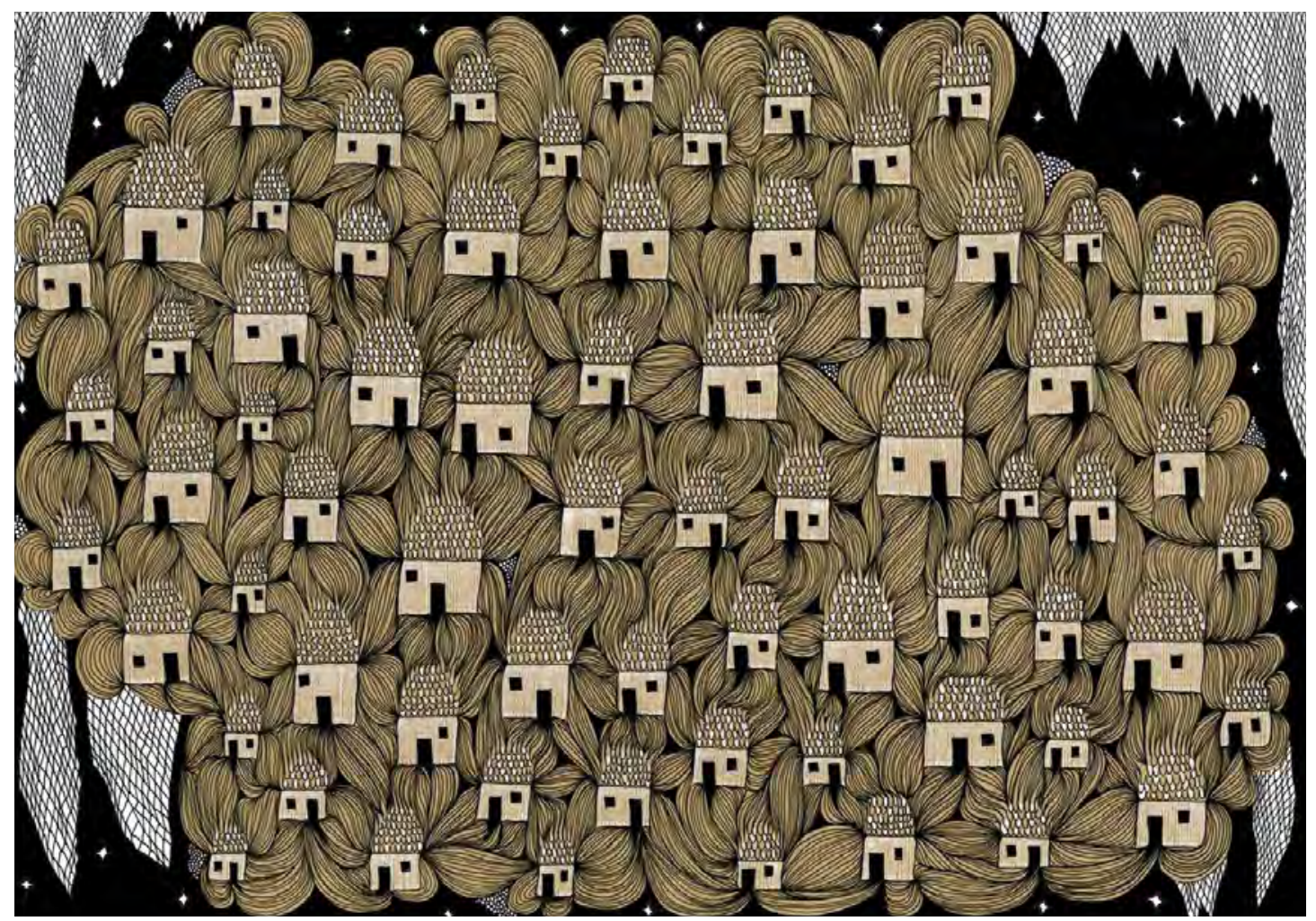

Fig.2.1 IIIustrated Invisible City 'Zaira', Karina Puente Frantzen

\section{Memory and Images}

In The Art of Memory, Francis Yates recalls 'ars memorativa', an ancient way of recalling and organizing memory by the Greeks by impressing 'places' and 'images' on memory (Yates, 1966, p. xi). We have come to call this system mnemonics - 'a system such as a pattern of letters, ideas, or associations which assists in remembering something'. We connect images and places to memories to preserve knowledge and culture.

\section{Memory and the City}

In The Architecture of the City, Aldo Rossi re-introduced and expanded upon Halbwachs' notion of collective memory. He believes that people are subject to a unique set of experiences that constitute a collective memory. Rossi expands on this, and anthropomorphizes the built environment as having a collective memory as well, one that is materialized through its persistences (traces) that withstand its transformations. 
The city is the locus of the collective memory. This relationship between the locus and the citizenry then becomes the city's predominant image, both of architecture and of landscape, and as certain artefacts become part of its memory, new ones emerge. In this entirely positive sense great ideas flow through the history of the city and give shape to it. (Rossi, 1982, p. 130)

This implies that collective memory exists and evolves both in the minds of people as well as in the city and its structure. It also implies that the locus of urban artifacts affects the functioning of memory.

\section{Memory and Places}

Peter Eisenman expands on Rossi's concept of locus in relation to 'urban artifacts' and 'place'. He writes that the locus in urban artifacts is created through time and by means of the succession of events that gives a place its distinct character (Rossi, 1982, p. 7).

The functioning of the locus "absorbs events and feelings, and every new event contains within it a memory of the past and a potential memory of the future [...] Buildings may be signs of events that have occurred on a specific site; and this threefold relationship of site, event, and sign becomes a characteristic of urban artifacts." (Rossi, 1982, p. 7). He implies that the memories absorbed and contained within the locus give places their identity, but most importantly, implies that the locus persists through new events and transformations (Rossi, 1982, p. 7).

In The Place of Memory, Donlyn Lyndon refers to 'place' as spaces that can be remembered in two ways: through formal structures of significance and through recurring or intense events. (Lyndon, 2009, p. 64-65). A similar definition is provided by Pierre Nora, whose work expanded upon Yates and Halbwachs' theories of 'memory places'. Nora extends their theories into the concept of Lieux de Memoire and defines them as "any significant entity, whether material or non-material in nature, which by dint of human will or the work of time has become a symbolic element of the memorial heritage of any community" (Nora \& Kritzman, 1996, p. xvii). They can exist in places, sites, or causes that coexist with material, symbolic and functional characteristics to trigger remembrance (Nora \& Kritzman, 1996, p. 14). To further elaborate on this, he writes:

[a]n archive is a purely material site that becomes a lieu de memoire only if imagination invests it with a symbolic aura. A textbook, will, or veterans' group is a purely functional object that becomes a lieu de memoire only when it becomes part of a ritual. The observance of a commemorative minute of silence, which might seem to be strictly symbolic act, disrupts time, thus concentrating memory (Nora \& Kritzman, 1996, p. 14).

A lieu can thus exist in "museums or archives, sites are objects, concepts, commemorations, novels (text) or symbols, and lastly, causes are constituted as events, such as rituals or habits (Holtorf, 2002). 


\section{Memory and Transformation}

Nora further discusses the transformative processes of memory. In Lieux de Memoire, he writes that places exist due to their capacity for metamorphosis and endless recycling (Nora, 1989, p. 19). He reiterates this notion, and states that although the fundamental concept of lieux is to "stop time and immortalize death [...] they thrive only because of their capacity for change, their ability to resurrect old meanings and to generate new ones along with new and unforeseeable connections" (Nora \& Kritzman, 1996, p. 15). Despite this, they remain Lieux de Memoire due to their to ability to retain residuals as they adapt (Nora \& Kritzman, 1996, p. 1).

The transformation of memories implies that the act of remembrance involves a constant act of retrieval and adjustment. With this notion, images and events stored within our memory are not 'frozen/permanent', but rather adapt as "the brain actively engages in the 'construction' of a memory during the retrieval process" (Bastéa, 2004, p. 10). As old meanings generate new ones, the past is imprinted with these new values and furthermore can inform action in the present. 



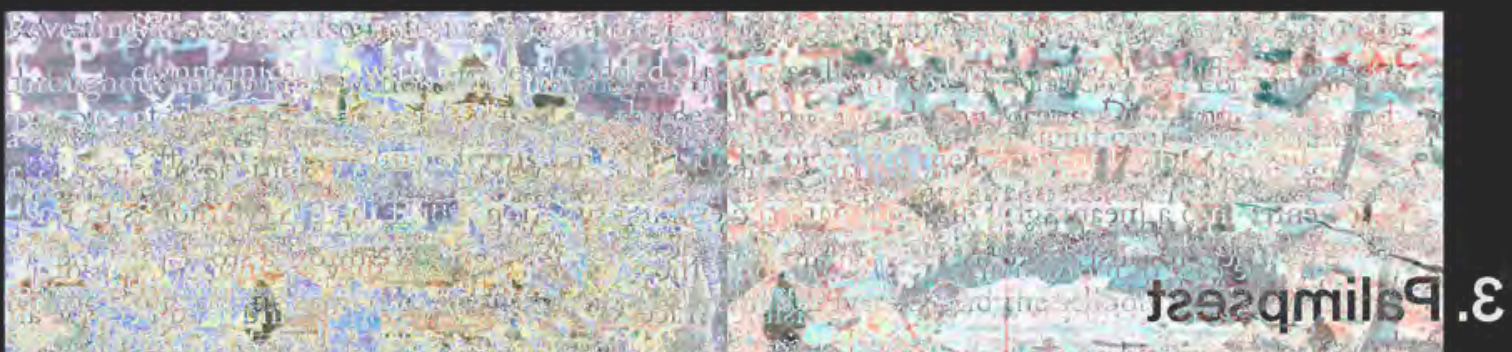

\section{Yomis bris tegeqmils9}

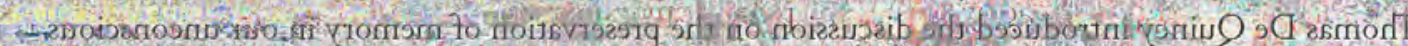

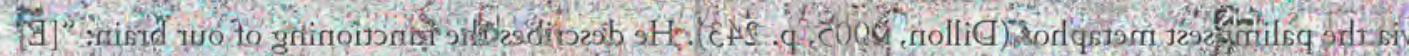

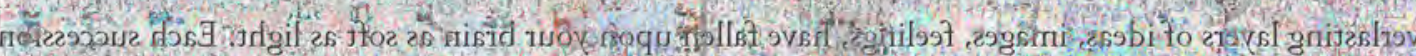

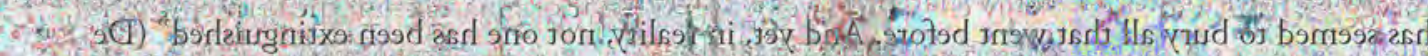

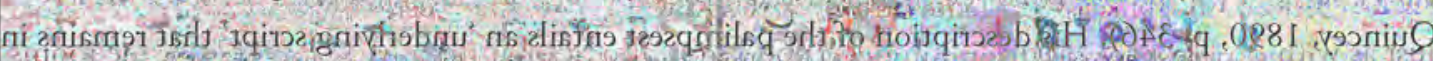

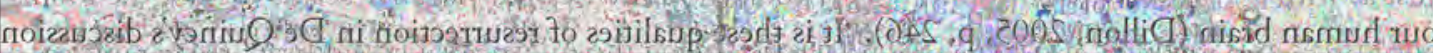
Co P.

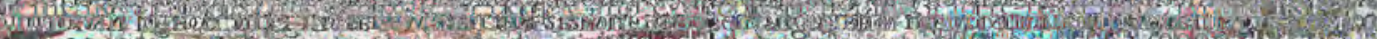

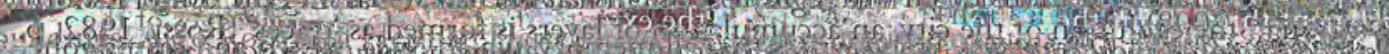

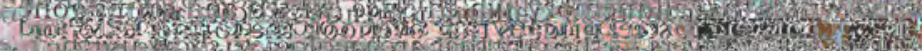

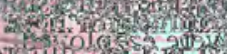

MH. H. W

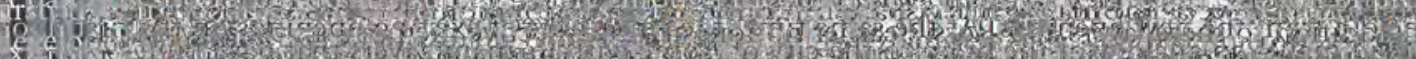
II m.

1. 1. tor

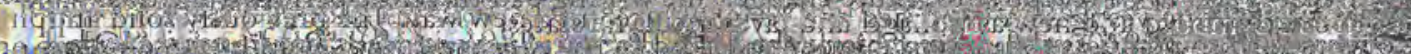

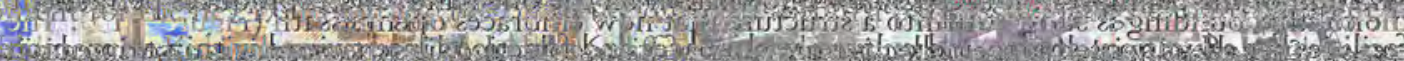

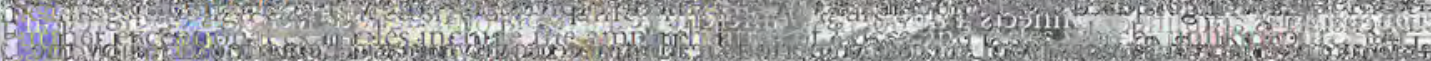
- 1503 .

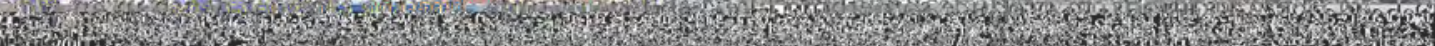

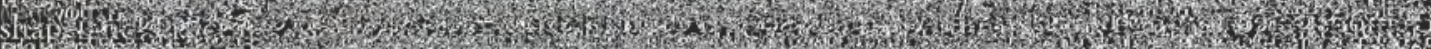

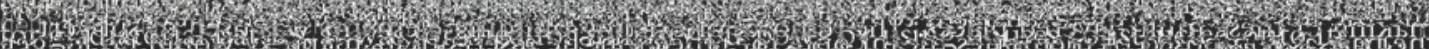

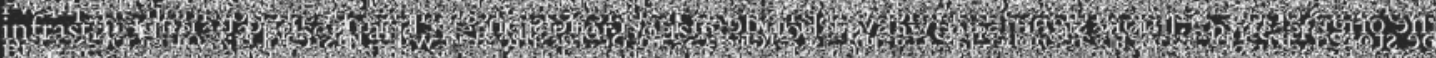

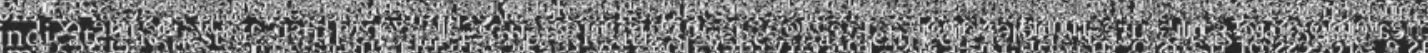

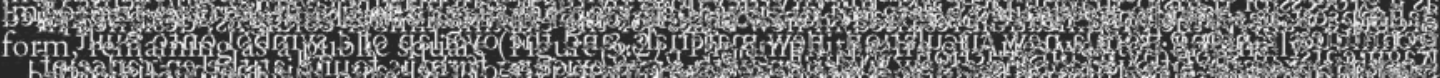

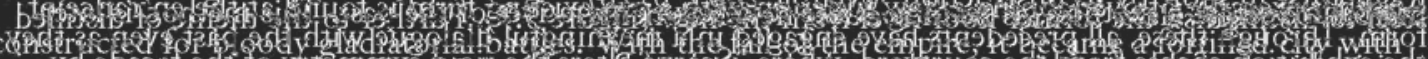

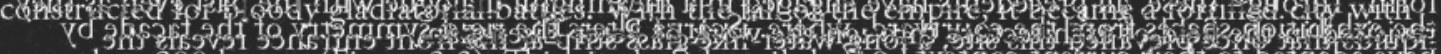

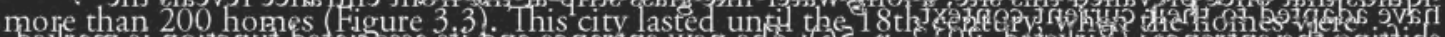

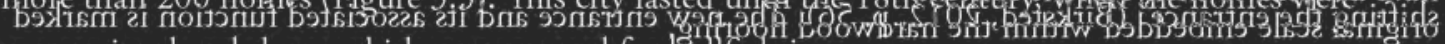
expropriated and the amphitheatre restored for bullfighting. 


\section{Palimpsest}

\section{Palimpsest and Memory}

Thomas De Quincy introduced the discussion on the preservation of memory in our unconscious via the palimpsest metaphor (Dillon, 2005, p. 243). He describes the functioning of our brain: "[E]verlasting layers of ideas, images, feelings, have fallen upon your brain as soft as light. Each succession has seemed to bury all that went before. And yet, in reality, not one has been extinguished" (De Quincey, 1890, p. 346). His description of the palimpsest entails an 'underlying script' that remains in our human brain (Dillon, 2005, p. 246). It is these qualities of resurrection in De Quincy's discussion on palimpsest that lead to comparisons with Sigmund Freud's analogy of the mystic writing pad.

In Civilization and its Discontents, Freud writes that all memory, which once existed and seems gone, is actually preserved as traces in our unconscious mind. This is the basis of his concept of 'regression', through which one can recall memories and "bring them back to light" (Freud, 1930, p. 16).

Freud makes an analogy of the brain to the city of Rome with its many layers that have built upon each other since Roma Quadrata (the oldest version of Rome). He notes that the vestiges of the transformation are still evident today in the archeology of memory-traces found beneath the city. Freud's concept of the Mystic Writing-Pad is a layered metaphor that represents the layered functioning of memory. In his text, he acknowledges the importance of the continuum of a 'memorytrace' that is also to be receptive to future change. The writing pad therefore performs the dual function of the palimpsest: it accepts new information on the one hand, and it produces permanent traces of memory on the other.

Sebastian Marot further speculates on the duality implied in Freud's concept of the preservation of cities as a model for the functioning of memory. Describing the concept as one that does not view the past as composed of memories meant only for reflection, he asserts that "memory would no longer be stored, in a perspectival order, as complete pictures, to be recalled at will. Instead it would be seen as a process of transformation that, like the city, develops by the rearticulating layering, and reuse of fragments- in short by reconstruction" (Marot, 2003, p. 28). 


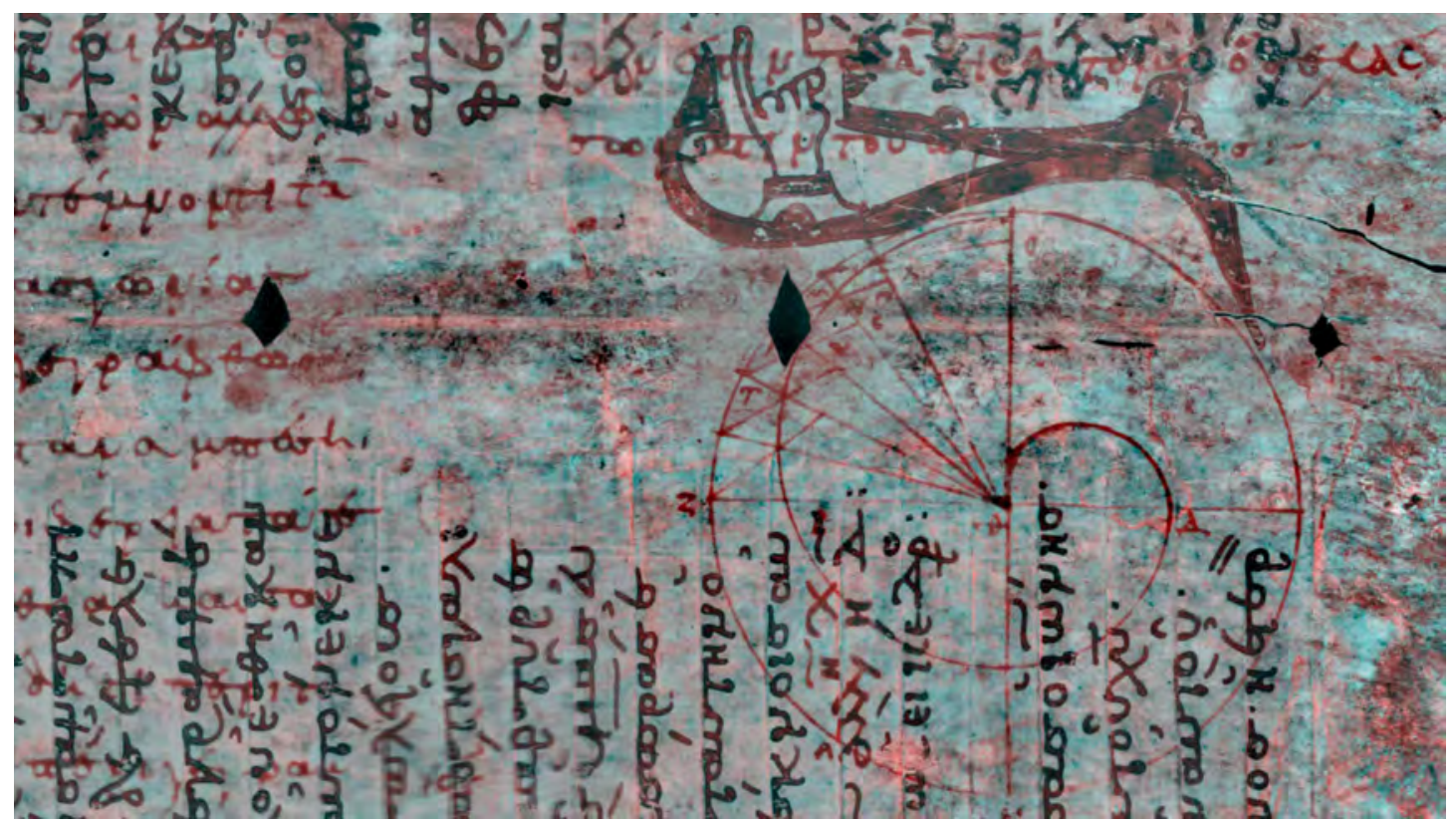

Fig.3.1 Archimedes palimpsest containing mathematical text circa 1000 (copied from original text from 287-212 B.C) layered with Christian liturgical text circa 1200

\section{Palimpsest Metaphor}

A palimpsest can refer to any surface where through the succession of its use, the accumulation of preexisting layers persist as ghostly reminders of the transformation and continuity of time. The term's etymology: Palimpsestos (Greek) = 'scraped again or rubbed smooth' dates back to the Ancient Greeks, who used first used wax-coated tablets for the recording of ideas, where manuscripts would be scraped off and written on again. The practice was adopted in $5^{\text {th- }}$ century Europe, where a palimpsest was made out of parchment, prepared and scraped animal hide. Due to its scarcity and cost, and because of its durability, the content could be scraped, washed off, and re-used, leaving traces of its past content for the next. Oftentimes, the construct of layers within a palimpsest brings to light different meanings through each successive use in different times (Figure 3.1).

The relationship of architecture to memory can be said to resemble a palimpsest: a rich, layered, transformative record. The consideration of architecture and its processes as a palimpsest can be a productive framework for transformation and design with memory and layered meanings. It would provide continuity and depth, even as it was receptive and enhanced by change. Architecture is an important externalization of human memory and layers in the grand palimpsest of time. 


\section{Palimpsest in Urbanism and Landscape}

The transformation of cities is a continuous process of creating and recreating. Thus, the city and its artifacts have a palimpsest structure, where the new stands in relation to the old, and the persistence of old forms points of reference around which new realities are built.

As author Italo Calvino frames it in the tale Invisible Cities, our recollections of cities can be attributed to the typology and symbolism of artifacts, imagery, and to the timelessness of cities themselves (Bari, 2017). The character of Marco Polo reports on 55 imaginative cities to the great Kublai Khan, stating their dominant characteristics. As the 55 descriptions layer on top of each other all with shared identities, it is revealed that the 55 descriptions are descriptions of one multi-faceted layered city, Venice (Calvino, 1974, pp. 86-87) (Bari, 2017).

The mid-1960s saw an unprecedented transformation of cities during post-war construction. This phenomenon brought forth the publication of numerous pieces of literature that offered critical interpretations of notions of the multi-layered nature of post-war cities. In The Architecture of the City, Rossi supports the notions of the city as a palimpsest. Without explicitly using the term, he describes how through the evolution of the city, an accumulation of layers is formed as 'traces' (Rossi, 1982, p. 128). He writes that, "one need only look at the layers of the city that archaeologists show us: they appear as a primordial and eternal fabric of life, an immutable pattern" (Rossi, 1982, p. 22).

In addition to these layers and Rossi's earlier notions about collective memory in the city, Mark Crinson echoes this quality in his observation of the city: "[I]t indicates the city as a physical landscape and collection of objects and practices that enable recollections of the past and that embody the past through traces of the city's sequential building and rebuilding" (Crinson, 2005, p. xi).

Kevin Lynch implies that there is an underlying continuity in our environment through a juxtaposition of old and new as 'collage' and layering' as he states;

'Layering' is used as a deliberate device of esthetic expression - the visible accumulation of overlapping traces from successive periods, each trace modifying and being modified by the new additions, to produce something like a collage of time. It is the sense of depth in an old city that is so intriguing. The remains uncovered imply the layers still hidden. (Lynch, 1972, p. 171)

Lynch's archaeological approach evokes Andre Corboz who was the first to directly introduce the term palimpsest as a metaphor for urbanism and landscape. Through the lens of archeology, Corboz applied the palimpsest as a method of 'reading' a site to discover narratives of the past. This method is later revisited in the field of architecture through the work of Peter Eisenman. 
Sebastian Marot was also influenced by Corboz's theories of palimpsest, as is evidenced by a project in Ithaca, New York, as well as by his writing on the relationship between palimpsest and memory. To illustrate Ithaca as a palimpsest, he traces the histories of three sets of significant figures, all of whom once visited Ithaca and have shared interests in landscape, architecture, and the history of cities. The first set of three are Ezra Cornell, Andrew D. White, and L.H. Bailey, who are recognized for their contributions to the establishments of Cornell University and the schools of Architecture and History, and Agriculture respectively. The second set of figures are three architects, Colin Rowe, Oswald Mathias, and Rem Koohlaas, who spent time in Ithaca during the 1960's, followed by their manifestos, Collage City, Berlin as a Green Archipelago and Delirious New York. The last set of figures are Robert Smithson, Gordon Matta Clark, and Vladimir Nbokov, whose underground work attempts to highlight landscapes and buildings facing removal. Marot culminates this research with theories of sub-urbanism and hyper-landscapes by defining them as territories that are conceived of as a palimpsest/ hypertext to be unfolded (Marullo, 2011).

\section{Medieval Times}

In medieval towns, the dynamic of people and events restructured and re-used the city and its buildings. Aldo Rossi and Herman Hertzberger provided extensive accounts of a number of monumental structures that were subjected to progressive transformation.

An example referenced by both architects is the city of Split in Croatia (formerly Yugoslavia), which developed from the palace of Roman Emperor Diocletian. Hertzberger notes: "the example of Split is especially interesting in that it demonstrates the divorcement of form and function so clearly" (Hertzberger, 1991, p. 101). Eisenman quotes Rossi as saying:

The city of Split which grew up within the walls of Diocletian's palace gave new uses and new meanings to unchangeable forms. This is symbolic of the meaning of the architecture of the city, where the broadest adaptability to multiple functions corresponds to an extreme precision of form (Rossi, 1982, p. 7).

Further exceptional examples include the amphitheatres of Lucca and Arles which, unlike Split, "not only permitted new forms of usage but even evoked such new applications by virtue of their specific shape and structure" (Hertzberger, 1991, p. 101). The Lucca amphitheatre was originally constructed for gladiatorial battles, it was fortified for military purposes by using houses constructed onto its infrastructure as a prison, and then later for housing. Modern day conditions at dell'Anfiteatro indicate the vestiges of the former amphitheatre's arches that defined each unit as well as its former form, remaining as a public square (Figure 3.2). The amphitheatre of Arles was too originally constructed for bloody gladiatorial battles. With the fall of the empire, it became a fortified city with more than 200 homes (Figure 3.3). This city lasted until the 18th century, when the homes were expropriated and the amphitheatre restored for bullfighting. 

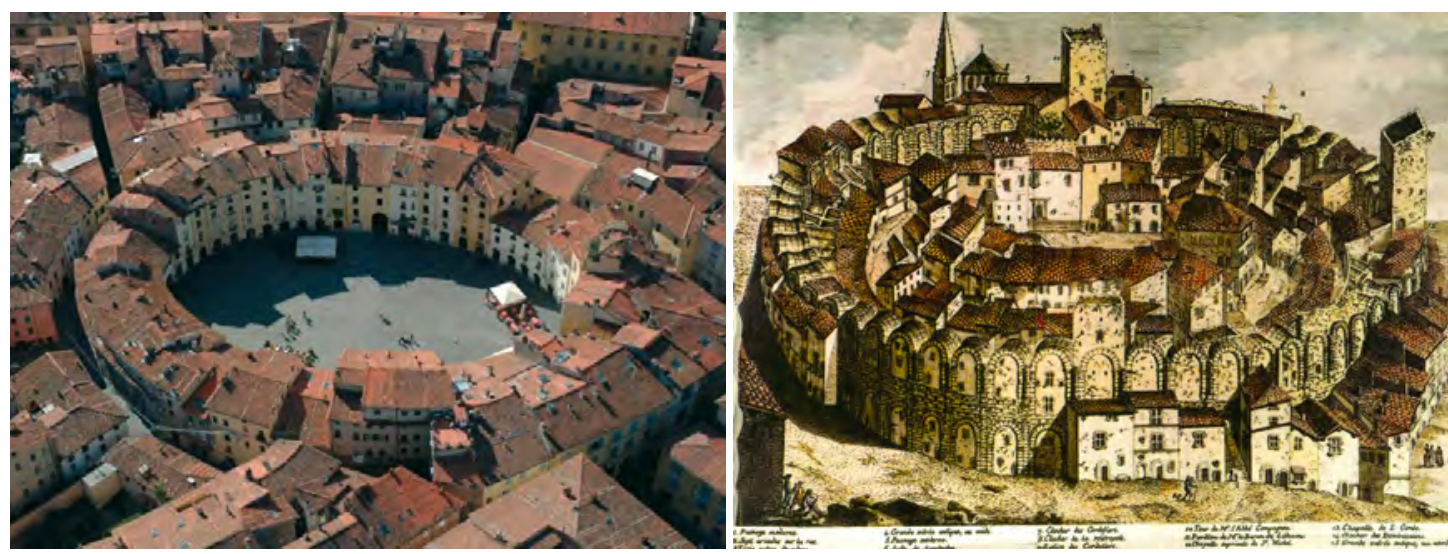

(left) Fig.3.2 Lucca Amphitheatre aerial at Piazza dell'Anfiteatro, modern day

(right) Fig.3.3 Amphitheatre of Arles drawing, Arles, France, 18th century

Rossi focuses on the example of the theatre in Nimes, which became another fortified city: "The amphitheater at Nimes had a precise and unequivocal form as well as function. It was not thought of as an indifferent container, but rather was highly precise in its structure, its architecture, and its form." (Rossi, 1982, p. 87).

The different amphitheatres, all intended for the same functions, succeeded in surviving their different histories by assuming new roles. In each of these examples, we see an underlying continuity of identity. Observations of them engage a discussion of form and are conducive to several important conclusions.

Hertzberger attributes this performance (the separation of form and function) to intrinsic 'competences' in form. Rossi considers the consequence to be 'propelling'. This idea extends to the connection of the past to the present-a record of time. Hence, through transformation where form is divorced from its original function, history ends and form reflects memory. Rossi states: "[O]ne can say that the city itself is the collective memory of its people, and like memory it is associated with objects and places" (Rossi, 1982, p. 130). 


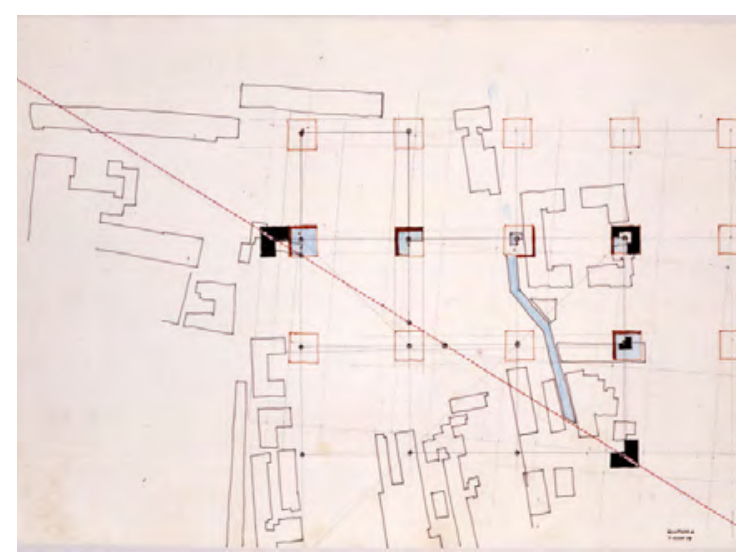

Fig.3.4 Cannaregio project, Peter Eisenman

\section{Palimpsest in Architecture}

Remembering is like construction and then traveling again through a space. We are already talking about architecture... Memories are built as a city is built, it could be said that architecture, from its beginnings, has been one of the ways of fixing memories.

\section{Umberto Eco}

Juhani Pallasmaa states that built structures "are significant memory devices in three different ways: first, they materialize and preserve the course of time and make it visible; second, they concretize remembrance by containing and projecting memories; and third, they stimulate and inspire us to reminisce and imagine" (Pallasmaa, 2009, p. 18).

In architecture, Peter Eisenman is notable for having explored the concept of palimpsest. Eisenman viewed architecture as text and 'writing' - a palimpsest open to multiple readings enabled by the idea of 'traces' (Eisenman, 2004, p. 163). For Eisenman, a project or idea begins with traces. They may not necessarily be physical — they may be history and place, but they are used to establish the 'site'. Architecture is realized by incorporating these traces (past conditions). His concept implies that there is no such thing as a true origin, that everything is preceded by traces. In this context, the process of transformation becomes a 'modification' of these persistent underlying forces - a constant rewriting of a palimpsest. This is seen in his unrealized Cannaregio project which traces Le Corbusier's unbuilt hospital in Venice (Figure 3.4), as well as the Romeo and Juliet project, developed for the 1986 Venice Biennale, where he weaves the different 'texts' to create a site that becomes a palimpsest. 


\section{Precedents}

Every new work of architecture intervenes in a specific historical situation. It is essential to the quality of the intervention that the new building should embrace qualities which can enter into a meaningful dialogue with the existing situation. For if the intervention is to find its place, it must make us see what already exists in a new light. We throw a stone into the water. Sand swirls up and settles again. The stir was necessary. The stone has found its place.

Peter Zumthor, Thinking Architecture

The qualities or layers that have accumulated and exist in the built environment become critical tools to engage in the design of new interventions and have the potential to be adjusted to serve new roles. The following interventions have been selected to be examined through the common themes and techniques of a palimpsest in which tangible or intangible layers have been added or removed through the changing locale. The result produces layered and multivalent spaces, similar to a palimpsest.

\section{Castelvecchio Museum, Verona, Italy, Carlo Scarpa, 1973}

Castelvecchio's transformations begin with a 12th-century wall Roman wall along the Adige River and the construction of the castle two centuries later by Lord Cangrande II della Scala and the Scaligeri family. The fall of the Venetian republic to Napoleon in the 18 th century was followed by the occupation and subsequent evacuation by the French and Austrians that brought about the barracks which now serve as the main gallery space. Antonio Avena's restoration in 1924 established the site as a museum, with the most recent modifications having been done by Carlo Scarpa (Verheij, 2015, p. 147). The analysis focuses on the Cangrande exhibit, a highly complex space that presents traces of all occupations.

\section{SESC Pompeia, São Paolo, Brazil, Lina Bo Bardi, 1982}

Converted from a 1920s steel drum factory, the SESC Pompeia now serves as leisure centre with facilities for education, sports, and culture, with spaces and functions intertwined within to promote healthy mixing and inclusivity (Lima, 2013, p. 174). The project was conceived at the end of Brazil's 20-year military dictatorship as it was transitioning into democratic rule. These tensions and aspirations, as well as the local geography, are incorporated into the design of the center. 


\section{Pinacoteca do Estado, São Paulo, Paolo Mendes da Rocha, 1993}

The Pinacoteca was originally completed in 1905 to house the Lyceum of Arts and Crafts and the first fine arts museum in São Paulo. After its most recent renovation/restoration that transformed key spaces, it continues to serve the original program of a museum, and stands as a testament to excellence in crafts and fine arts.

\section{Corkin Gallery, Toronto, Canada, Shim and Sutcliffe, 2004}

Located in what was formerly the Gooderham and Worts Distillery, a former spirit storage was modified into a gallery for fine art photography. The design of the Corkin Gallery layers modern insertions within the buildings' industrial heritage while amplifying and giving new meaning to the existing elements evocative of its former use.

\section{CaixaForum, Madrid Spain, Herzog De Meuron, 2007}

Converted from the fabric of a 1899 Mediodia Power station formerly "stitched into the social history of the city describing 19th-century aspirations to civic and social improvement in Madrid" (Sharr, 2012, p. 40), the CaixaForum cultural center houses an expanded program that includes music, literature, art, film, and social and educational programs for the city, thereby continuing the cultural significance of the site.

\section{Kolumba Museum, Cologne, Germany, Peter Zumthor, 2007}

At the time of its existence, the St. Columba church was the most important church and symbol of the diocese (Zeballos, 2012). It was destroyed during the Second World War, leaving a few remaining Gothic vestiges and the statue of the Virgin. Less than half a decade later, Gottfried Bohm's 1949 post-war reconstruction of the chapel coined the Madonna of The Ruins was built to commemorate the destroyed church, hold the statue, and stand as a symbol of hope (Davey, 2011). Its most recent addition, the Kolumba museum, includes 16 different exhibition rooms that house the Roman Catholic Archdiocese's collection of art, as well as an excavation space that symbolizes the loss and memory of the site. 


\section{Scraping, Removal, Traces, Carving, Incisions, Re-surface, Traces}

In the built environment, the transformation of a site implies the removal of past layers to make way for new ones. Conventional methods often fail to incorporate a site's remaining vestiges. In contrast, the palimpsest method suggests that as each layer - tangible or intangible-- is removed, the new layer will embody vestiges from its past.

\section{Material}

At the Caixa Forum, the removal of the building's stone plinth liberated and transformed the ground plane entirely (Figure 3.5). It created a continuous covered space underneath the newly-raised building that would draw people into its center from the abutting piazzas- one already existing and the other opened after the demolition of a gas station (Figure 3.6) (Etherington, 2008). These moves provided relief for the narrow and densely packed streets and alleyways, and also fostered further gathering spaces in what is the city's cultural district. The architects describe this separation as the creation of two worlds - above the ground which houses the entrance lobby, gallery's, restaurants, and administrative offices and below the ground which houses the auditorium and service spaces (Etherington, 2008).

The exterior shell is penetrated with three new fully glazed rectangular openings that allow for light and views. Their varying sizes and locations ignore the old rhythm and order that further distinguish the old from the new openings. At the same time, the remainder of existing openings on the first floor were infilled to accord with the already infilled windows on the second floor; the result presented a contrast between the existing solidity and the new incisions.

These incisions at the CaixaForum (the removal of the plinth and introduction of new windows on a solid facade) serve as an example where through the removal of an existing building element, the remaining existing vestiges are modified and re-introduced in a new way. The previously solid and monolithic building is subverted into a structure that now embraces openness.

The removal of building elements can also reveal a buried layer. An example of this is observed at the Corkin Gallery, where central to the design are the rows of 6'-high masonry walls previously embedded within the floor to support large storage. The depression of the floor surfaced the height of the walls, making evident their stature and former use as load-bearing walls (Figure 3.7). In their new state, they serve as spatial dividers and parameters for the insertion of new functions and spaces. In the dropped gallery, the modification resulted in new bases for the existing timber columns, designed in steel to distinguish the former floor level from the new (Figure 3.8). Further to the theme of distilled liquids that once prevailed this site, a long water-like glass strip at the front entrance reveals the original scale embedded within the hardwood flooring. 
Revealing a building's tectonics can trigger recall of its former use and become a recurring theme throughout many interventions. For instance, as mentioned the Corkin Gallery's former function as a spirit house was amplified by the resurfacing of building elements important to its history and use. A similar execution was done at the Pinacoteca and the SESC Pompeia's most recent modifications, where the original building tectonics were revealed via sandblasting. At the Pinacoteca, the original red brick of the exterior and interior is re-surfaced and similarly the concrete and brick at the SESC Pompeia (Williams, 2009) (Condello \& Lehmann, 2016, p. 59).
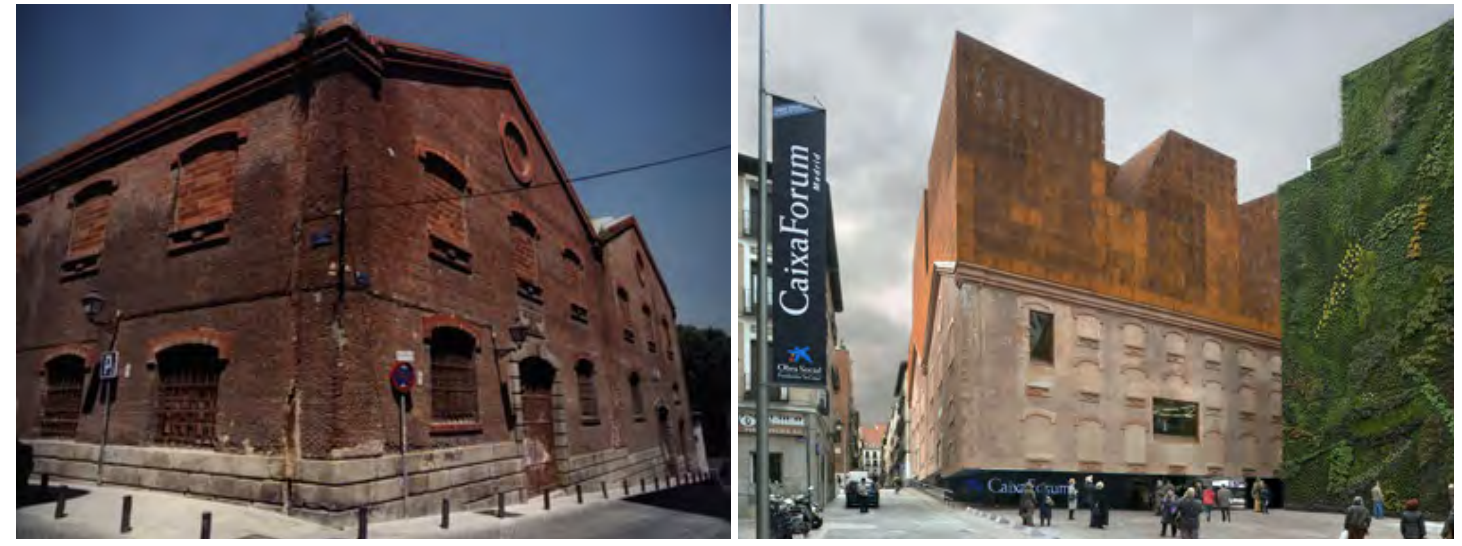

(left) Fig.3.5 Former power station prior to CaixaForum addition

(right) Fig.3.6 CaixaForum view from the abutting piazza

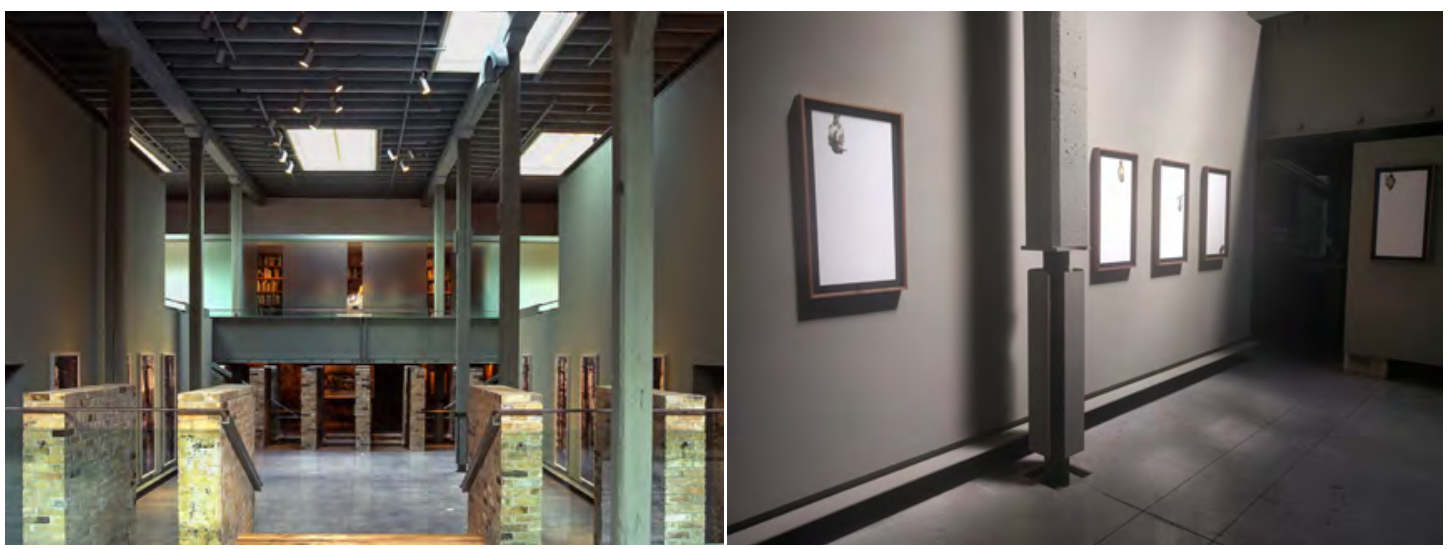

(left) Fig.3.7 Corkin Gallery looking towards main gallery area and the surfaced masonry walls

(right) Fig.3.8 Corkin Gallery new steel base at existing timber columns 


\section{Symbolism}

The form and placement of incisions can speak to an additional intangible layer. At SESC Pompeia, Bo Bardi employed incisions to symbolize the layer of nature and local geography, as well as the political tensions in Brazil. She employed water symbolism via troughs around the building's exterior and also through the shallow arterial reflecting pools in the lounge area of the leisure center; these had originally been designed as zig-zags and were then made curvy to mimic the geography of the São Francisco River (Figure 3.9) (Lima, 2013, p. 164).

The 'Spanish civil war holes' on the new sports complex tower, a recurrent theme in Bo Bardi's projects, carve the marks of the political tension in the region after the military regime (Figure 3.10) (Lima, 2013, p. 181). Similar to the arterial ponds, their imperfect forms and shapes appear as if carved by hand and additionally carry the layer of labour that originates from the former factory.

Just as with Bo Bardi's execution of water symbolism, Carlo Scarpa's negative seams around the rooms and spaces at Castelvecchio were achieved by referencing the Adige River around the castle and also the local Italian geography (Birksted, 2012, p. 57). These seams created platforms that modulated movement throughout the castle. To further define the extents of the platforms, the edges of the rooms were made of clear stone.

In Scarpa's work and throughout the museum, objects that are materially or chronologically different are separated via seams and transitions. This separation is achieved by employing processes of "separation, excision, and contrast" (Schultz, 2014, p. 16). Perhaps the most complex separation that displays this exists in the space for the statue of the Cangrande (Figure 3.11). The space was modified from an interior to an exterior one and serves as a transitional point that is visible from a multitude of locations throughout the museum and its grounds (Figure 3.12). It symbolizes a big 'reveal-joint' in which "the theme of the joint has a central significance for the autonomy of the elements and becomes a symbol of connection and separation alike" (Schultz, 2014, p. 79).

Contextually, the space connects a number of different occupations throughout Verona's expansion. It combines Caserma, the former French barracks built in the 18th century along the Adige that enclosed the courtyard and currently hosts the exhibitions, the Reggia, built by the Scaligeri family, and the Porta del Morbio, translated to medieval gate and formerly used as a connection between two sides of the $12^{\text {th- }}$ century commune wall, that was resurfaced through Scarpa's renovation after the removal of an $18^{\text {th- }}$ century Napoleonic monumental staircase (Schultz, 2014, p. 80) (Barrie \& Bermudez, 2016, p. 204). 

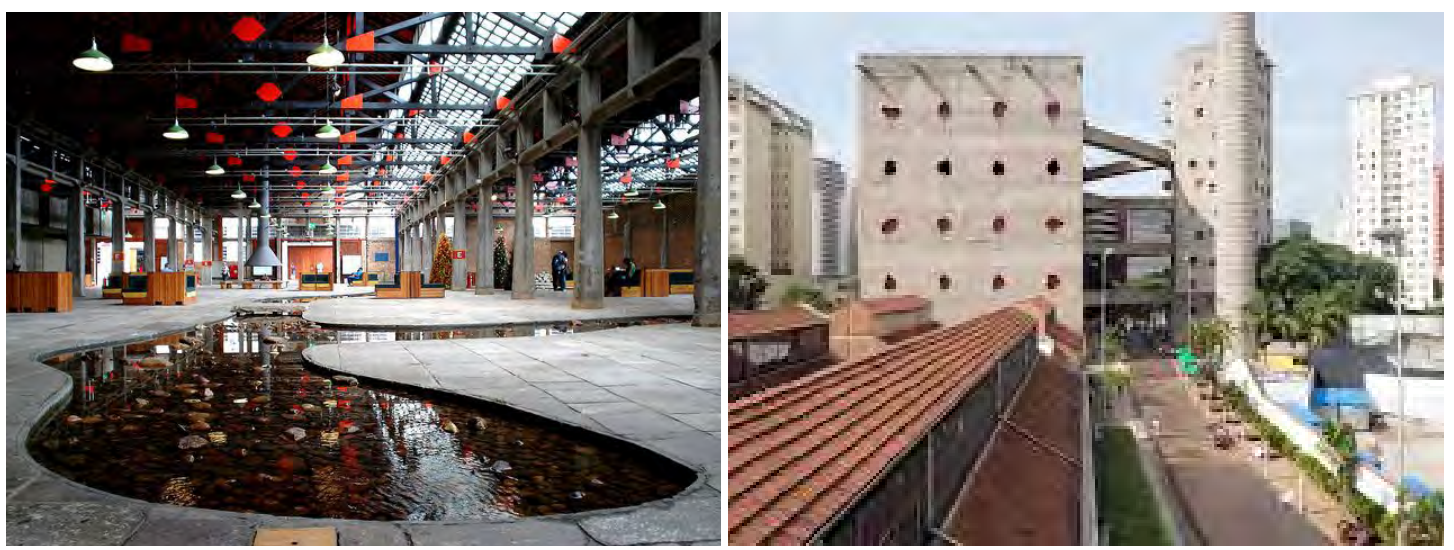

(left) Fig.3.9 SESC Pompeia view of large lounge and arterial pond

(right) Fig.3.10 SESC Pompeia view of complex looking towards sports complex towers
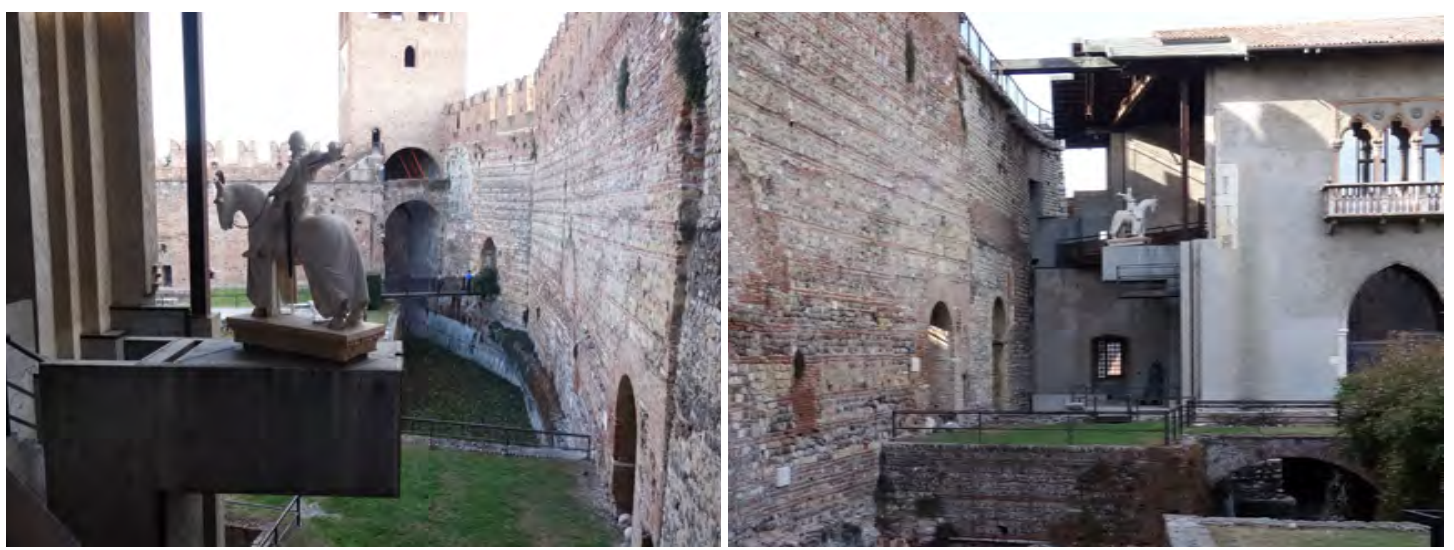

(left) Fig.3.11 Castelvecchio Museum view towards the space for the Cangrande statue from the courtyard, the 12th century Roman commune wall on the left and former 18th century Napoleonic barracks on the right

(right) Fig.3.12 Castelvecchio Museum space for the Cangrande statue 


\section{Overlapping, Simultaneity, Weaving}

In the palimpsest, the addition of new content is overlapped with the old, resulting in multiple layers that exist simultaneously. This process of stratification can be conceived of as layering of the physical and the functional.

\section{Spatial Overlap}

A common theme that has been observed are spatial overlaps via the introduction of a new paths or bridges. It allows for a new guided movement through space, suspending the visitor between multiple moments. An example of this is found at the Kolumba Church's 'excavation area', the remaining ruins of the church that was destroyed during the Second World War. This space becomes central to the memory of the event. A new sharp winding passage guides visitors' movement over the remains allowing them to cross and observe the destroyed ruins (Figure 3.13). The juxtaposition of wood and stone further adds to the quality of overlap.

Passages can also be intertwined to provide more than one singular way to experience the space. For example, Da Rocha's modifications to the central courtyards at Pinacoteca suspend the visitor in the courtyards through multiple levels of lightweight steel bridges that overlook the former exterior grounds (Figure 3.14). Visitors can also occupy the ground plane and observe the spanning bridges above.

At the Corkin Gallery, the 3' spaces in between the revealed masonry, previously used to run service pipes, now concentrate circulation through the overlapping of an old form with a new function. At the lobby, a wider staircase was inserted between the walls to lead visitors down into the main gallery space. Similar but smaller stairs were inserted into a second set of walls that lead visitors to a rear gallery space. Perpendicular to this, two sets of stairs were inserted into the historical arches. Above the second set of walls, a hovering bridge connects the two sides of the upper gallery level, overlapping the circulation on the bridge with circulation through the masonry walls beneath (Figure 3.15). The suspension is amplified with one side open to the main gallery; the other side is peeled back to reveal the tops of the historic arches and view of the use below.

At Castelvecchio, the Cangrande space is similarly layered with walkways and passages that provide multiple ways to experience it. As previously mentioned, the Cangrande is also visible from the courtyard and the commune wall (Figure 3.16).

Another example of overlapping a new function with a pre-existing form is found at the entrance of the exhibition spaces from the courtyard, where "Scarpa alters the rigid symmetry of the facade by shifting the entrance" (Birksted, 2012, p. 56). The new entrance and its associated function is marked via an intersecting plane inserted into the opening. 

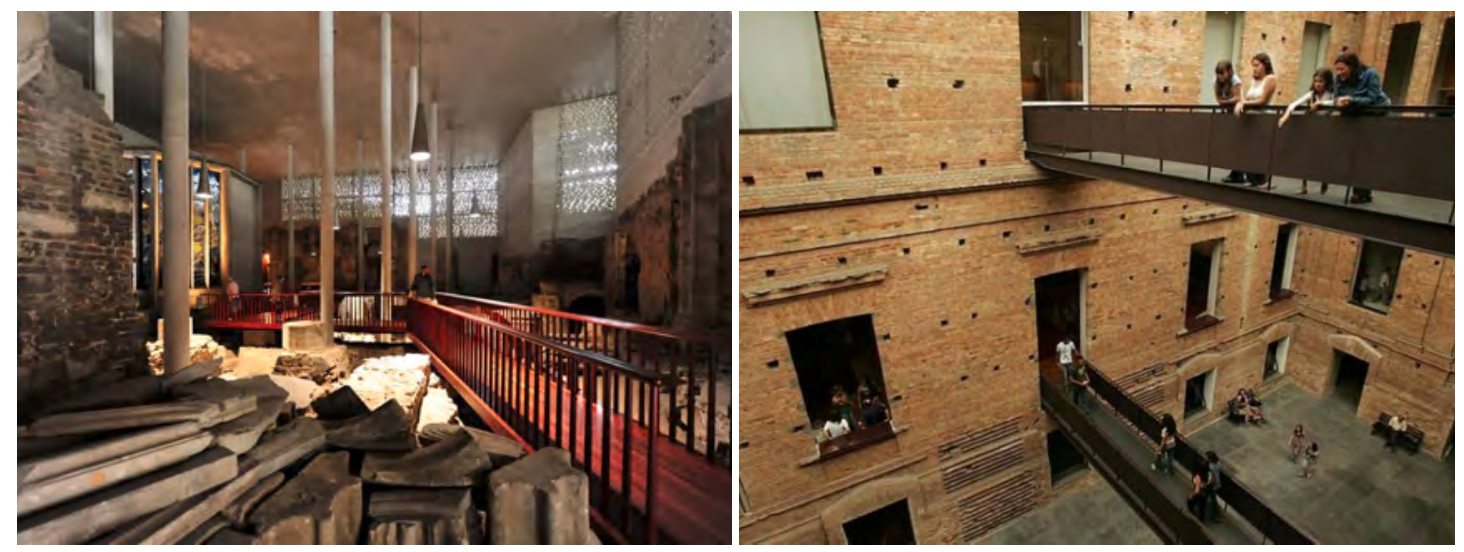

(left) Fig.3.13 Kolumba Museum view at modern day 'excavation area' layered with new winding passage

(right) Fig.3.14 Pinacoteca view of bridge crossing
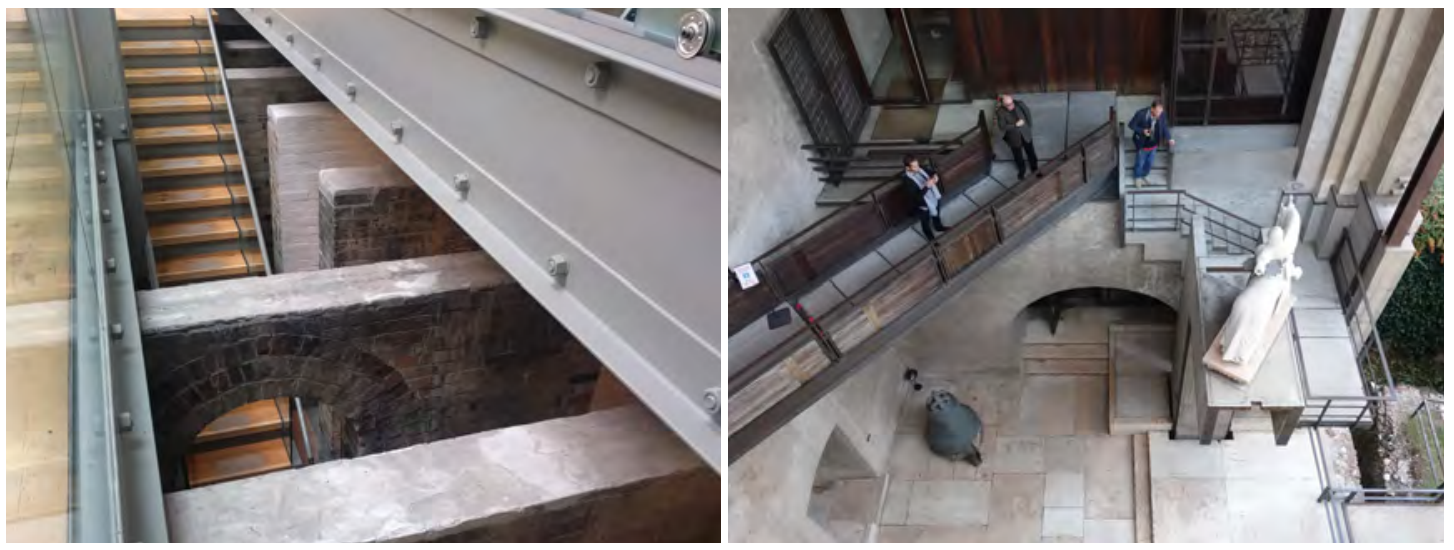

(left) Fig.3.15 Corkin Gallery view from second level bridge overlooking masonry walls

(right) Fig.3.16 Castelvecchio Museum Cangrande space as seen from commune wall 


\section{Atmosphere}

Spatial qualities and the atmosphere of a space can also recall a past condition. A desired atmosphere is often achieved via the use of light and shadows, materials, and sound. At the Kolumba Museum's excavation area, the brick material allows the shadows and diffused light to re-create the sacred atmosphere that once existed in this very location (Figure 3.17). The high ceilings resemble those found in sacred spaces, while the effect of minimal intervention amplifies a sense of desolation. The overall atmosphere "shows more clearly and movingly than almost any other contemporary building the continuity of Christian faith" (Davey, 2011). Further to the use of light and shadow at Kolumba, an additional overlapping layer is the sense of sound. It adds to the overall spatial quality of the space and triggers memory as "you become aware of strange soft music in addition to muted street noises. Pigeon Soundings by Bill Fontana takes, mixes and abstracts the sounds of the pigeons that used to flock on the site. (Davey, 2011). Furthermore, the old churchyard is recalled at the center of the museum while a secluded garden is meant for reflection (Figure 3.18) (Davey, 2011).

At the Pinacoteca, the exterior condition of the courtyards is maintained via a lightweight web-like glass ceiling that allows light to flood the voids (Figure 3.19). To further its lightweight quality, the new ceiling extends over the previous parapets and into adjacent spaces. An exterior condition was also desired at the SESC Pompeia, where the space was meant to be an extension of the city and landscape. To amplify this openness and spatial quality, a number of strategies were employed. Similar to the Pinacoteca, skylights and glazing replaced sections of the roof to allow for light to flood the spaces. The glazing rests on top of light trusses that span from one building to another, thereby allowing the openness of the former ground plane of the drum factory to remain uninterrupted (Figure 3.20). Trellised partitions and perforated brick allow for even further light and transparency. 


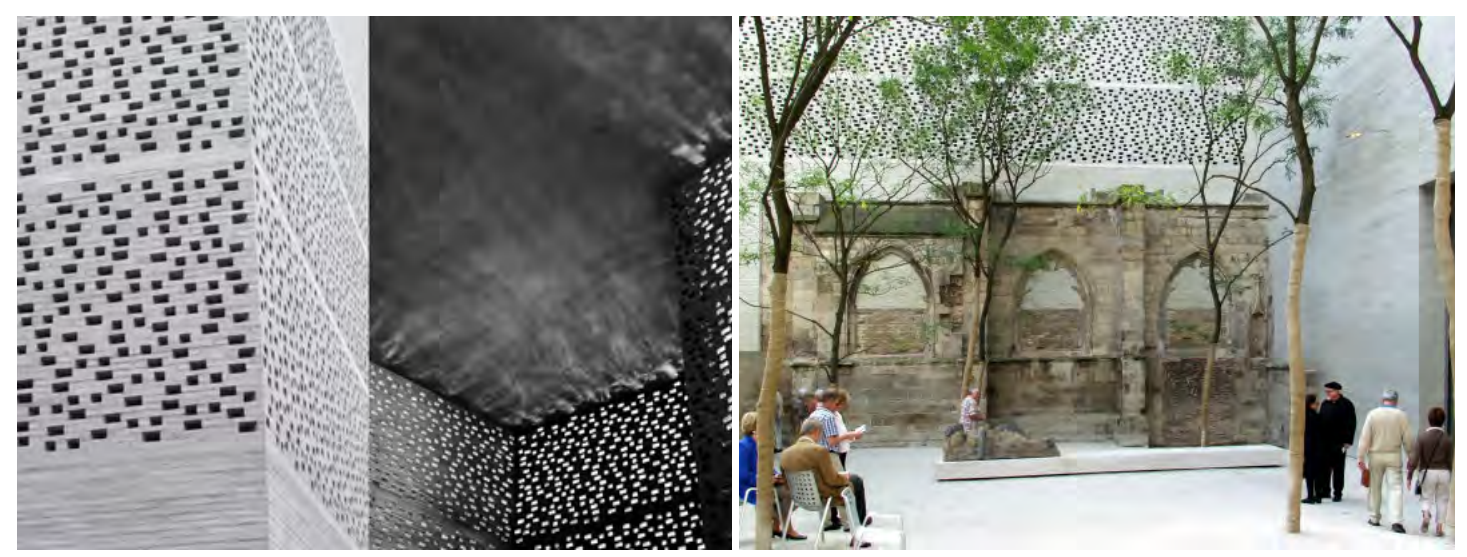

(left) Fig.3.17 Kolumba Museum perforated brick

(right) Fig.3.18 Kolumba Museum outdoor courtyard
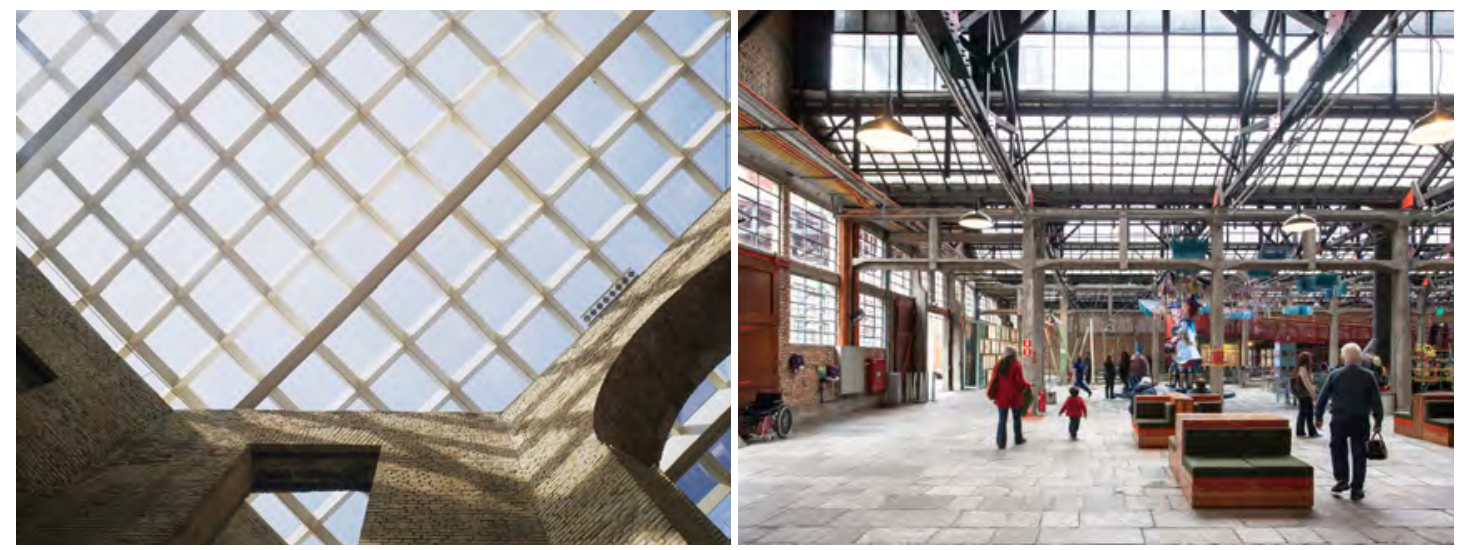

(left) Fig.3.19 Pinacoteca new glass ceiling above courtyards

(right) Fig.3.20 SESC Pompeia view at lounge entrance 


\section{Material Overlap}

In addition to referencing earlier notions of revealing the tectonics of pre-existing elements, the addition of new materials and their constructions can also carry a trace of the past.

In the case of individual elements, not only the mechanics of how they are installed but of their manufacture as well are made visible. Traces of how they were tools and used become an additional component of the design [...] The placement of material has didactic components. Form and choice can carry memories of context that create mental connections between buildings and cultures. (Schultz, 2014, p. 16)

At the Corkin Gallery, with the removal of a lower ceiling and the addition of a higher one, the new floating walls' height references the height of the old walls, allowing for the former lower height to continue to be read below the new floating ceiling ("Corkin Gallery," 2010). It serves as an example where the placement and form of a material references something past.

At The Kolumba Church, a central theme of the addition's exterior shell is the layer of 'craft'. Zumthor's monolithic addition stands in juxtaposition to Gothic ruins, while the texture, scale, and warm hue of the handcrafted new brick, carries memories of past construction methods (Figure 3.21). Its craftsmanship references Roman masonry via "mortar of nearly the same colour as the bricks and very thick horizontal joints" (Davey, 2011). The perforated brick screens further continue the layer of craft, while simultaneously allowing for the material to produce a diffused ambiance on the interior of the spaces.

At the CaixaForum, the addition of new Corten steel panels (at times perforated to allow for a variety of lighting conditions) complements the existing masonry, yet also allows for the new insertion to be read (Figure 3.22). The use of steel suggests a nod towards its industrial past. Furthermore, the rooftop extension's hipped roof-scape and form were also influenced by the surroundings and the landscape. (Etherington, 2008). Subtractions at the roof visually broke the monolithic form into smaller volumes, but also allowed for light to enter through the voids.

The process of stratification in Carlo Scarpa's work can often be observed in fragments and details. As mentioned, the joints between moments are modified and sharpened to serve as transition zones within the spaces. The result is a desired narrative that reveals elements of the building's locale, history, and material. Though the elements are typically isolated from one another, the resultant co-existence complements each of them and results in a blurring of chronology between elements. (Schultz, 2014, p. 16). To sharpen the narrative, Scarpa layers a combination of materials such as steel, wood, stone, marble, concrete glass, tiles, as he introduces new fragments. 
What was there earlier remains in existence like a kind of palimpsest and begins a communication with the newly added elements. The way layers applied at different periods of time are made visible illustrates the development of the buildings. Different epochs and different ways of using forms can exist side by side with their content legible. (Schultz, 2014, p. 16)

Another form of material overlap not mentioned yet is the method of re-use. Prior to Scarpa's modification, Avena had modified the facade of the Caserma facing the courtyard: he inserted Gothic fragments from a nearby palazzo, thereby emphasizing the theme of re-use that is central to the palimpsest.
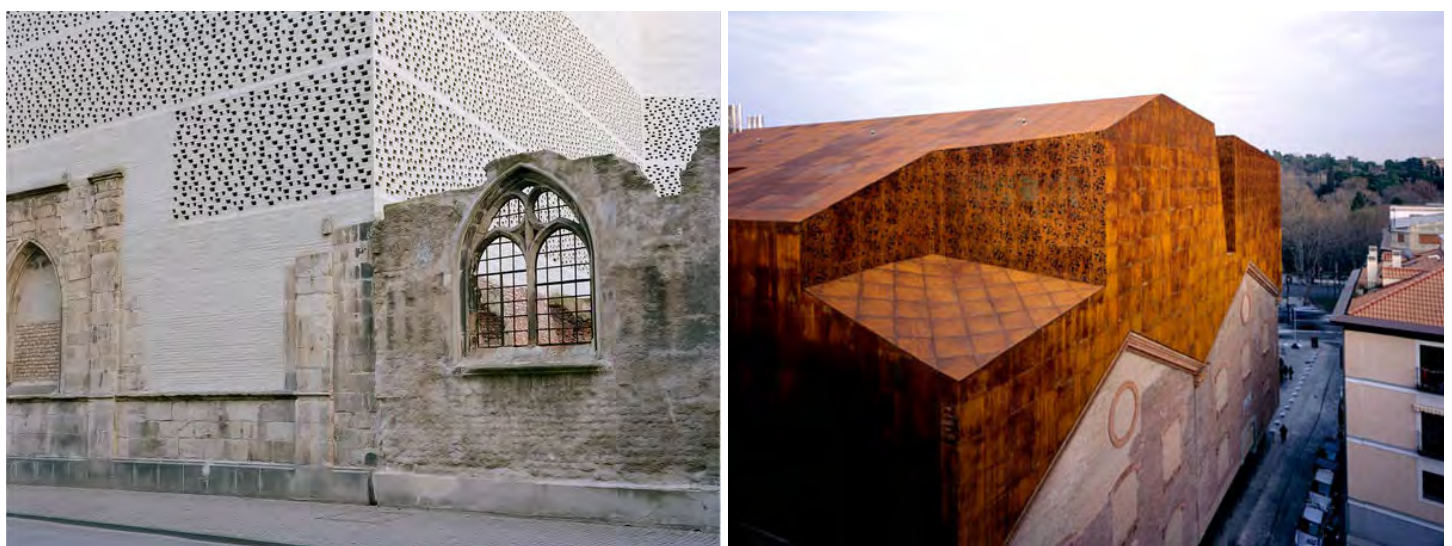

(left) Fig.3.21 Kolumba Museum exterior view close-up

(right) Fig.3.22 CaixaForum's aerial view of hipped roof-scape 


\section{Symbolism}

Similar to the layer of craft at Kolumba, the SESC Pompeia's three new concrete towers carry a layer symbolism that also speaks to the locale and history of the site. The towers were erected and conceived to emulate the old Brazilian military forts near the coast (Lima, 2013, p. 169). Two of them, both sports complexes with a variety of functions, stand on either side of a covered black-water stream, connected via eight walkways/bridges that cross and overlook the water. The third one, the water tower, reveals the central and reoccurring theme of labour associated with the history of the site and with the design of the new institution (Figure 3.23). For its design,

Bo Bardi developed a system of four sliding pieces with interior and exterior wooden forms shaped like two half-circles with slightly conic sections. Each ring was one meter ( $3 \mathrm{ft}$.) high, which allowed one section of reinforced concrete to be cast per day. This system allowed workers to place burlap sacks in the gap between the previously cast section and the bottom of the circular form just before they poured concrete into it. On removal of the forms, an irregular bas-relief emerged from each successive step, creating the image of running concrete around the tower, which suggest the importing of human hands on an otherwise mechanical process. (Lima, 2013, p. 173)

Furthermore, the existing structure and a number of building elements of the former factories remained unmodified, paying respect to the history of the place and allowing for this to continue to be read, with the exception of the sandblasted existing concrete and brick walls mentioned previously (Condello \& Lehmann, 2016, p. 59).

Another reoccurring theme at SESC Pompeia was influenced greatly by the Brazilian landscape and waters. Symbolism is prominent in Bo Bardi's early sketches that depict the aspirations for the design. In addition to the shallow arterial reflecting pools, the design initially included unrealized artificial trees and lower platforms intended "to emulate the islands and banks among the river" (Lima, 2013, p. 164). Similarly, the reading library's raw concrete reading pods are suggestive of the Brazilian gray mountains (Figure 3.24) (Lima, 2013, p. 163).

\section{Conclusions}

Demonstrated through various interventions, several central techniques have been observed in the making of these multi-layered places. The removal of existing building elements was used to subvert the original use or, more significantly, reveal a hidden layer. Incisions are further used to imprint meaning onto structures. The overlap of new content within existing elements displays various techniques ranging from a new circulation, new materials, and the overlap of a symbol onto built form. Through these, all precedents have engaged in a meaningful dialogue with the past even as they have adapted to their current context. 

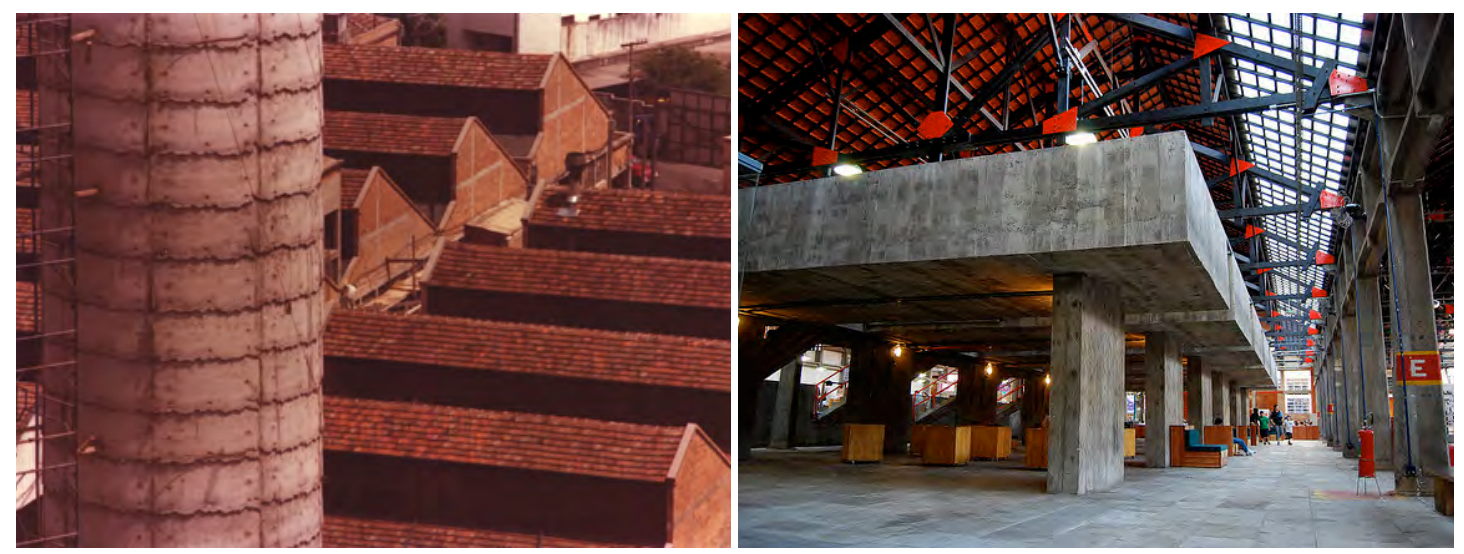

(left) Fig.3.23 SESC Pompeia concrete water tower

(right) Fig.3.24 SESC Pompeia concrete reading pods next to large lounge 



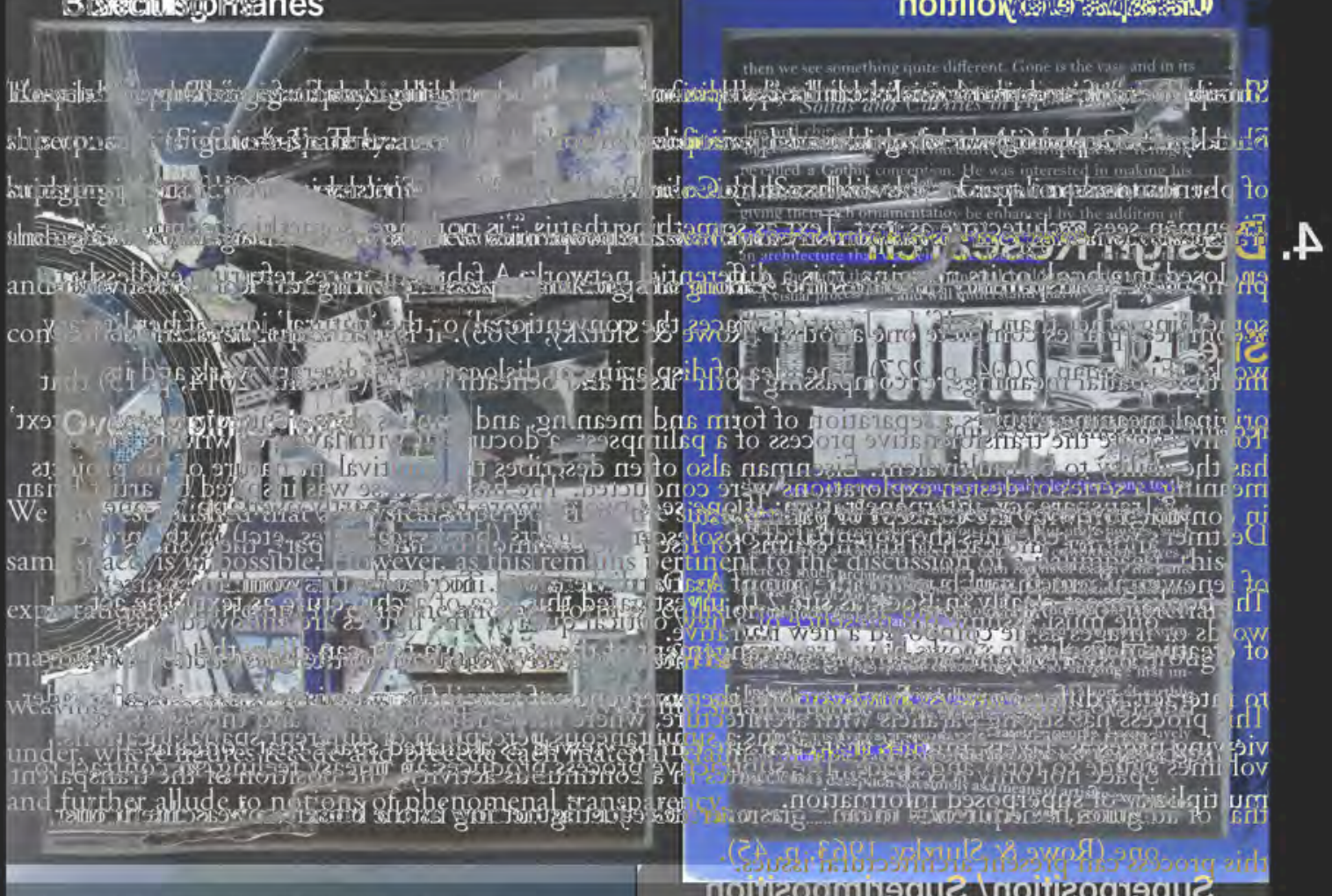

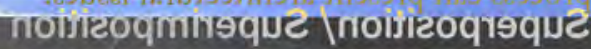

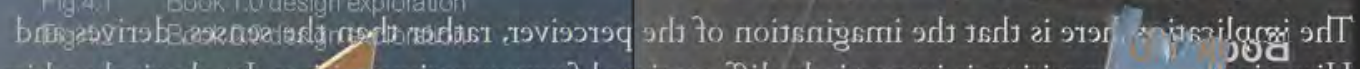

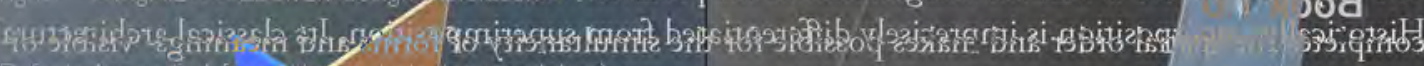

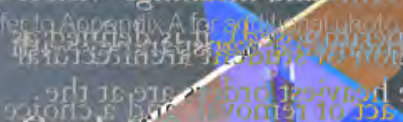
Book in slquith

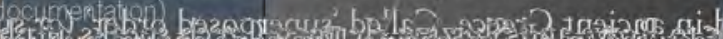
3

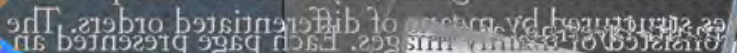

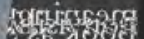

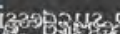

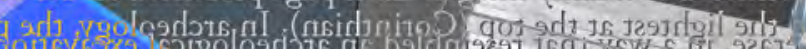

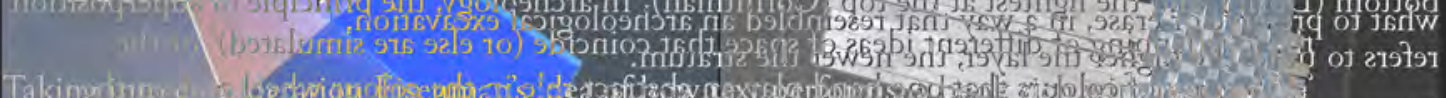

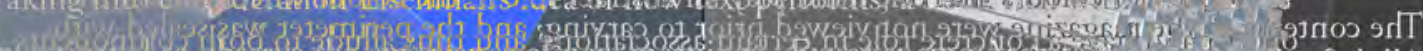

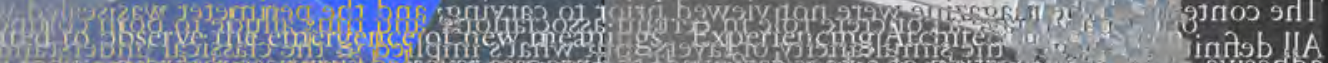

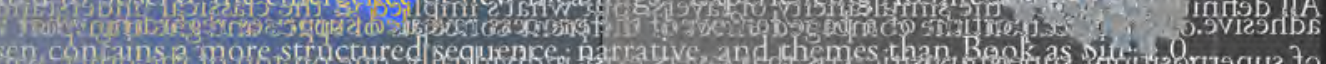

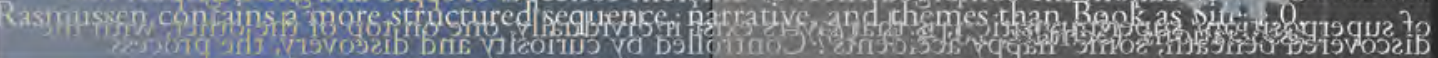

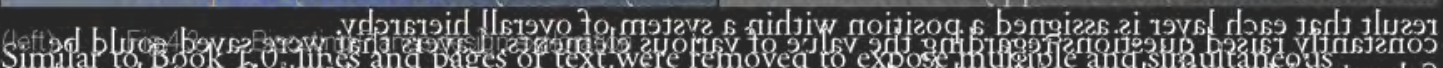

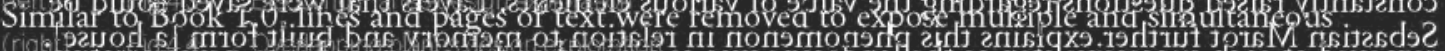

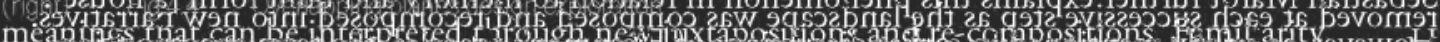

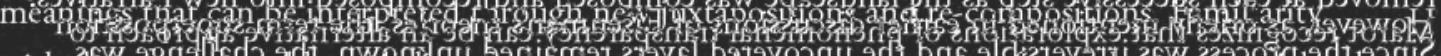

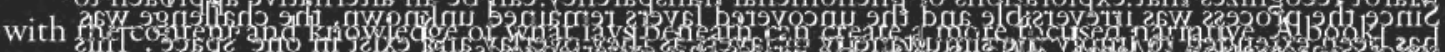

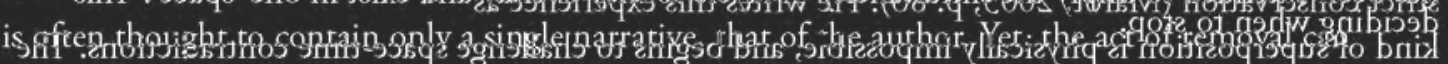

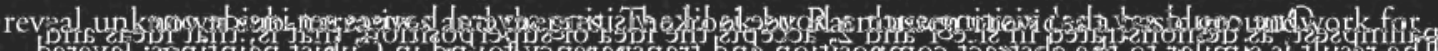

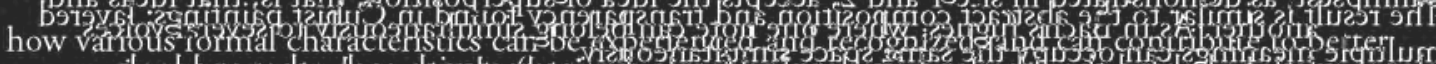

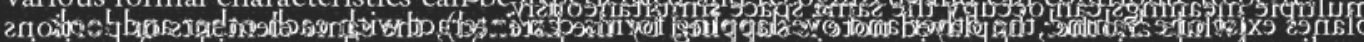
appreciation of architecture. Excerpts from the text present an interesting sub-narrative that describes

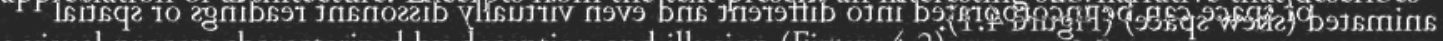

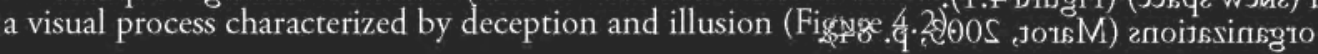




\section{Design Research}

\section{Site 1.0}

To investigate the transformative process of a palimpsest, a document with layers of writing and of meaning, a series of design explorations were conducted. The first of these was inspired by artist Brian Dettmer's work redefines the potential of obsolescent artifacts (books, cassettes, etc.) in the process of renewing them through reinterpretation. As Dettmer carved into books, he would retain certain words or images as he composed a new narrative.

This process has strong parallels with architecture, where three-dimensionality and the resultant volumes allude to form and space. The subtractive process produces an uneasy feeling, in contract to that of addition, which tends to be more reversible. Just as cutting into a book can be contentious, this process can present architectural issues.

\section{Book 1.0}

Book as Site 1.0 is featured in 325 magazine, Ryerson's annual publication of student architectural work. The content consisted of mainly images. Each page presented an act of removal, and a choice of what to preserve or erase, in a way that resembled an archaeological excavation.

The contents of the magazine were not viewed prior to carving, and the perimeter was sealed with adhesive. With each portion of a page removed, the process revealed surprises regarding what was discovered beneath, some 'happy accidents'. Controlled by curiosity and discovery, the process constantly raised questions regarding the value of various elements. Layers that were saved could be removed at each successive step as the landscape was composed and recomposed into new narratives. Since the process was irreversible and the uncovered layers remained unknown, the challenge was deciding when to stop.

The result is similar to the abstract composition and transparency found in Cubist paintings: layered planes exist one behind the other and overlapping forms can interact with each other and look animated (skew space) (Figure 4.1). 


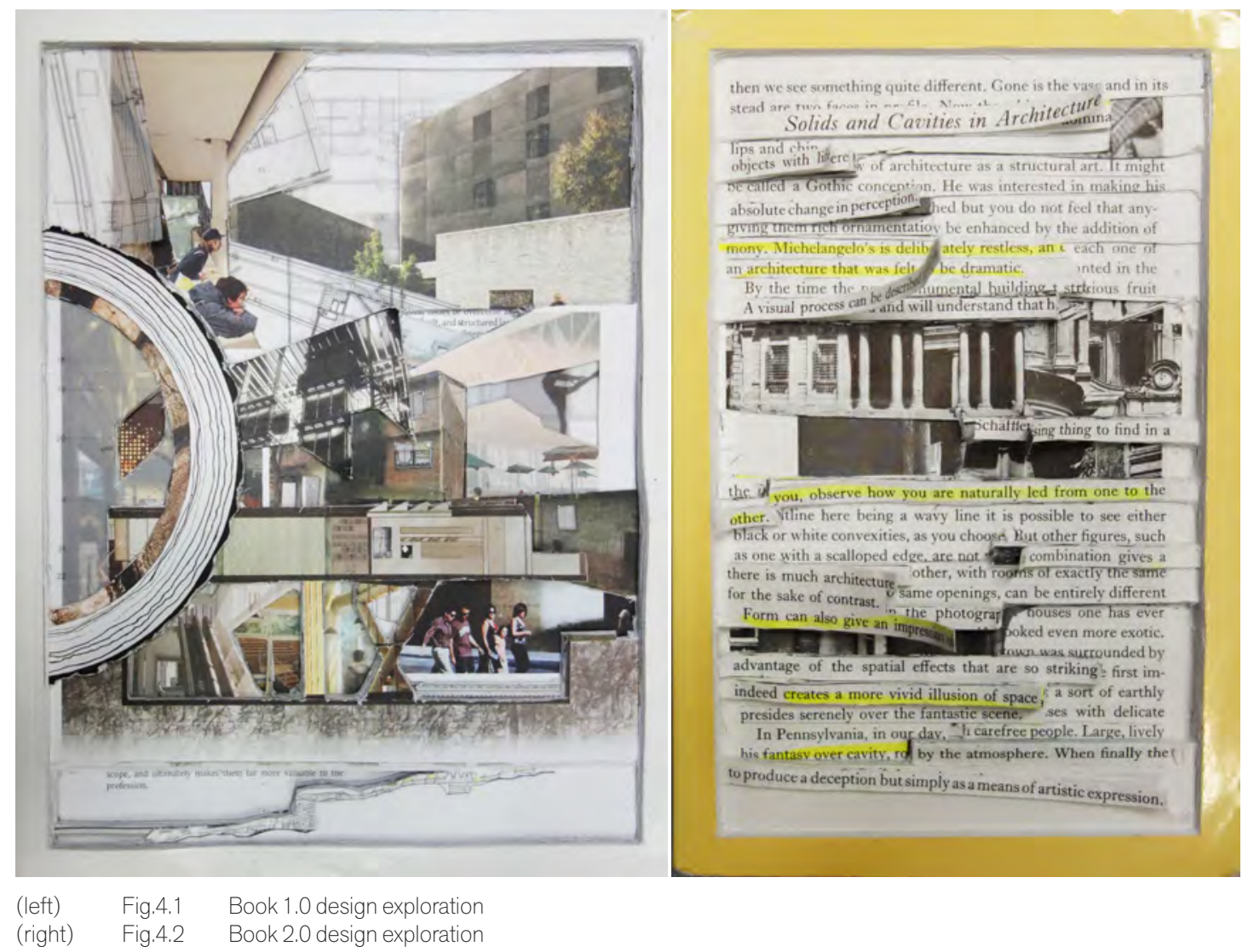

(Refer to Appendix A for additional photo documentation)

\section{Book 2.0}

Taking into consideration Eisenman's idea of how text performs, a book rich with text can be investigated to observe the emergence of new meanings. Experiencing Architecture by Steen Rasmussen contains a more structured sequence, narrative, and themes than Book as Site 1.0.

Similar to Book 1.0, lines and pages of text were removed to expose multiple and simultaneous meanings that can be interpreted through new juxtapositions and re-compositions. Familiarity with the content and knowledge of what lays beneath can create a more focused narrative. A book is often thought to contain only a single narrative, that of the author. Yet, the act of removal can reveal unknown sub-narratives and themes. The book by Rasmussen provides a basic groundwork for how various formal characteristics can be experienced and recognized, and can contribute to better appreciation of architecture. Excerpts from the text present an interesting sub-narrative that describes a visual process characterized by deception and illusion (Figure 4.2). 


\section{Creative Demolition}

This process of 'creative demolition' breaks down the sequence and structure that once supported each book into a completely new story or composition.

Eisenman sees architecture as text. Text as something that "'is no longer something complete, enclosed in a book or its margins, it is a differential network. A fabric of traces referring endlessly to something other than itself' [...] text 'displaces the conventional' or the 'natural' idea of her literary work" (Eisenman, 2004, p. 227). The idea of displacing or dislocating the literary work and its original meaning implies a separation of form and meaning, and implies that architecture read as 'text' has the ability to be multivalent. Eisenman also often describes the multivalent nature of his projects in conjunction with the concept of palimpsest.

The books, most clearly in Book as site 2.0, investigated this idea of architecture as text. The act of creative demolition shows how a re-arrangement of the words in a text can allow the elements to interact in different ways. Furthermore, the emergence of new information and meanings from viewing pages as 'layers' implies that each site can be viewed as a dilated space that contains a multiplicity of superposed information.

\section{Superposition/ Superimposition}

Historically, superposition is imprecisely differentiated from superimposition. Its classical architectural meaning developed in ancient Greece. Called 'superposed order' (or superimposed), it is defined as a succession of stories structured by means of differentiated orders. The heaviest orders are at the bottom (Doric), and the lightest at the top (Corinthian). In archeology, the principle of superposition refers to time: the higher the layer, the newer the stratum.

All definitions suggest the simultaneity of layers. But what's implied in the classical understanding of superposition/ superimposition, is that layers exist individually, one on top of the other, with the result that each layer is assigned a position within a system of overall hierarchy.

However, as briefly mentioned in earlier discussions of Eisenman's theories, the term superposition has been extended to imply the simultaneity of layers as they overlay and exist in one 'space'. This kind of superposition is physically impossible, and begins to challenge space-time contradictions. The palimpsest, as demonstrated in 1 and 2, accepts the idea of superposition, that is, that ideas and multiple meanings can occupy the same space simultaneously. 


\section{Bisecting Planes}

Despite the challenges of physical superposition, abstract physical models were made to investigate this concept (Figure 4.3). They attempt the bisection of two planes, with the imagined/perceived superposition of the two elements existing at the intersection. Small reveals are cut to accentuate the collision invisible to the eye. The size of reveal allows for the continuity of the planes to exist, and thus intersect. Through the process of making, the models confront and confirm the physical contradictions of superposition.

\section{Overlapping Planes}

We have established that a physical superposition, the simultaneity of two objects occupying the same space, is impossible. However, as this remains pertinent to the discussion of a palimpsest, this exploration will attempt to examine another form of collision where the union of the two materials may indicate a blurring of, and perhaps hybrid state of, the converging layers (Figure 4.4). Through weaving, the material is broken down and dissolved into smaller units. The act of going over and under, where figures recede and precede each material 'claims for itself the common overlapped part' and further allude to notions of phenomenal transparency.
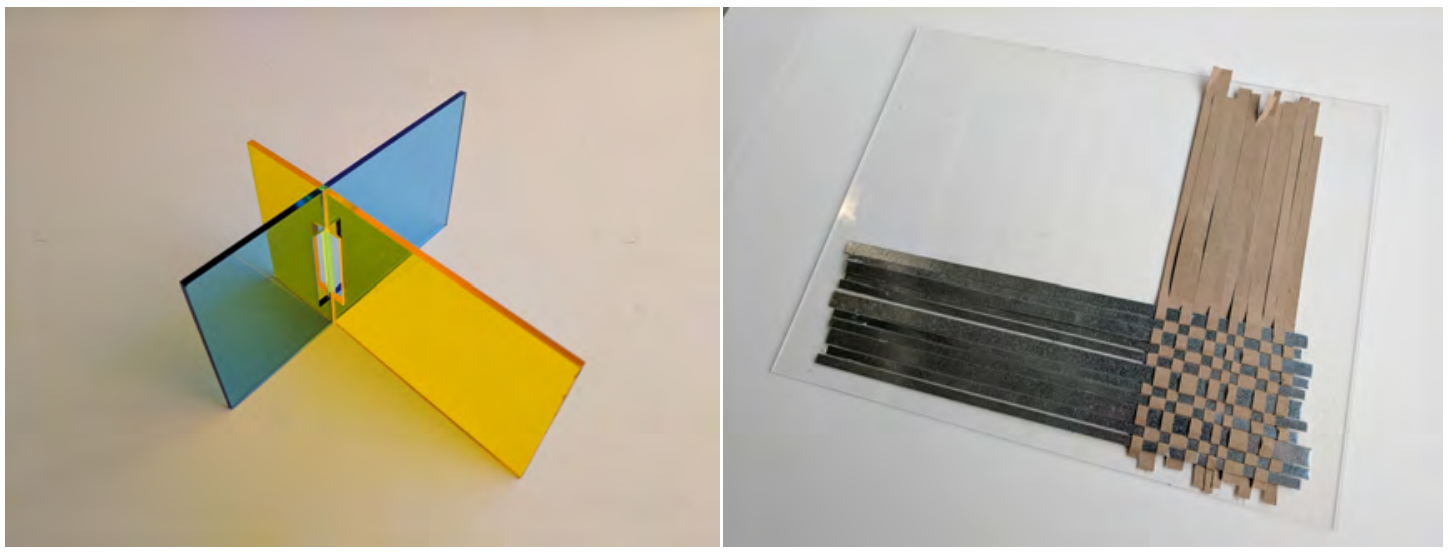

$\begin{array}{lll}\text { (left) } & \text { Fig.4.3 } & \text { Bisecting Planes design exploration } \\ \text { (right) } & \text { Fig.4.4 } & \text { Overlapping planes design exploration }\end{array}$ 


\section{Transparency}

Simultaneity, interpenetration, and the "conditions to be discovered in a work of art" (Rowe \& Slutzky, 1963, p. 161) with regards to superimposed forms are all terms that allude to notions of phenomenal transparency as discussed by Colin Rowe and Robert Slutsky in 1963. Literal transparency is a type of visual porosity attributed to properties of materials such as glass, whereas phenomenal transparency describes the reading of space made possible with stratified planes, where incomplete planes complete one another (Rowe \& Slutzky, 1963). It is assumed that each layer has multiple spatial meanings, encompassing both "itself and beneath itself" (Schultz, 2014, p. 13) that require constant re-reading.

Transparency, interpenetration: If one sees two or more figures partly overlapping one another, and each of them claims for itself the common overlapped part, then one is confronted with a contradiction of spatial dimensions. To resolve this contradiction, one must assume the presence of a new optical quality. The figures are endowed with transparency; that is, they are able to interpenetrate without an optical destruction of each other. Transparency however implies more than an optical characteristic; it implies a broader spatial order. Transparency means a simultaneous perception of different spatial locations. Space not only recedes but fluctuates in a continuous activity. The position of the transparent figures has equivocal meaning as one sees each figure now as the closer, now as the further one (Rowe \& Slutzky, 1963, p. 45).

The implication here is that the imagination of the perceiver, rather than the senses, derives and completes the spatial order and makes possible for the simultaneity of forms and meanings- visible or non-visible. Further to Rowe and Slutzky, Herman Czech speaks of phenomenal transparency with regard to 'historical multi-layering' as the

[t]he 'overlapping of different ideas of space that coincide (or else are simulated)' or the 'ambiguity of colours that one hand play an abstract role in the colour wheel and on the other hand have a concrete role in certain associations' and thus allude to both components of stratification, the combined effect of different concepts of space and the transport of associations. (Schultz, 2014, p. 16)

Sebastian Marot further explains this phenomenon in relation to memory and built form [a house]. Marot recognizes that explorations of phenomenal transparency can be an alternative approach to strict conservation (Marot, 2003, p. 86). He writes this experience as

One could say that visiting such a house is like visiting several houses set inside one another. As in Bach's fugues, where one note can belong simultaneously to several voices (while another, unplayed note is supplied by the listened), the same elements or portions of space can be incorporated into different and even virtually dissonant readings or spatial organizations (Marot, 2003, p. 84). 


\section{Conclusions}

These abstract investigations highlighted the themes of overlap, simultaneity, and perception. Their superpositions of time-space transcend temporal conditions and can therefore become a tool in bridging past and future conditions. Through this, the result resembles that of a palimpsest, where ambiguous forms and colours dwell within the successive layers. 



\section{Lieux de Memoire in Architecture}

The design project is investigated using Pierre Nora's definition of Lieux de Memoire. To reiterate the definition, these realms can be defined as places, sites, and causes in which cultural memory crystallizes. They trigger a group's collective remembrance through the co-existence of "three sensesmaterial, symbolic and functional" - and they must always coexist (Nora \& Kritzman, 1996, p. 14). To demonstrate this architecturally, the definition is extended to include formal and significant qualities of memorable spaces in architecture.

Formal aspects of a site include material constituents of colour and texture, but are also considered to include an object's overall composition, form and characteristics. Exposed materials of steel columns and trusses can trigger remembrance of an industrial past, while form and rhythm can trigger memories of an architectural style from the past. Even an absence or void between elements can be symbolic, and can be used as a formal expression.

The significance of a site is dependent upon the qualities that deem it important or valuable. These can include an event or an object, and often related to how an individual, or a collective, identifies with it. While Symbolism is representation of an idea or concept, significance focuses on the meaning/ essence of something. This can be manifested through a representation of its form and typology as "they signify the context and totemic meaning from which collective identity emerges" (Nora \& Kritzman, 1996, p. x).

Lastly, the functional is related to architecture in terms of an experience or purpose (Nora \& Kritzman, 1996, p. 19). For example, regarding circulation and how people used or move throughout the site, a certain gesture can be used to indicate a movement, habit or ritual. The use of light and shadows can also add to the overall spatial atmosphere of a previous function.

The concepts are explored at a site in downtown Toronto that will provide an opportunity to engage with a multitude layers, is open for redevelopment, and plays a vital role in the public realm, spaces that are collectively shared and remembered. 


\section{Site 2.0 Layers}

The city absorbs, uses, and regenerates every form of movement. Even scholars, years apart, seem to agree that, in certain phases of history, the very essence of the metropolis lay in its market and busy streets.

(Calabi, 2004, p. xxiii)

We have witnessed this in the history of great commercial cities, where urban transformations were reflected in the changing function of marketplaces. In 1803, the expanding town of York initiated its first public market called the Market Square, now known as the St. Lawrence Market and located at King and Jarvis Streets. It was the first of its kind and the center of public gatherings and civic functions that ranged from public markets to prosecutions.

In 1834, the year of the incorporation of City of Toronto, the rapid growth of the city resulted in the expansion to the area west of Peter Street, annexed for military purposes (garrison reserve/common). The new western boundary became Bathurst Street, Queen Street (formerly known as Lot Street) on the north and Parliament Street on the east (City of Toronto, 2012, p. 11).

To accommodate the needs of residents traveling great distances to the Market Square, the Dominion Government reserved two additional plots of land for public markets. The first of the two, declared St. Patrick's Market in 1836, was located between current day McCaul and John Streets on Queen Street West and continues to exist today. The second, the West Market Square (later renamed St. Andrew's Market), was declared shortly after in 1837 and located on the land that stretches from Richmond (formerly Simcoe Street) to Adelaide Street, between Brant and Maud Street (formerly West Market street). The market surpassed St. Patrick's in size and became the second largest of the three. The selected site is now home to the Waterworks building on the north and St. Andrew's Playground on the south (Figure 5.1) (City of Toronto, 2012, p. 11). 


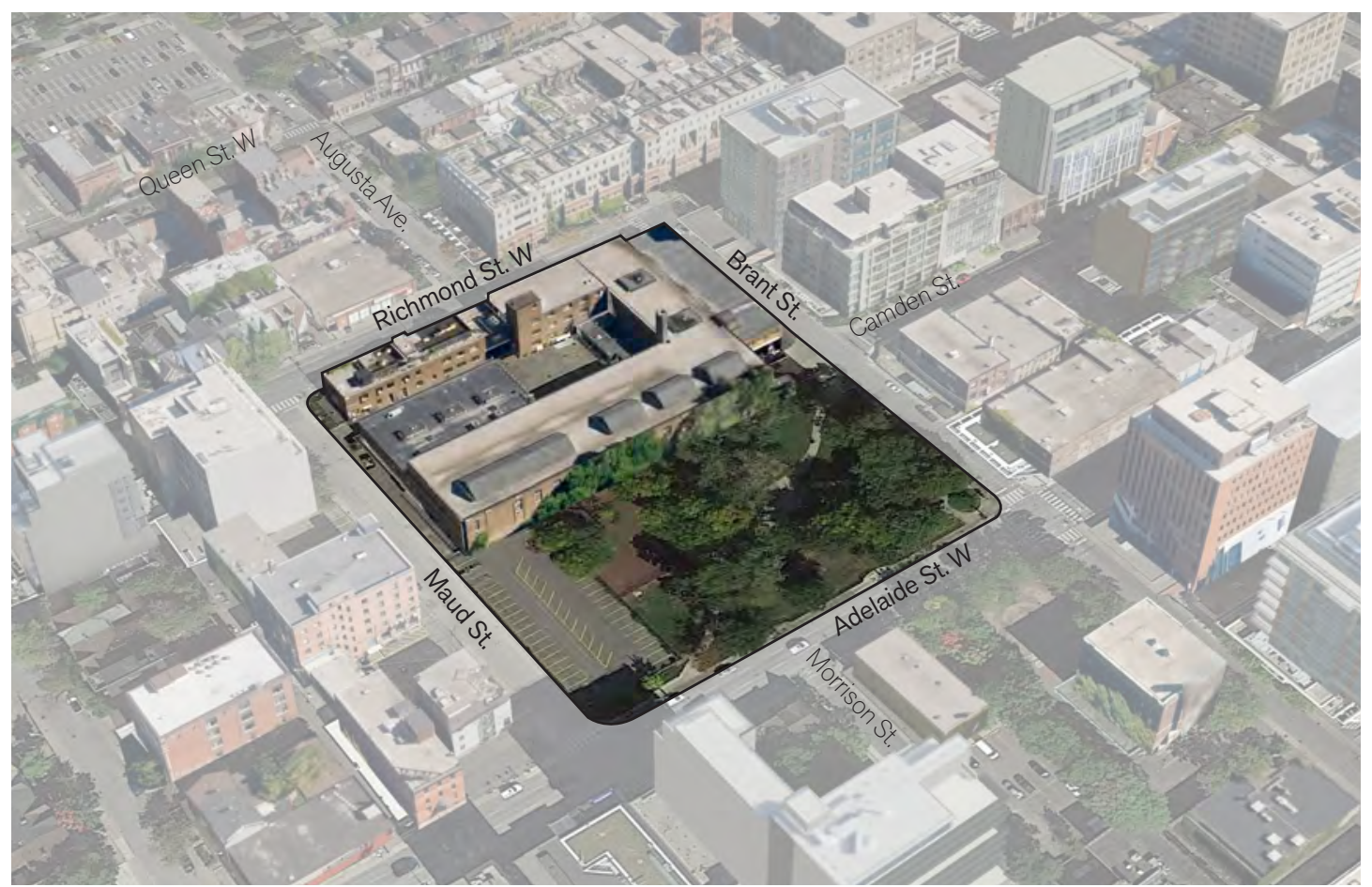

Fig.5.1 Site 2.0 Location Map 


\section{The West City Market}

In the West City Market square, the block of land was initially used as an open-air market where vendors sold their produce from temporary tented market stalls (Taylor, 2010, p. 33). With population rising and inhabiting western extents, the advent of public transportation via stagecoaches (called Omnibuses), and the great fire of 1849 which destroyed much of St. Lawrence Market, there was an increased demand for a permanent structure on the west side of the city.

In 1850, a wooden structure was erected at the centre of the site by architect Thomas Young, who also designed the original wooden St. Patrick's Market building (Taylor, 2010, p. 33). Following the civic roles of the previous two markets, the West Market Square hosted a police station and a fire bell (Taylor, 2010, p. 33) (Robertson, 1974, p. 576). In The Villages of Within, the author provides the following description:

Along the outside walls were produce stands, with canvas awnings sheltering the patrons from the hot summer sun and the rains of spring and autumn, as well as the snows of winter. At the south end of the square, on Adelaide Street, they erected a shelter to protect the horses from the elements. The remainder of the square was green space to accommodate carts, wagons, and the Saturday morning shoppers. Friends greeted friends, in the background the sound of neighing houses and rumbling wagon wheels [...] It was a gathering place to socialize and chat with friends and neighbours. Housewives purchased vegetables, grains, meat, and fish. (Taylor, 2010, p. 33)

The signals of the fire bells were also used to notify residents of certain times of the day, for example " $[s]$ cientists at the observatory at University College send a signal to the town's fire halls when the sun approached its peak at 11:55 am. The fire halls would ring their bells, allowing anyone with a stopped or slowing timepiece to synchronize it with the rest of the city." (Bateman, 2016).

As the landscape continued to rapidly urbanize, the city saw the opening of first of its railway in 1853, one that cut through St. Andrew's ward and continued along Front Street, the former shoreline (Boles, n.d.). As a result, many lots along Front Street were beginning to transform into industrial and manufacturing sites. 


\section{The 1860 Fire}

Ten years after its opening, the West Market Square structure was consumed by a fire. In Landmarks of Toronto, the author provides the following excerpt:

The last fire for 1860 was that which destroyed St. Andrew's market [...] A few minutes before the twelve on the night of December 26, Acting Sergeant Dunlop observed flames bursting through the roof near the centre of the building, and ran to the spot, accompanies by several constables. An attempt was made to get at the fire bell, but the intense heat rendered this impossible [...] The building cost five thousand dollars in 1850, and was the property of the corporation. Origin of the fire was not known. (Robertson, 1974, p. 632)

Following the fire, the site operated as an open-air market yet again.

\section{St. Andrew's Revival}

Toronto's first official streetcar route (horse drawn) was laid down in 1861. It consisted of two major lines, and made transportation to and from city centres easier. The first ran on the same path as the Omnibus (Yorkville to St Lawrence) and the second went from Yonge to Ossington (formerly Dundas) along Queen St West, just one street north of the selected site (Brader, 2015).

With improved accessibility and an increase in residents, the reconstruction of a larger market and grand hall called St. Andrew's Hall and Market occupied the empty site (Figure 5.2 to Figure 5.4). It was located further north on the site fronting Richmond Street and designed in Renaissance Revival style in white brick by architect William Irving (Taylor, 2010, p. 36). To commemorate the opening of the new square and building, "a civic ball was held [...] Ladies in formal long dresses and elegant gentlemen in frock coats attended. It was a long remembered gala.” (Taylor, 2010, p. 36).

In its opening years, the market's stalls and general stores thrived. On the first floor, "the stalls on the east side contained five butchers, and there were eight on the west side. [In 1880] None of the stalls was empty" (Taylor, 2010, p. 37). To accommodate for more, overhanging eaves permitted for extra stalls to be erected on the outside (Taylor, 2010, p. 38). The second floor's grand hall hosted civic and social functions where "people gathered to listen to visiting soloists, guest lectures, and politicians, as well as to attend religious gatherings and hear authors or other persons of interest" (Taylor, 2010, p. 39). The building serves as an integral part of the community and the social centre of the west. In addition, the, Toronto Public Library opened its second location on the ground floor of the Hall building in 1884, making it the only library in the western part of the city (Taylor, 2010, p. 39) (ERA Architects, 2016, p. 8). 

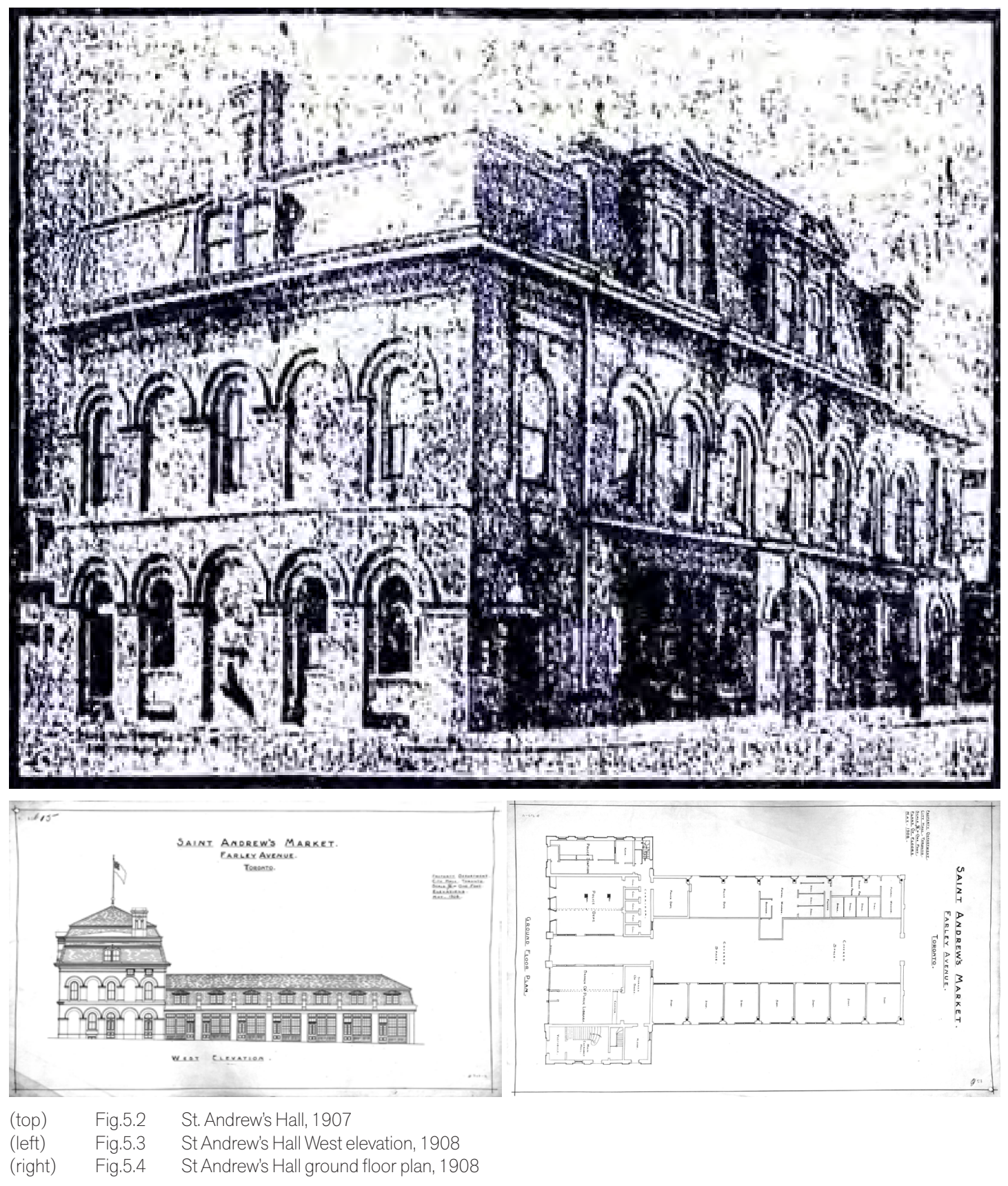

(Refer to Appendix B for additional documentation) 


\section{The Annex Building}

With rise of shops on Spadina Avenue, the demand for marketplaces slowly declined. In an effort to revive market activity, a large red-brick annex building was constructed on the northwest corner, with a courtyard in the middle (Figure 5.5 to Figure 5.7) (Taylor, 2010, p. 38). Construction commenced in 1889 and opened in 1893. A feasibility study from 1931 completed by the Water Works

Department describes the annex building as

$[\mathrm{C}]$ onstructed of nine-inch bricks and was erected with steel beams. The roof beams were forty seven feet in length, the roof hoarding four feet by four and a half feet, with the planking 1.75 inches thick. The coal room and boiler room were in the basement and the first floor contained storage space, as well as management offices. A woodworking shop was on the second floor" (Taylor, 2010, p. 41).

The stalls in the annex hosted shops and market stalls selling produce such as vegetables and meat, as well as hay and feed supplies (Taylor, 2010, p. 38). There was also a smaller structure on the west, across from current day Camden Street that was the 'weigh house', where merchants would weigh their produce (Taylor, 2010, p. 38).

The Annex was also home to police station number 3 (Taylor, 2010, p. 37). As the need for room increased, the market stalls in on the north-eastern portion of the building converted into prison cells, with women on the ground and men in the basement. (Gladstone, 2012).

As the structures were built on the northern portion of the site, the city built a new thoroughfare continuing from Camden Street that severed the block in half. 

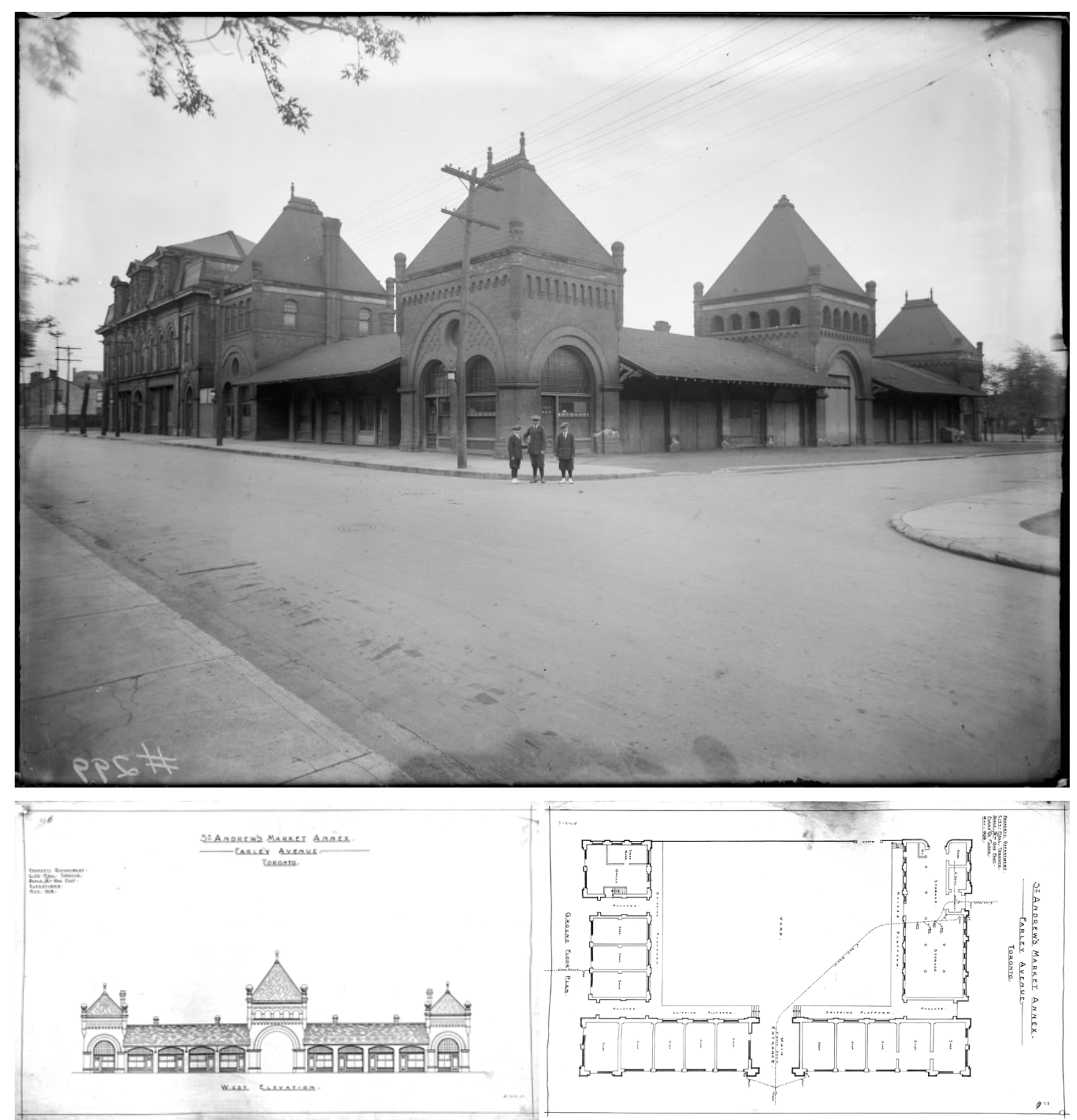

(top) Fig.5.5 St. Andrews Market Annex Building, 1921

(left) Fig.5.6 St. Andrew's West Annex Building West elevation, 1908

(right) Fig.5.7 St. Andrew's Market Annex Building ground floor plan, 1908

(Refer to Appendix B for additional documentation) 


\section{The Changing Landscape}

By the turn of the century, technological advancements along with the advent of electric streetcars saw major advancements in transportation and accessibility in the city. Many of the homes on Spadina Avenue and Queen Street were commercialized into shops and stores (Taylor, 2010, p. 40). As a result, demand in the market was declining and "by the year 1900, the butchers had all departed from the market. In the main building of the market, only two of the interior spaces were occupied. The York Rangers rented one as a storeroom, and the other the Police Patrol Department leased [...] In the Annex, the decline was also visible as fewer merchants and more businesspersons rented space" (Taylor, 2010, p. 40).

From the vendor's side, the policies put in place by the municipal government imposed a new market fee on the vendors. In addition to the municipal policies, new market rules stated that vendors could not sell their goods within a certain distance from the market square. In combination, these new rules and policies forced vendors into becoming tenants of the market building and pay the new fees while facing decreased income due to a dwindling customer base. (ERA Architects, 2016, p. 9)

The landscape was also influenced by the Great Fire of 1904, which destroyed the manufacturing sector along Front and Bay. Due to the site's close proximity to shipping and rail lines, the industrial and manufacturing sector re-surfaced in the King-Spadina neighbourhood, resulting in the decline of residential housing and a change in demographics within the neighbourhood (City of Toronto, 2012, p. 12).

\section{St Andrew's Playground}

During the market's decline in 1909, the park south of the markets was designated as Toronto's first children's playground and used for supervised public recreational activities. Similar programs had already been implemented within the other markets. For instance, in 1890 St. Patrick's Hall and the St Lawrence Market installed iron basketball hoops inside their halls (Bateman, 2016). Play and recreation became an important layer of this site and the city around this time.

The park was declared as St. Andrew's playground and incorporated a wading pool, a pavilion that housed washrooms and indoor recreation space for special events, dispersed teeter-totters and swings, as well as a wire fence running north south that once divided the park into two (Taylor, 2015). Archival images show children participating in organized recreation (Figure 5.8 to Figure 5.10).

Directly south of the park was the Brant Street Public School. During its commencement in 1926 "it was in the heart of a vibrant residential community. The 1920s was an era when families were larger than today, and the school housed a considerable student body" (Taylor, 2010, p. 51). 

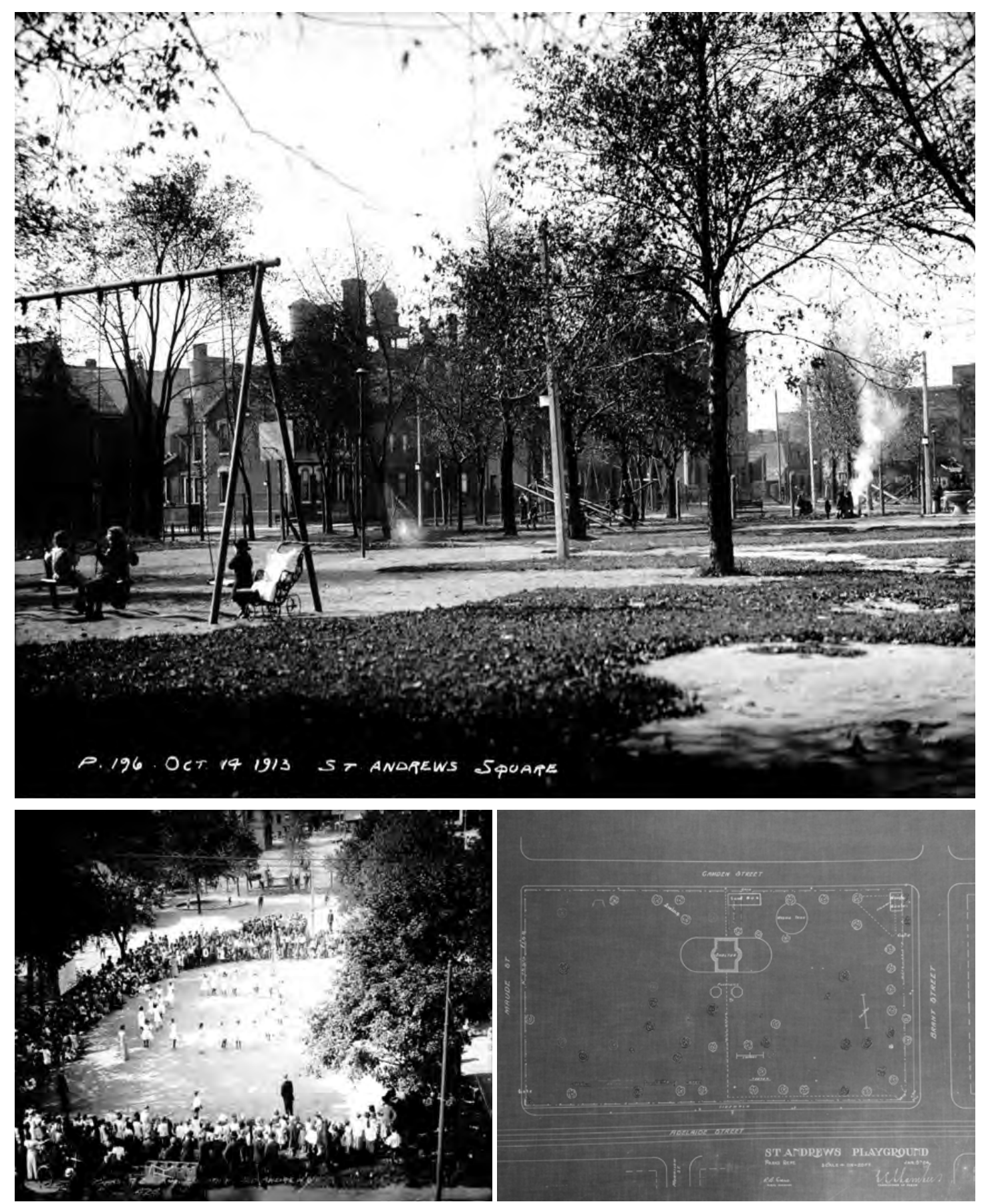

(top) $\quad$ Fig.5.8 St. Andrew's Playground swing set, 1914

(left) Fig.5.9 St. Andrew's Playground maypole dancing, 1914

(right) Fig.5.10 St. Andrew's playground map, 1924 (Refer to Appendix C for additional documentation) 


\section{Market closure and the Waterworks Building}

By 1910, marketplace activity had declined even more. Most of the spaces were used as storerooms, with the few remaining becoming the police station, six fruit vendors, the weigh scales, and in the annex. All that remained were a cabinetmaker, a builder, a carpenter, and a tea shop. (Taylor, 2010, p. 40). Despite efforts to revive marketplace activity, the buildings eventually closed in 1912.

That same year, City Council received a plan to demolish the building and replace it with a new public works facility. Although the proposal was accepted, the site remained dormant until 1931 when the Waterworks Department initiated feasibility studies to convert the St. Andrew's Hall \& Market buildings into the new facility (Taylor, 2010, pp. 40-41). However, the buildings would eventually be demolished in 1932 to make way for the new Waterworks horseshoe- shaped building that continues to exist today (Figure 5.11 to 5.14 ).

The demolition of the market buildings and construction of the new public works building was conceived of by the federal, provincial, and municipal governments as a make-work project to aid unemployed men during the Great Depression (City of Toronto, 2012, p. 12) (ERA Architects, 2016, p. 9).

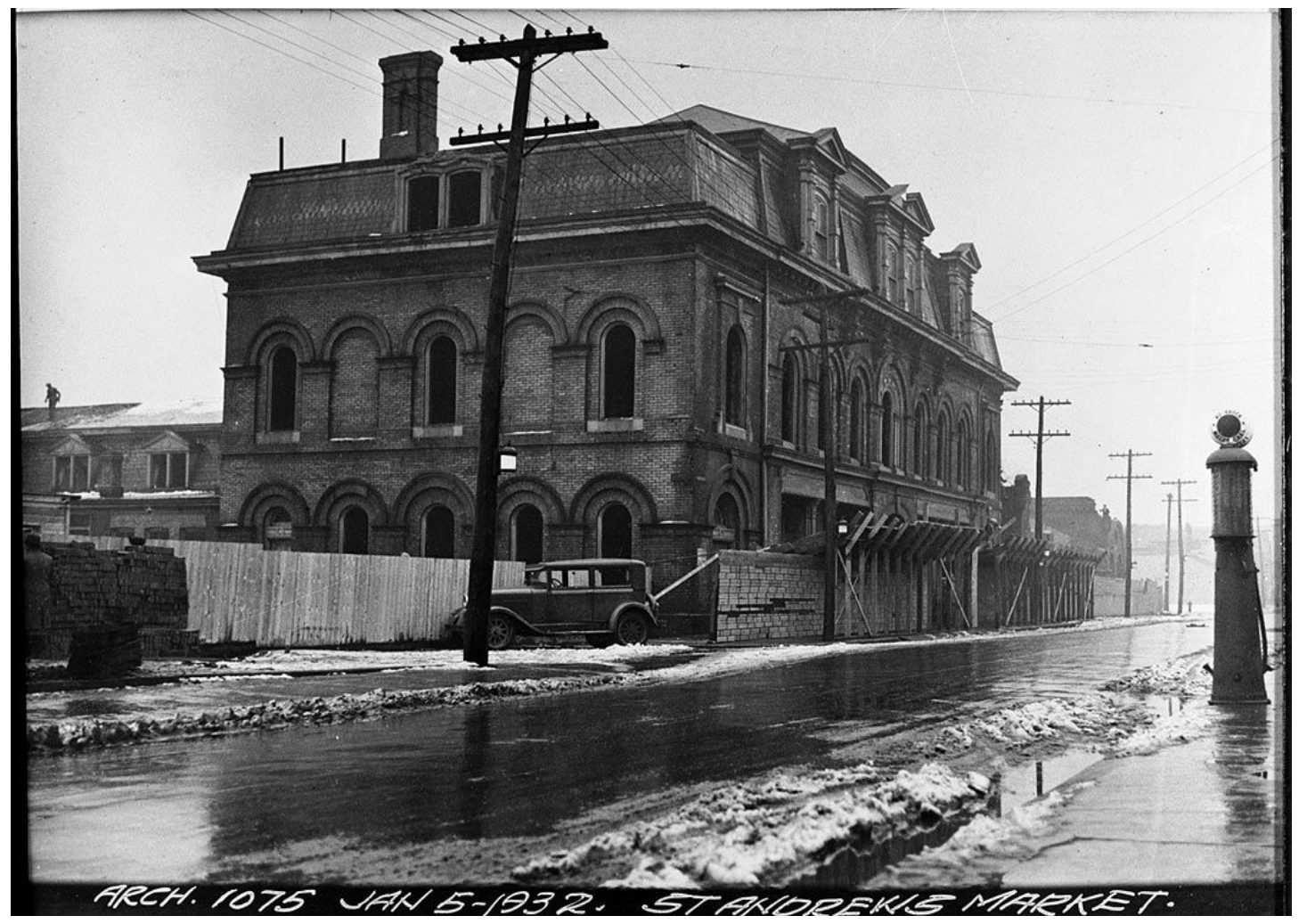

Fig.511 St. Andrew's Market demolition, 1932 

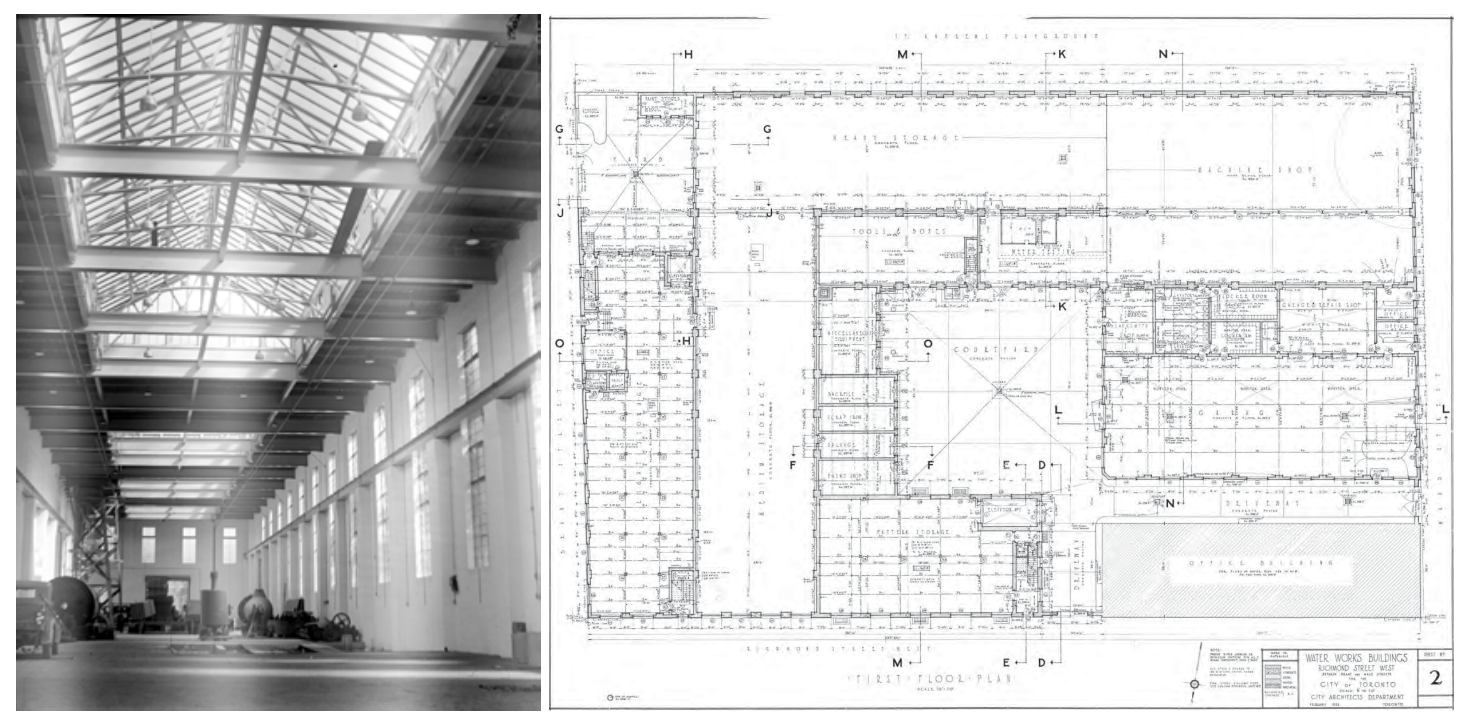

(left) Fig.5.12 Waterworks building inside machine shop, water maintenance machine, 1932, J.J.. Woolnough

(right) Fig.5.13 Waterworks Building - sheet \# 2 First Floor Plan, 1932

(Refer to Appendix D for additional documentation)

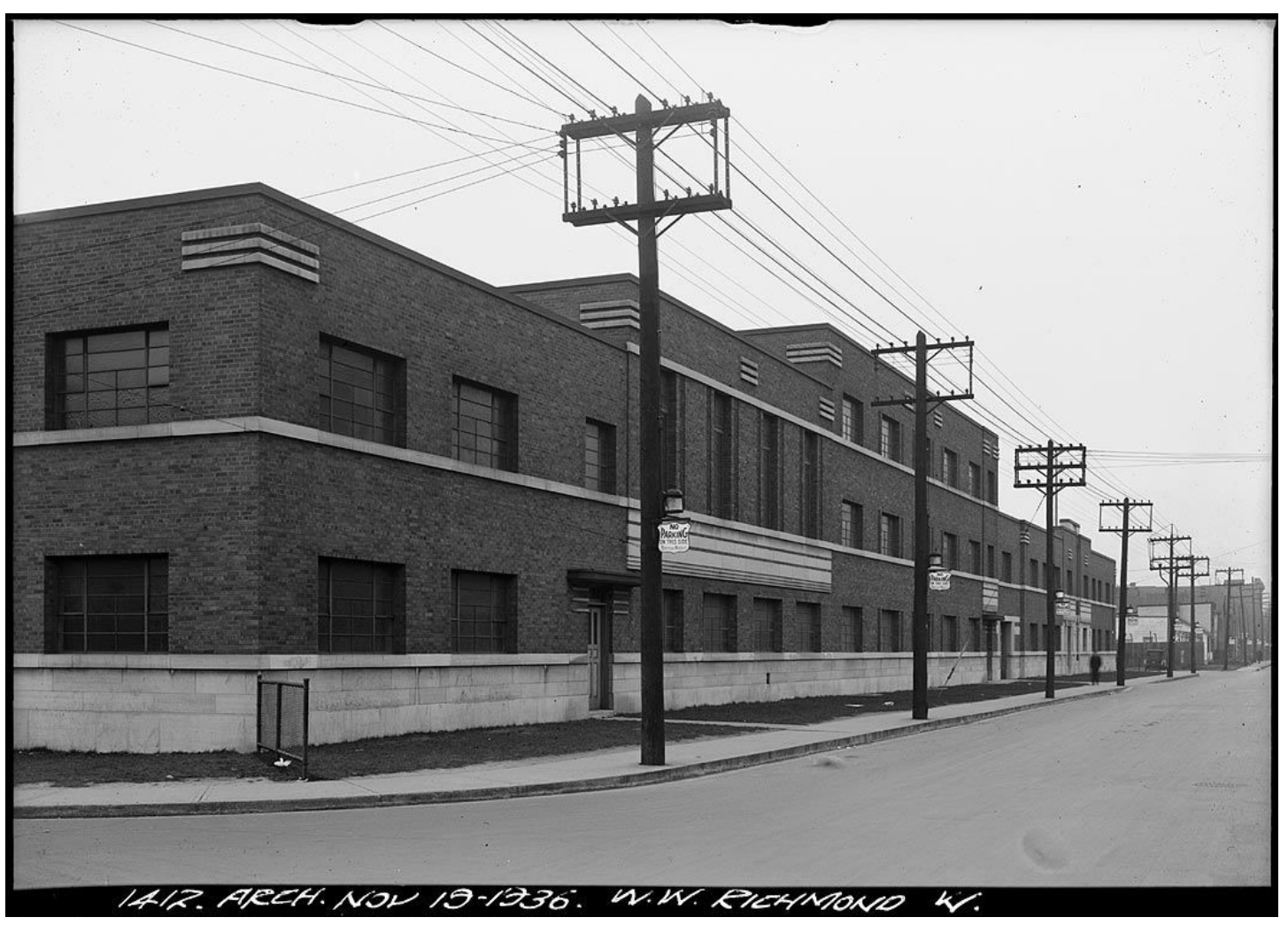

Fig.5.14 Waterworks, 1936 
The building was constructed to house facilities that purified city water at a time when the Garrison Creek had just been transitioned into a subsurface sewer due to pollution; its continuing use was a pressing issue for urban health (Yu, 2016). It was designed by city architect John James Woolnough in Art Deco style (ERA Architects, 2016, p. 15). This style originated in France just before WWI and gained popularity in North America in the 1920s and 1930s and influenced fashion, art, and architecture.

The new full-block building consists of eight sections and was primarily constructed as a water treatment facility, with large storage facilities in the south and west buildings (Figure 5.15). The 2-storey machine hall was designated for heavy storage, a machine shop, a boiler area, and a testing pit in the southern portion (volume 1) fronting at St. Andrew's Park. The space was connected to the medium storage on the east (volume 2) and one-storey building designated for light storage (volume 3).

In the courtyard, the garage storages had previously hosted a paint shop, salvage services, and a number of other smaller programs (volume 4). Attached to the south hall on the west, Maud Street was the one-storey garage fronting Maud Street (volume 5). This space hosted a repair shop, blacksmith and worker support spaces. Central to all these volumes is an outdoor courtyard (volume 6) with a vehicular access driveway leading from Maud Street as well as a covered driveway accessed midway from behind through the Richmond Street facade.

The administrative side of the building consisted of the volumes fronting Richmond Street. At the time of its construction, the north-west volume was called the 'office building' (volume 7) hosted city worker offices and a drafting room. A three-storey volume attached to the office building on the east (volume 8) hosted a pattern storage area and pattern shop. During the Great Depression, textile and fabric warehouses provided employment for women. This neighborhood gained a reputation for involvement in the 'rag trade' and it continues to be a clothing district with clothing stores and a suitable name, the Garment District.

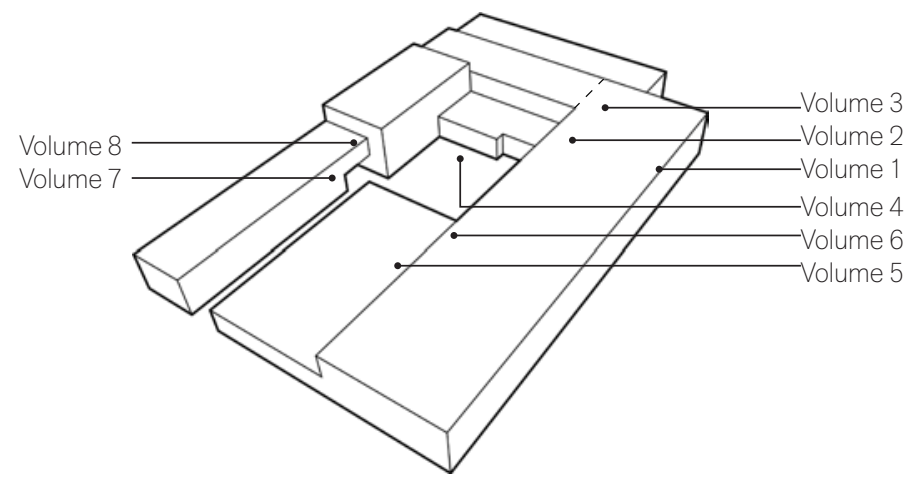

Fig.5.15 Waterworks Program Diagram, 1932 
In the 1970 s, the manufacturing industry in the urban core began relocating to the suburban periphery and outsourcing their services to other countries. As warehouses experienced a decline, "prevailing zoning regulations for the area specified industrial use only and property owners, not permitted to lease to non-industrial tenants and facing high vacancy rates, began demolishing buildings with heritage value in order to reduce realty taxes." (GDNA, n.d.)

Then in the mid-1990s it became obvious that land use restrictions needed to be loosened. In 1996 a zoning change resulted in the elimination of traditional land use restrictions and re-designation of these districts as "regeneration areas" to encourage re-investment, create housing opportunities and offer creative spaces for new businesses. Two "heroes" behind this innovative legislation were then-Mayor Barbara Hall and urban activist Jane Jacobs. (GDNA, n.d.)

Archival photographs indicate that St. Andrew's Park and the south facade of the Waterworks had drastically changed by 1974 (Figure 5.16). On the building, the bottom half of the windows had been infilled and the skylights covered with glazing. In the park, the wading pool, central shelter, and all fencing (around and through the middle of the park) had been removed. The teeter-totters and swings that were previously dispersed throughout the park were also removed and replaced with a downsized playground area at the to the north-east corner of the park. The photographs also illustrate the addition of a wading pool in the north-west side of the park as well as a parking lot.

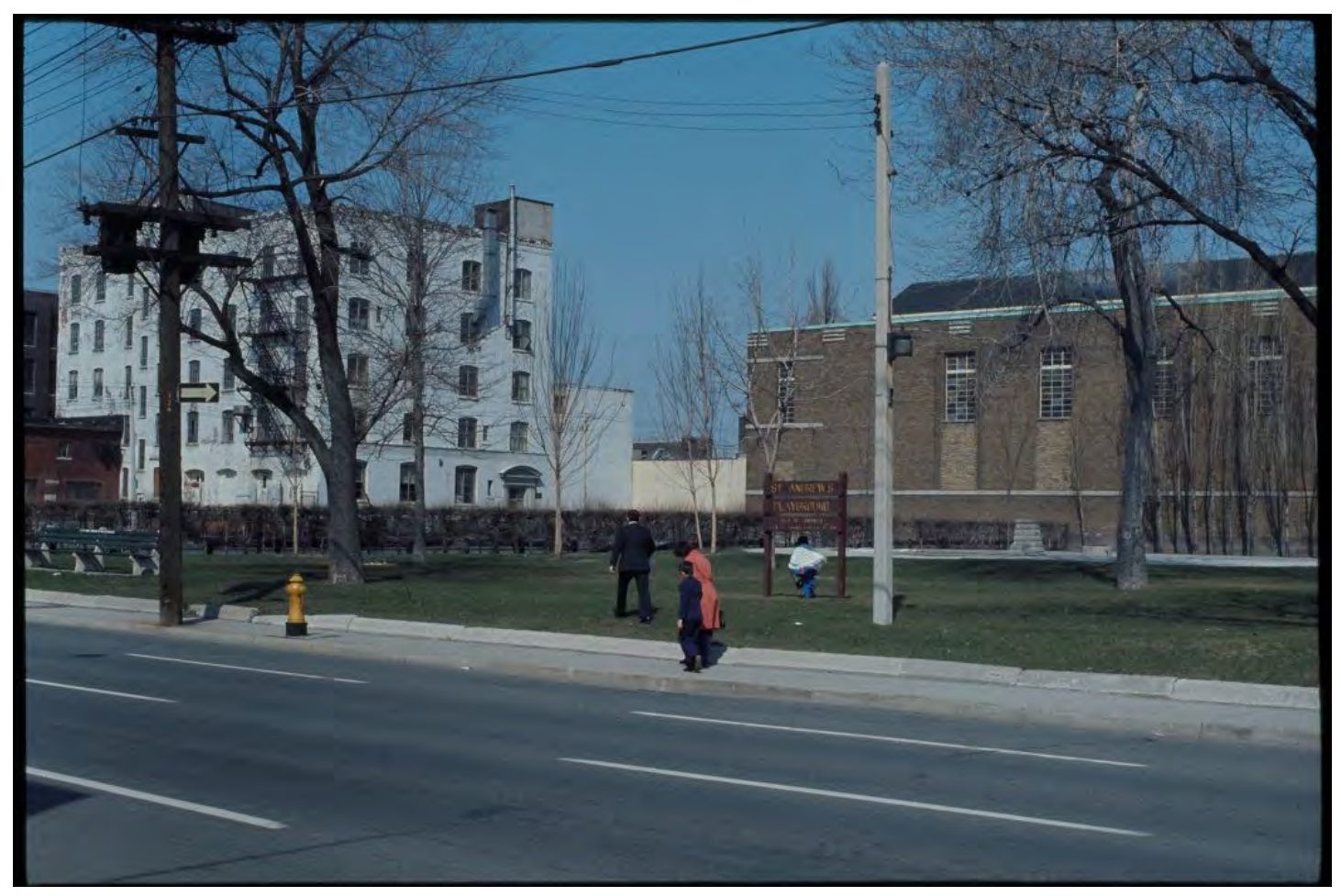

Fig.5.16 St. Andrew's Playground looking north-west, 1974 


\section{Current State}

Currently, the Waterworks building and St. Andrews Park have persevered and continue to endure amidst the city's rapid developments. Since its inauguration as a water treatment facility, the building has taken on many different functions. Due to its large volume and sectioned structure, the site can host a multiplicity of functions.

\section{Style and Construction Materials}

A notable feature of the building is its Art Deco character. Formally, the building had a horizontal and streamlined presence characteristic of this style (Figure 5.17 to Figure 5.20). The rectangular segmented windows are arranged in continuous bands (horizontally and vertically). The window sills become continuous horizontal bands of stone that run around the entire course of the building and further divide each story. Finishing off the top and bottom is a flat roof topped with coping; at its base, a continuous stone plinth wraps around the majority of the building.

The Art Deco style often adapted materials a variety of materials in its construction. At Waterworks, each volume is clad with brick, complete with stone, metal, and wood detailing. Using these materials, while displaying a high level of craftsmanship, the buildings are often decorated with traditional motifs and symbols from previous eras.

On the exterior of each volume, the intricate stonework, such as the 3-course stone banding that wraps around the upper corners, demarcates each volumes or caps entryways. A dogtooth brick details is often observed flanking windows on all elevations, add further texture to the flat facades. Steel detailing is used in the overhead canopies above entryways.
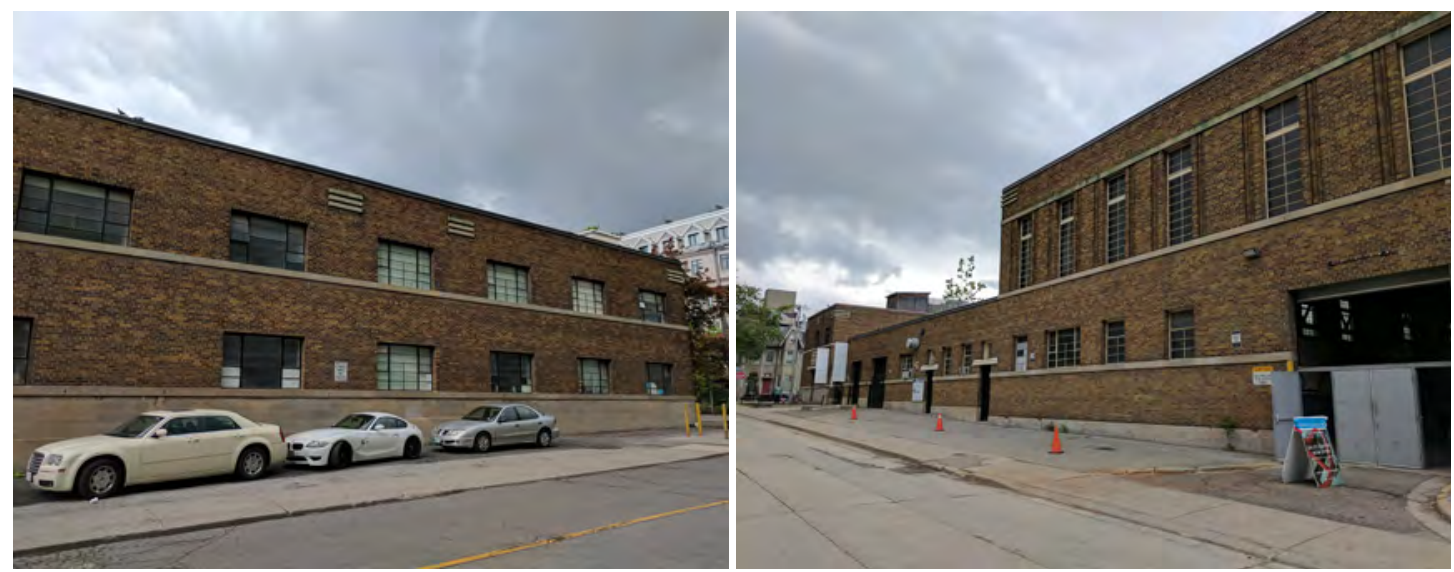

(left) Fig.5.17 Waterworks at Brant street looking north-w est

(right) Fig.5.18 Waterworks at Maud Street looking north-east 

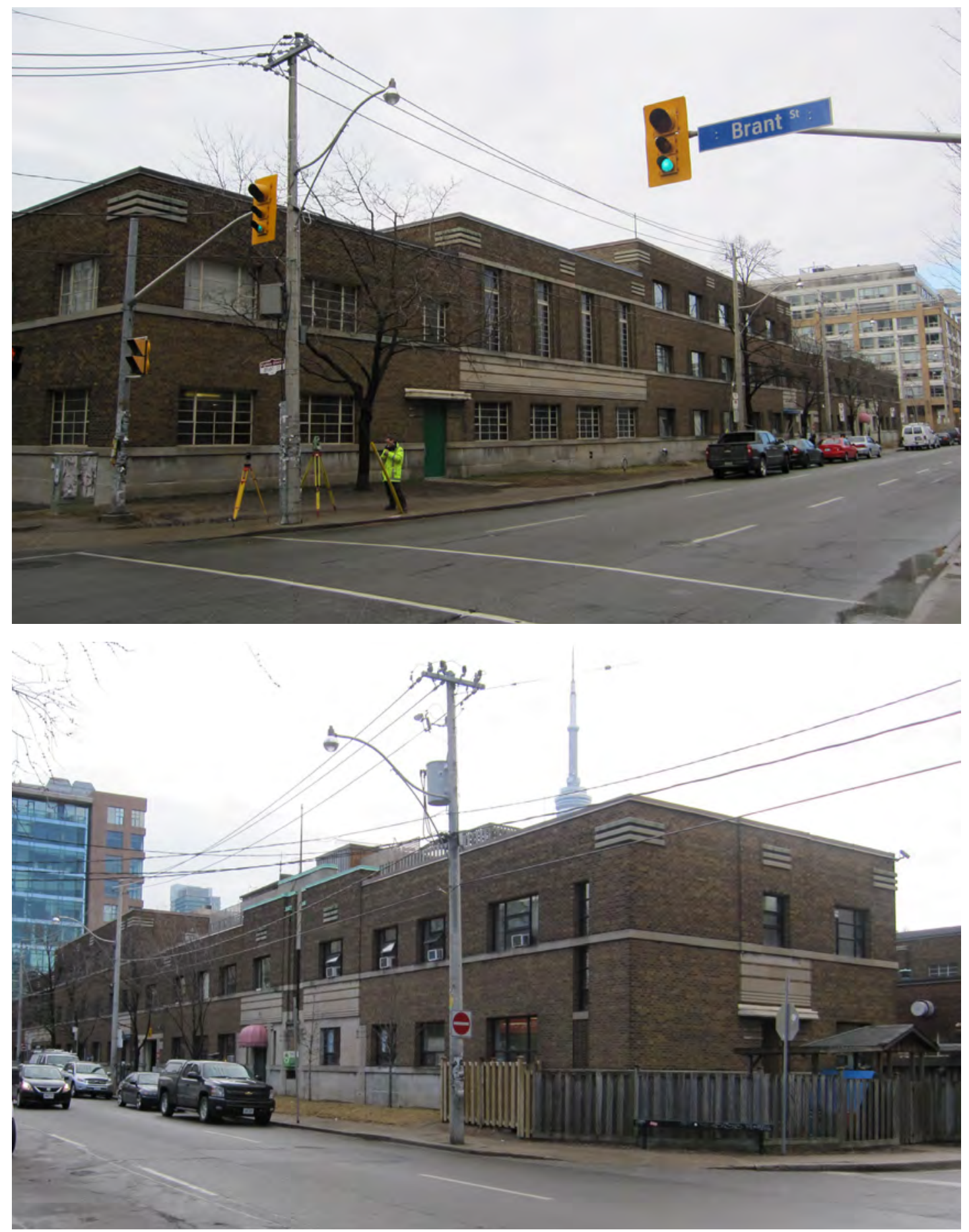

(top) Fig.5.19 Waterworks at Richmond and Brant Street looking south-west, 2012

(bottom) Fig.5.20 Waterworks at Richmond and Maud Street, 2012 


\section{Richmond Volumes and Office Building Entrance}

The volumes fronting Richmond Street most recently hosted a social services agency, a daycare and Montessori school with a play area on the north-west and a roof-top playground. As well as smaller offices occupied by city divisions (for instance, Toronto Parking Authority) as well smaller businesses/ organizations.

The former office building, at the corner of Maud Street and Richmond Street, is the location of the main entrance of the administrative side (Figure 5.21). The entrance is pushed in from the facade, to give the 'theatrical' appearance of receding layers, an effect often found in grand Art Deco style entrances (Figure 5.22). Adding further dimension, the doorway and adjacent window is framed with intricate stonework. The upper two windows are topped with a 3-course banding, further marking it as the main an entryway (Figure 5.23). Capping all of this is a chevron detail with the year '1932' (the year of its construction) etched into the stonework.
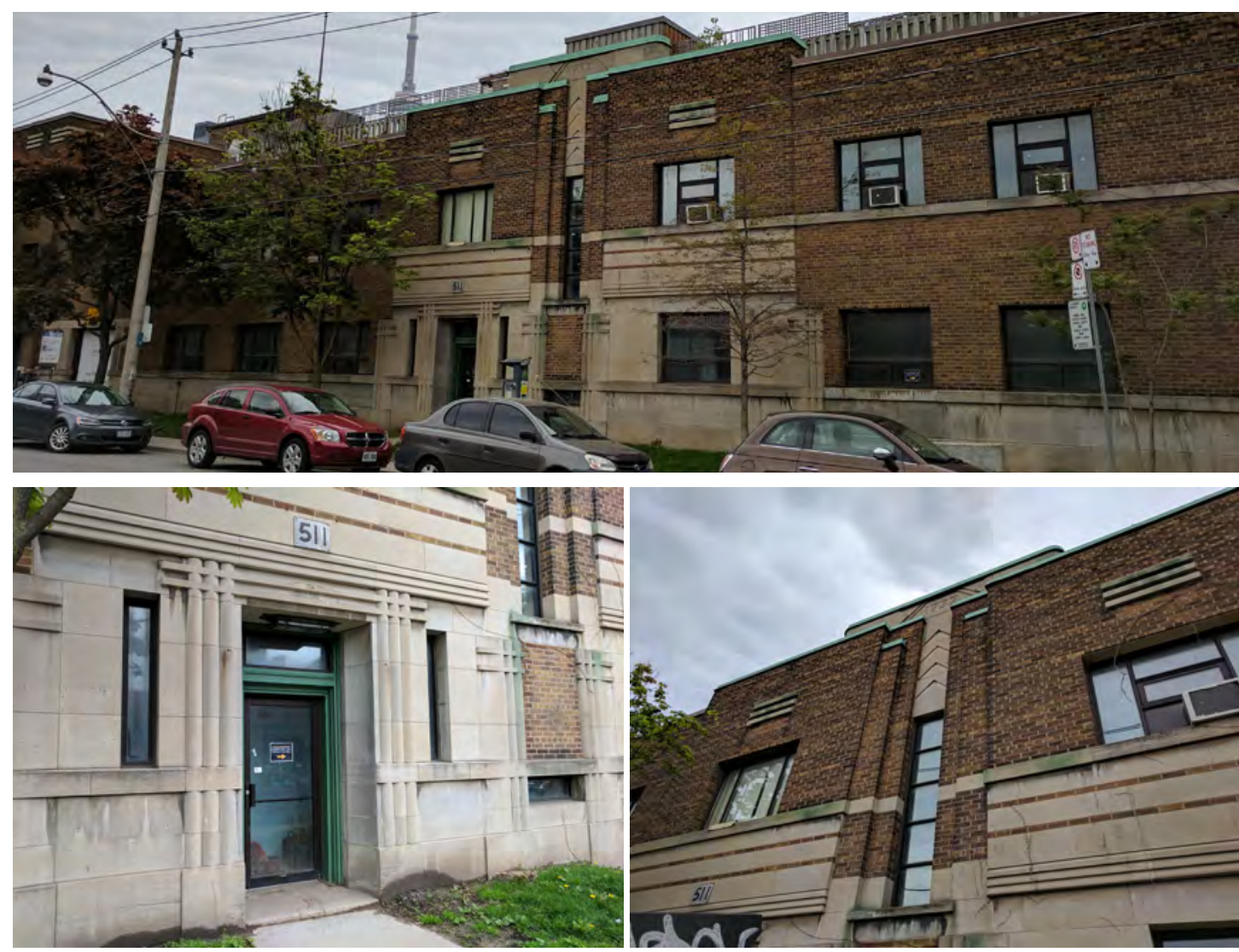

(top) Fig.5.21 Waterworks 511 entrance

(left) Fig.5.22 Waterworks 511 entrance

(right) Fig.5.23 Waterworks 511 entrance 


\section{The Central Courtyard}

The outdoor courtyard is located centrally with regard to the volumes. It is bordered by the south and east halls, the 1-storey garage on the west, and the pattern storage on the north (Figure 5.24 and Figure 5.25). The south and east halls have decorative pilasters with stone caps that organize the bays and openings. On the west is a single storey garage and on the east a row of single-garage storage space sitting against the east hall facade that is currently shared with a youth transitional home. A tall chimney stack on the south-east corner stands tall above all volumes. Two discrete driveways from Maud Street and Richmond Street into the courtyard. The Maud driveway is located behind the office building, with an intricate metal gate that continues to exist. The Richmond street driveway exists under the office building second story extension.
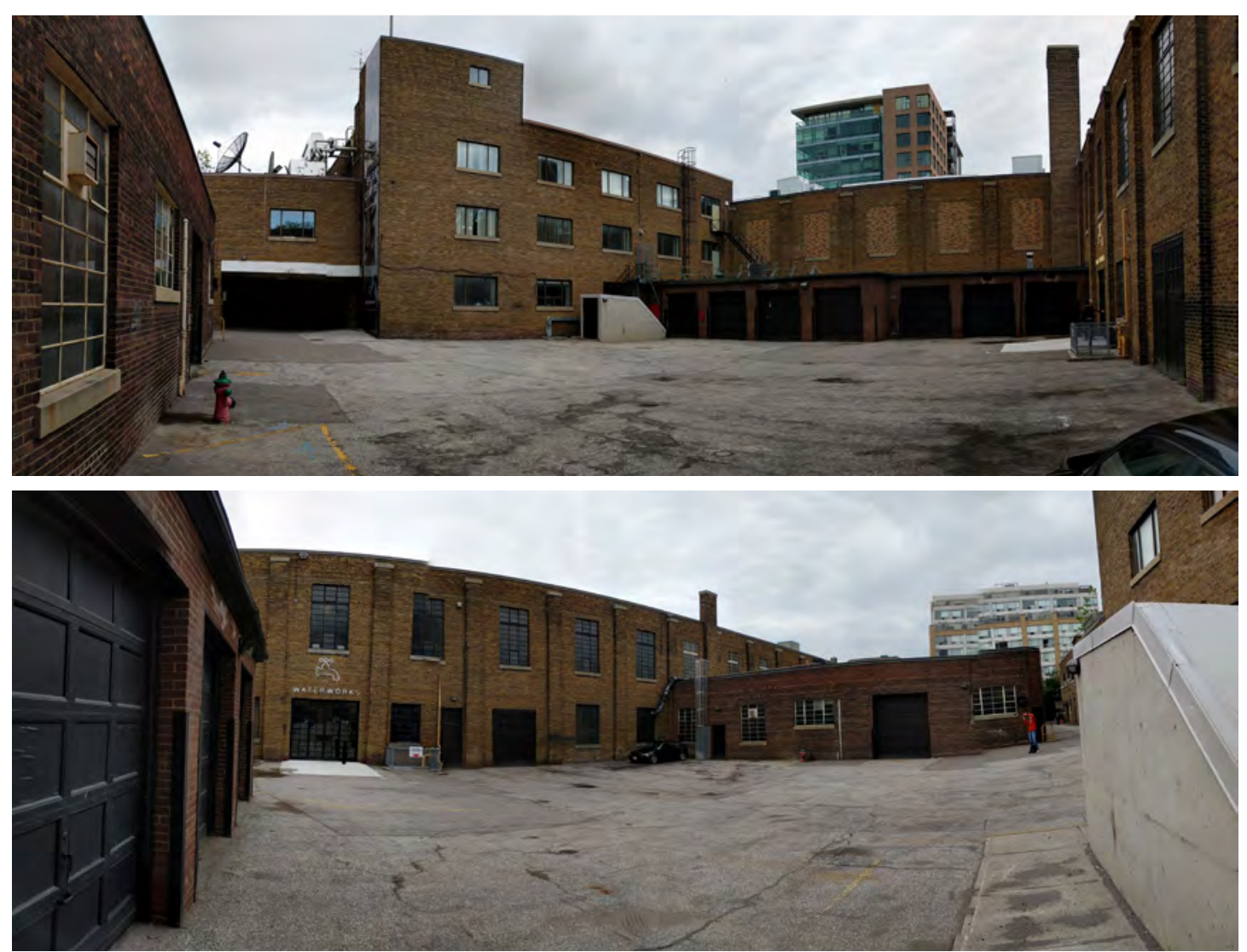

(top) Fig.5.24 Waterworks courtyard looking north-east, from left to right: 1-storey garage building, Richmond driveway, pattern storage building, 1-storey garage storage building/ Eva's Phoenix building, south hall building

(bottom) Fig.5.25 Waterworks view of courtyard looking south-west, from left to right: 1-storey garage storage, south hall building, garage building 


\section{The South Hall}

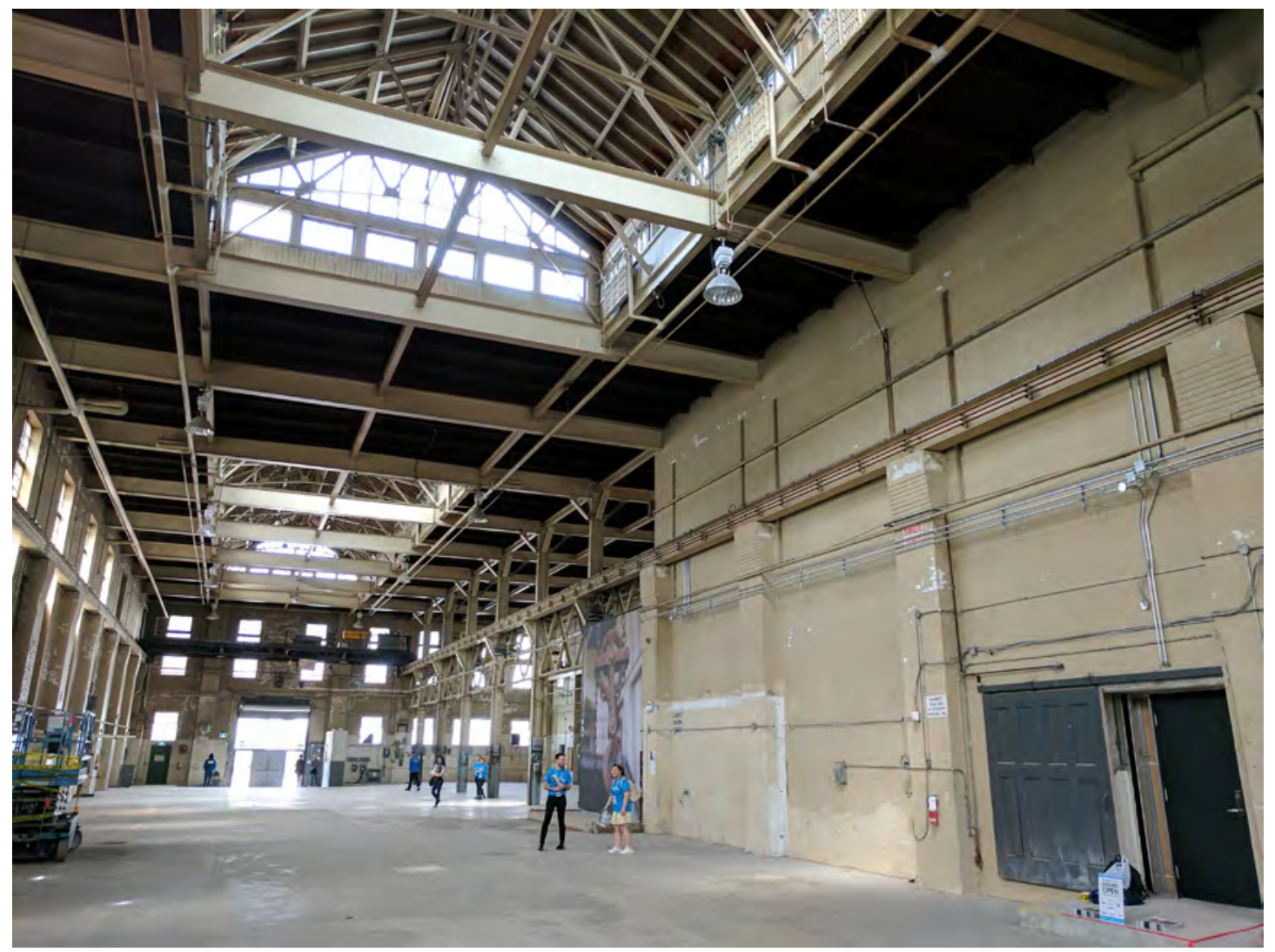

Fig.5.26 Waterworks south hall loading area looking west towards Maud Street

On the interior, the thoroughfare in the south hall connecting Maud to Brant Street is observed through the eastern and western garage doors. It roughly aligns with the removed Camden Street extension. This linearity is complemented with four original skylights (Figure 5.26 and Figure 5.27). A reduced natural lighting condition exists, with most of the original glazing on the skylights covered in addition to the infilled windows on the south front St. Andrew's Park. Similar to the courtyard, the interior of the south hall has piers organizing the openings. The piers are topped with a decorative stepped brick and stone and a capped stone similar to that in the courtyard. The exposed steel structure on the interior of the hall contributes to the industrial atmosphere of the space. Examples of this are the steel trusses inside the skylights and the truss latticework in the eastern portion of the hall. Wood is found on the original ceiling purlins, the original wood barn doors, a former original wood floor, with pieces of wood inlaid to resemble masonry have been recently removed following the recent purchase of the site (Figure 5.28). Within the south hall volume exists an area formerly called the 'pit'. The floor has an existing incision that reveals three large boilers protruding out of the basement (Figure 5.29). 


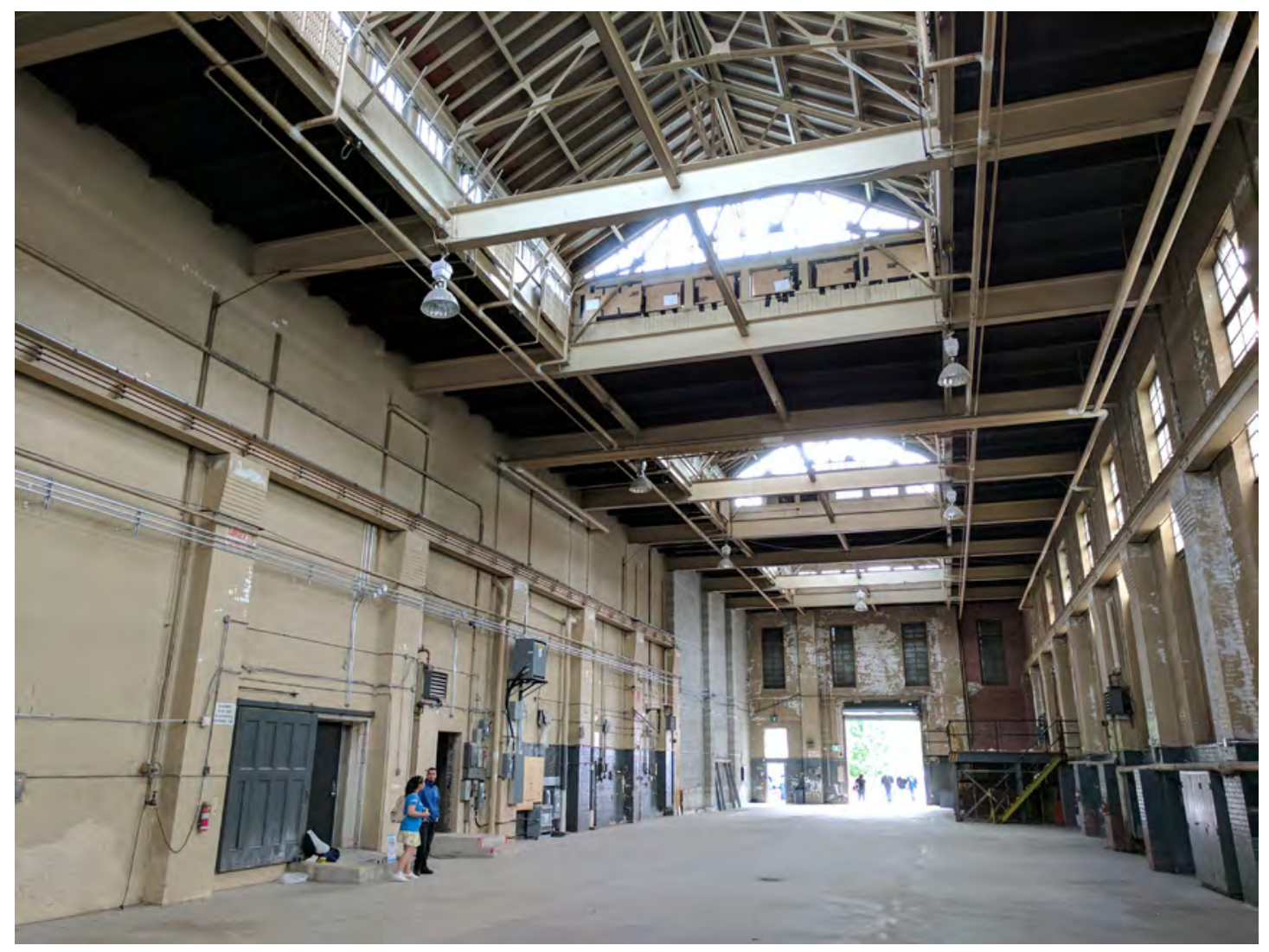

Fig.5.27 Waterworks south hall looking east towards Brant Street
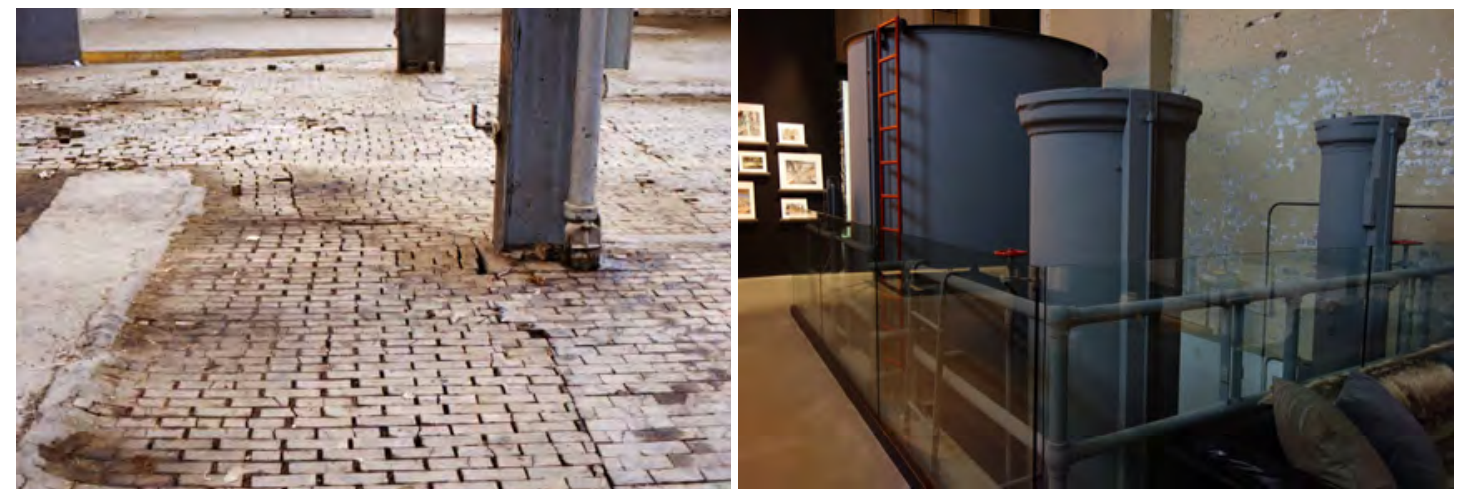

(left) Fig.5.28 Waterworks wooden block flooring in the south hall

(right) Fig.5.29 Photography of existing boilers at the Pit

This south hall was most recently used for solid waste management prior to being used as a venue for events and galas that served the entertainment district located to the west. The long, tall, and unobstructed space is versatile as far as use, and can hold a large number of occupants. 


\section{St. Andrew's Park}

The southern exterior wall of the hall fronts St. Andrew's Park. The masonry-infilled windows create a solid, monolithic backdrop to the activities on the south side of this block (Figure 5.30). The large off-leash dog area located in the north-west corner of the park is often frequented by area residents. Located just east of this is a children's playground and a shaded seating area (Figure 5.31 and Figure 5.32). The large trees in the park are some of the oldest in the neighbourhood. Some predate all transformations after the incorporation of the city. Since the site was situated on the former Garrison reserve, it is said that some of the trees carry wounds from the war of 1812 (Taylor,

2010, p. 18).

In June 2009, the parking lot west of St. Andrew's Park hosted a market (Figure 5.33 and Figure 5.34) (Taylor, 2010, p. 44). This initiative was organized by community residents and local groups who provided cooking demonstrations and samples of food (Taylor, 2010, p. 44). The market was named the MyMarket, and although it was only temporary, its popularity as a focal point in the community serves as evidence for the demand for a market in the community (Palassio \& Wilcox, 2009, p. 251) (Gordon, 2009).

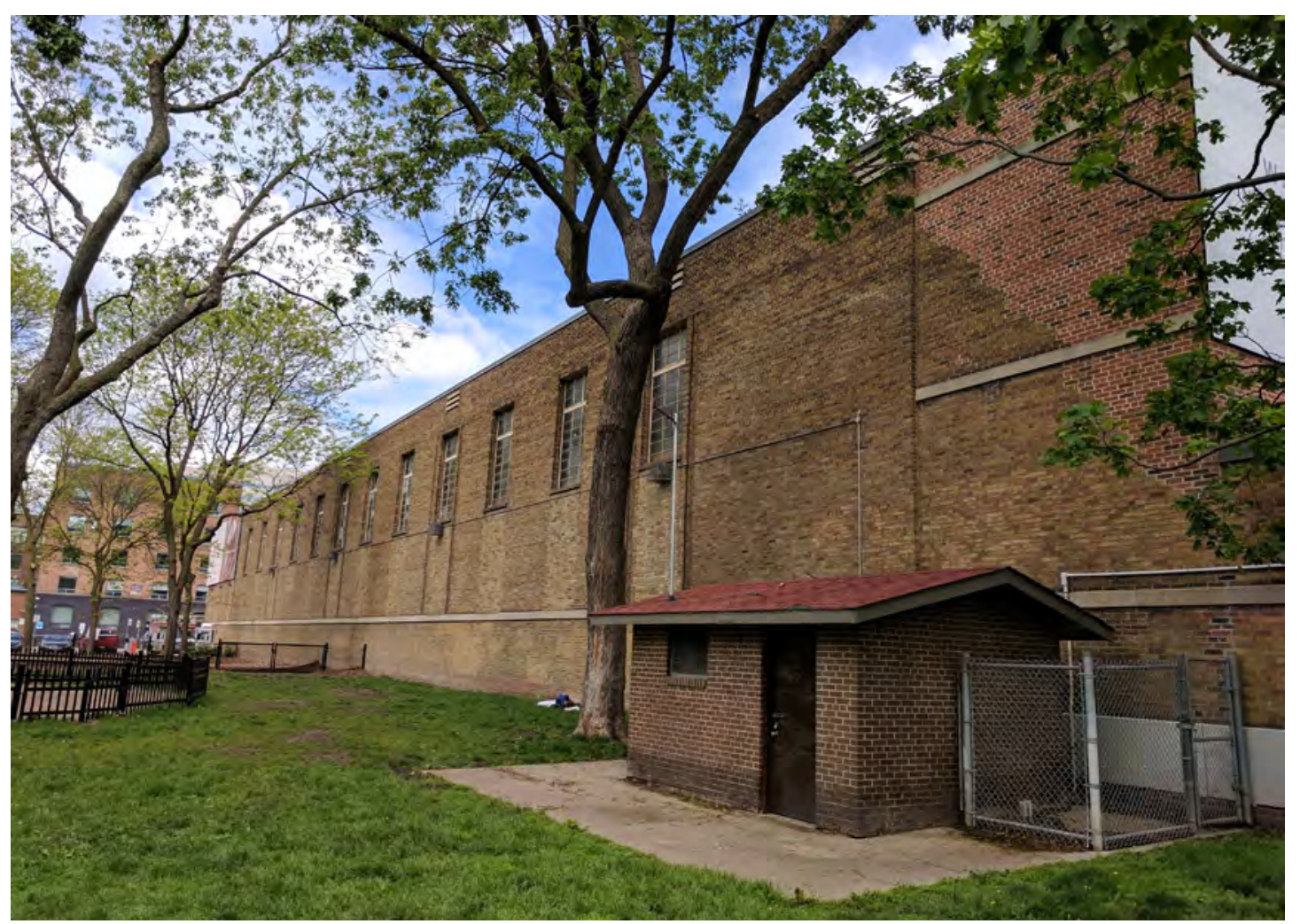

Fig. 5.30 Waterworks rear facade at St. Andrew's Park looking north-west 

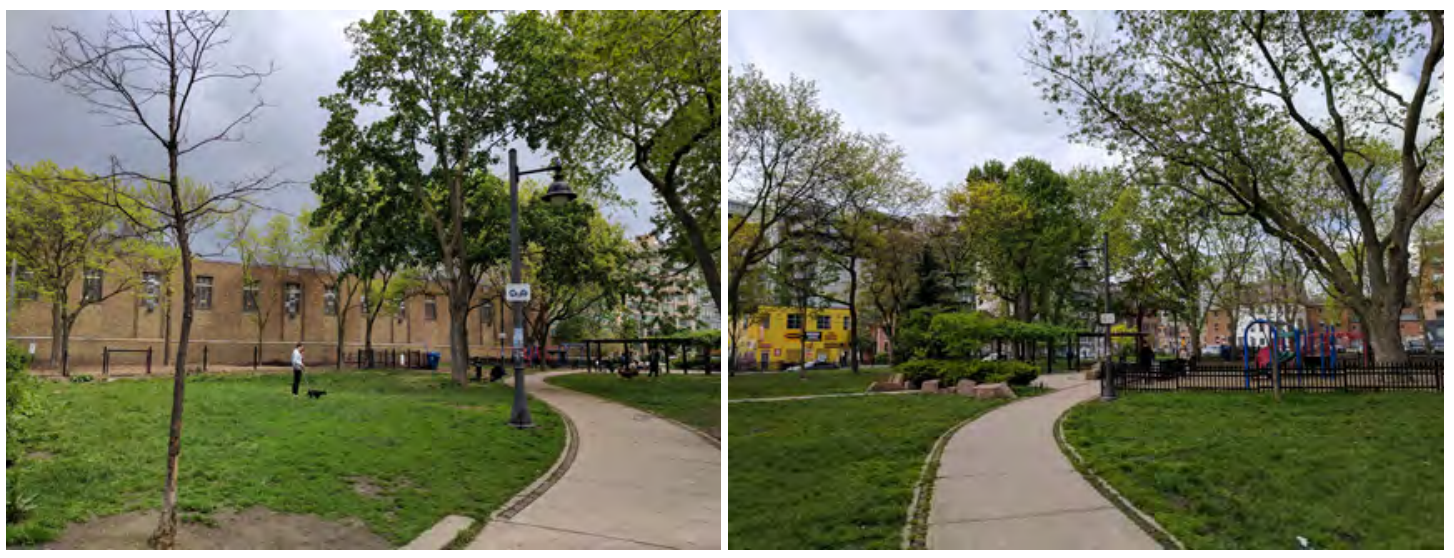

(left) Fig.5.31 St. Andrew's Park looking north-east, from left to right: off-leash dog area, children's playground, shaded seating area

(right) Fig.5.32 St. Andrew's Park St Andrew's Park looking north, from left to right: children's playground, shaded seating area
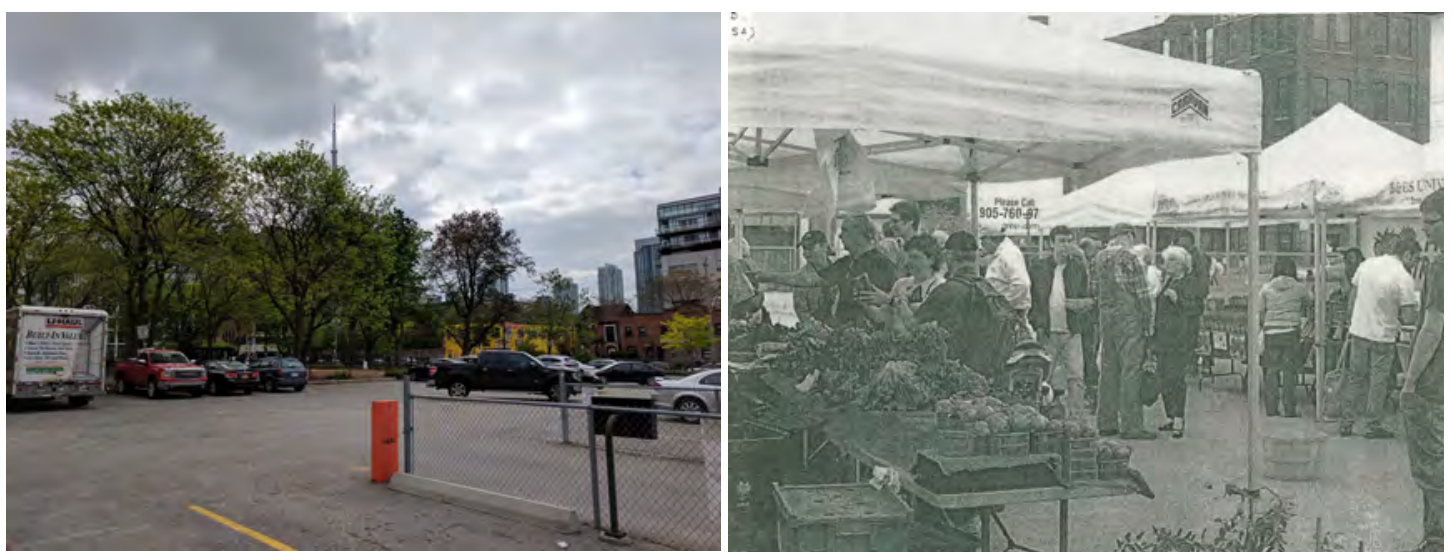

(left) Fig.5.33 Waterworks parking lot west of St. Andrew's Park

(right) Fig.5.34 Waterworks MyMarket at the rear parking lot, 2009 


\section{Eva's Phoenix}

On the corner of Richmond Street and Brant Street, the north- eastern portion of the site is now home to Eva's Phoenix since late 2016 (Figure 5.35). It functions as transitional housing, providing accommodation for 50 homeless persons in 10 townhouses organized along the western exterior wall as well as the eastern exterior wall that is shared with the central atrium space (Figure 5.36). While living in transition, the youth have access to training and counseling that will help them become selfsufficient.
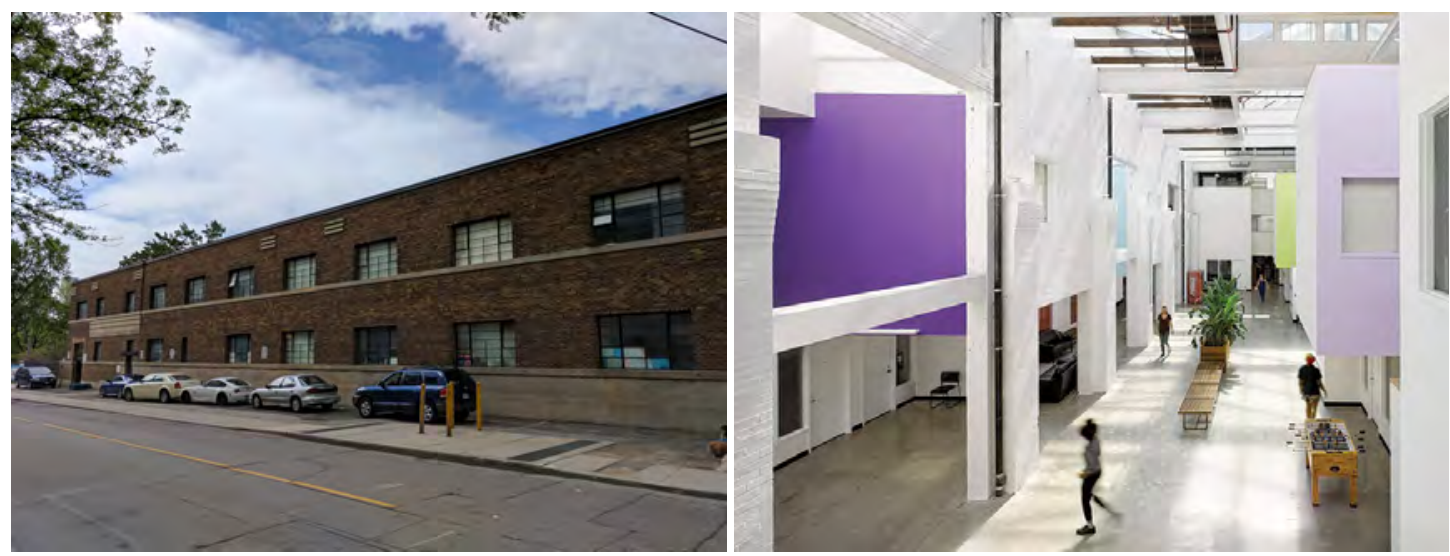

(left) Fig.5.35 Waterworks photograph of Eva's Phoenix at Brant Street

(right) Fig.5.36 Waterworks Eva's Phoenix at central atrium space

Similar to the make-work strategy employed during the Depression era with the Waterworks building, Eva's Phoenix employed about 50 homeless youth for the construction of its original location, as well as for the most recent renovation at the Waterworks building (Skinner, 2016).

The facility will share a party wall with the future occupants of the remainder of the site that has been sold for development. As a result, the interior thoroughfare between the large storage areas on the east and south was infilled with concrete block. But more significantly, with fenestrations facing the courtyard; the youth's bedrooms and kitchens were also infilled.

\section{Site Conclusions}

Throughout its evolution, the site has played a vital role in shaping the city, helping to form its identity and collective memory. It hosted many firsts that helped establish the west end of Toronto, for instance its marketplace and public library, as well as the city's first supervised children's playground. It has also played a crucial role in giving back to the city in times of need, whether it was pumping clean water, providing employment or providing shelter for the homeless. All these elements combined underscore the site's deep connection to the public realm and its role as a critical element of the city. 


\section{Proposed Developments and Recent Shifts}

Recent transformations in Toronto's rampant developments have wiped out many lots belonging to civic landmarks that helped shape the city we live in today. Following this trend a number of proposals have been approved for the surroundings.

On the north side of Waterworks, at 520 Richmond Street West, an existing one-storey commercial warehouse rental center for building equipment or contractor supplies will soon be demolished and transformed into a 13-storey mid-rise mixed-use building (Figure 5.37). The proposed building is located on the north-west corner of Richmond Street and Augusta Avenue, backing Graffiti Alley. Similar to the proposal at Waterworks, the ground-floor retail is also topped with 12 stories of condo units and will soon stand next to existing 3-storey Victorian row houses on Richmond Street facing Waterworks.

Fronting Brant Street and St. Andrew's Park, at 51 Camden, the Ace Hotel will soon occupy the south-east corner of Camden and Brant (Figure 5.38). The 13-storey building will be clad with red brick, concrete panels, and weathered steel will complement the industrial history of the site.

Directly south of the park, a change is proposed at 445- 451 Adelaide Street West, the corner of Adelaide and Morrison Street: a mixed-use 11-storey office building with retail on the ground level.
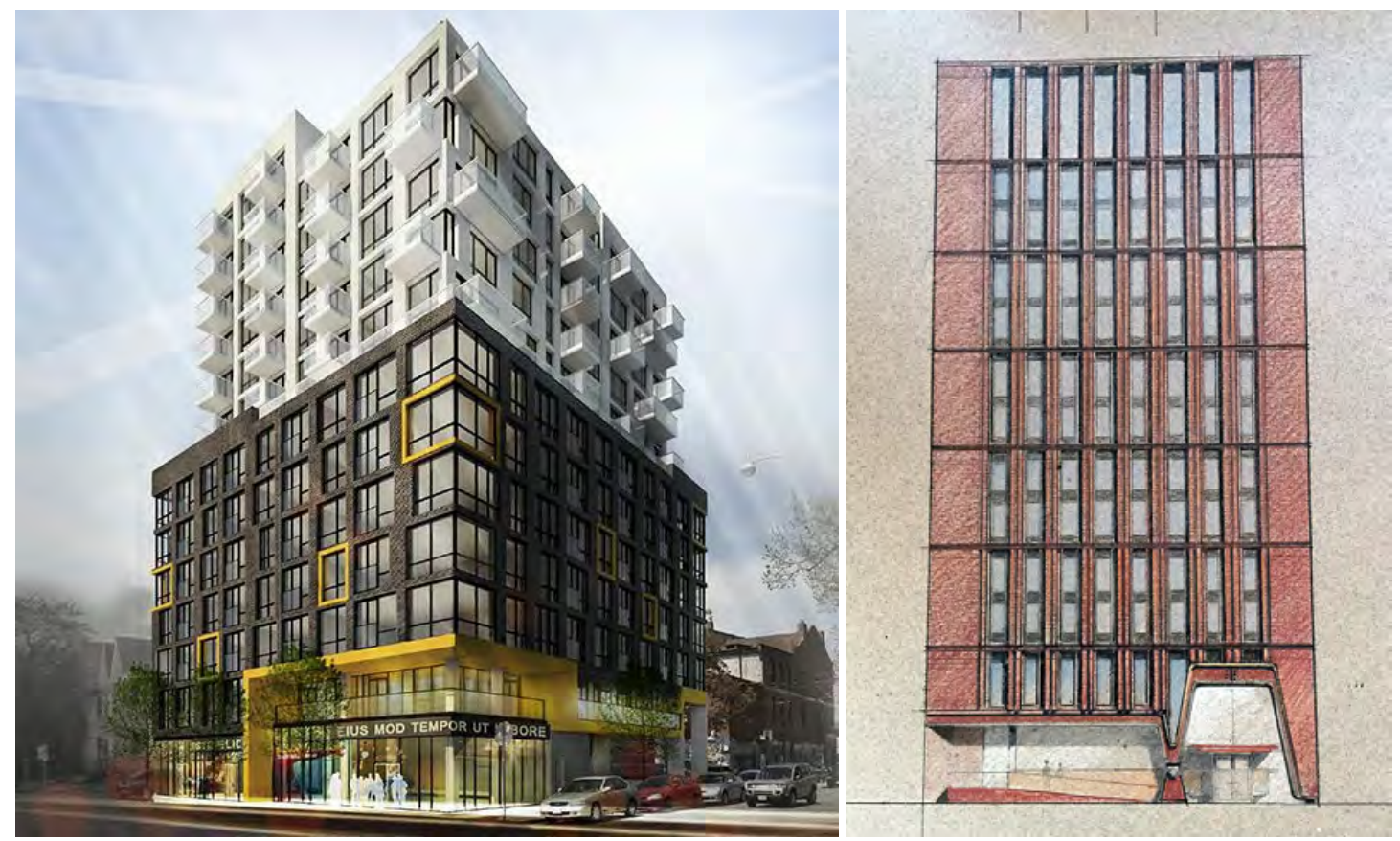

(left) Fig.5.37 Proposed future development at 520 Richmond Street

(right) Fig.5.38 Proposed future development at 51 Camden Street 


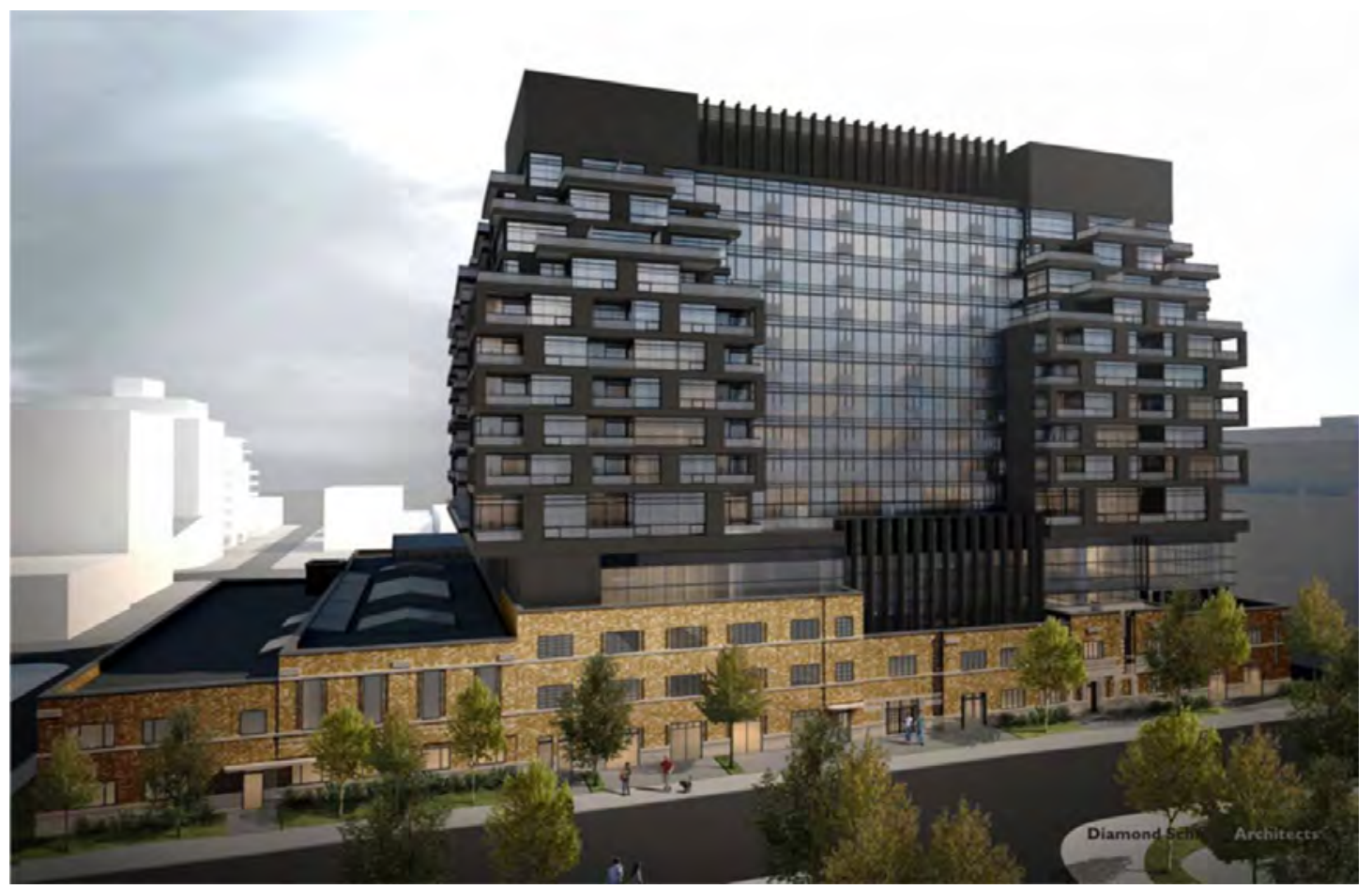

Fig.5.39 Proposed future development addition from Richmond Street

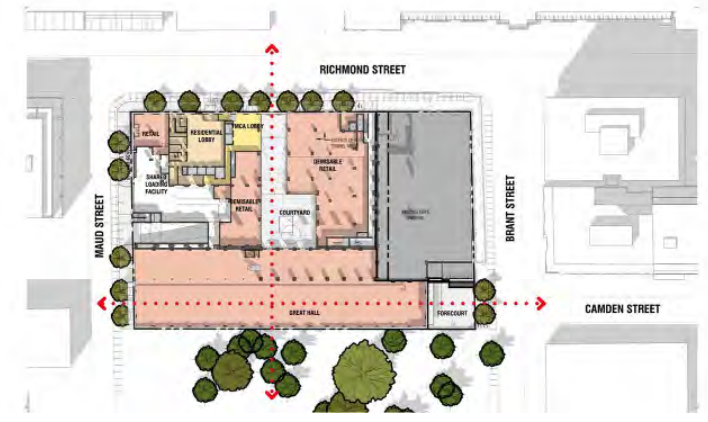

Fig.5.40 Waterworks proposed development ground floor $\mathrm{p}$

However, the most significant development in the area is a proposal regarding the Waterworks building itself. The western portion of Waterworks has been approved to become a mixed-use midrise development (Figure 5.39). The proposal sees the removal of all recent occupations within the building. Instead, a ground-floor retail area complete with a public food hall and a reduced courtyard in envisioned (Figure 5.40). The second and third-floor YMCA amenities are topped with 10 stories of condo units (Figure 5.41). The condo units sit on top of the existing building with minor modifications on the exterior. The new proposal includes an underground parking area, resulting in the extension of the park onto the existing parking lot in the rear. 


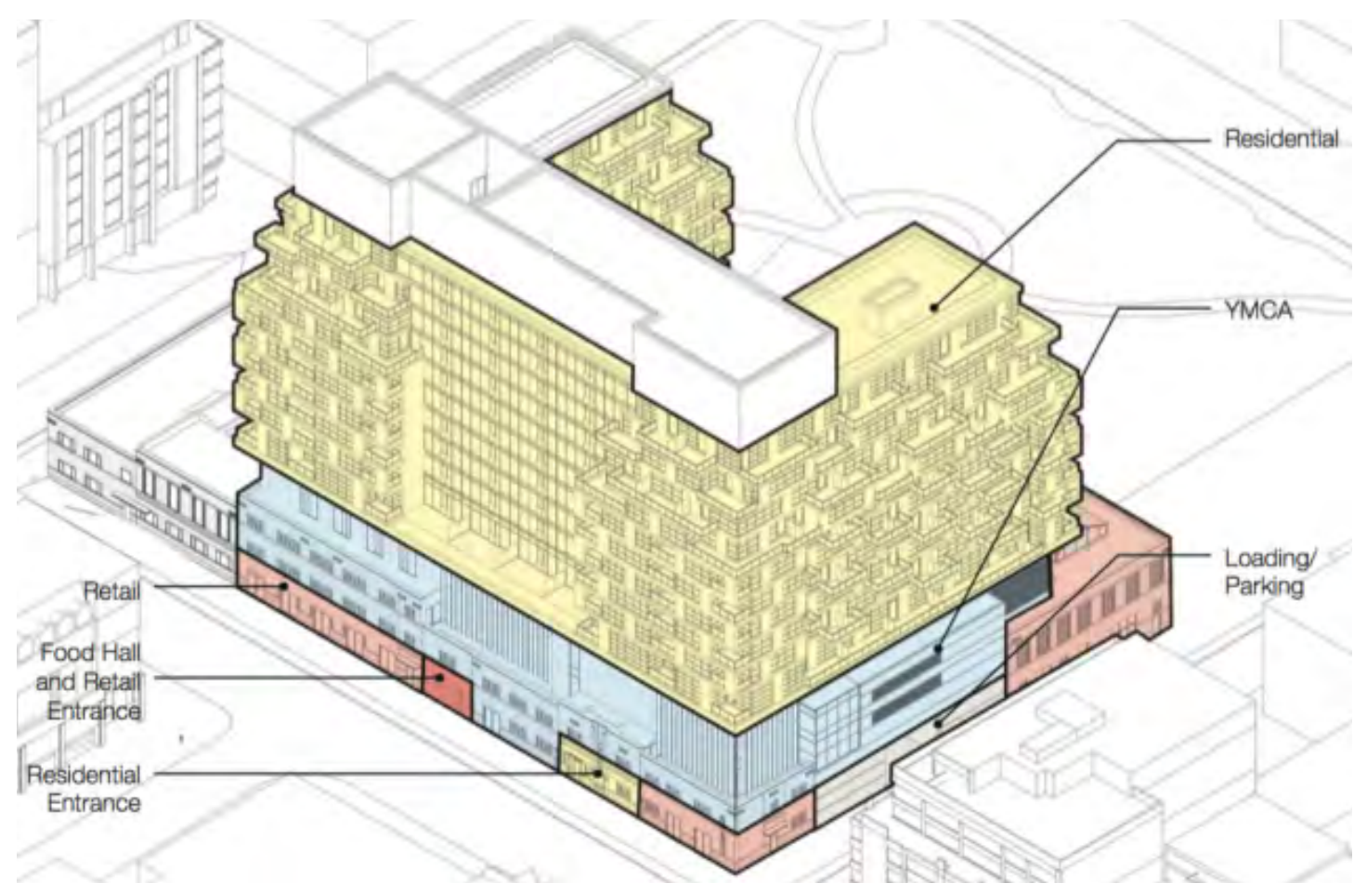

Fig.5.41 Proposed development program diagram

Recent shifts as observed on the future layer of Waterworks present a shift in society's civic priorities and a threat to the spirit of Waterworks which may, like many other public sites, have its significance forgotten as the sites are redeveloped. The shift from public to private, as evidenced by the proliferation of condos and towers and by the future proposal for the site, has resulted in a radical transformation of the cityscape: it now features densely packed skyscrapers, while vital public spaces have been gentrified and privatized. The result is that there is very little functional and physical relief indicated by the massive scale additions and limited variety of public programming.

The 10-storey additional massing suppresses the existing building and also looms over the abutting park. In the design of the podium and ground floor, the diminished courtyard, favours exclusivity, limits programmatic opportunities and a sense of the old courtyard is lost. A weak axial connection is lost as it enters the south hall and neglects the building's deep connection to the park. The decision to infill the party wall, blocking out the entry of sunlight into the bedrooms and kitchens of Eva's Phoenix shows a lack of concern for inclusiveness. These elements combined underscore elements of the site's palimpsest that are missing from the future proposal.

In response to this, an investigation into a more suitable projection for the site is needed. One that engages vital components that formed its identity and collective memory. 


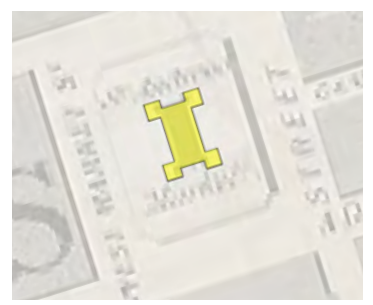

(left) Fig.5.42 1850-1860 West Market Square tracing

(right) Fig.5.43 1850-1860 West Market massing

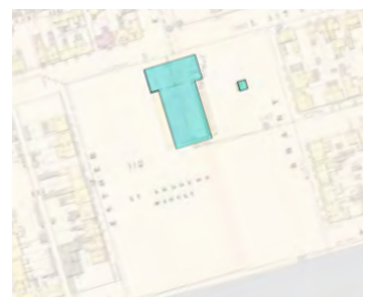

(left) Fig.5.44 1880-1932 St. Andrew's Market \& Hall tracing

(right) Fig.5.45 1850- 1880 massing overlay

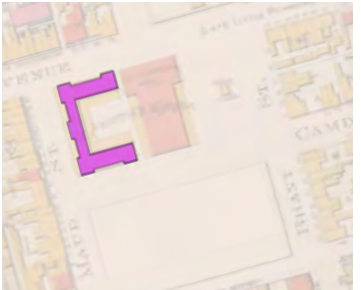

(left) Fig.5.46 1893-1932 St. Andrew's Market Annex Building tracing

(right) Fig.5.47 1850-1893 massing overlay

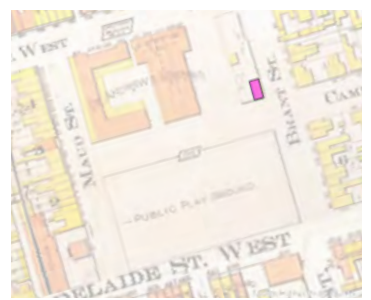
(left)
Fig. 5.48
1910- 1932 tracing
(right) Fig.5.49 1850- 1910 massing overlay

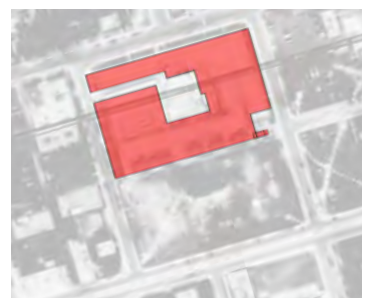

(left) Fig.5.50 1932- present Waterworks building tracing (right) Fig.5.51 1850- 1932 massing overlay
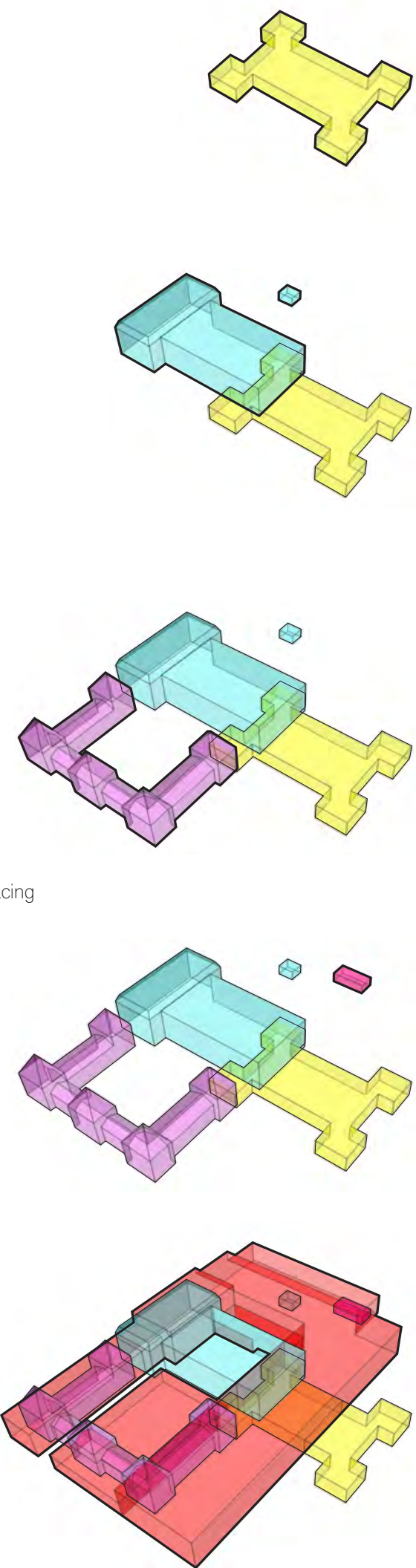

Architecture of Memory 


\section{LDM Explorations}

To visualize the different spaces, past and present, the different buildings on the site must be traced (Figure 5.42 to 5.51). For the next study, the tracings were collapsed into one drawing and matrixa superposition of all structures (Figure 5.52). Using transparencies, the overlapping forms from different time periods were seen to indicate different degrees of spatial contestation. An investigation into the most contested area is found to overlap built form 3 different time periods (Figure 5.53). The organization of these forms layered in one space provides a framework for the application of strategies and for areas of focus where ideas can be best explored.

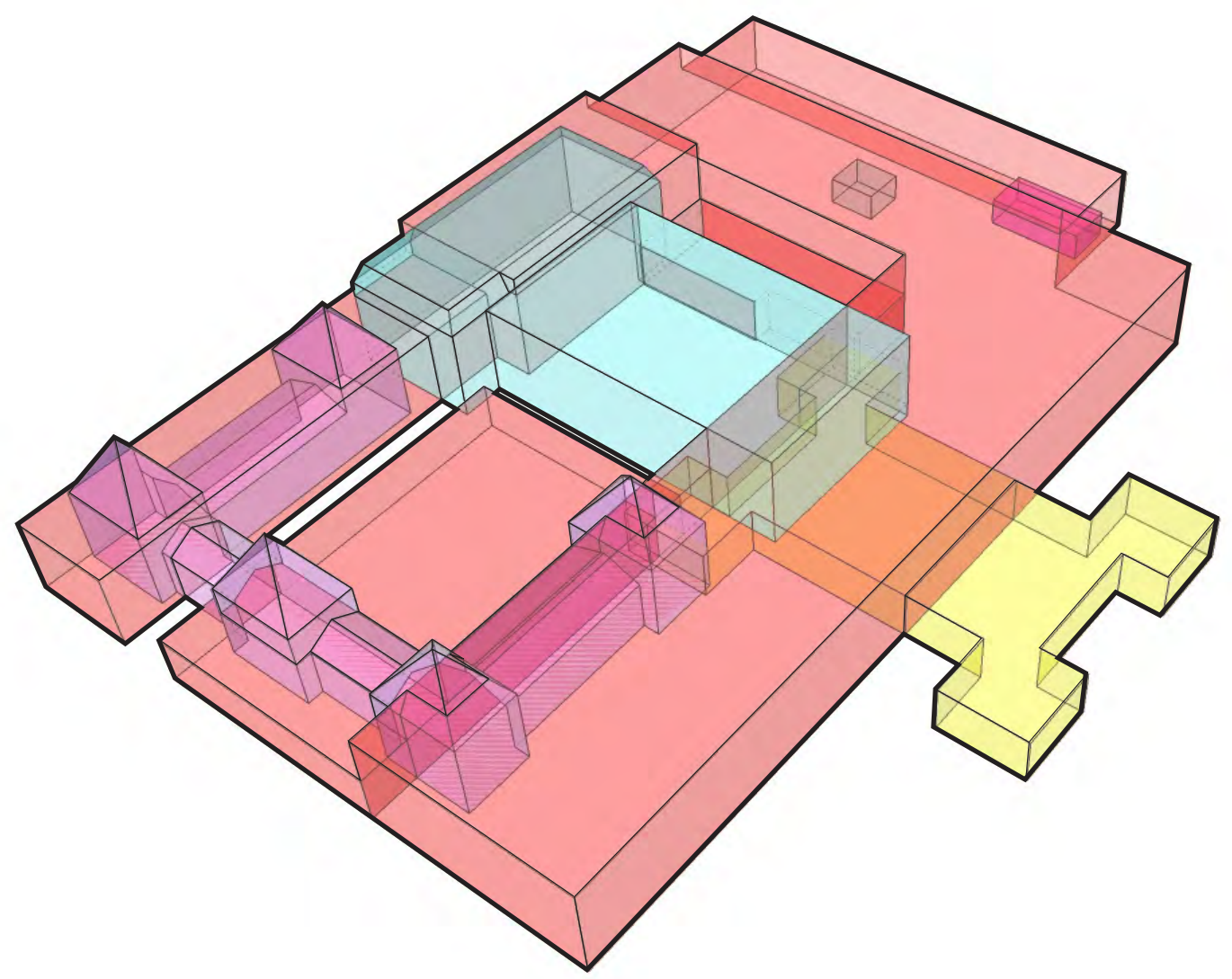

Fig.5.52 1850- 1932 massing overlay (large) 

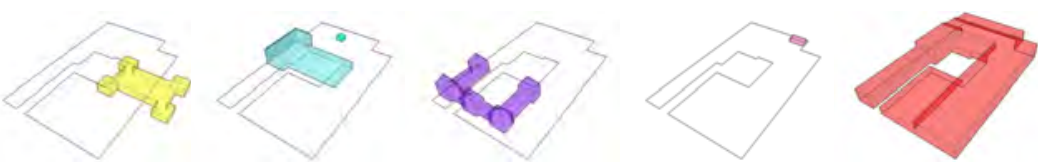

1850

1860

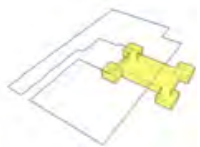

1880

1932
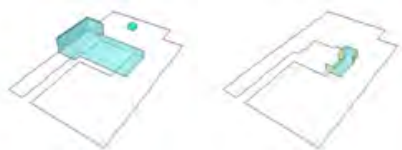

1893

1932
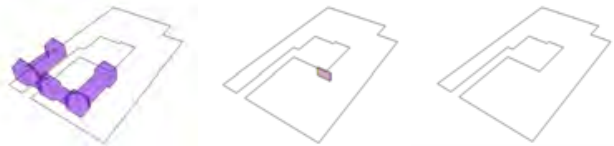

1910-
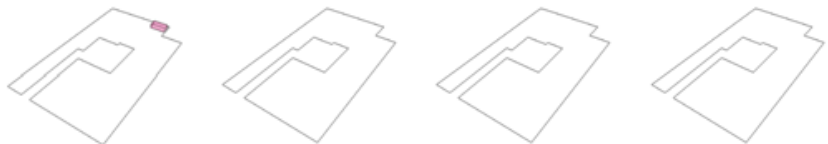

1932-

present
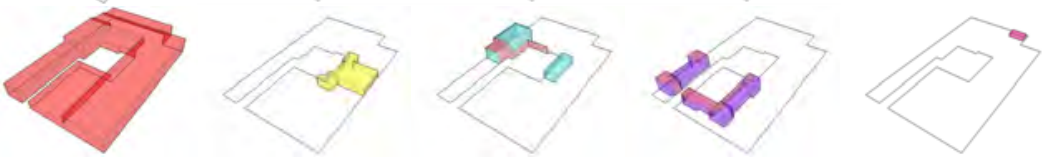

Fig.5.53 Massing overlay matrix (highest degree of overlay indicated in black box) 
1850- 1860

1880- 1932

1850-1860

1893- 1932
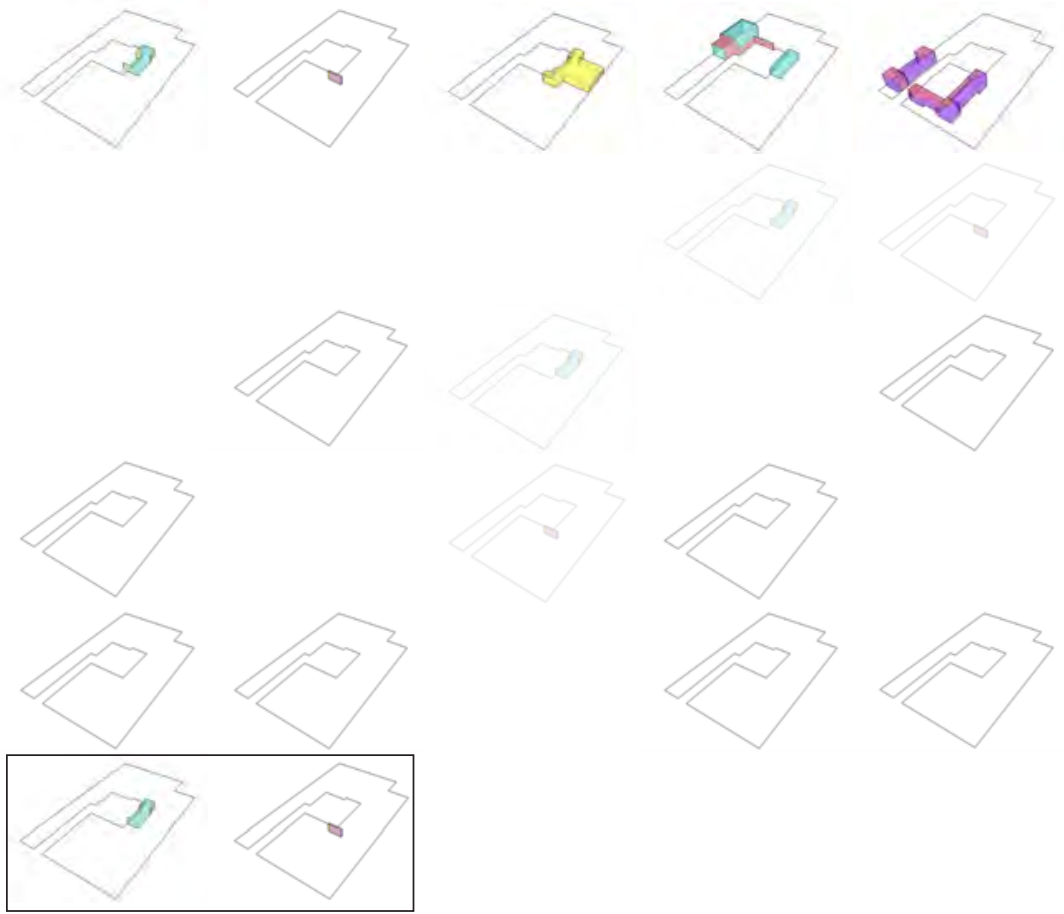
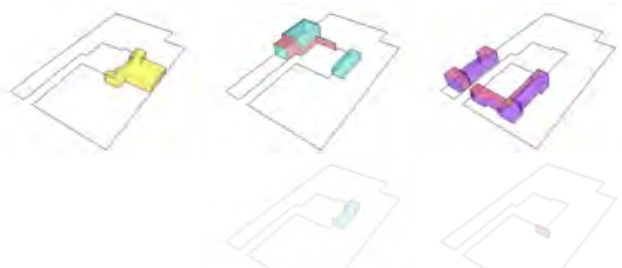

1850-1860

1932-present 1932-present

1893- 1932

1932- present

1910- 1932

1932-present
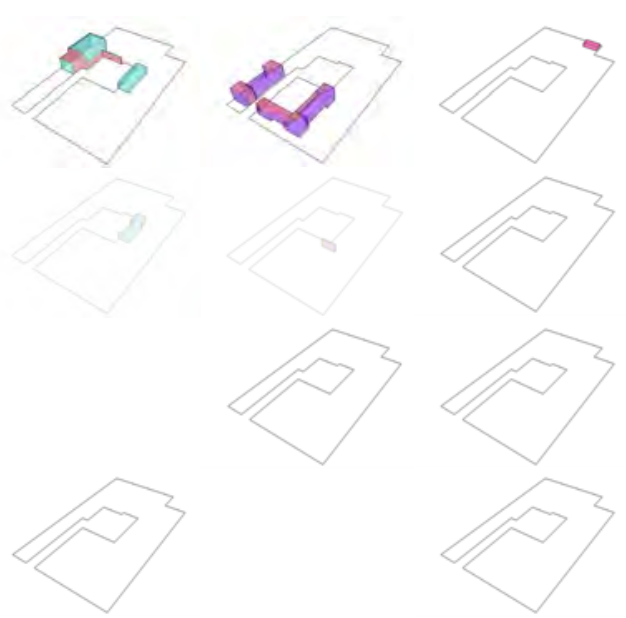

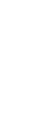


A similar analysis was performed functionally as function also informs the intangible meaning of a Lieux de Memoire. This served to investigate the overlap of function and occupation throughout the evolution of this site. The functional palimpsest begins to potentially inform an overall general program and reveal hidden themes and meanings of the site, as well as its relationship to the city (Figure 5.54).

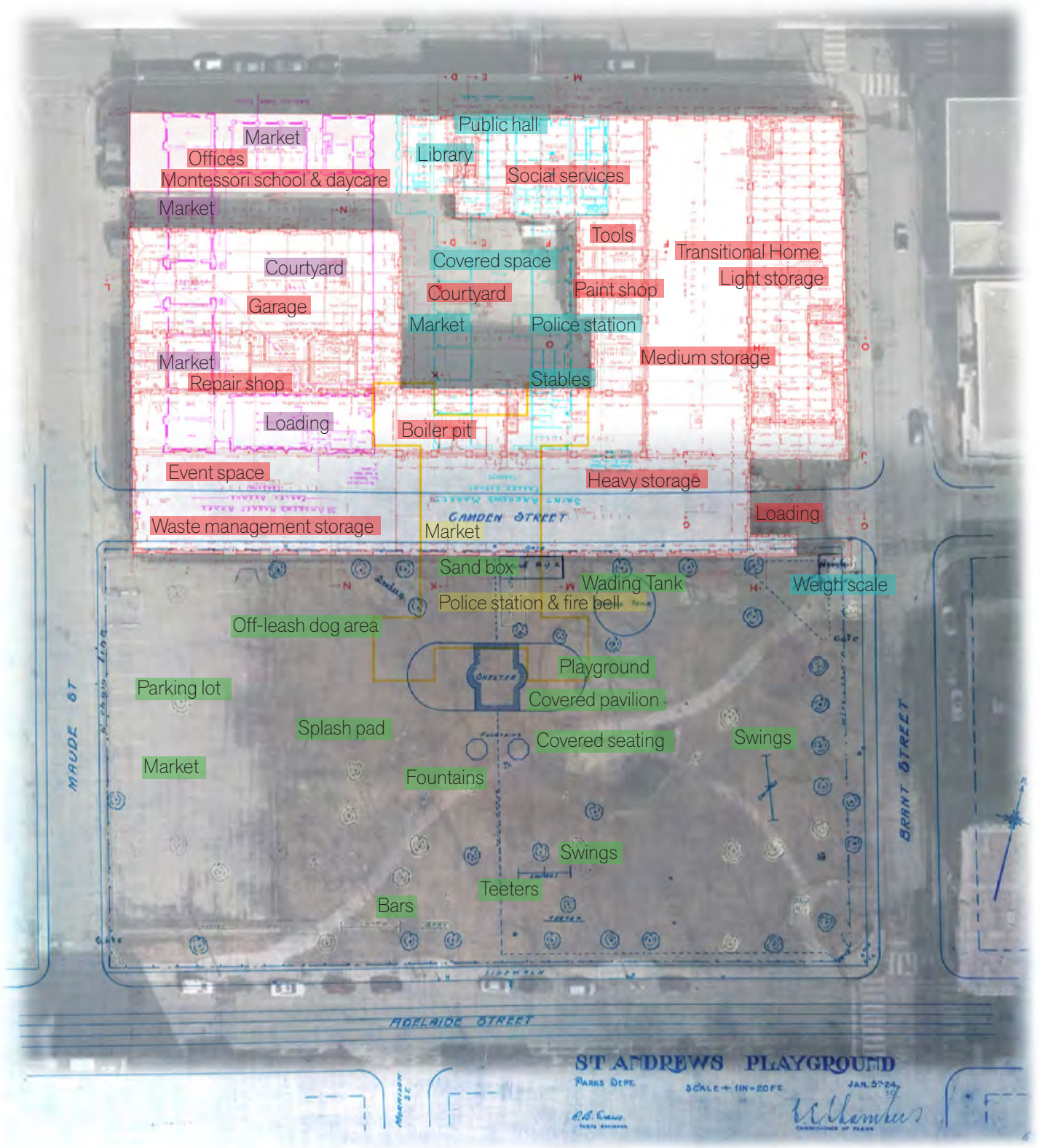

Fig.5.54 Overlap of all programs since 1850 
As mentioned, Kevin Lynch suggests that there is an underlying continuity in our environment formed by a juxtaposition and contrast of old and new meanings and form (Lynch, 1972, p. 171). Regarding these alterations as 'collage' and 'layering', he describes the process as "traces modifying and being modified by new additions" (Lynch, 1972, p. 171). This was experienced in the book explorations and similarly in the creation of these next collages that focus on highlighting function and significance of this site (Figure 5.55 to Figure 5.57). Each image or layer that is added forces a reconsideration of the overall narrative and composition.

\section{Collage 1}

The site's deep ties to the marketplace have persisted through recent attempts by the community to revive the marketplace in the parking lot. A fire in 1860 destroyed the very first marketplace, and eventually the site became associated with water in the form of the Waterworks facility that was vital in supporting the growing city at the time, presenting the opposing themes of water and fire. In addition to infrastructural support, the construction of the Waterworks building itself supported the community by providing work during the Depression. Furthering the theme of labour, the most recent renovation of Eva's Phoenix employed transitional youth in its construction.

\section{Collage 2}

The outdoor courtyard was the site for many important civic and social functions in the past. When the second rebuilt market went into decline it housed a library (Toronto Public Library's second location) and a police station, converting the market stalls into prison cells. A grand community hall hosted lectures and talks of a political and religious nature. The building would be demolished for the Waterworks building in 1932, but similar functions have recently re-surfaced in the south hall, which is often rented for events and celebrations.

\section{Collage 3}

In addition to the main building's obvious connection to water, water was also a recurring feature of the playground in the form of splash pads and wading pools. Dubbed Toronto's first children's playground, it was a major recreational hub for a residential community strongly rooted in family. Traces of this usage persisted until recently in the form of a daycare complete with a hidden rooftop playground. 


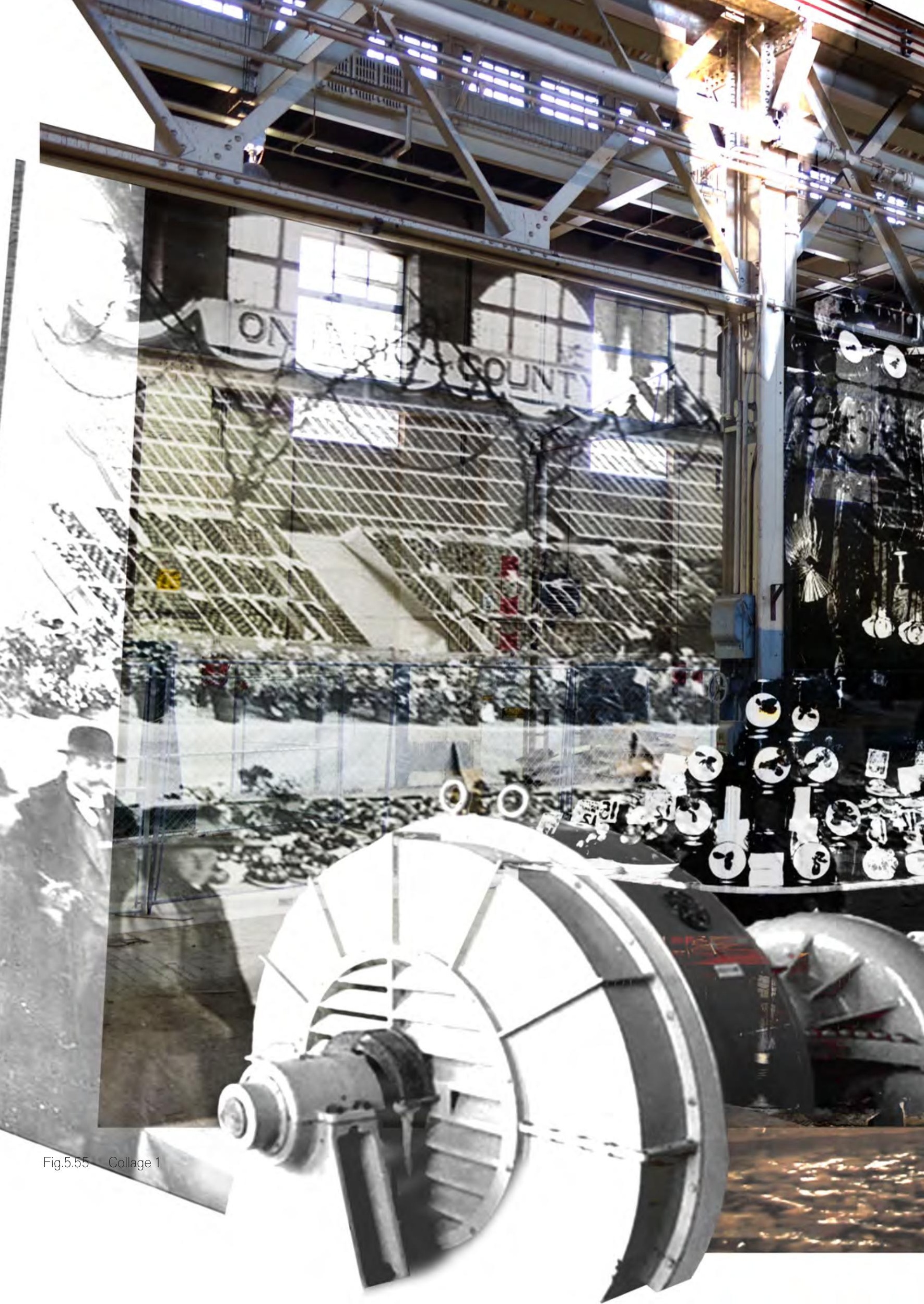




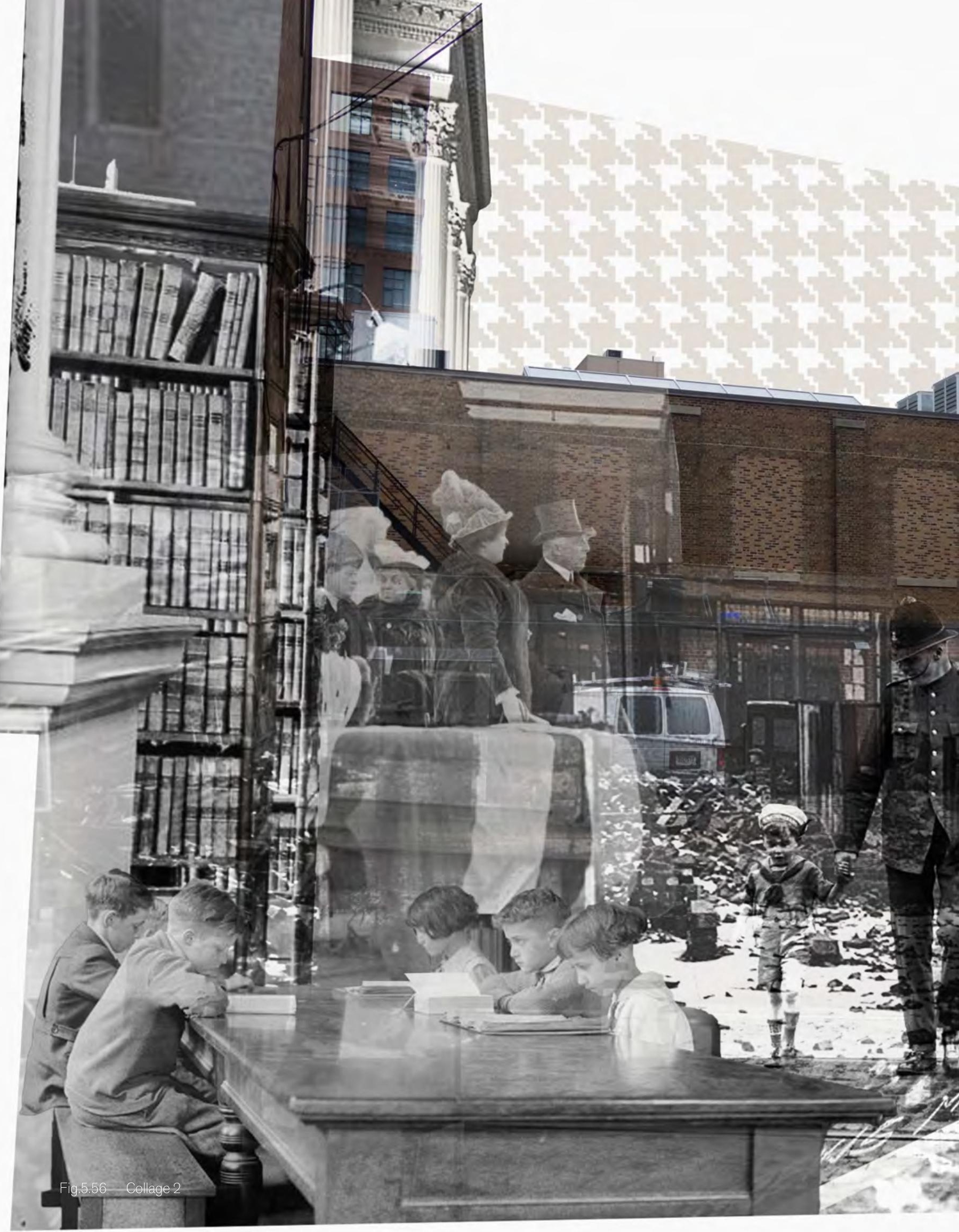




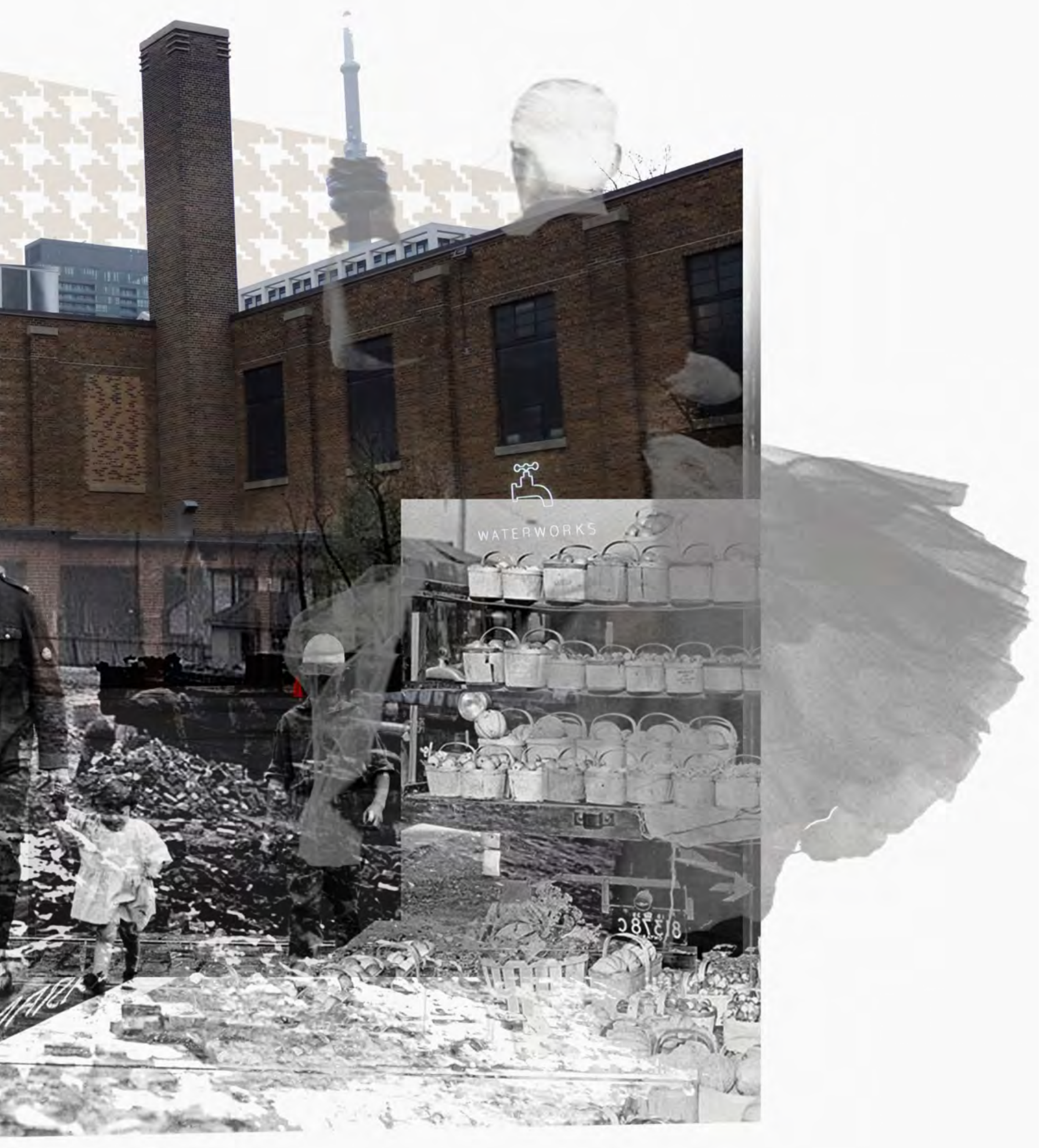



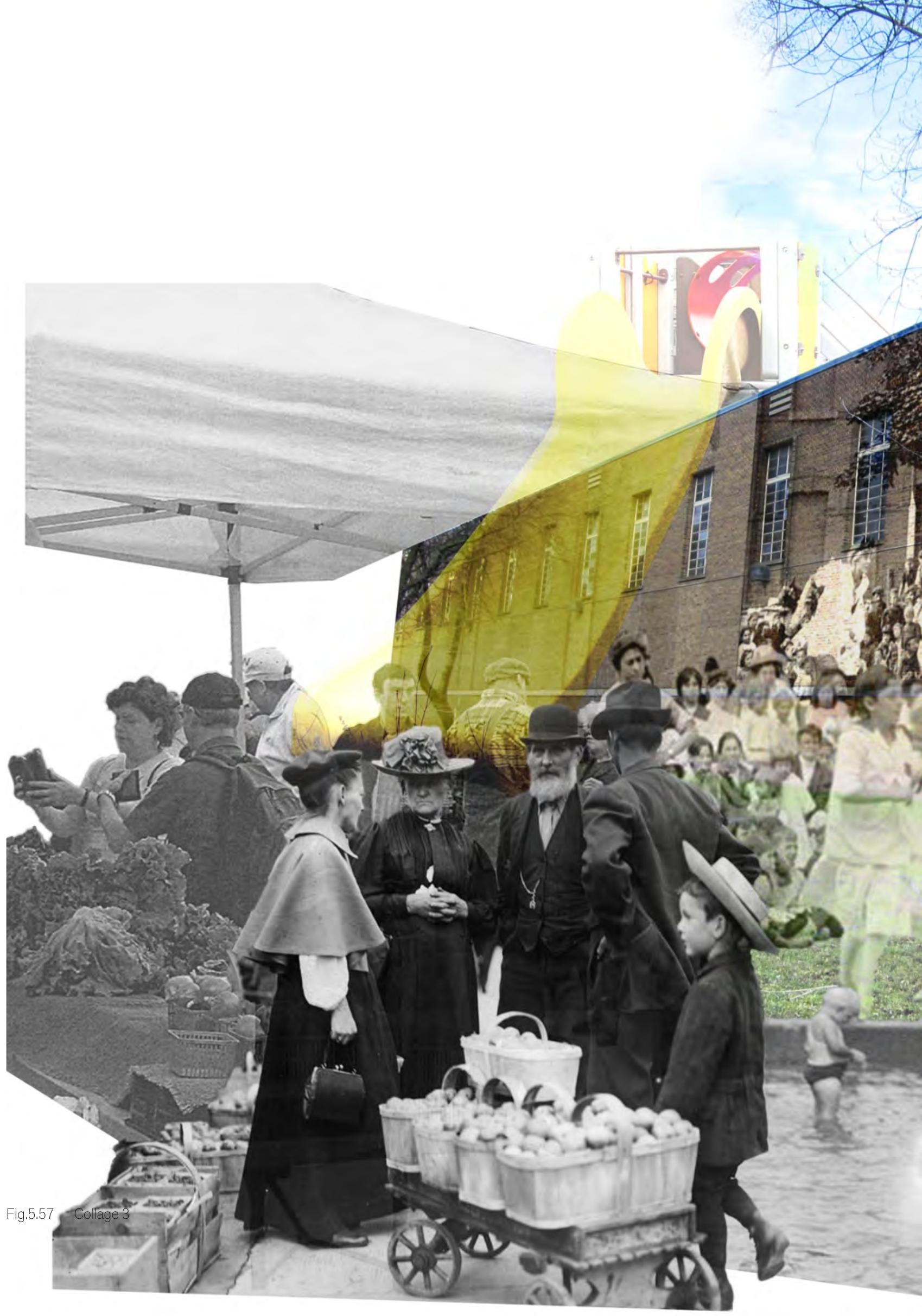



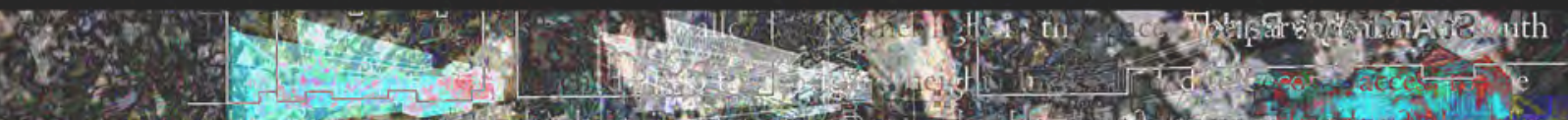

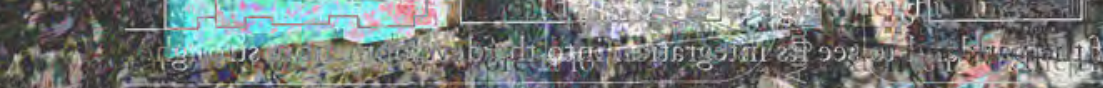

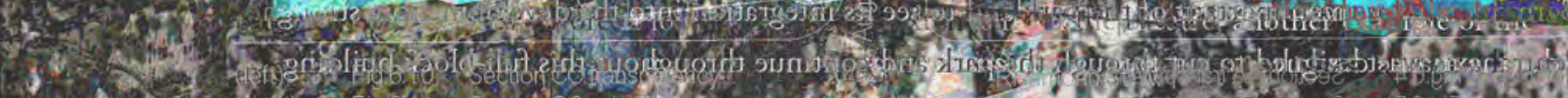

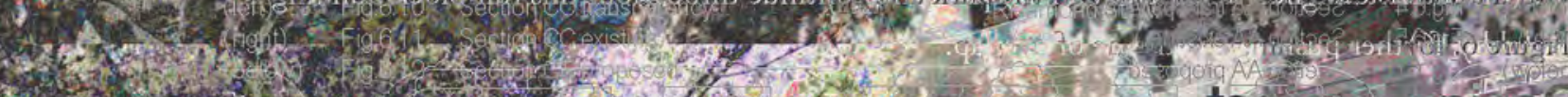

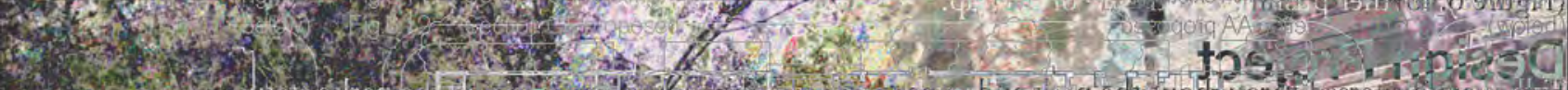
* 2.

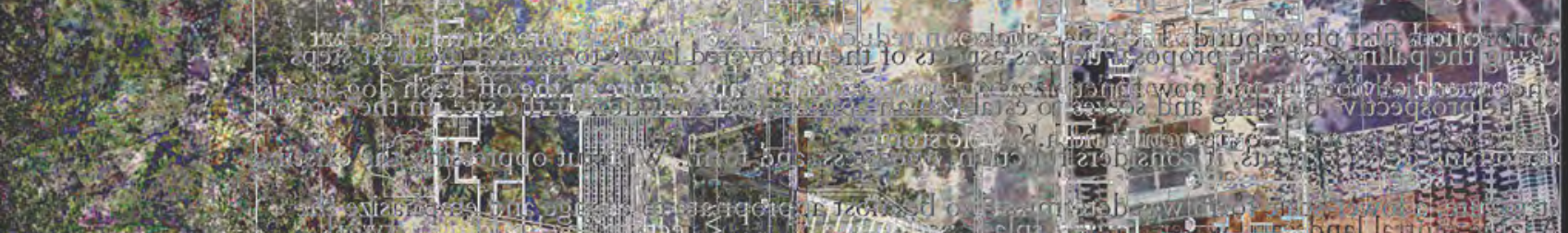

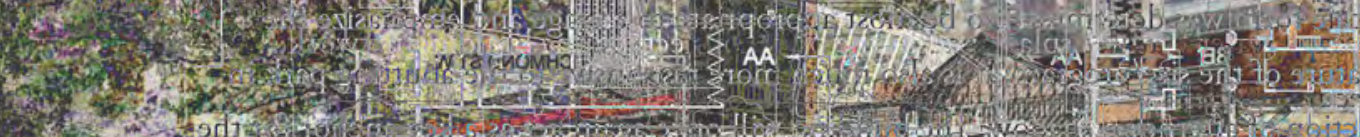

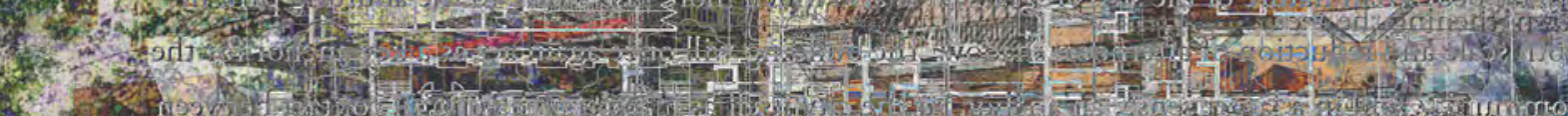

17.7.

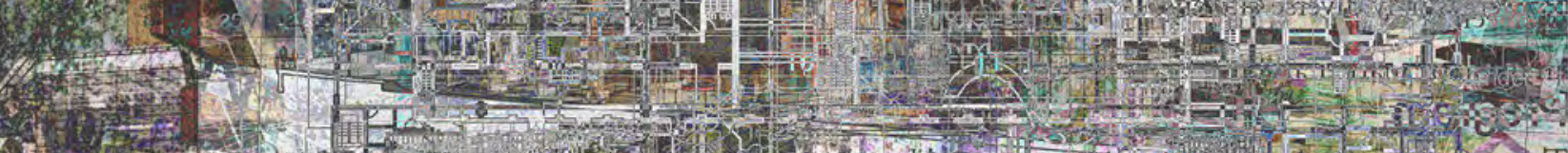

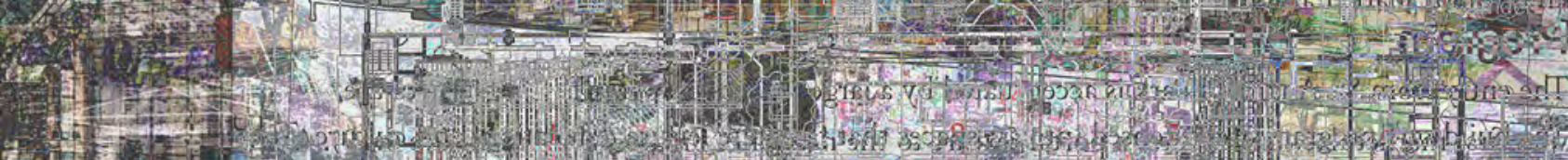

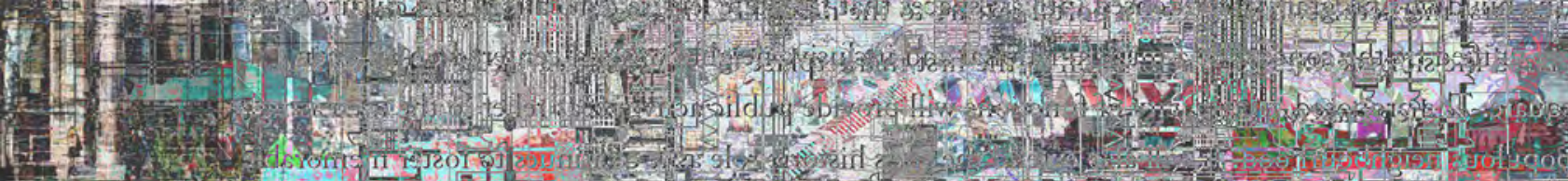

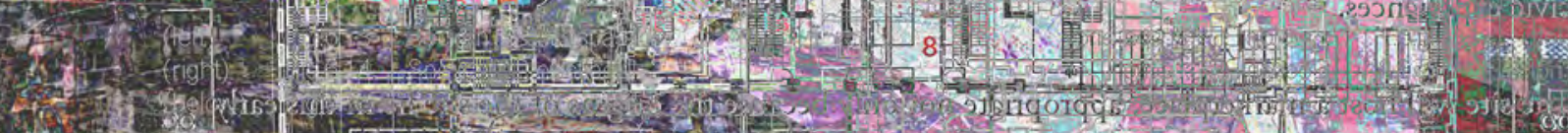

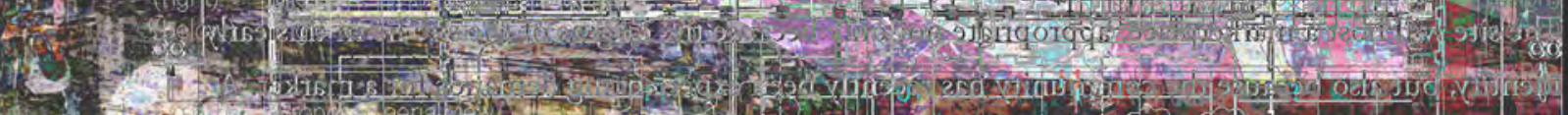
thes

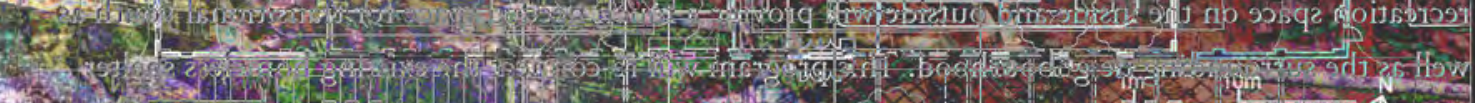

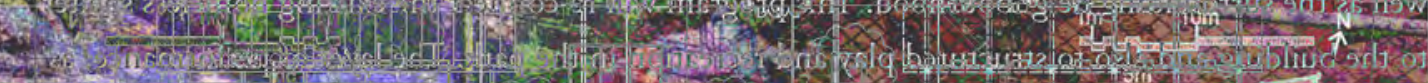

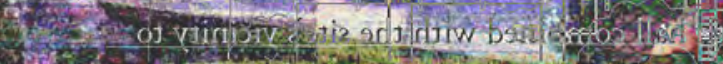

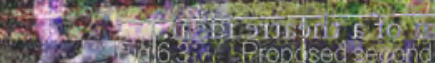
to

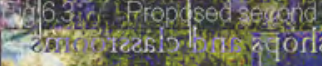

s. (2)

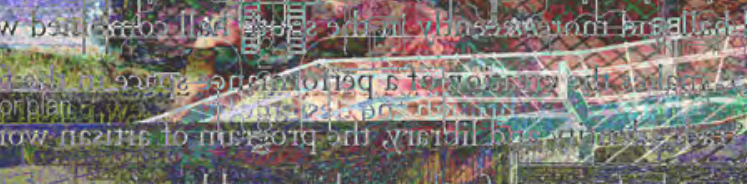

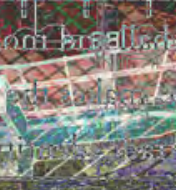
$\frac{10}{10}$ $\operatorname{lic}^{2}$ fivis $\operatorname{lins} 20$ -

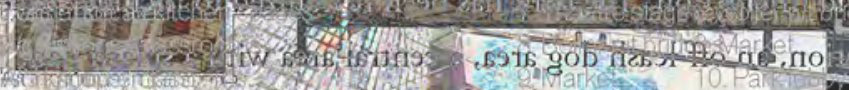

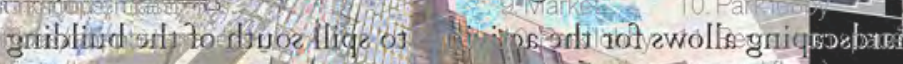
-1.

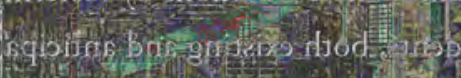




\section{Design Project}

Using the palimpsest, the proposal utilizes aspects of the uncovered layers to inform the next steps of the prospective building and serves to establish an appropriate evolution of the site. In the face of upcoming developments, it considers function, openness, and form. Without oppressing the existing structure, a lower-scale form was determined to be most appropriate to engage and emphasize the public pedestrian nature of the site/program; it is also much more responsive to the abutting park in both scale and reduction of afternoon shadow. The building will once again act as a key anchor for the community, and in a larger sense, an anchor for the city itself as it fosters meaningful contact between its increasingly diverse citizens.

\section{Program}

The building's program is condensed into six spaces that facilitate leisure, education, and culture. They are unified by the concept of a multifunctional and inclusive neighbourhood centered on an open square. The proposed multiplicity of functions will provide public activities as relief to the increasingly populous neighbourhood. It will also extend the site's historic role as it continues to foster memorable civic experiences.

The site will host a marketplace; appropriate not only because the origins of the site lie in this early identity, but also because the community has recently been experiencing demands for a market. A recreation space on the inside and outside will provide a much needed space for transitional youth as well as the surrounding neighbourhood. This program will re-connect the existing homeless shelter to the building and also to structured play and recreation in the park. The layer of performance, as seen in the former grand hall and more recently in the south hall combined with the site's vicinity to the entertainment district, makes the creation of a performance space in the form of a theatre ideal. In a nod to the early rag trade identity and library, the program of artisan workshops and classrooms will continue these traditions by fostering further making and learning. For the surrounding industry and residents, both existing and anticipated with the explosion of condo construction in the area, the building will host offices and daycare. The central square allows for the programs and participants to spill into this space for further mixing and interaction. The park has been revitalized to include space for a market extension, structured recreation, an off-leash dog area, a central area with a splash pad, and a kids play ground. Increased hardscaping allows for the activities to spill south of the building and into the outdoors. 


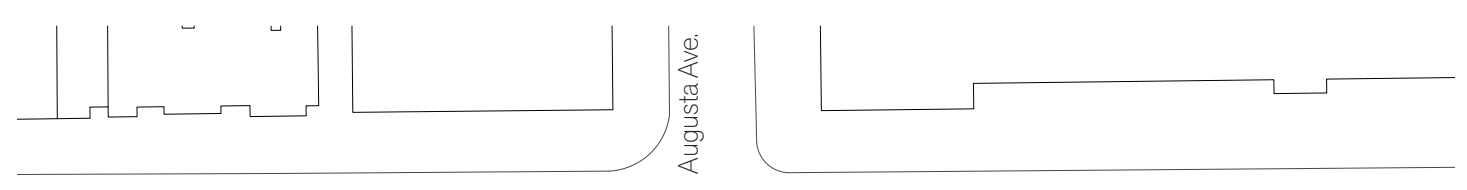

Richmond St. W.

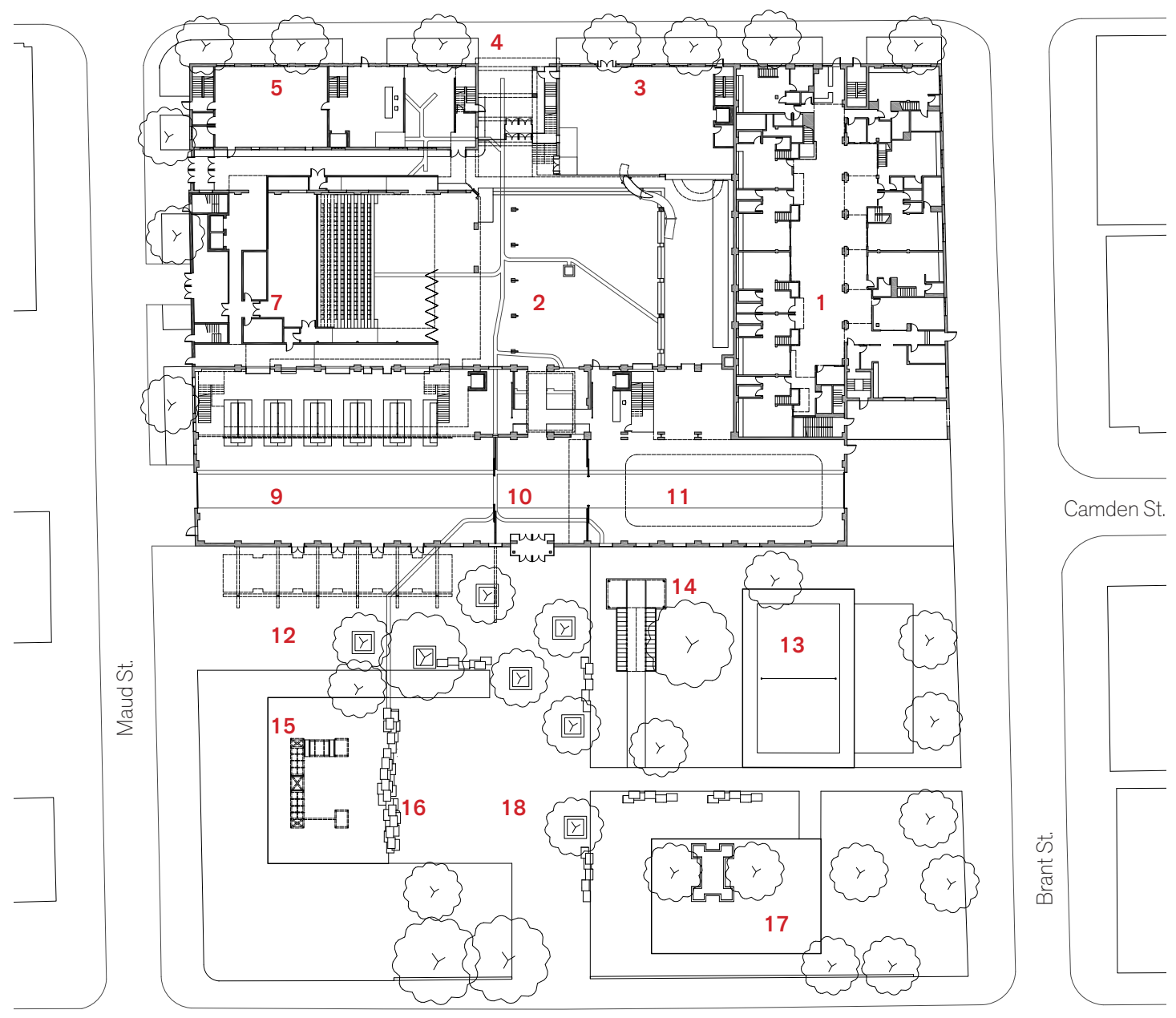

Adelaide St. W.

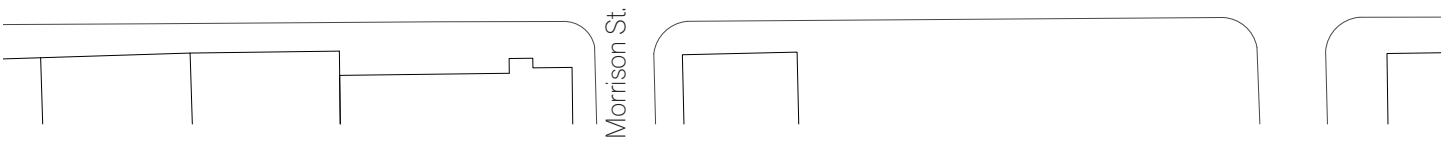

Fig.6.1 Proposed site plan

1. Eva's Phoenix kitchen spaces

2. Central square

3. Workshops/classroms

4. Richmond entrance

5. Offices/support space

6. Theatre back of house, washrooms, loading
7. Theatre stage level

8. Boiler pit bridges

9. Market

10. Park lobby

11. Recreation space

12. Outdoor patio
7. Theatre stage level

8. Boiler pit bridges

9. Market

10. Park lobby

11. Recreation space

12. Outdoor patio 


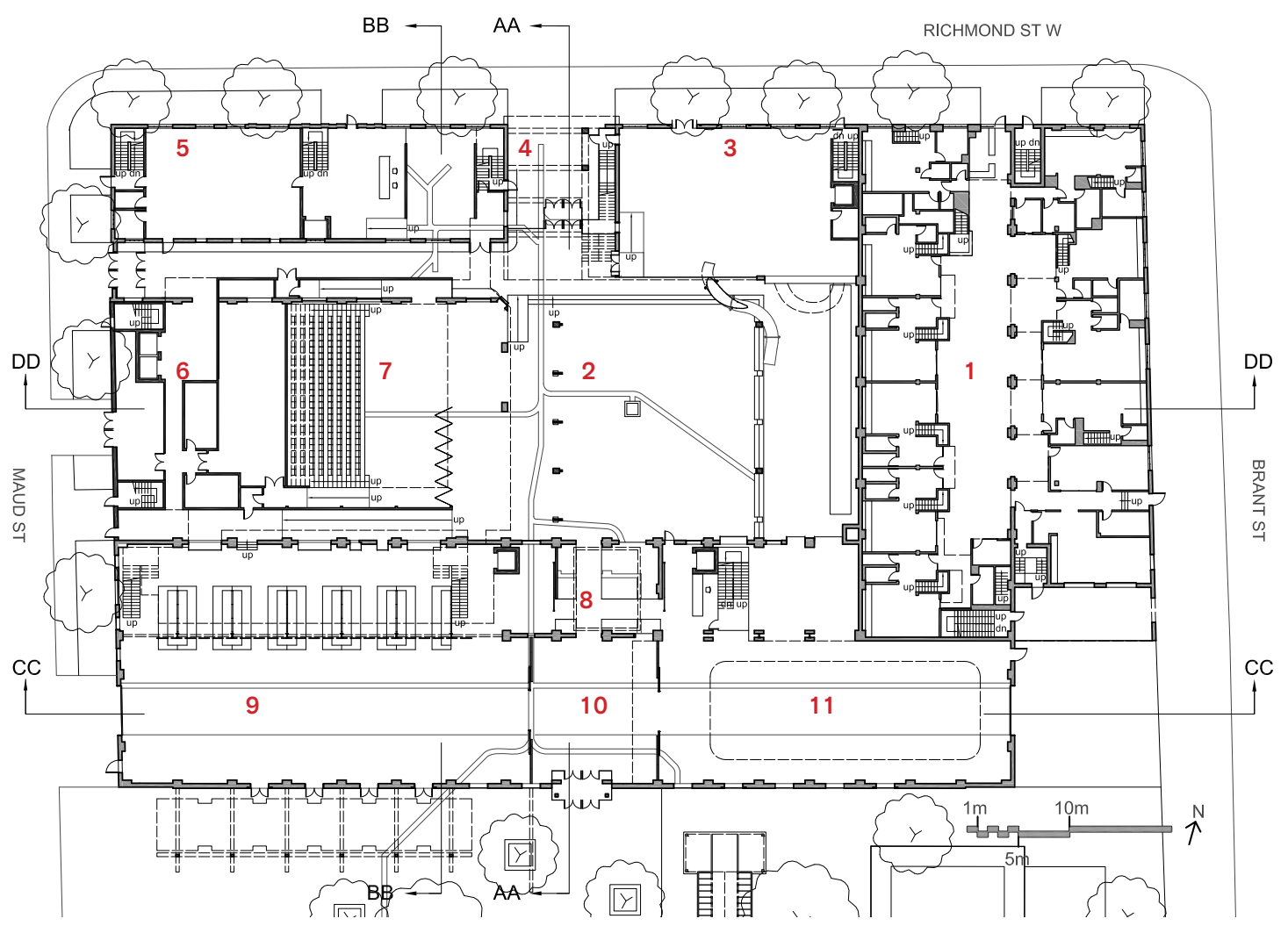

Fig.6.2 Proposed ground floor plan 


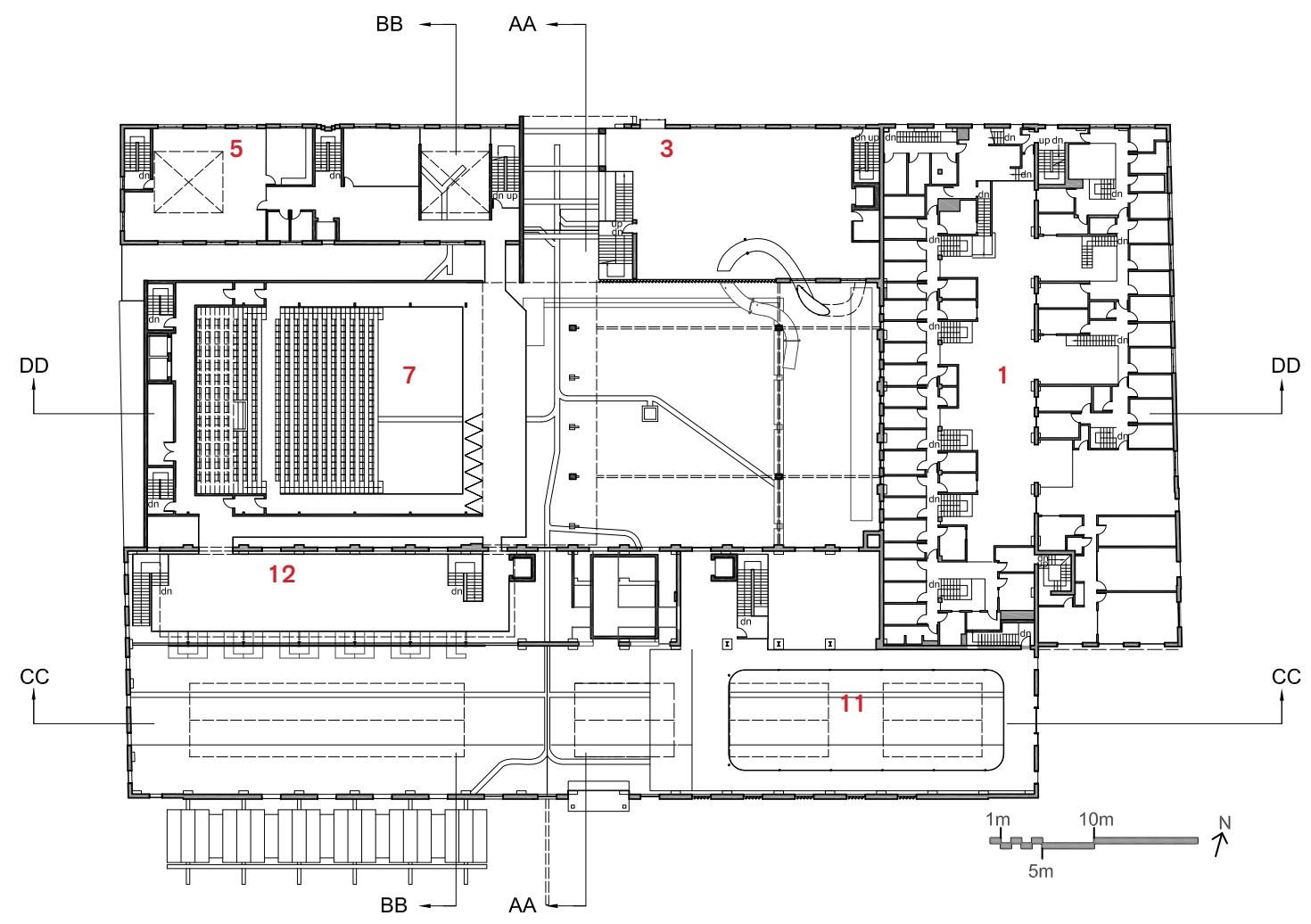

Fig.6.3 Proposed second floor plan

1. Eva's Phoenix kitchen spaces (ground floor, existing) Eva's Phoenix bedrooms (second floor, existing)

2. Central square

3. Workshops/ classrooms

4. Richmond entrance

5. Offices/ support space

6. Theatre back of house, washrooms
7. Theatre stage level (ground floor), theatre balcony level (second floor)

8. Boiler pit bridges

9. Market

10. Park lobby

11. Recreation space (ground floor), recreation track level

(second floor)

12. Mezzanine 


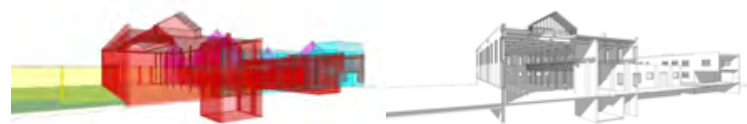

(left) Fig.6.4 Section AA transparency

(right) Fig.6.5 Section AA existing

(below) Fig.6.6 Section AA proposed
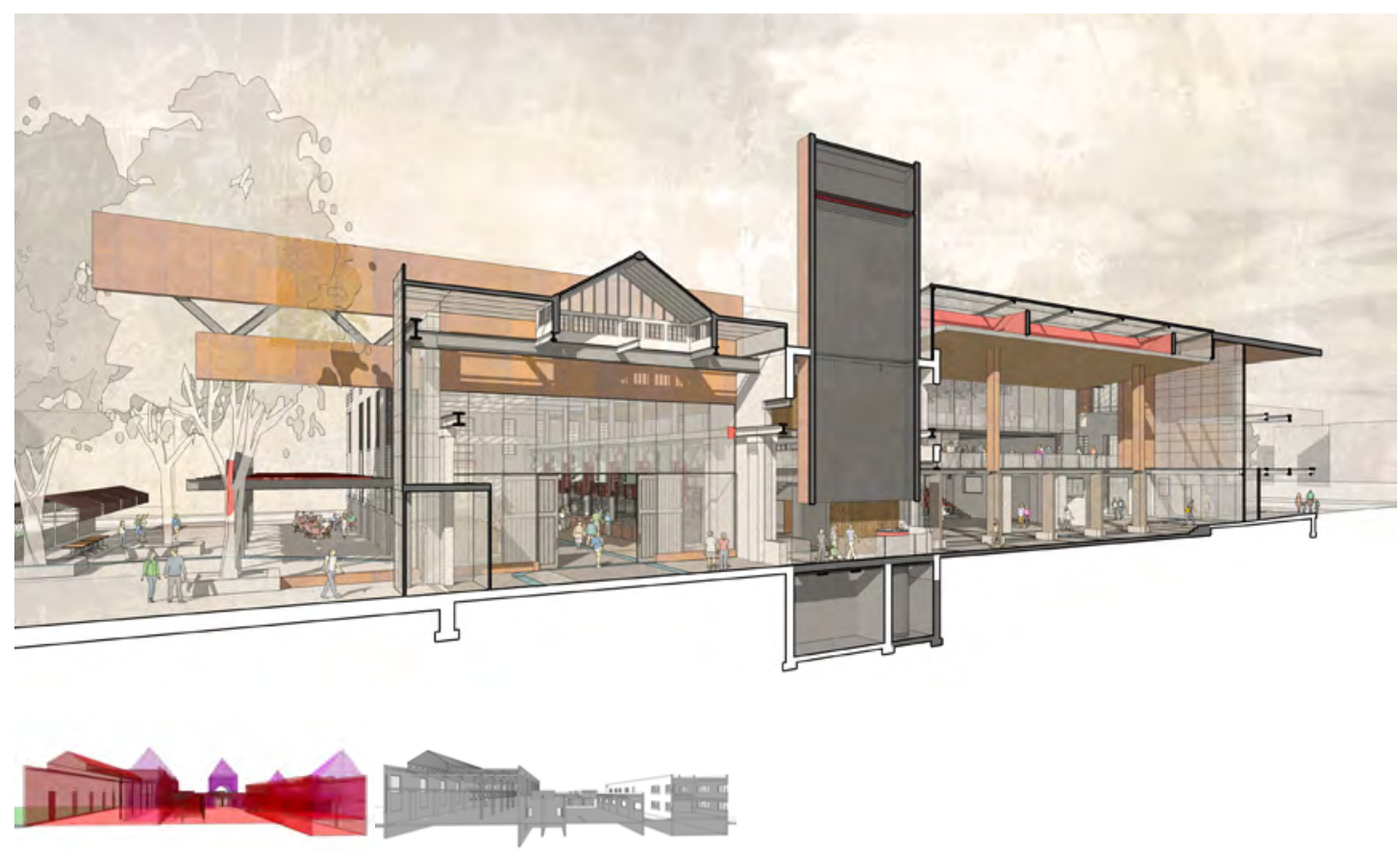

(left) Fig.6.7 Section BB transparency

(right) Fig.6.8 Section BB existing

(below) Fig.6.9 Section BB proposed

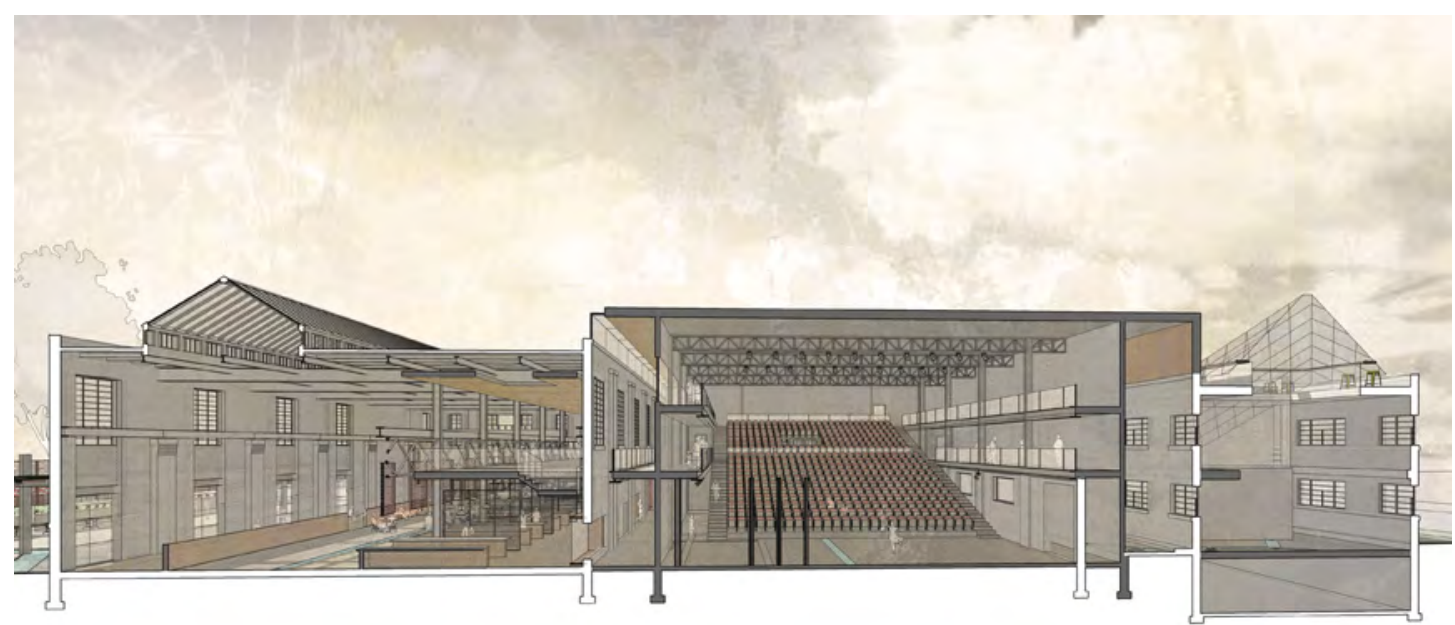



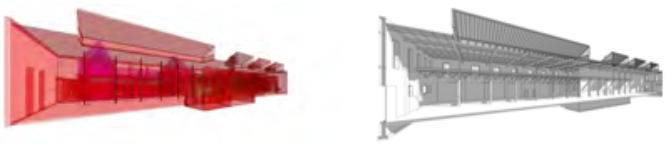

(left) Fig.6.10 Section CC transparency

(right) Fig.6.11 Section CC existing

(below) Fig.6.12 Section CC proposed
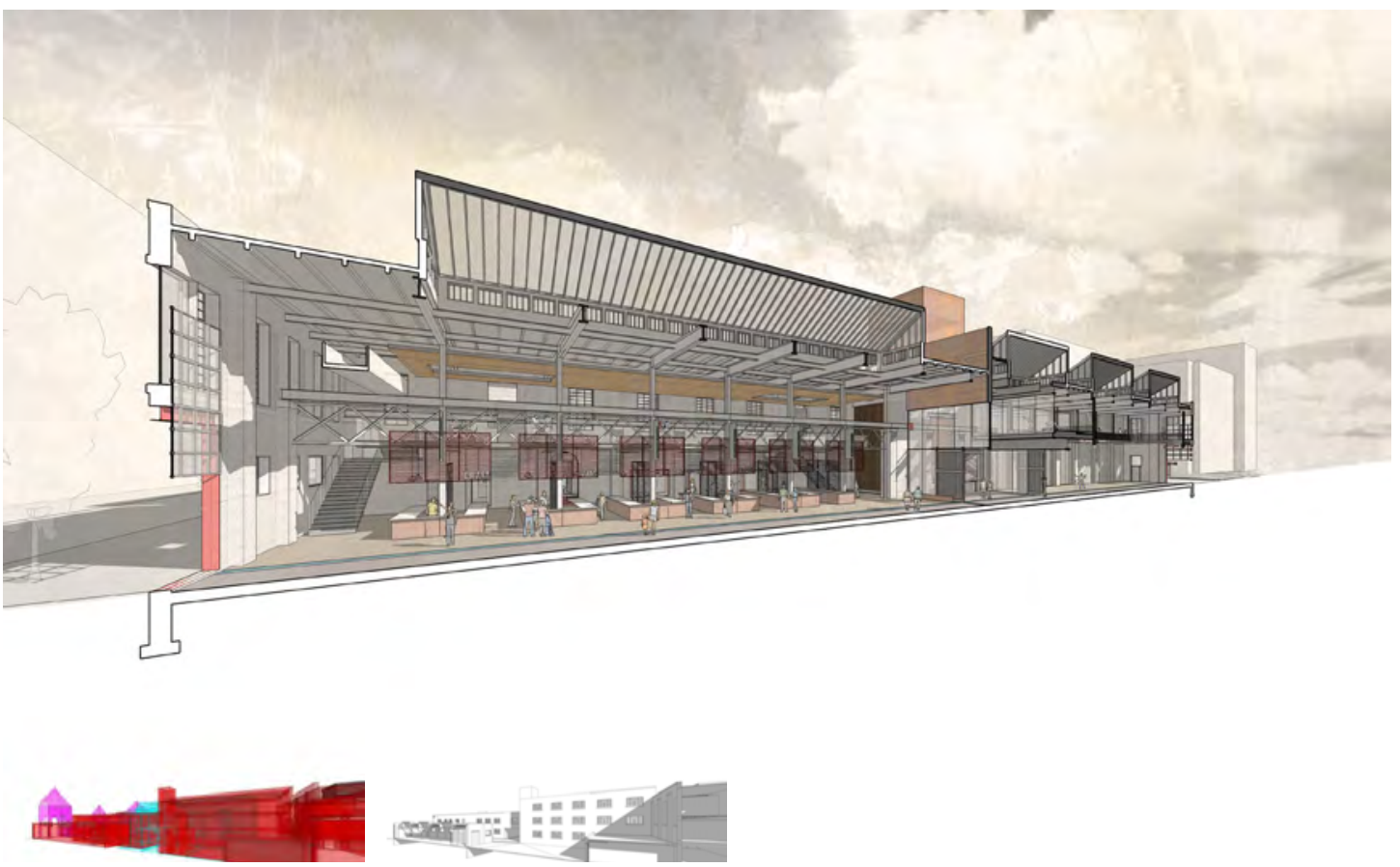

(left) Fig.6.13 Section DD transparency

(right) Fig.6.14 Section DD existing

(below) Fig.6.15 Section DD proposed

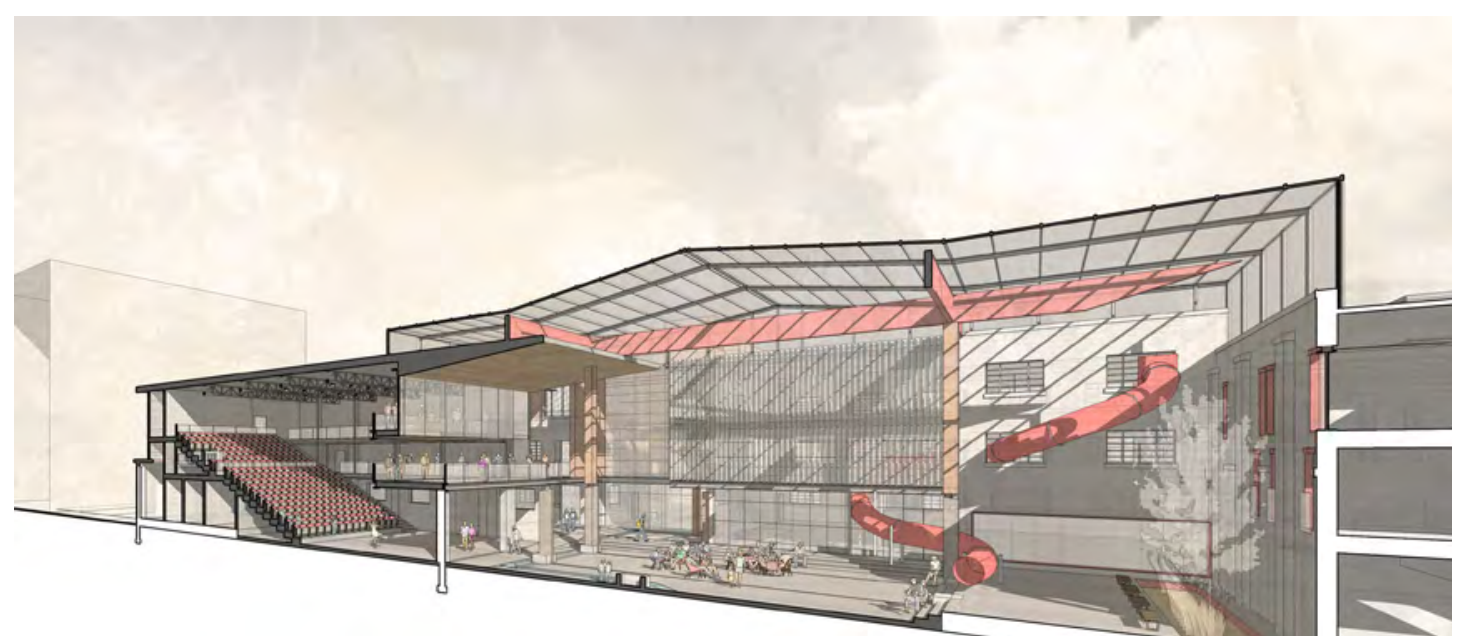




\section{St Andrew's Park}

To acknowledge the important of the park and to see its integration into the development, a strong central axis was designed to cut through the park and continue throughout this full-block building (Figure 6.16).

Follies are dispersed throughout the park and enhance its playful quality, emphasizing the park's status as Toronto's first playground. The objects take on reduced forms of previous three structures that once occupied the site and now function as a seating and fountain feature in the off-leash dog area, a children's playground equipment, and a bicycle storage.

A large central landscape water feature/ splash pad in the park connects to the building network, strengthening the recurring theme of water that prevails on the site (Figure 6.17).

Dispersed throughout the site, removed brick from the demolition of building parts at Waterworks has been re-used to form a seating feature. On the north-west corner of the park a new canopy serves an outdoor market and seating area.

The entry from St. Andrew's Park is accentuated by a large projecting plane that references the very first marketplace and creates a portal feature to the new one (Figure 6.18 and Figure 6.19). A glazed incision, centered on the location of the first marketplace of 1850 , breaks the long facade and reinforces the axial connection. 


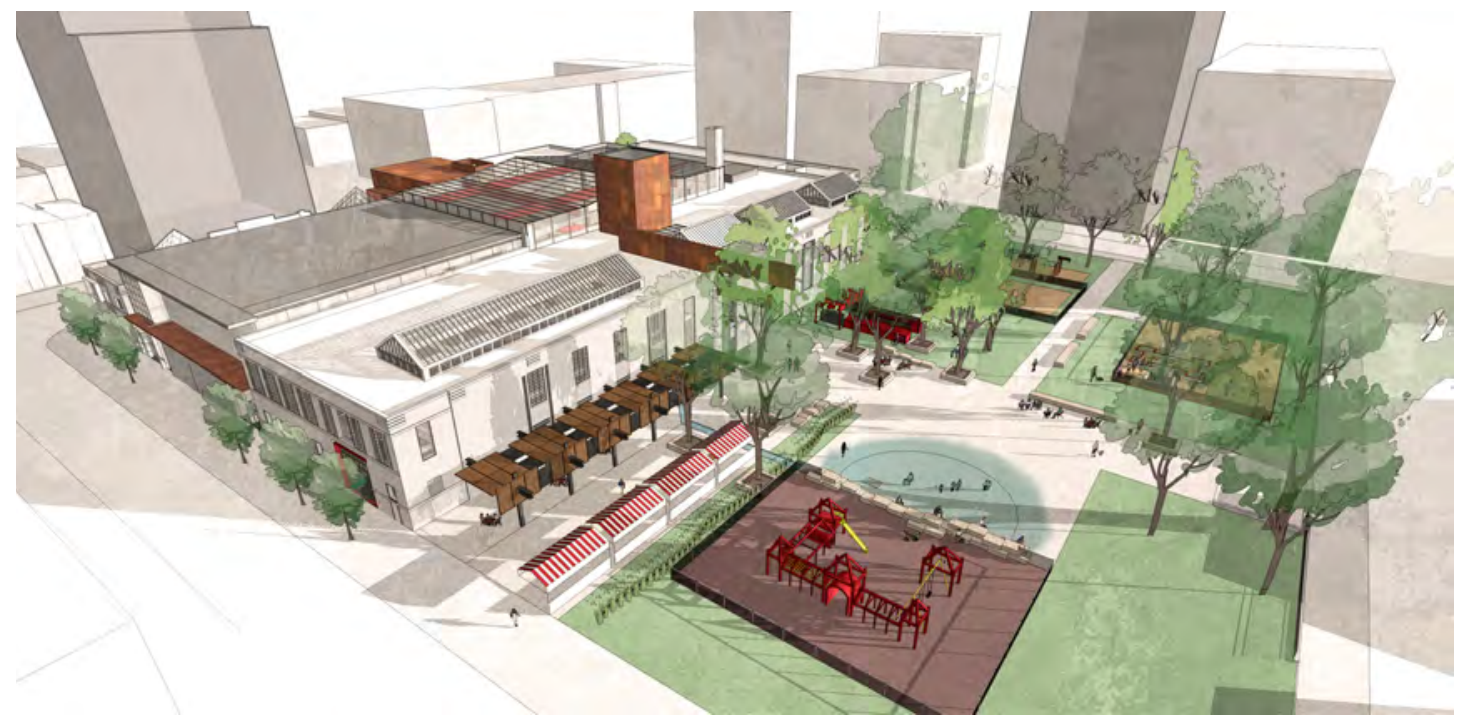

Fig.6.16 Proposed aerial view 


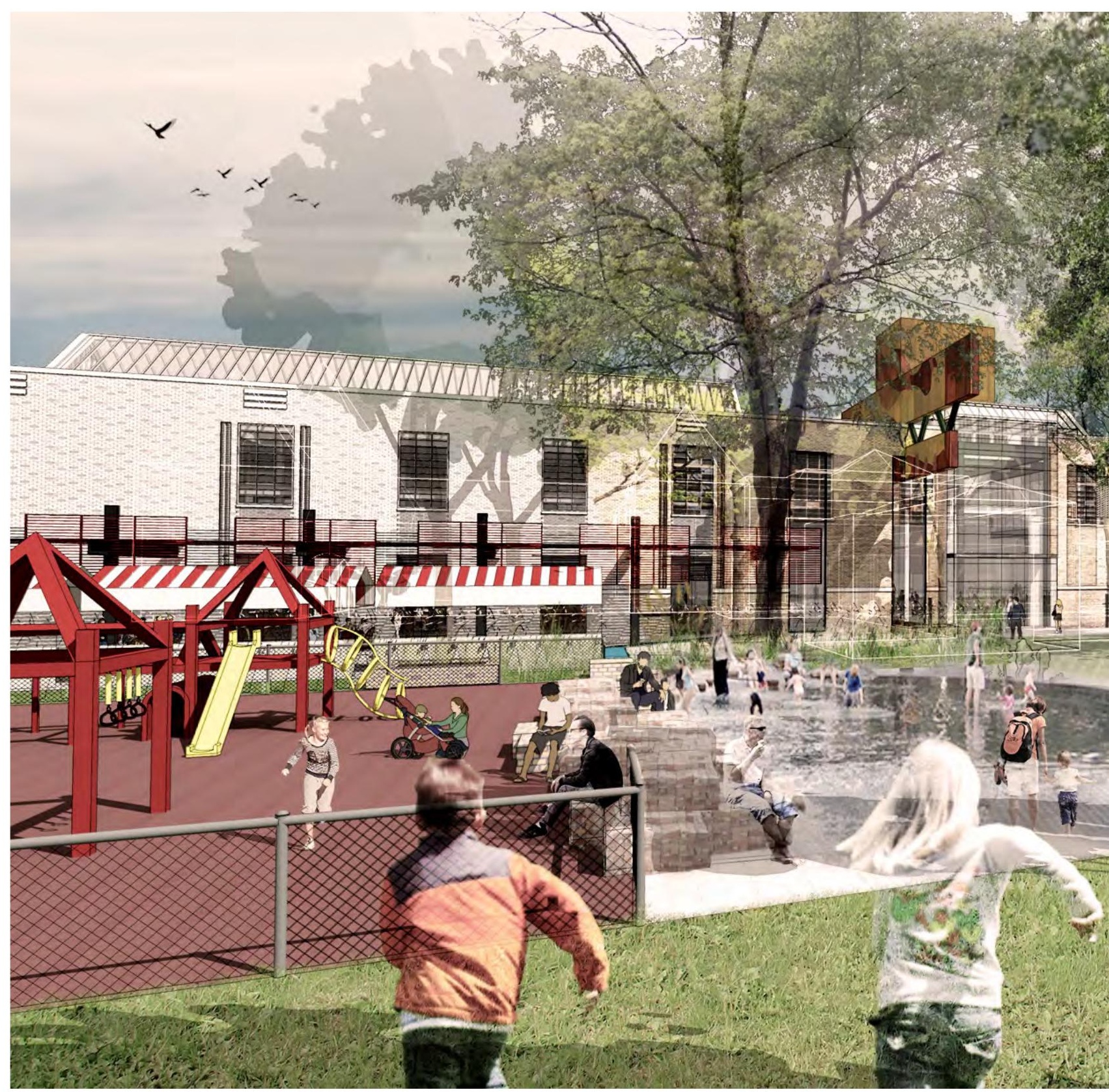

Fig.6.17 Proposed view at St. Andrew's Park looking north 


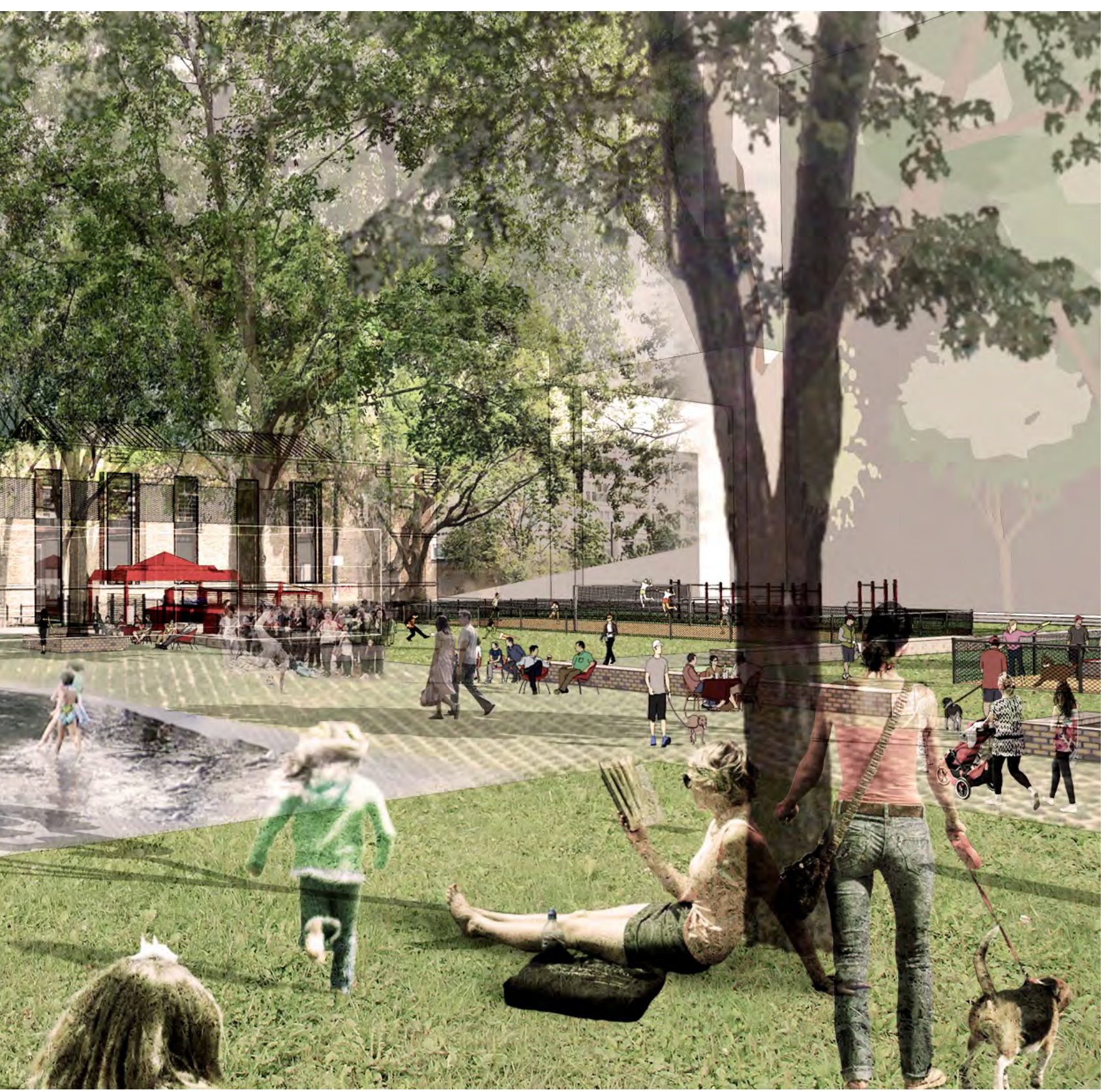




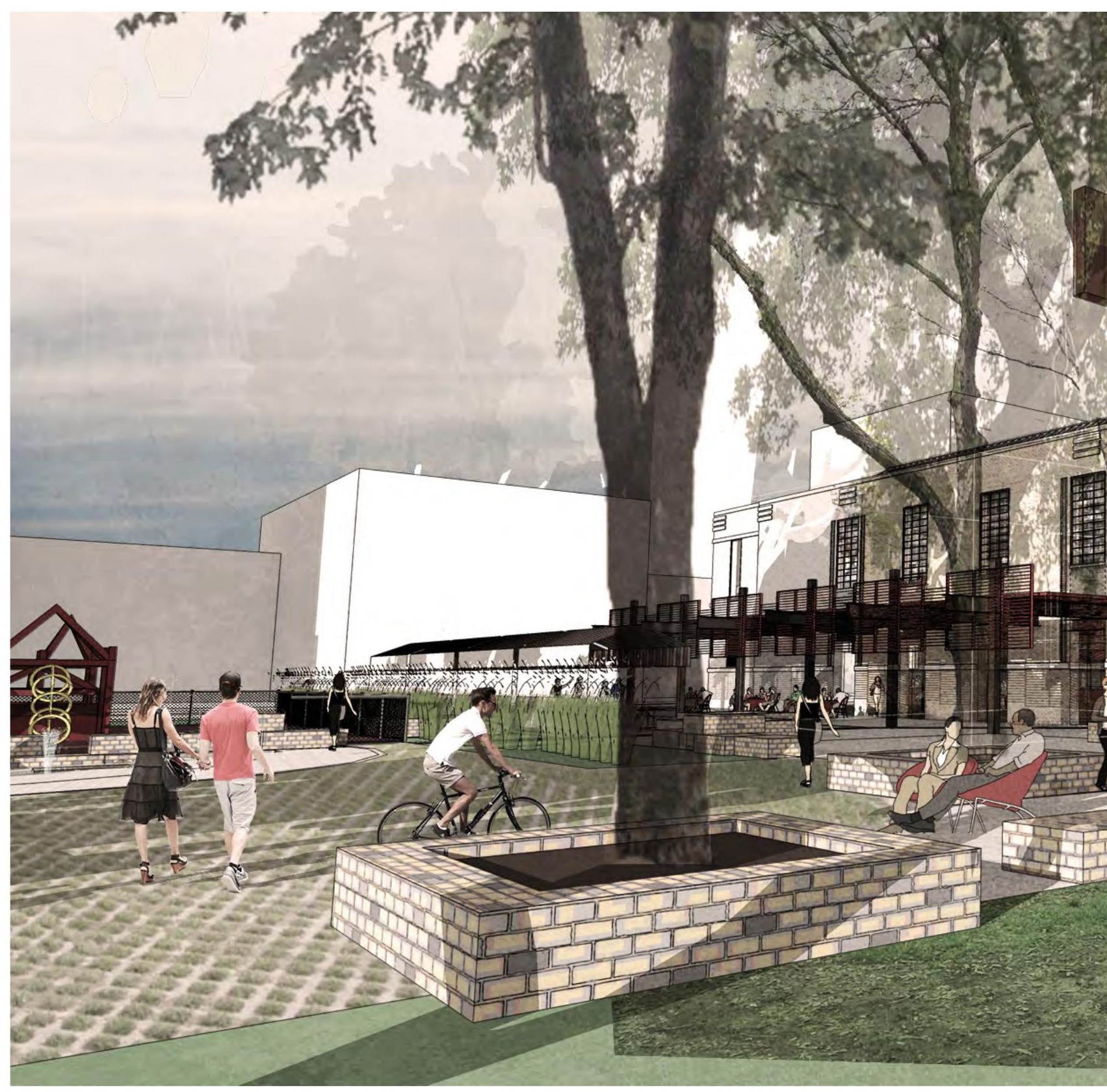

Fig.6.18 Proposed view at St. Andrew's Park entrance

(opposite) Fig.6.19 Proposed view at St. Andrew's Park entrance 


\section{Park Entry}

Barn doors reference the complex's original doors (Figure 6.20). They allow for the functions on either side (the market and the recreation) to mix and overlap. On one side, the recreation track overlooks the lobby, further pushing the theme of overlap.

Two large incisions on existing masonry wall reveal the boiler pit and thoroughfare towards the axial connection. The skylight remains blocked up, and the roof around it is glazed. This reversal permits the covered skylight to remain as a layer.

\section{Recreation Space}

Play and recreation are concentrated in the south-east portion of the building that connects the outdoor volleyball/ fitness area with a recreational facility. The new facility will provide a much needed space for the Eva's Phoenix youth. A portion of the north wall that currently divides the volumes has been removed (with the exception of the piers), extending and revealing the central square in the recreational area.

The perimeter crane runway beam of the Waterworks water treatment facility becomes the support for the second-level running track (Figure 6.21). New upper openings along the south wall overlooking the park allow for further light to enter the track level; their exterior is clad with a dogtooth brick screen.

\section{Marketplace}

The site's origin as a marketplace provides an important layer of its palimpsest. The resurfacing of this function will help the local community as well as play a large role in serving the other building programs.

The linear space complements the market type and creates an indoor street condition. The existing thoroughfare from Maud to Brant through the market and recreation is maintained utilizing the concept of transparency (Figure 6.22). As mentioned, this allows for overlap and also amplifies the trace of Camden Street, a street that existed on the location of the south hall before the construction of the Waterworks building eliminated it. 
The skylight glazing was restored to allow for further light in the space. The partially infilled south windows are once again opened up to their original heights and extended to become access to the patio and park. Furthermore, a lounge mezzanine extends from the theatre, another example of the integration and overlapping of form and function.

\section{Boiler Pit}

The most spatially contested area is centered on the current pit that houses the waterworks boilers. Pedestrian traffic is concentrated with intersecting steel bridges over the pit that connect to the main halls as well as the central square and park lobby (Figure 6.22). The bridges over the revealed existing foundations enclose the original boilers.

The site's importance is emphasized by its greater height. This is achieved through a dark and confined volume hovering above the bridges. Its chimney form symbolizes the fire that consumed the first market (Figure 6.24). The original wood-block flooring of the south hall is re-purposed as a feature wall and entrances to the market hall. 


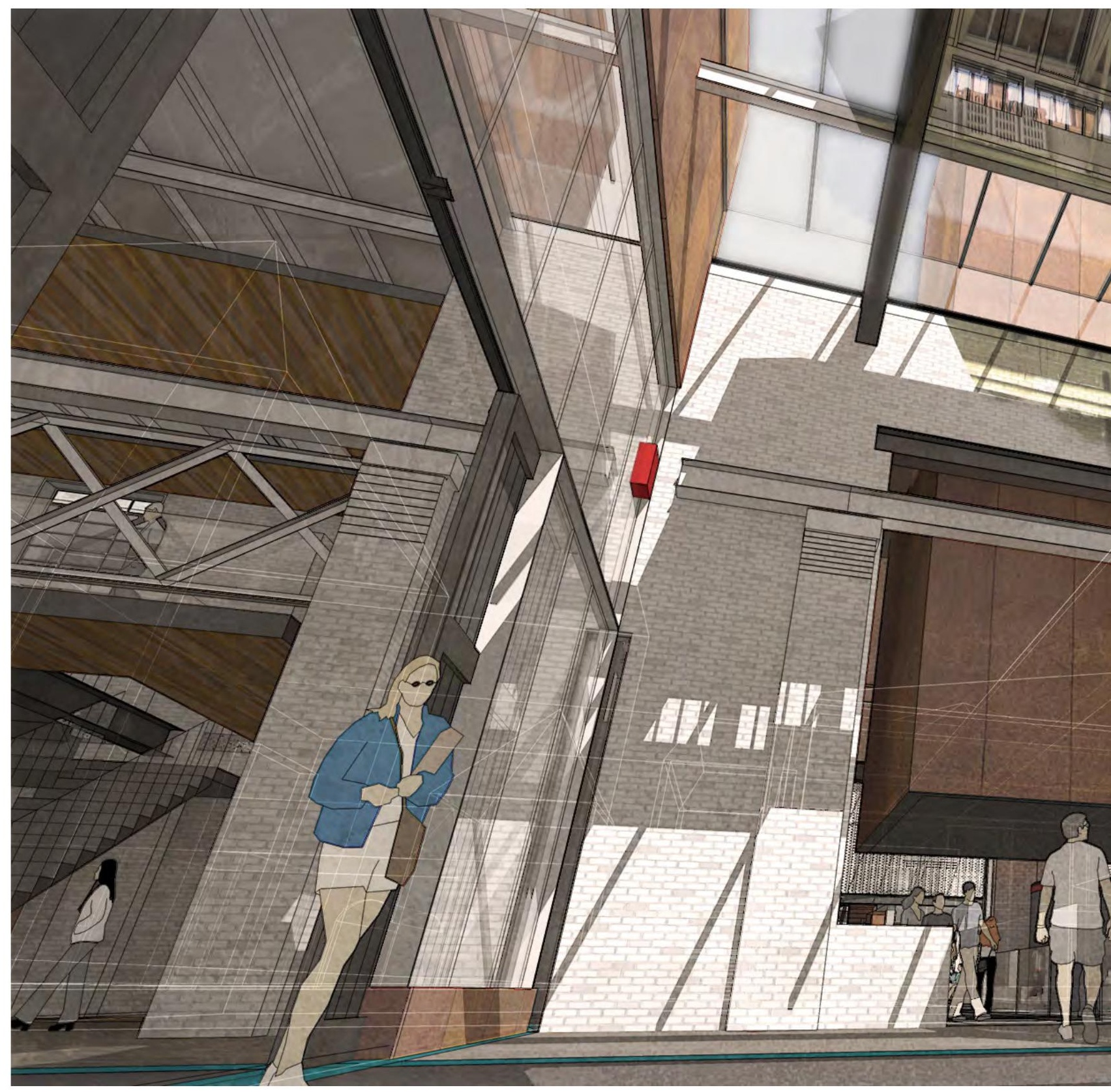

Fig.6.20 Proposed Park Lobby looking North 

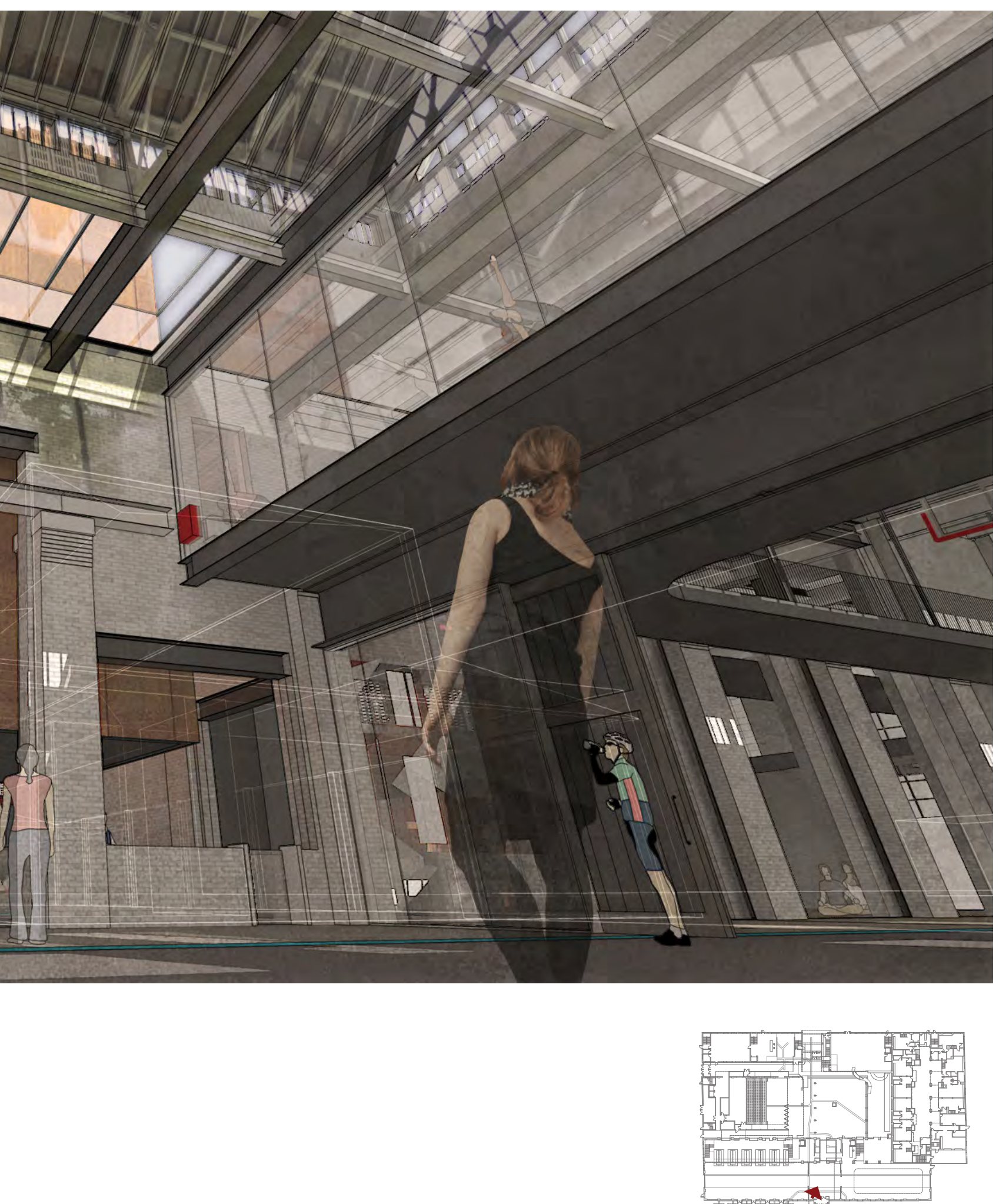


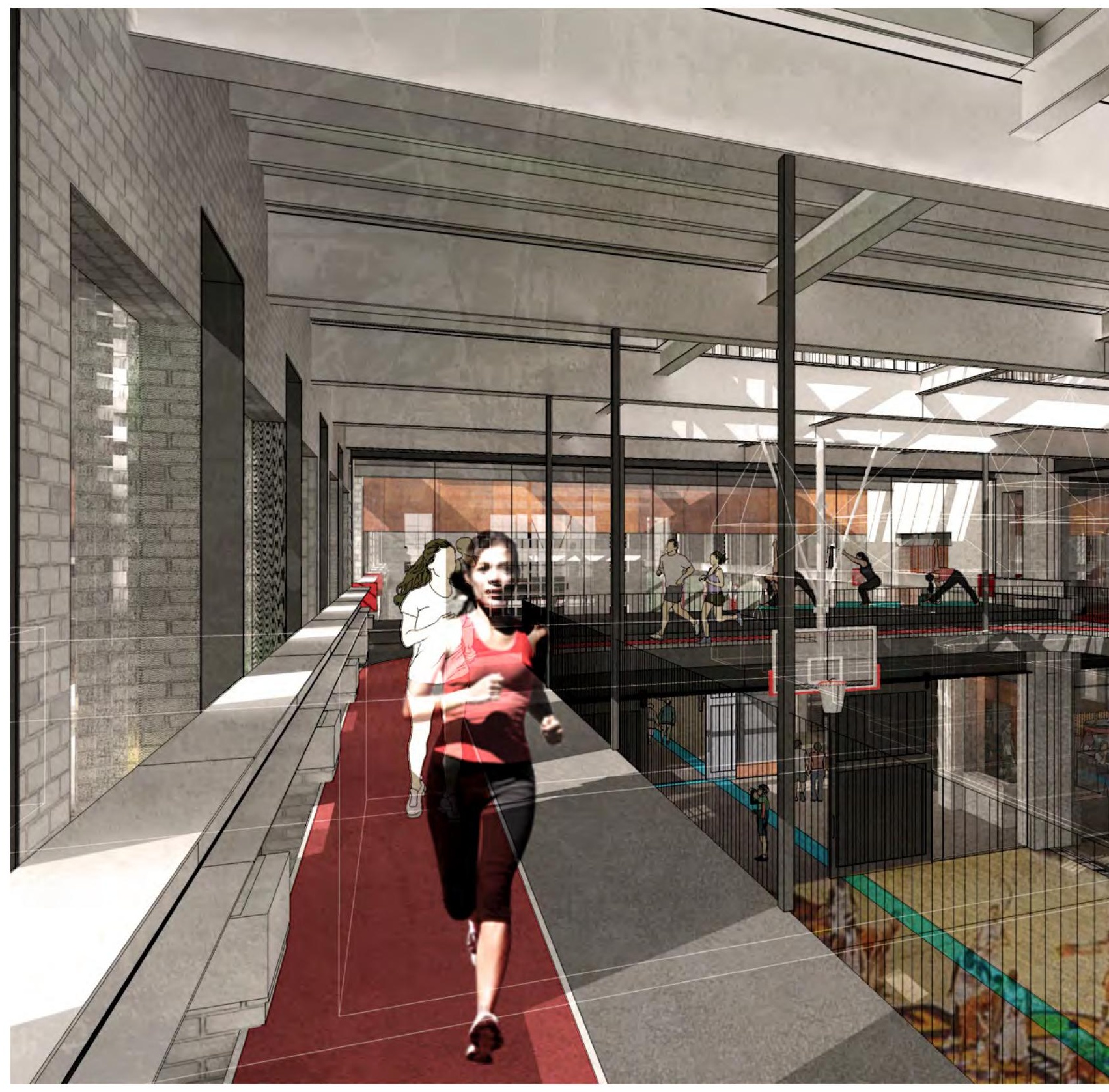

Fig.6.21 Proposed Recreation space at track level looking West 

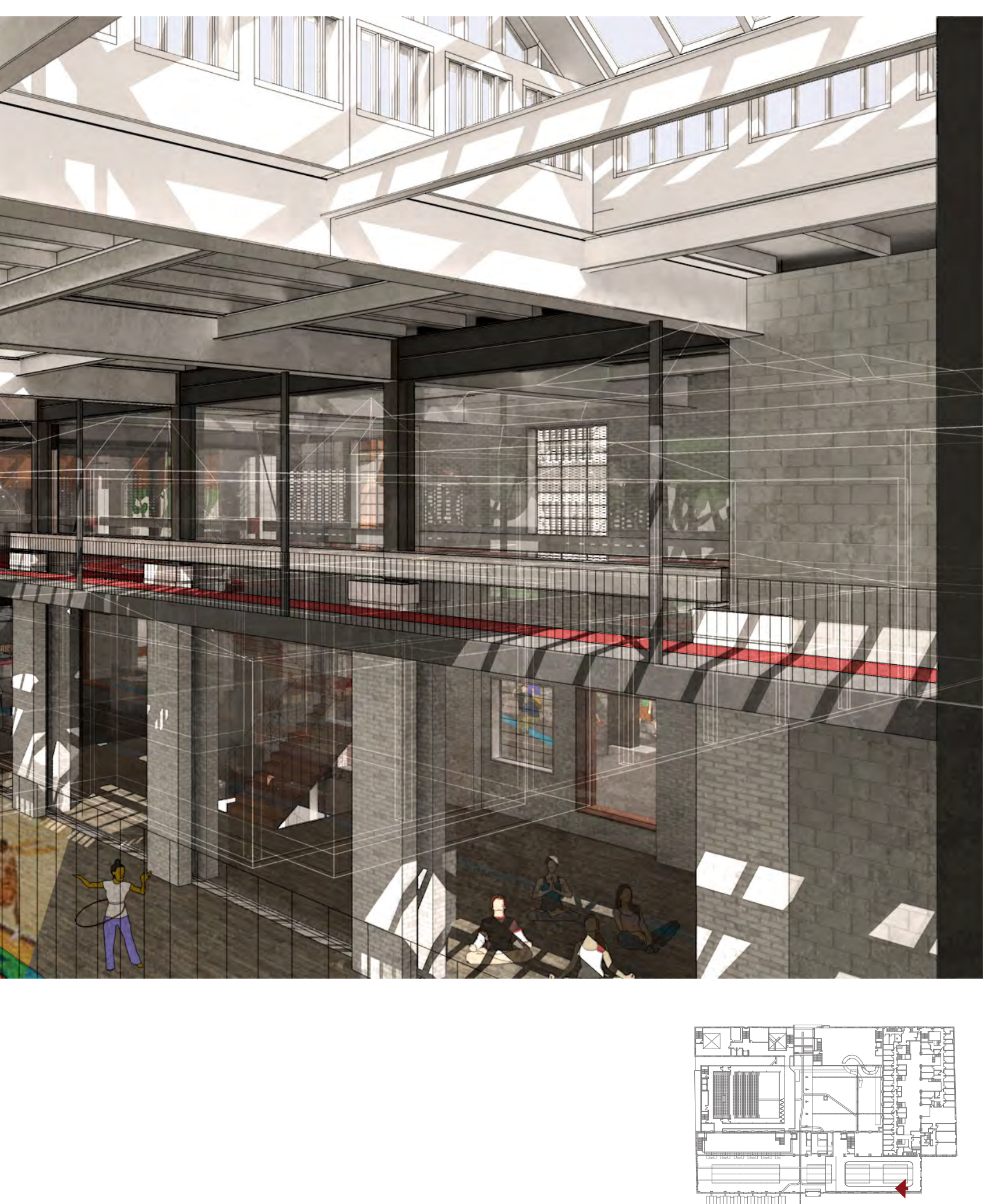


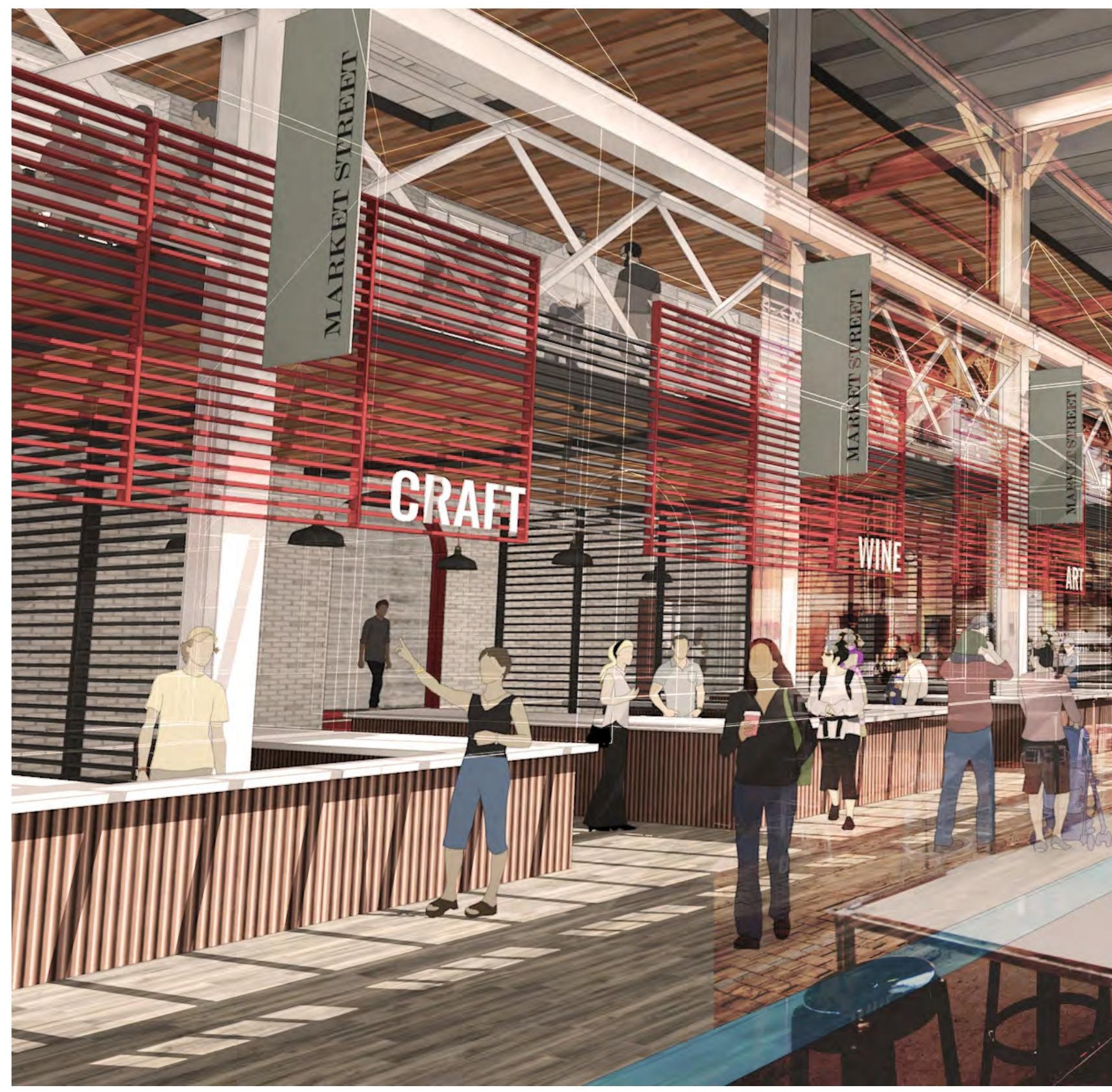

Fig.6.22 Proposed Market looking East 


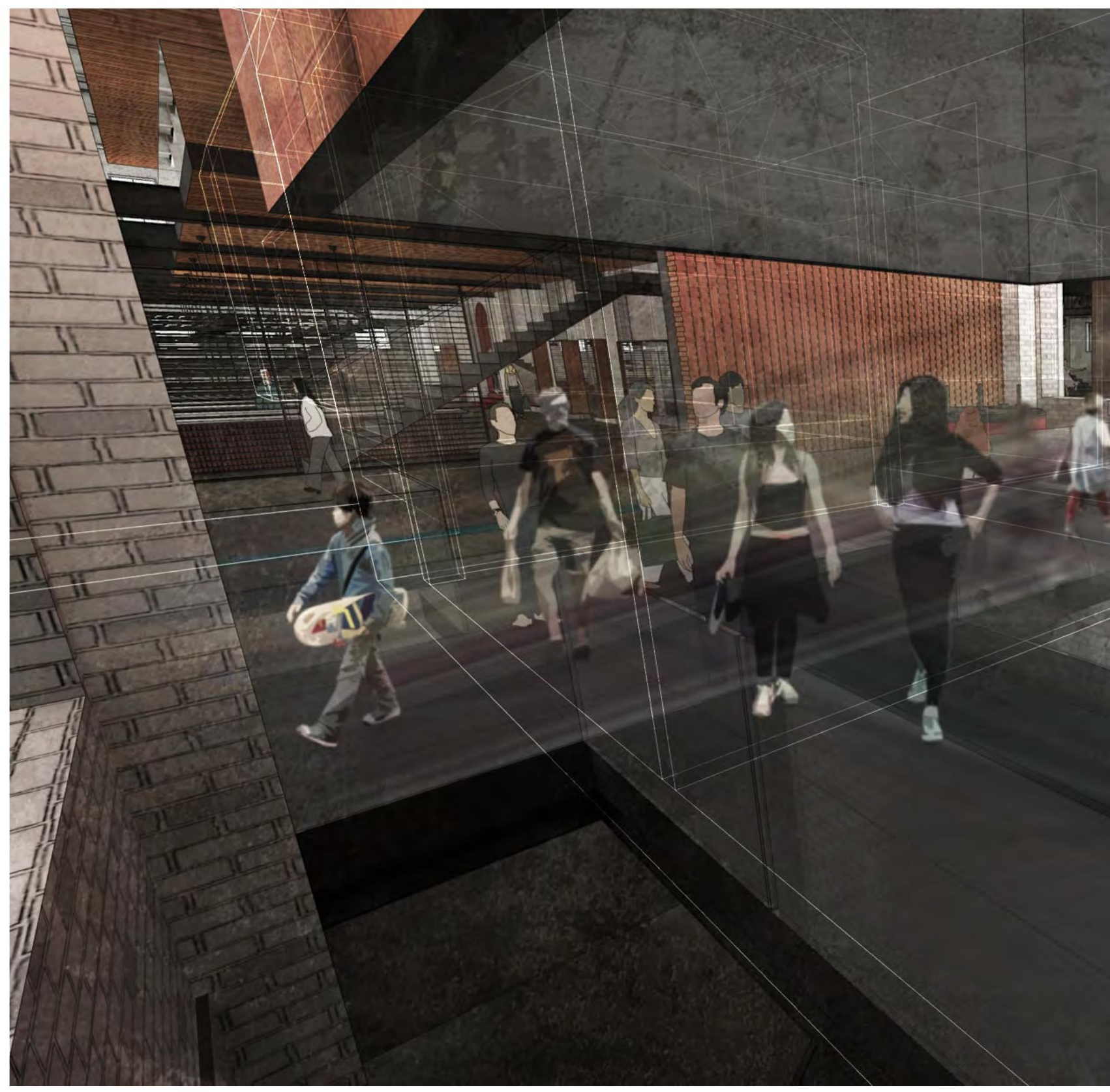

Fig.6.23 Proposed bridges at Boiler Pit

(opposite) Fig.6.24 Proposed chimney skylight at Boiler Pit 


\section{The Central Square \& Theatre}

The central square is depressed below ground level imprinting the extents and mass of the oncepresent market and hall building (Figure 6.25). The drop reveals the existing central culvert- now a water feature, and new forms representing the old market foundations that guide the user through the atrium. The drop addresses the grade different on the site, and also creates an opportunity for perimeter steps that can be used for informal seating and a 'stage' condition is created opposite the theatre wall, against the wall of Eva's Phoenix.

A slide protrudes from the office building, recalling the rooftop playground, and serves to connect the floors to the courtyard while evoking a layer of play and recreation.

The old function of the pattern storage is made explicit through a new and improved south facing facade for the proposed workshop building. The dogtooth brickwork employed as a screen symbolizes the pattern of fabric and celebrates the presently discrete brickwork on the existing facades (Figure 6.26). Brick becomes a primary material and together with the craftwork symbolizes the layer of labour associated with the site.

Occupying the west side of the central square, the current site of the garage volume, is a new theatre. The concrete volume is cast within the void of the old yard of St. Andrew's annex yard. Extending its function of bringing people together, the theatre aims to do the same. The theatre is about communicating and learning by sharing stories and experiences. It is expected to host speakers and gatherings as the site once support, but also light performances (Figure 6.27). Balconies create standing spaces and less formal gathering areas to foster greater engagement for a variety of performances and events. Unlike typical theatres the front wall can be opened essentially extending the stage into the atrium.

Remnants of the garage volume's skylights overlapping with the new seating reveal an unexpected opportunity for the re-use of these elements as balconies (Figure 6.28).

Expressive of the central role the building once had, the proposed courtyard is designed as the confluence of the complex's many functions. It is here that the functions mix and patrons interact. This connection is emphasized through visual transparency-expansive south glazing for the office workspaces, windows for Eva's Phoenix, and a clear theatre backdrop (Figure 6.29).

The glazed roof maintains the ambiance of an outdoor courtyard. The dominant water layer of the site is surfaced through a network of water features that run through many of the spaces following the waterworks infrastructure. 
The Eva's Phoenix fenestrations that were recently blocked up would be reopened, providing the bedrooms and offices with windows into the central square (Figure 6.30).

\section{Richmond Entry}

The entry from Richmond Street provides relief from the massing by mean of the removal of an existing second-story extension. On Richmond Street, transparency is provided to draw people through. The bold insertion was made between the old pattern storage and the office components and aligns with the extension of Augusta Avenue from the north (Figure 6.31).

Remnants of the old bridge connection are seen through the revealed beams as you walk through this space (Figure 6.32). 


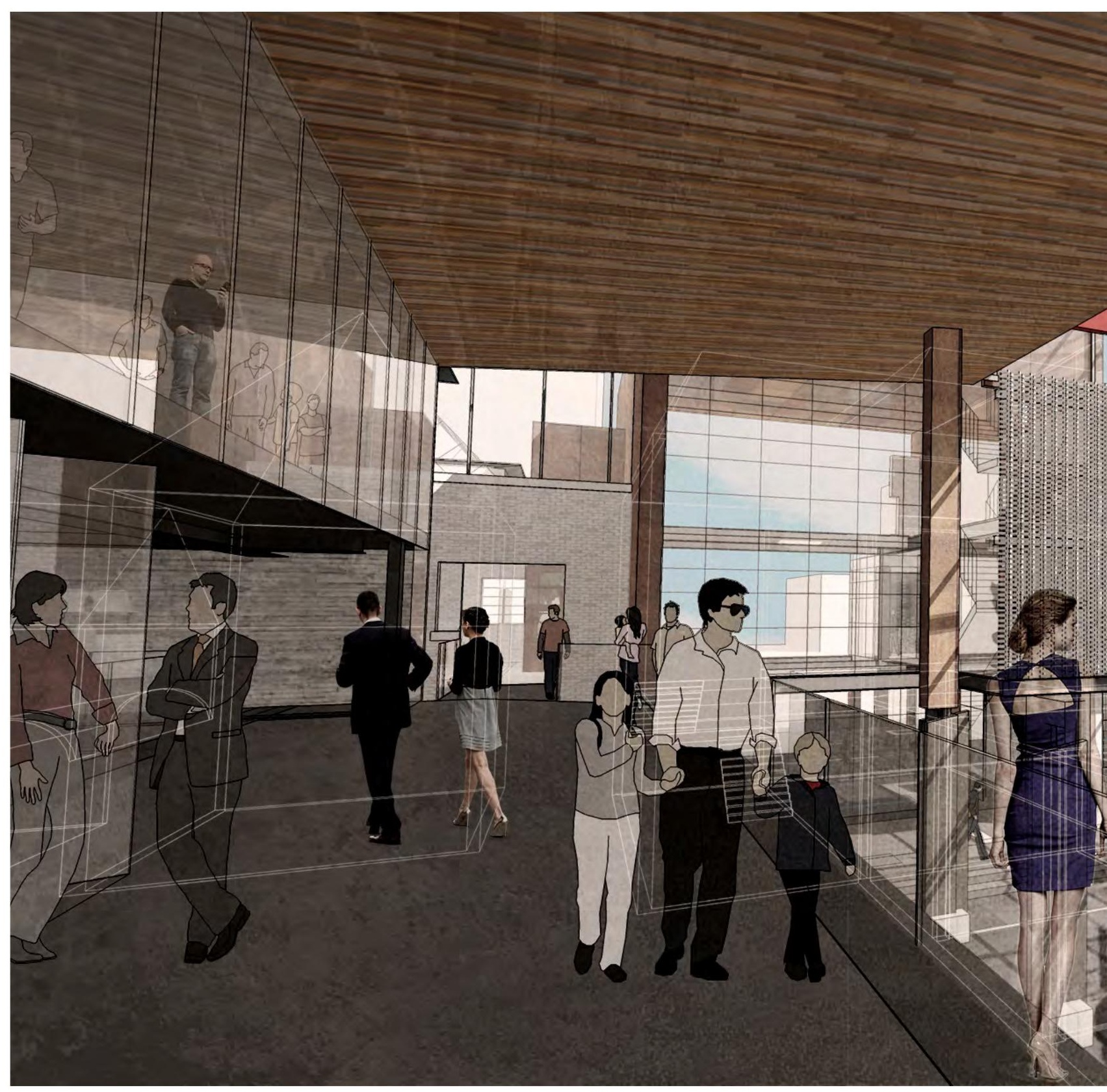

Fig.6.25 Proposed view at Central Square from theatre balcony looking north-east 


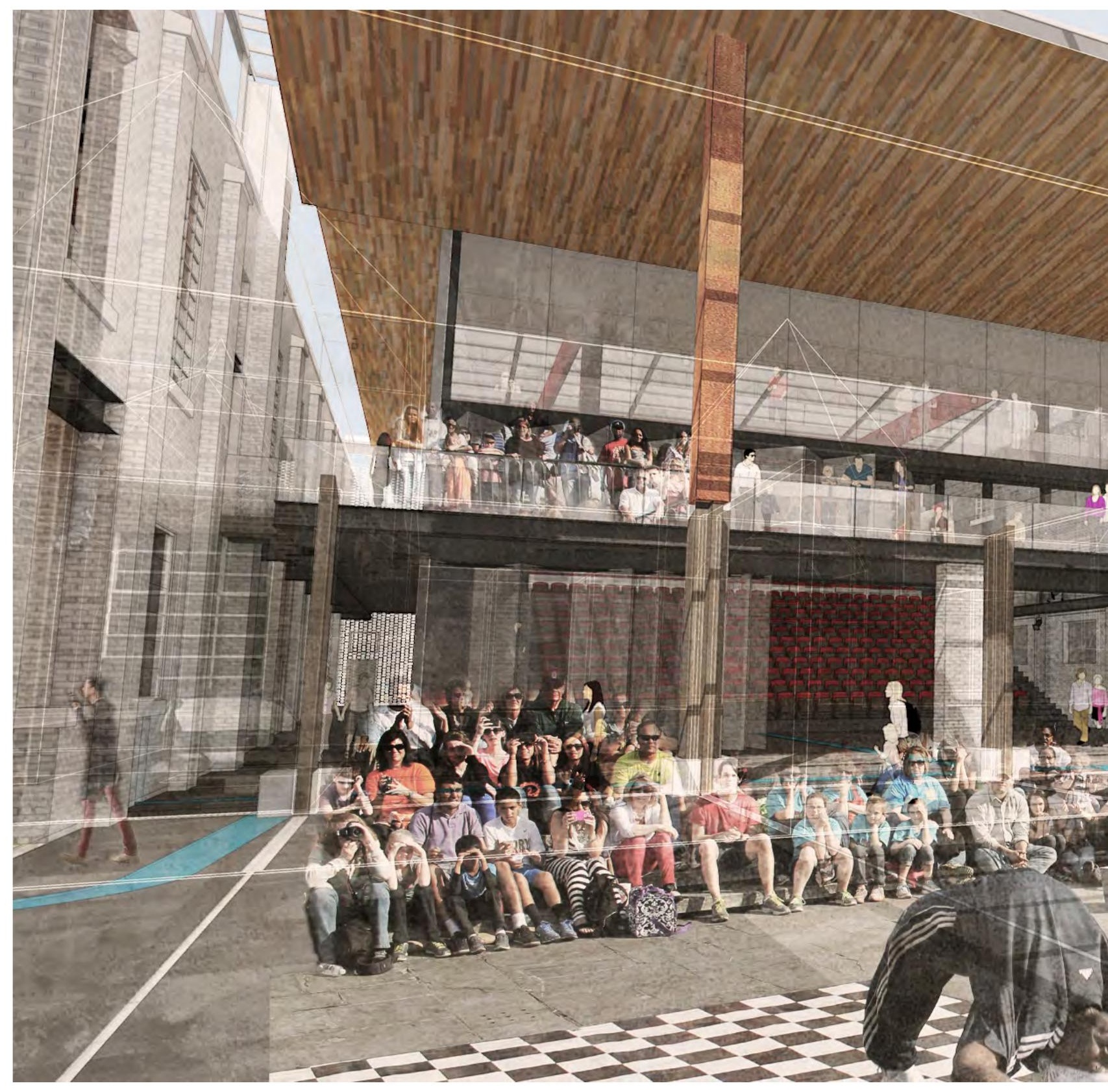

Fig.6.26 Proposed view at central square looking west towards theatre 

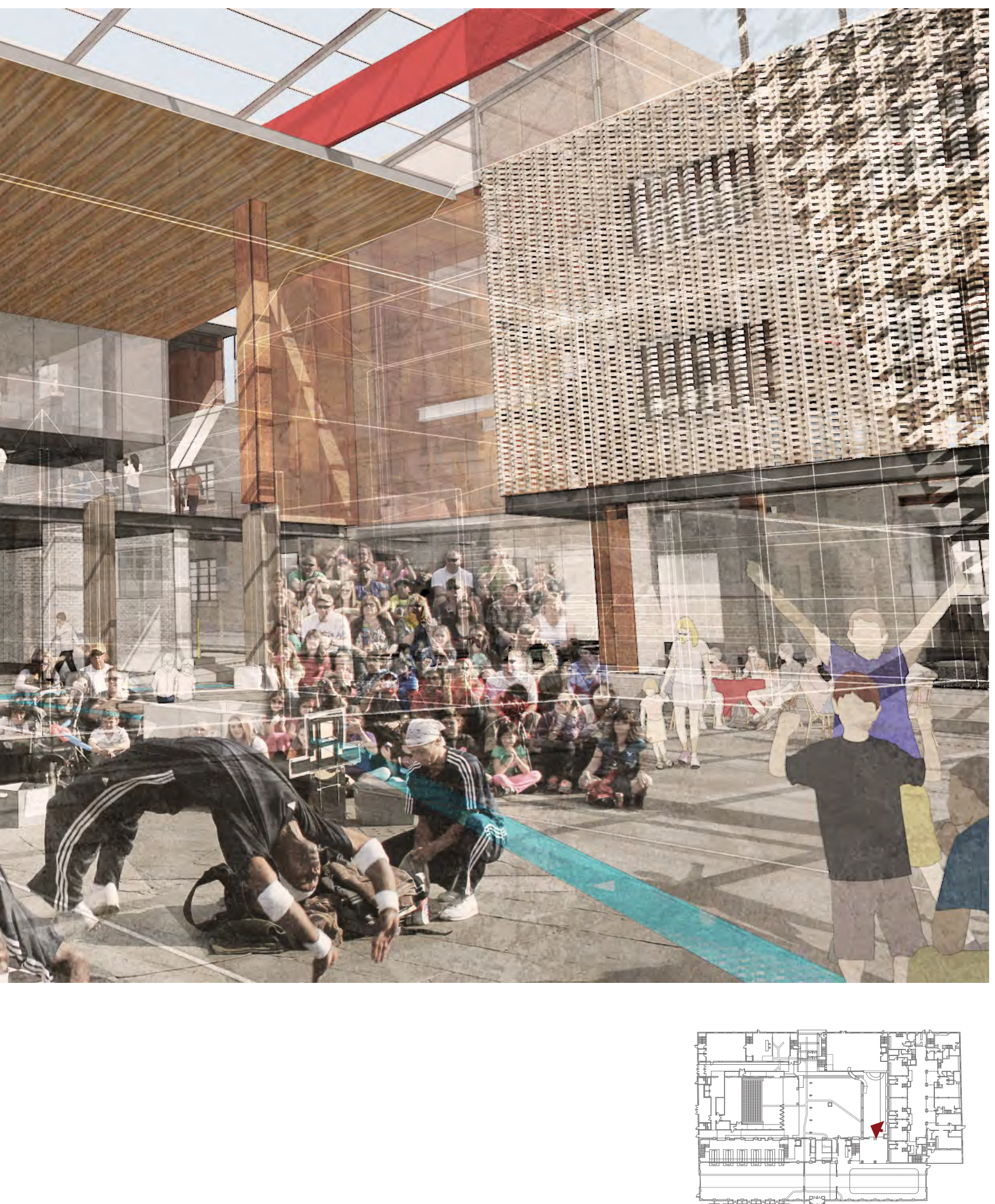


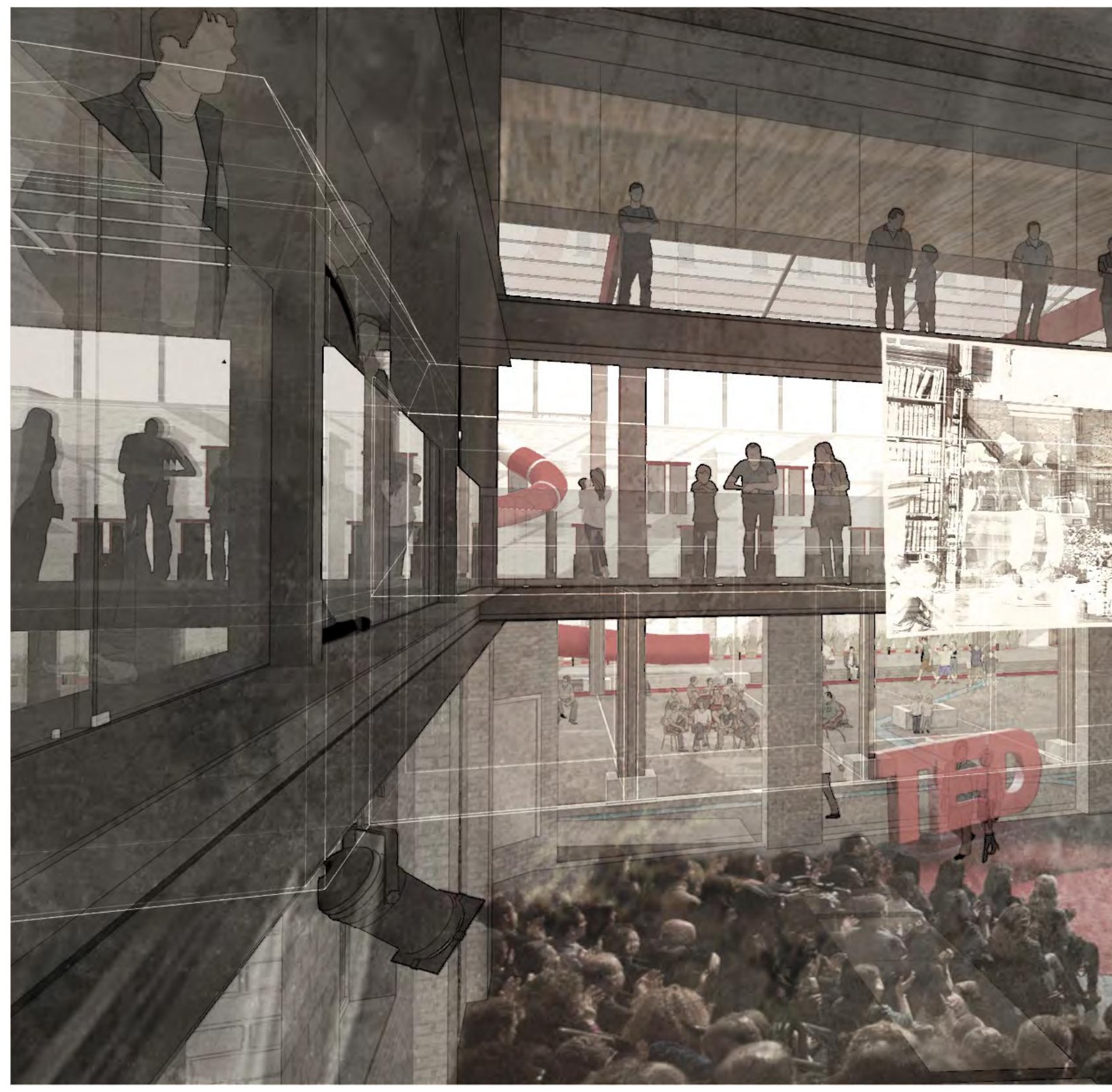

Fig.6.27 Proposed view inside theatre looking east towards central square (opposite) Fig.6.28 Proposed view of skylight balcony 

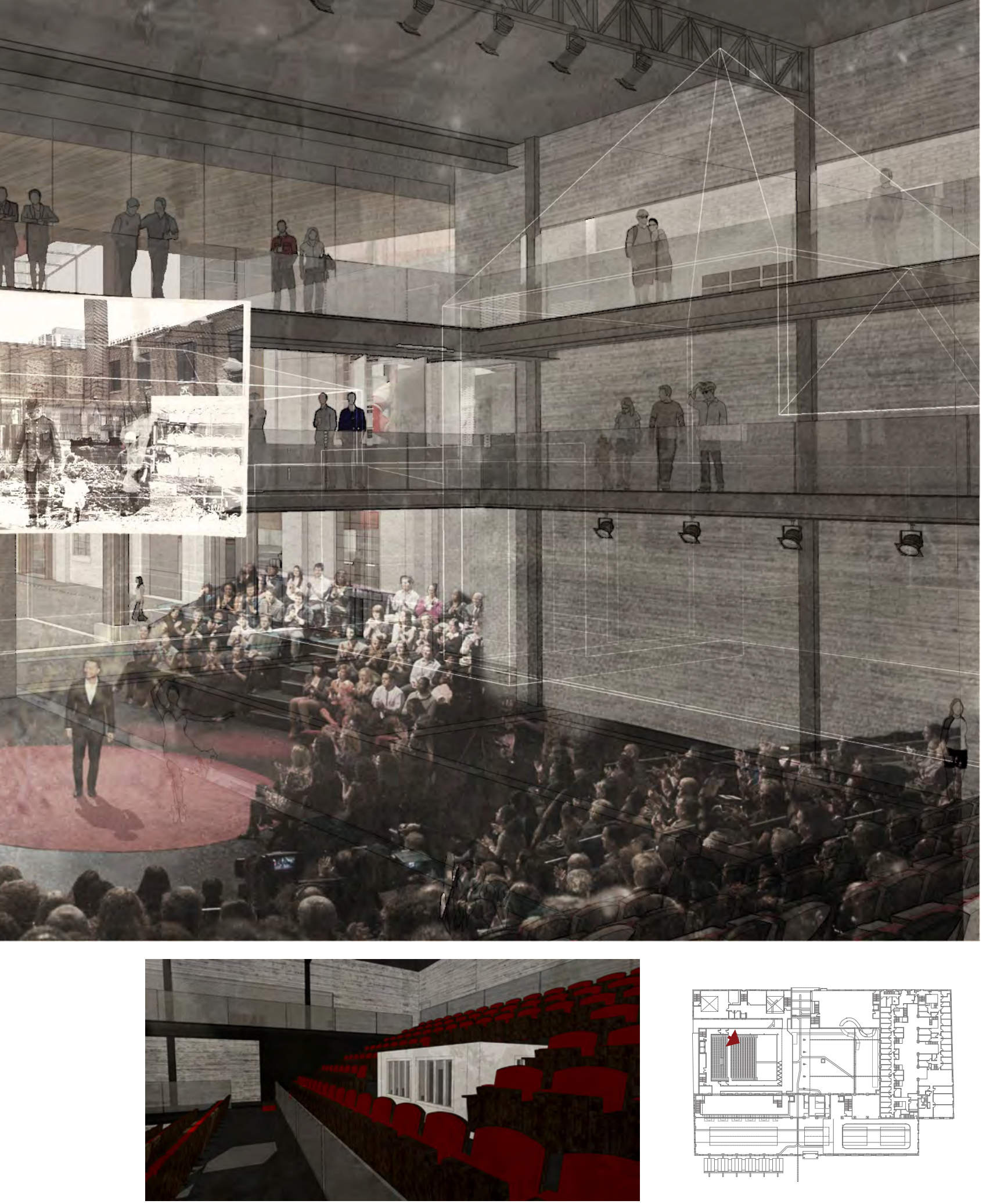


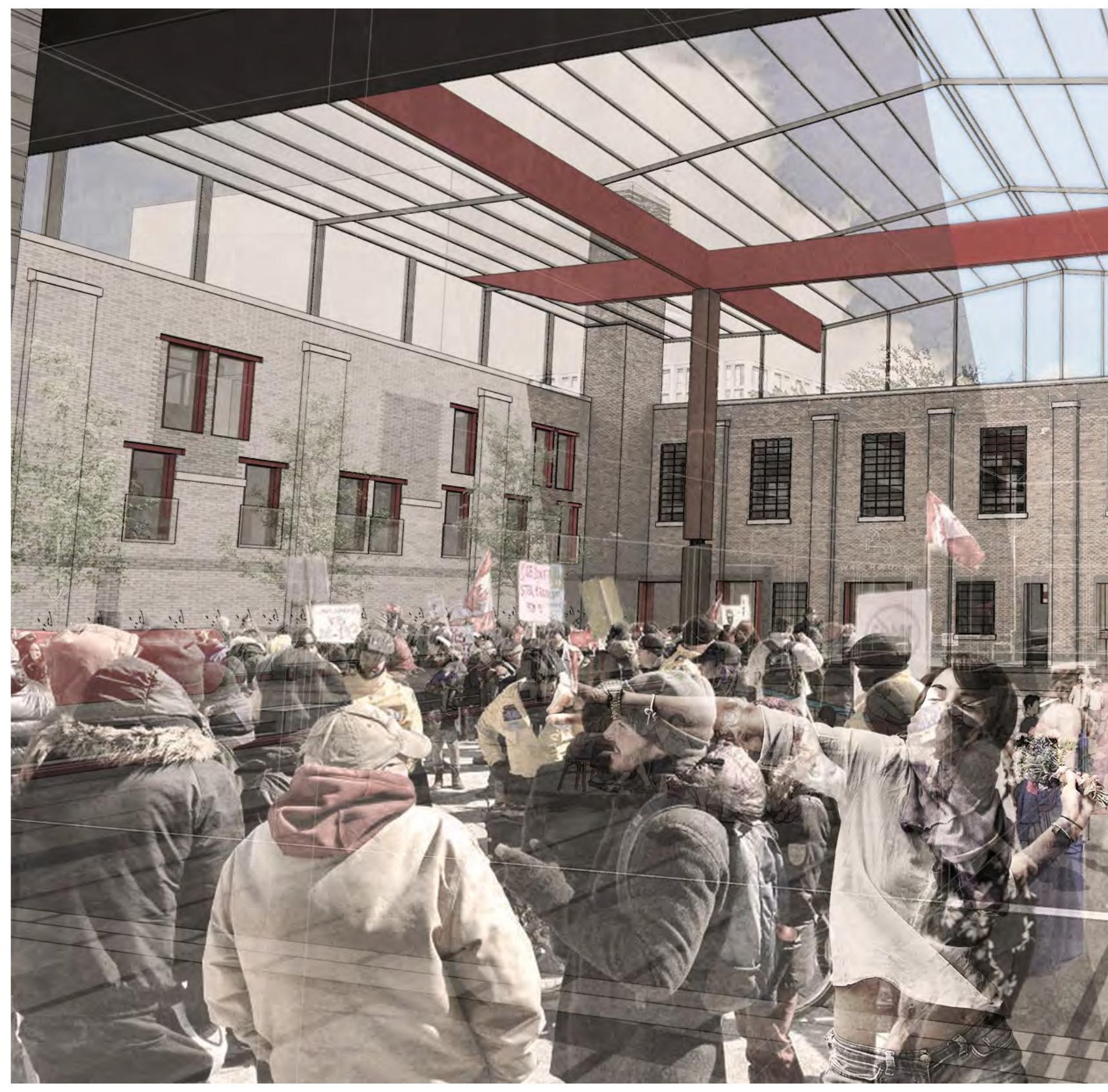

Fig.6.29 Proposed view at central square's Richmond entrance looking south

(opposite) Fig.6.30 Proposed view of new windows at Eva's Phoenix wall, east of the central square 

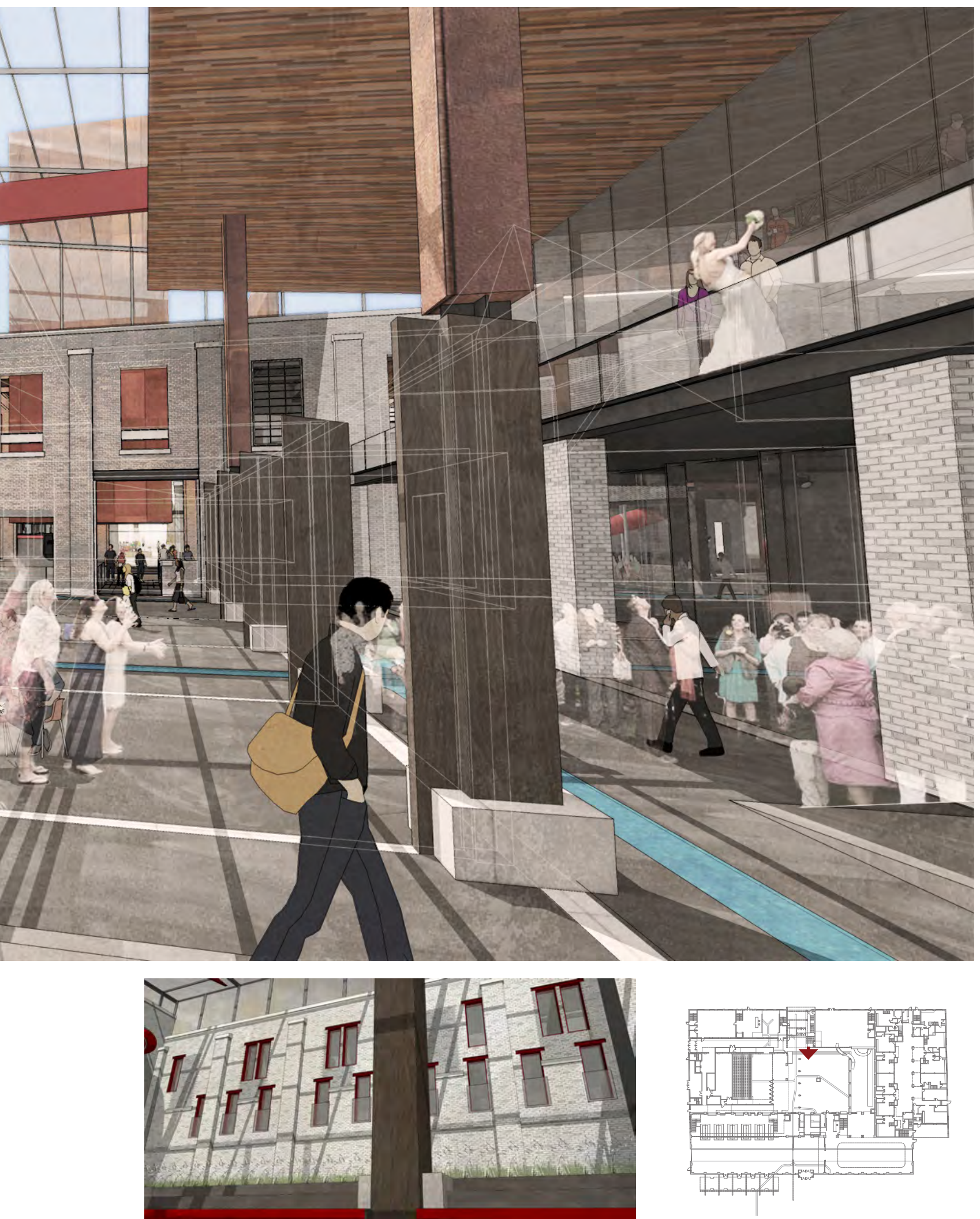


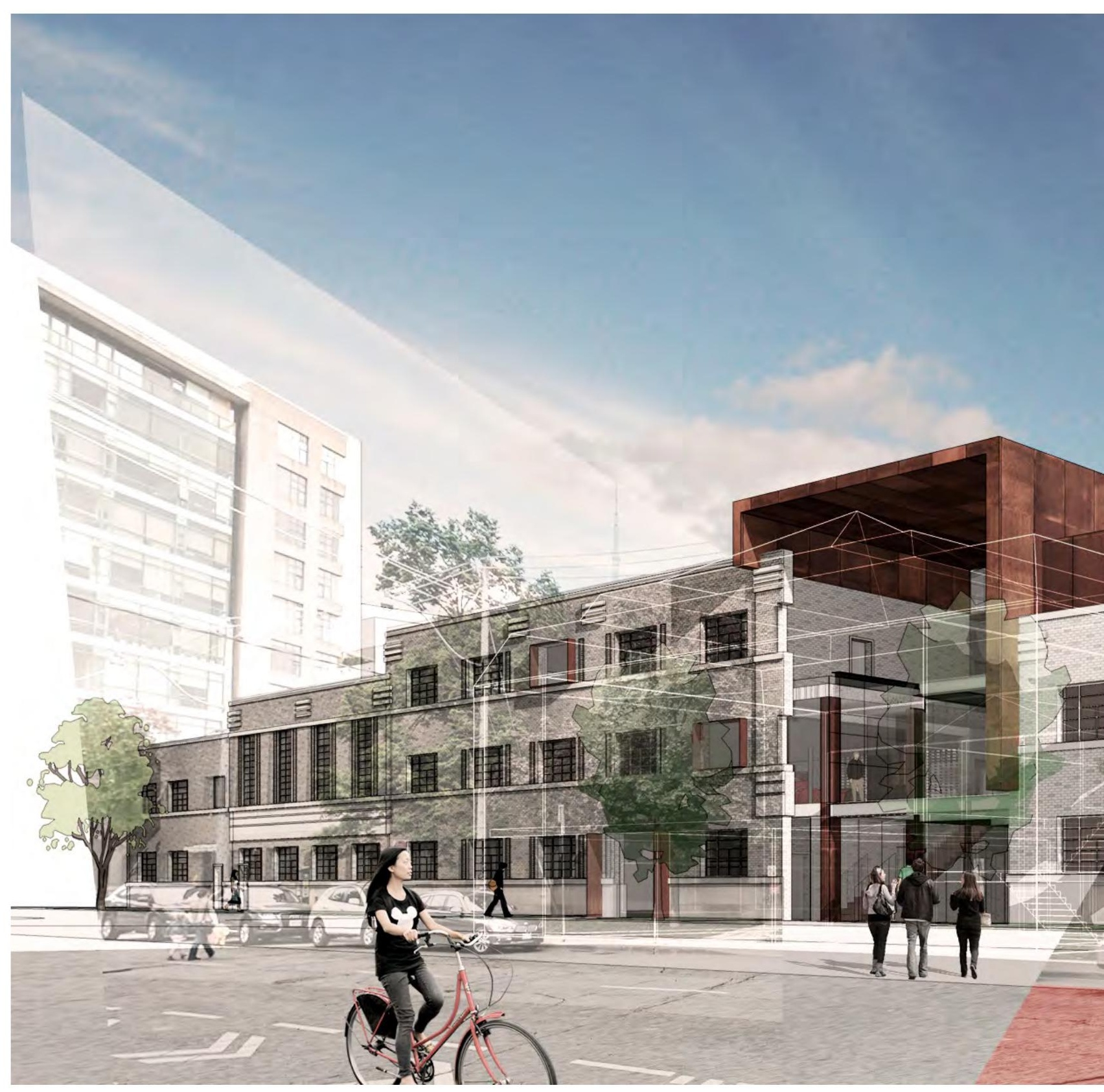

Fig. 6.31 Proposed view of Richmond Street entrance looking south-east (opposite) Fig.6.32 Proposed Richmond Street entrance revealed beams 

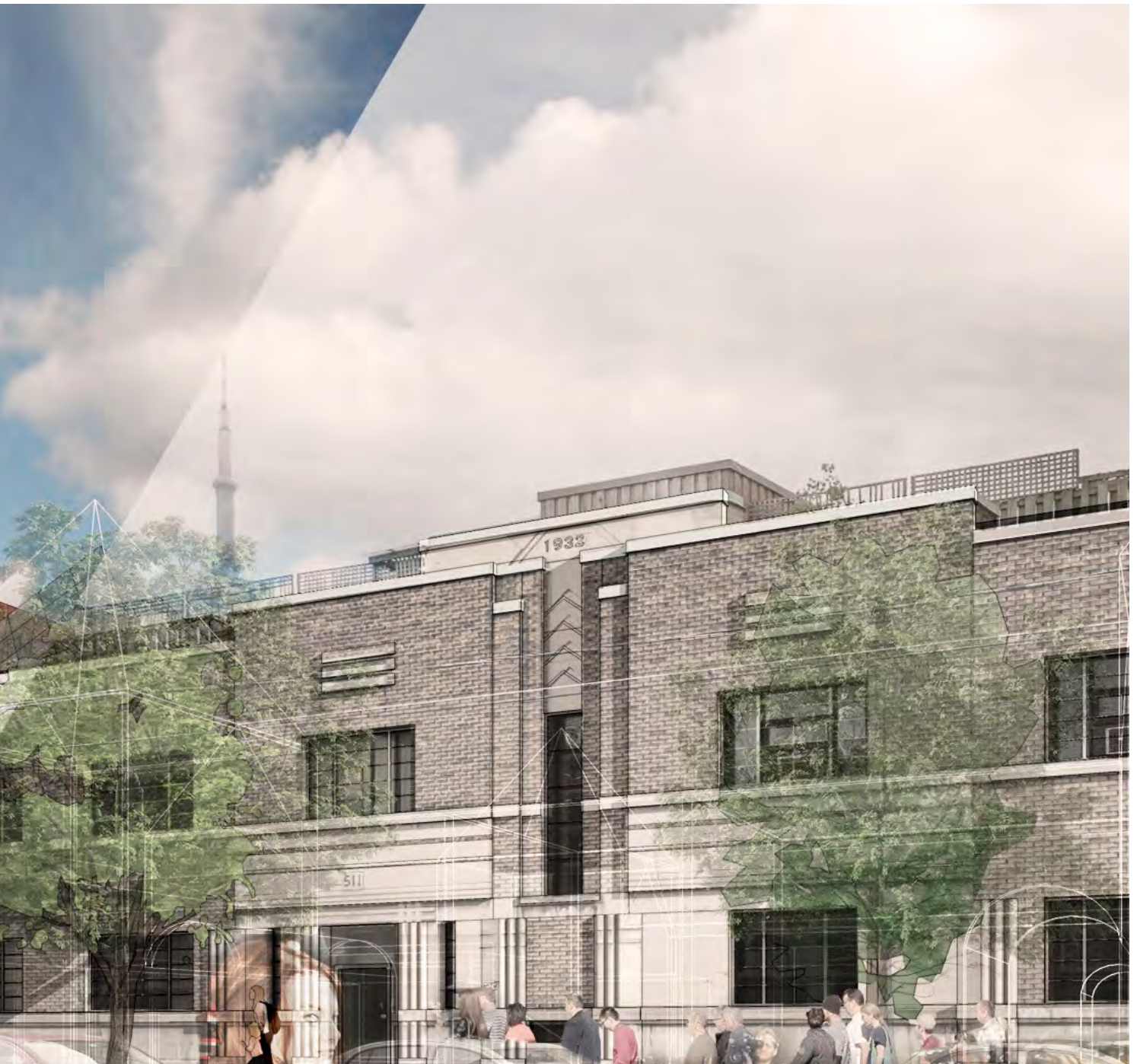

4. 1 (1)

195.
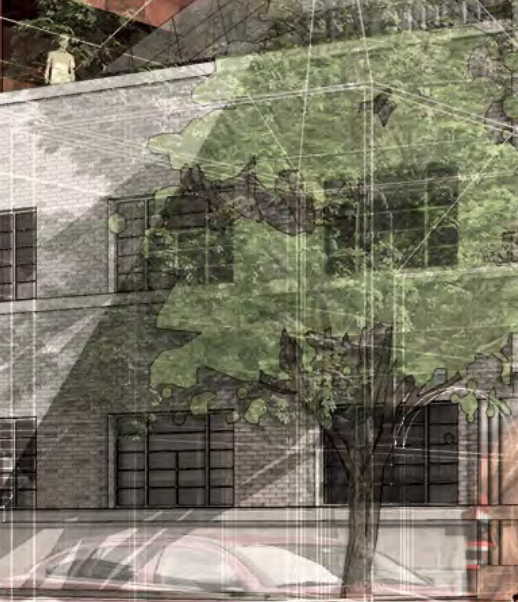

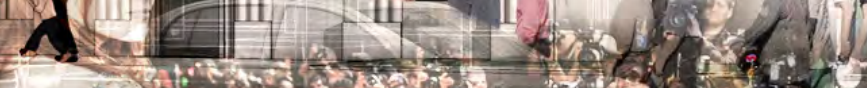

1. 20 id 200
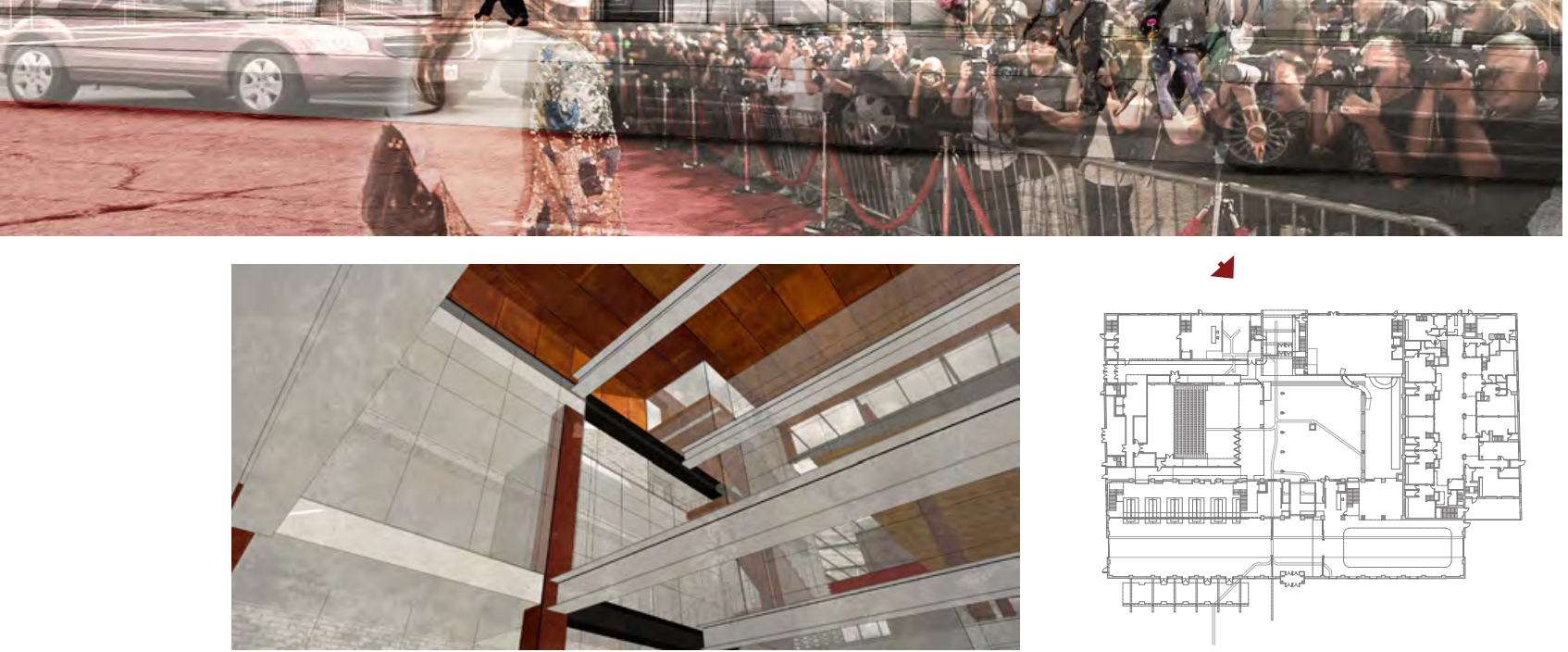


\section{Conclusions}

The themes investigated during earlier design explorations and precedent studies allowed for a proposal that incorporates concepts of a palimpsest. More significantly, they allowed for more informed decisions when modifying the building into the desired narrative.

When viewing the site as a palimpsest, as superpositions of its material and immaterial layers compressed into one space and time, the following conclusions were made. As mentioned, the overlap of function and significance throughout its evolution highlighted an overall civic and public identity, and helped establish the site's ultimate function as a multifunctional and inclusive public building. The overlap of form informed opportunities for the modification of building elements and the introduction of new spaces.

When operating on the site, the process of creative demolition performed a dual function, allowing for the selective removal of building elements while permitting unremoved traces to remain. Formally, this can be seen at the park entrances, where a careful incision in the building introduced a new thoroughfare; however, in doing so, it also imprinted the overlay of the first market. Through creative demolition, the resurfaced or unremoved traces have the potential to serve the new setting. This is evident through the depression of the central square where the resurfaced elements from past forms or infrastructure now serve as seating, as well as in the theatre where a re used skylight from the former garage becomes a balcony in its new setting.

The desired simultaneous perception of all layers in the proposal additionally employed theories of transparency. This is evidenced by the overlay of built form through the removal and addition of building elements, and was further developed in the modification of the south hall and in the theatre front wall via literal transparency. The perception of past layers is further explored via the overlay of symbolism and form. This is illustrated through the design of the new pattern storage wall and pit chimney, where the symbols of labour and fabric, as well as the tragic fire, were formally executed. 
Through these methods, the proposed contemporary layer presents an intentional interference of new programming to mix with all pre-existing material and immaterial layers. Functionally, the selection of resurfaced activities, provided new opportunities to be advanced and developed to suit current conditions. The mixing of new programming and events, creates seemingly awkward clashes, overlaps, intersections and collisions of form, function, and meaning where unexpected relationships and encounters may emerge. The new building will be productive in creating new conditions, events and reading of the space. These deliberate moves are meant to prompt questions and reflection and thus promote an awareness of the architectural palimpsest. 



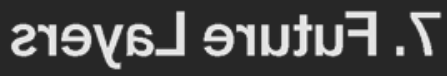

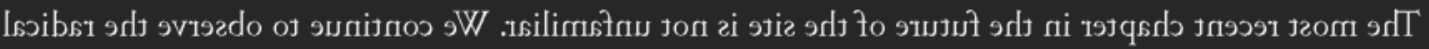
2xh10w19ts

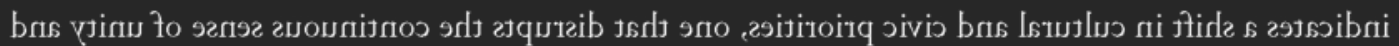

.grignolsd

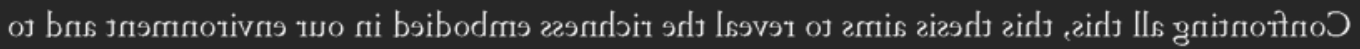

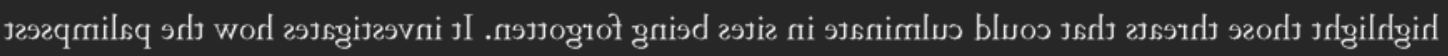

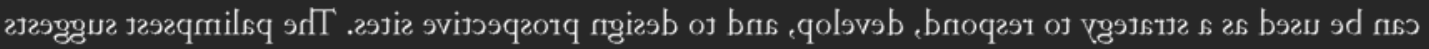

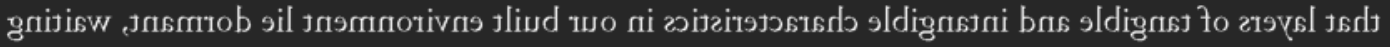

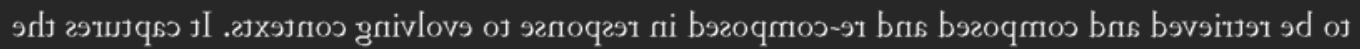

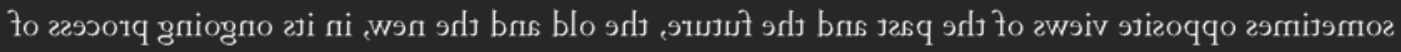

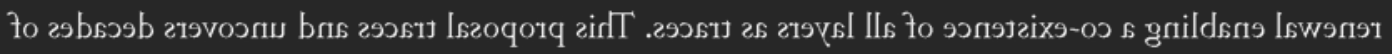

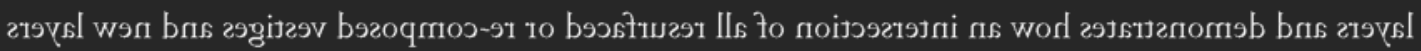

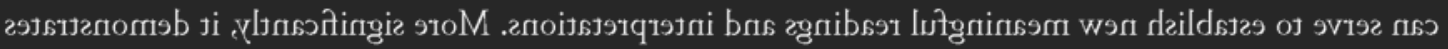

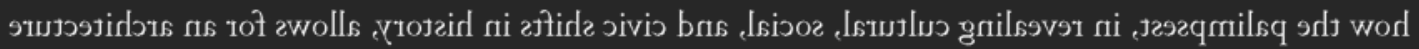

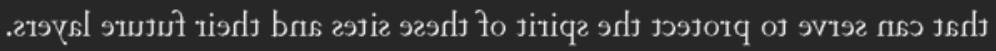




\section{Future Layers}

The most recent chapter in the future of the site is not unfamiliar. We continue to observe the radical transformation of public spaces in Toronto and many other cities. The loss of sites like Waterworks indicates a shift in cultural and civic priorities, one that disrupts the continuous sense of unity and belonging.

Confronting all this, this thesis aims to reveal the richness embodied in our environment and to highlight those threats that could culminate in sites being forgotten. It investigates how the palimpsest can be used as a strategy to respond, develop, and to design prospective sites. The palimpsest suggests that layers of tangible and intangible characteristics in our built environment lie dormant, waiting to be retrieved and composed and re-composed in response to evolving contexts. It captures the sometimes opposite views of the past and the future, the old and the new, in its ongoing process of renewal enabling a co-existence of all layers as traces. This proposal traces and uncovers decades of layers and demonstrates how an intersection of all resurfaced or re-composed vestiges and new layers can serve to establish new meaningful readings and interpretations. More significantly, it demonstrates how the palimpsest, in revealing cultural, social, and civic shifts in history, allows for an architecture that can serve to protect the spirit of these sites and their future layers. 

Appendices 


\section{Appendix A}

Site 1.0 Book Explorations

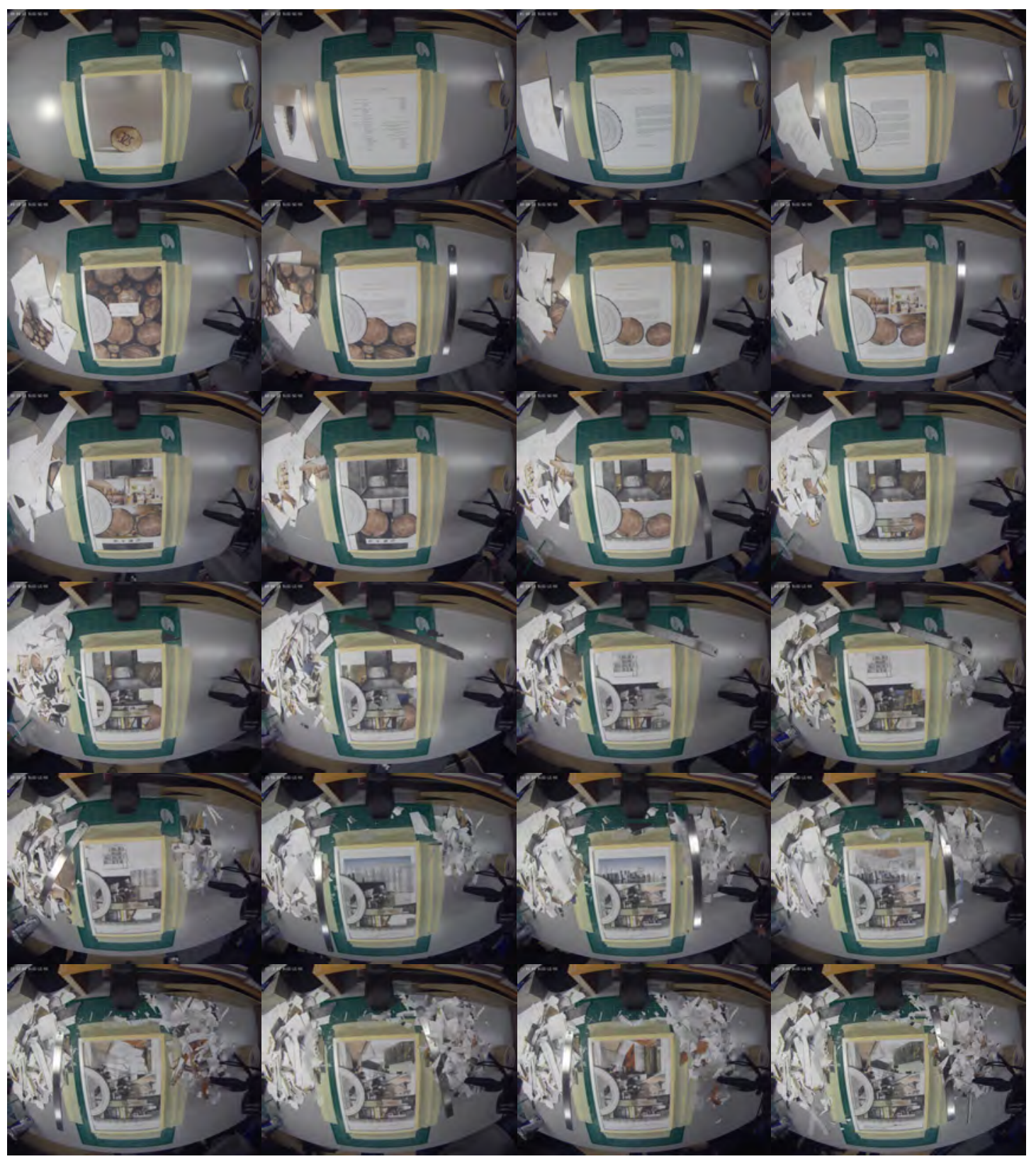

Fig.8.1 Book 1.0 process images

(opposite) Fig.8.2 Book 1.0 


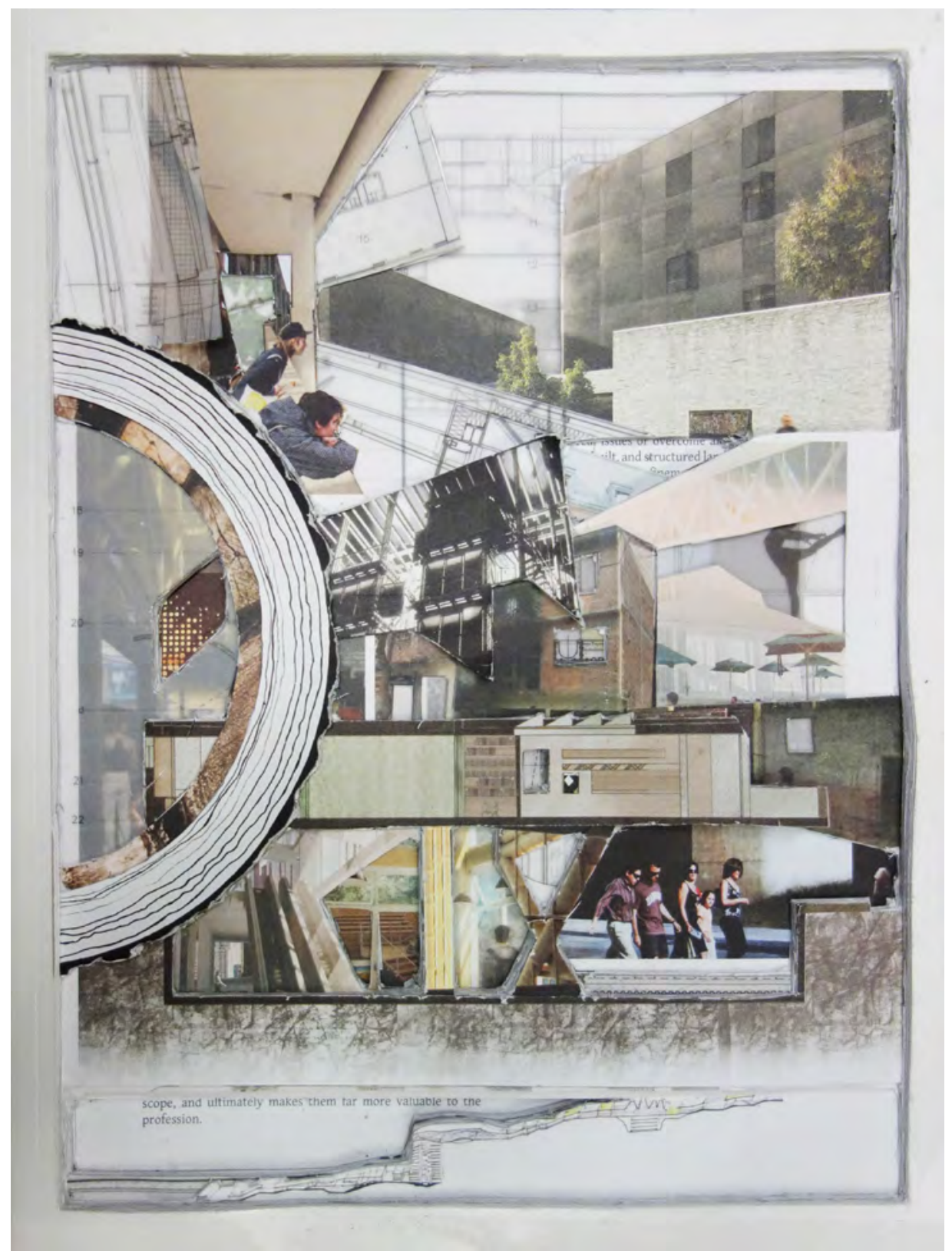




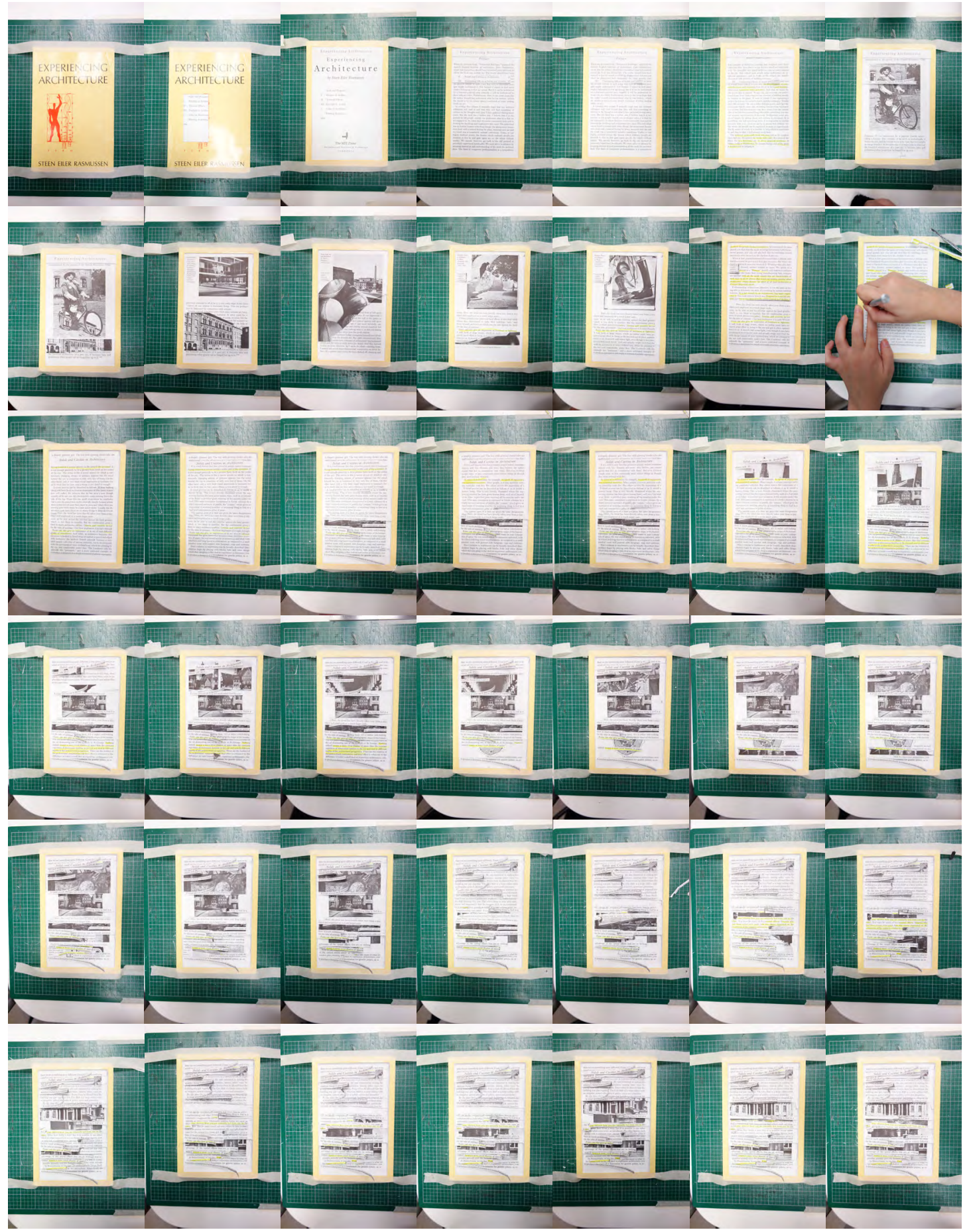

Fig.8.3 Book 2.0 process images

(opposite) Fig.8.4 Book 2.0 


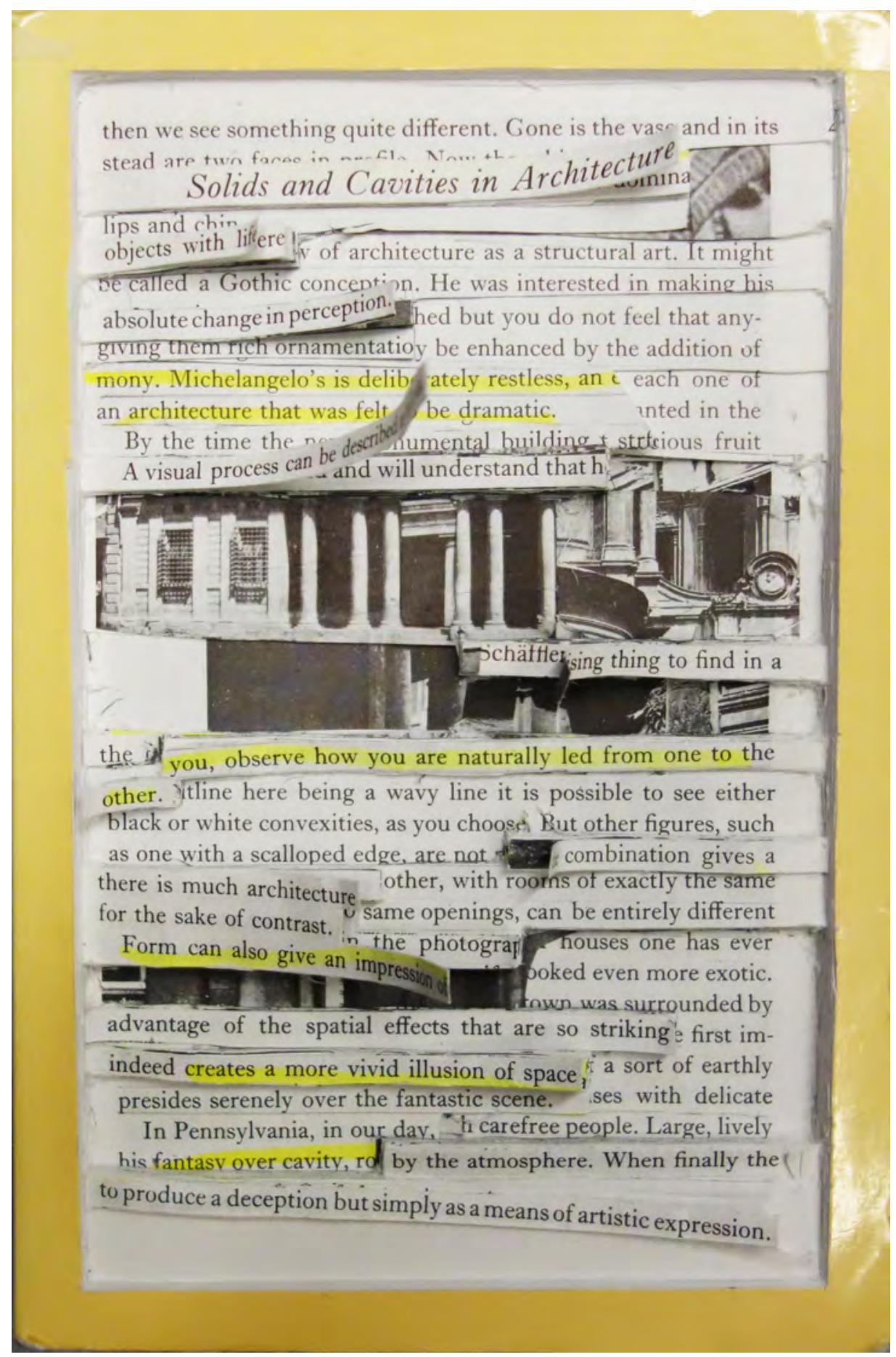




\title{
Appendix B
}

St. Andrew's Market \& Annex Drawing Set (1908) \& Archival Photographs

\author{
(drawing set) \\ Fig.8.5 St. Andrew's Market West Elevation, 1908 \\ Fig.8.6 St. Andrew's Market North Elevation, 1908 \\ Fig.8.7 St. Andrew's Market Ground Floor Plan, 1908 \\ Fig.8.8 St. Andrew's Market Second Floor Plan, 1908 \\ Fig.8.9 St Andrew's Market Annex Building West Elevation, 1908 \\ Fig.8.10 St Andrew's Market Annex Building Ground Floor Plan, 1908
}



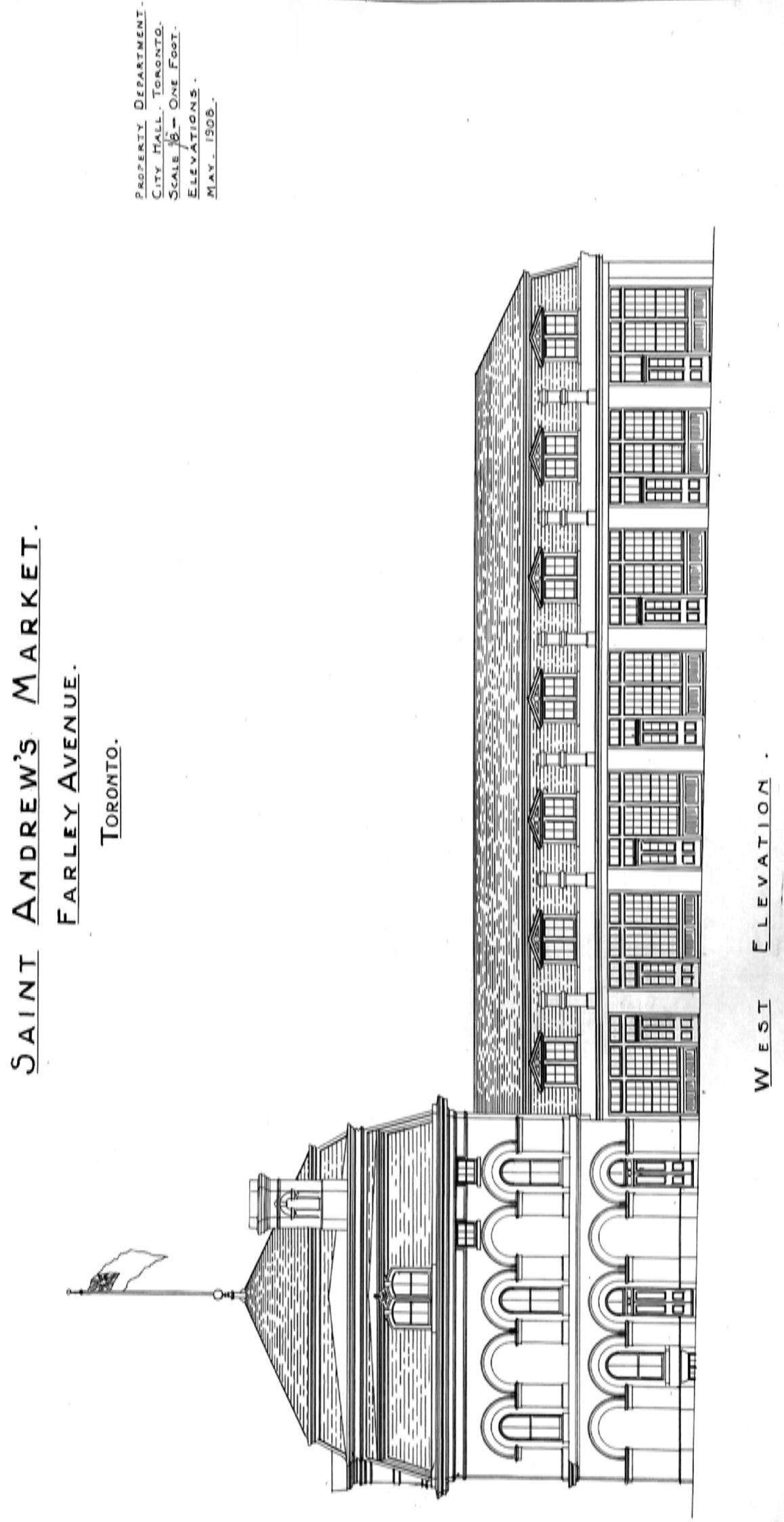
SAINT ANDREW'S MARKET.

FARLEy AVENUE.

Property Department.

TORONTO.

CITY HALL-TORONTO.

SCALE $1 / 8$ - One Foot.

PLANS OE FLOORS.

MAY -1908 .

$$
8 \text {. }
$$
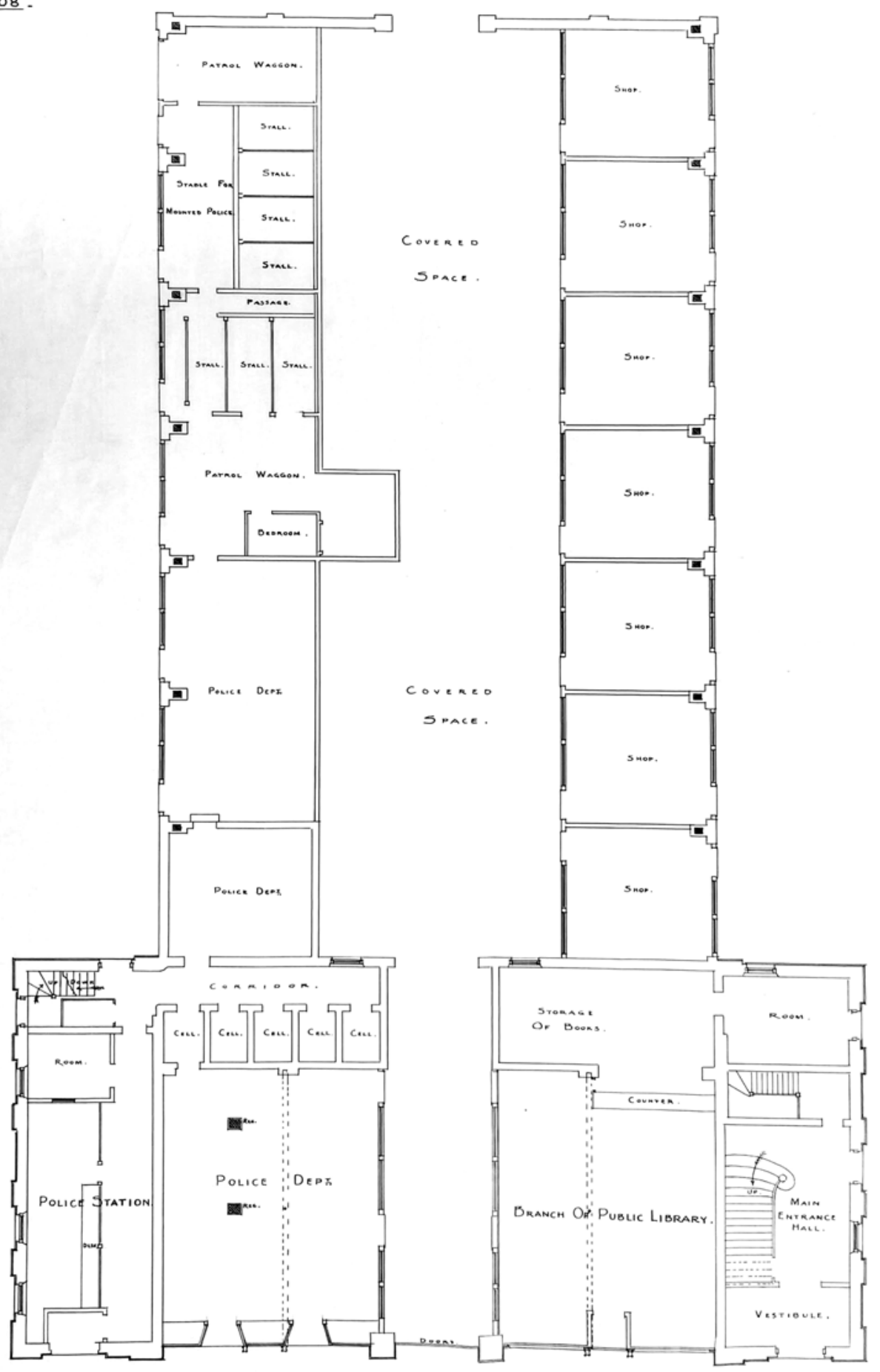

GROUND FLOOR PLAN. 


\section{SAINT ANdREW'S MARkEt.}

farley avenue.

TORONTO.

Property Department.

Citr HaLl - TORONTO

Scale 1/8"- One Foot.

PLANS OF Floors \& Roor.

MAY - 1908.

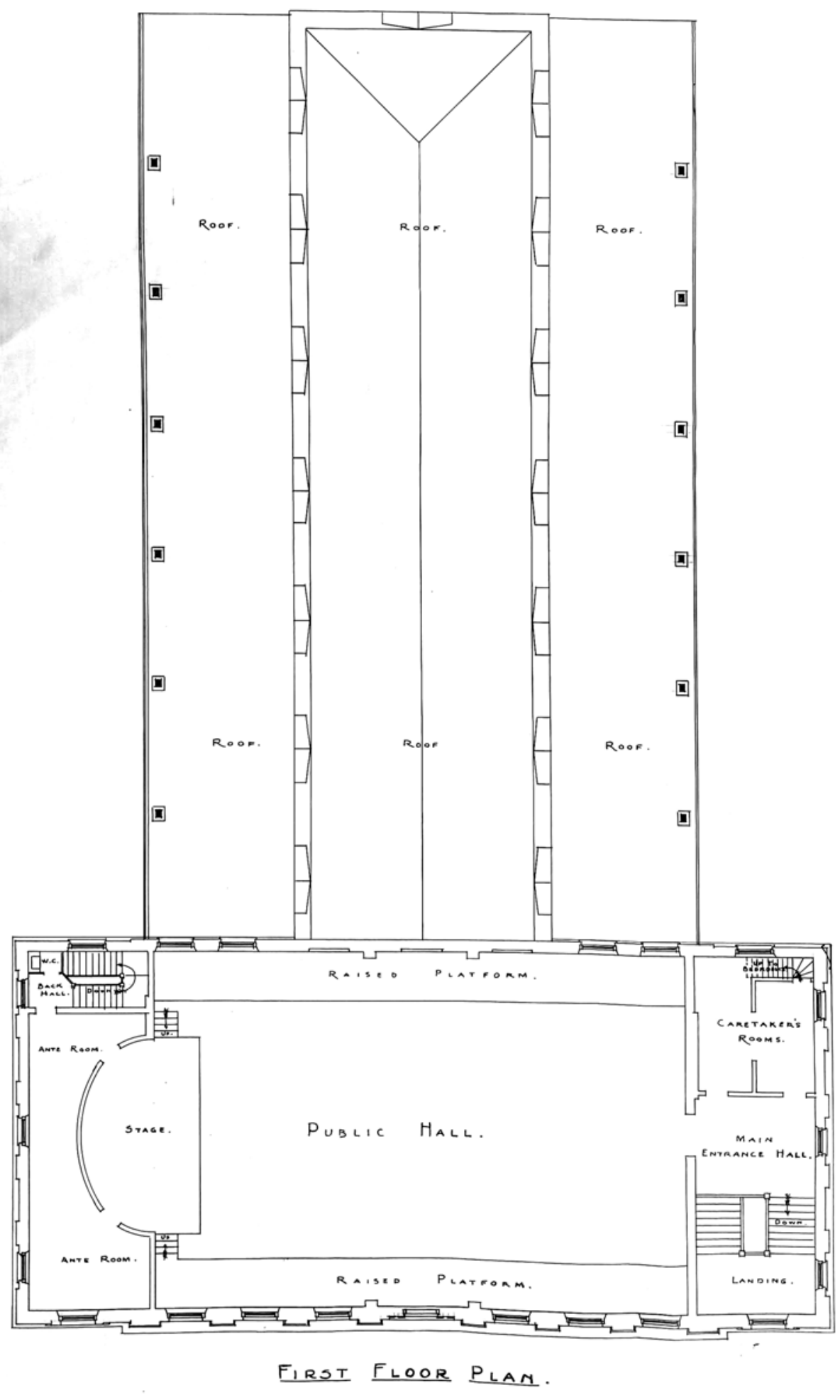




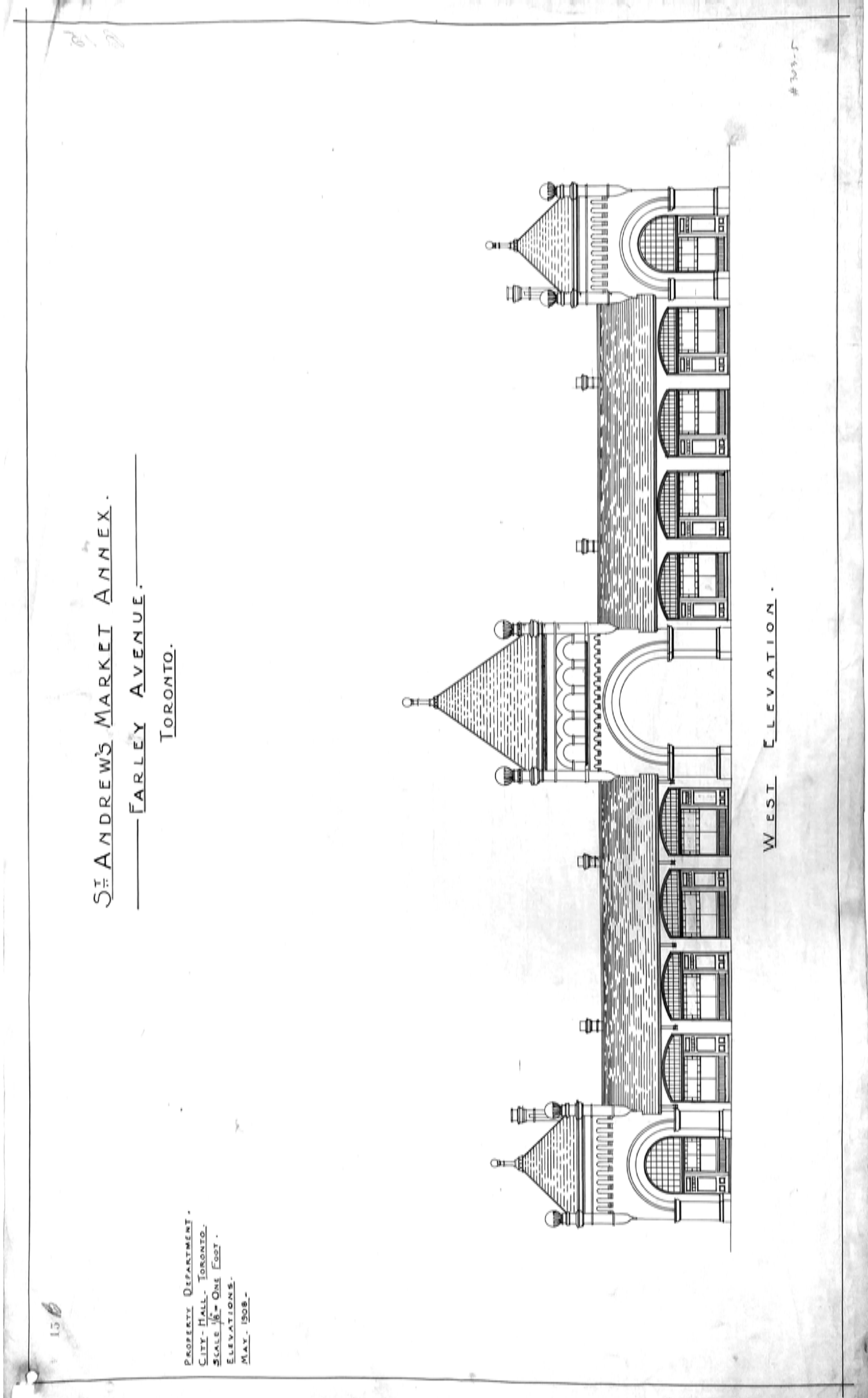


ST ANDREW'S MARKET ANNEX.

FARLEY AVENUE.

PROPERTY DEPARTMENT

TORONTO.

CITY- HALL. TORONTO.

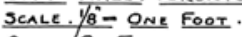

PLANS OF FLOOR.

MAY - 1908 .
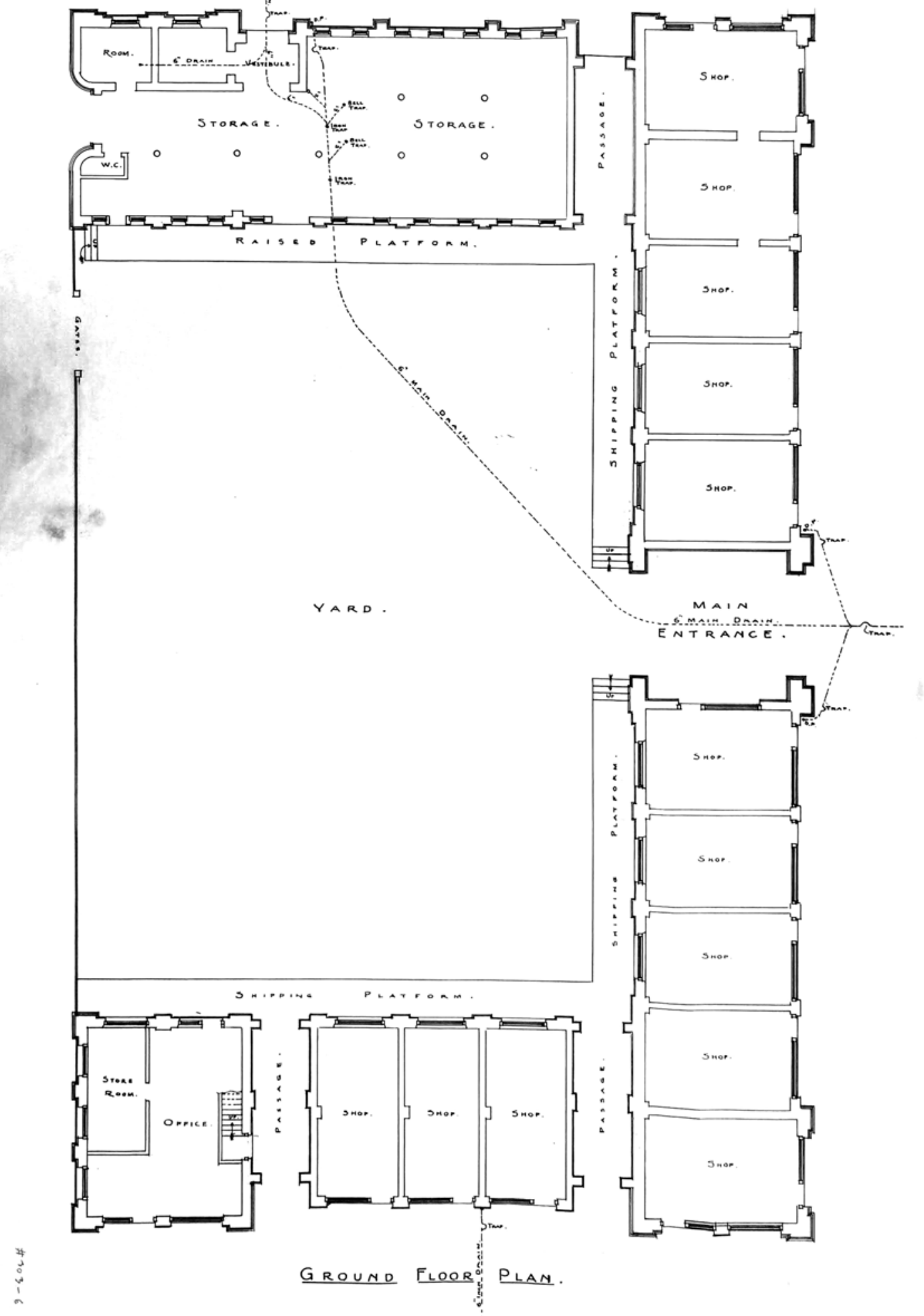

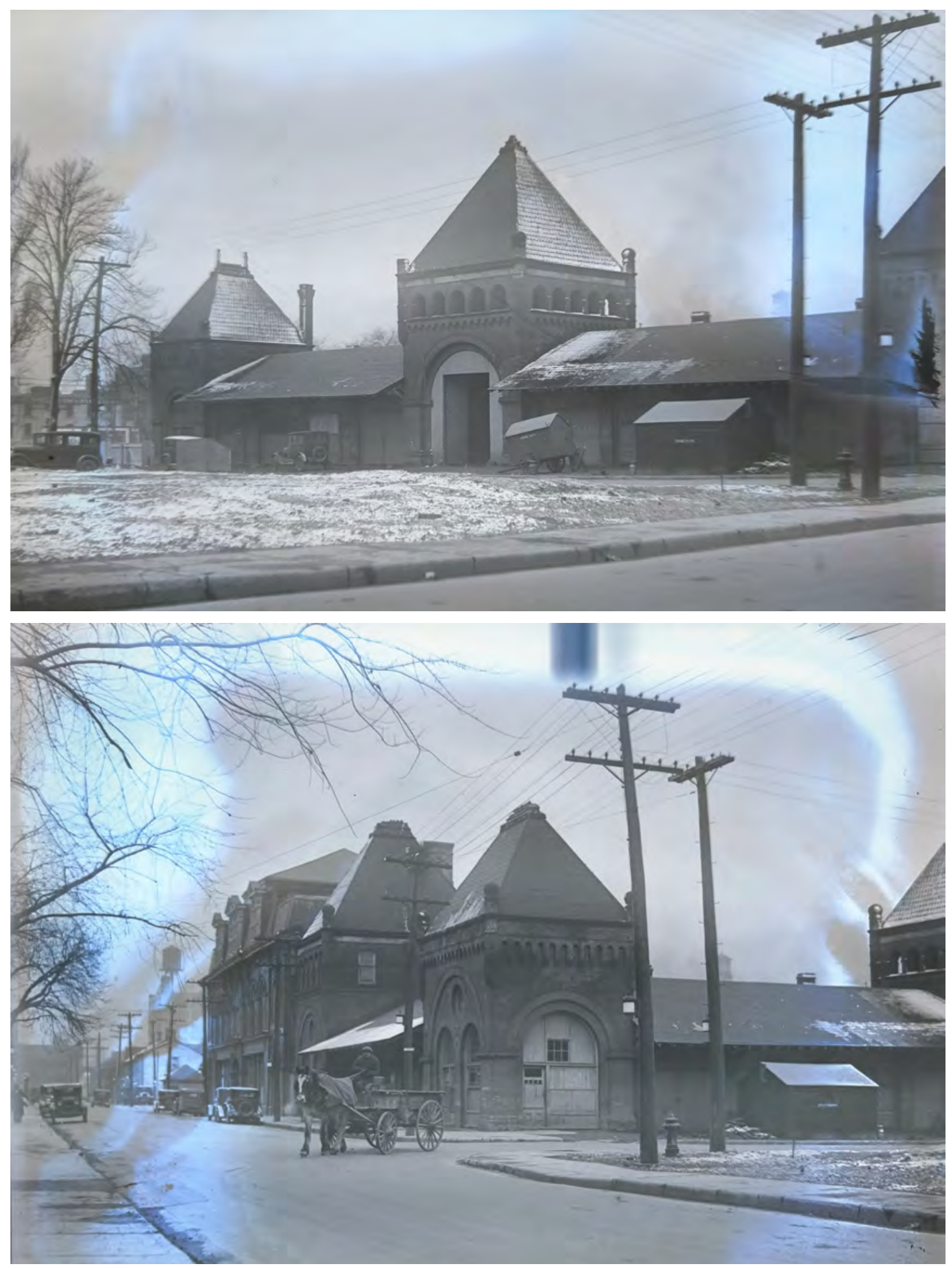

(top) Fig.8.11 St. Andrews Market Annex Building, 1931

(bottom) Fig.8.12 St. Andrews Market Annex Building, 1931 


\section{Appendix C.}

St Andrew's Playground Map (1908) \& Archival Photographs

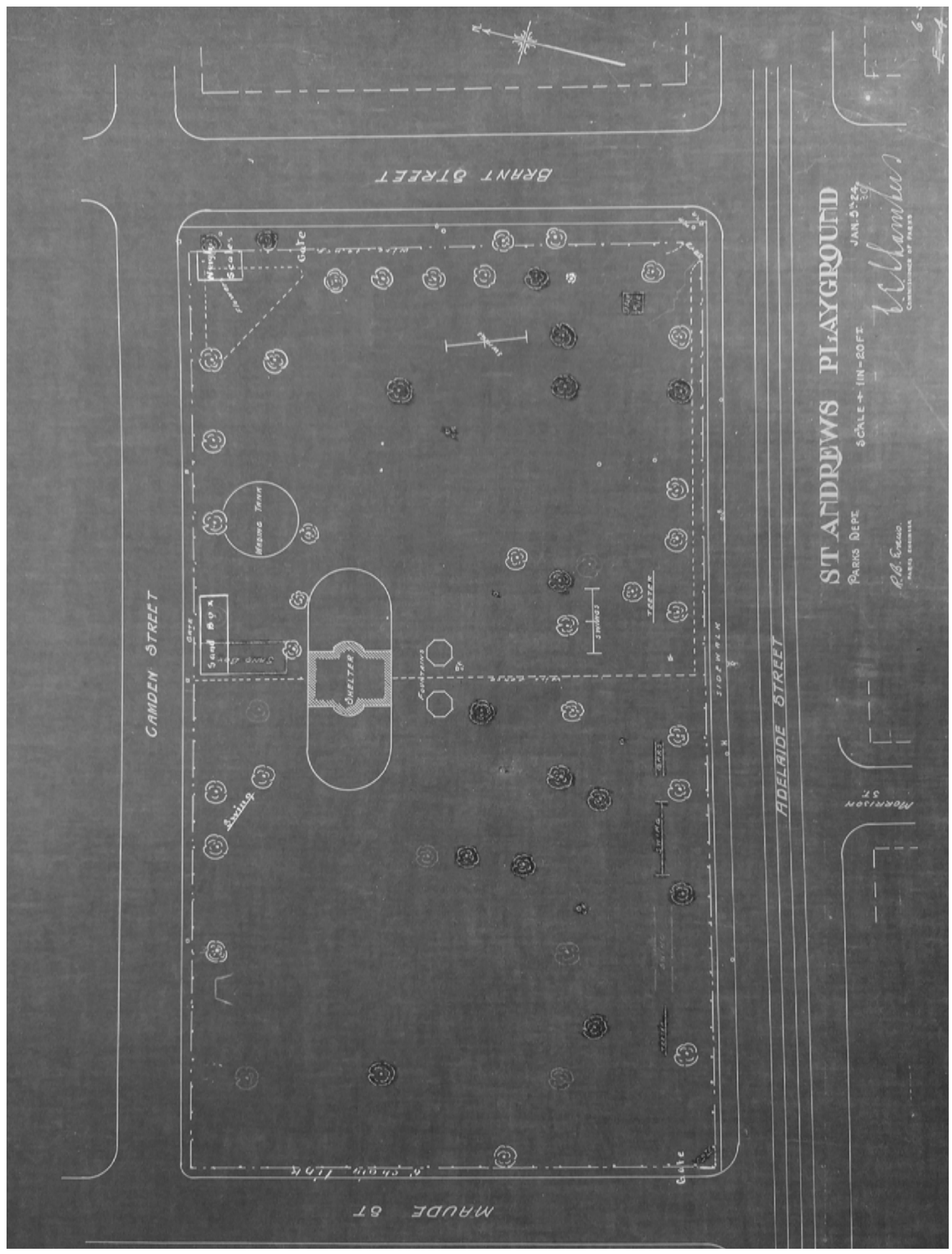



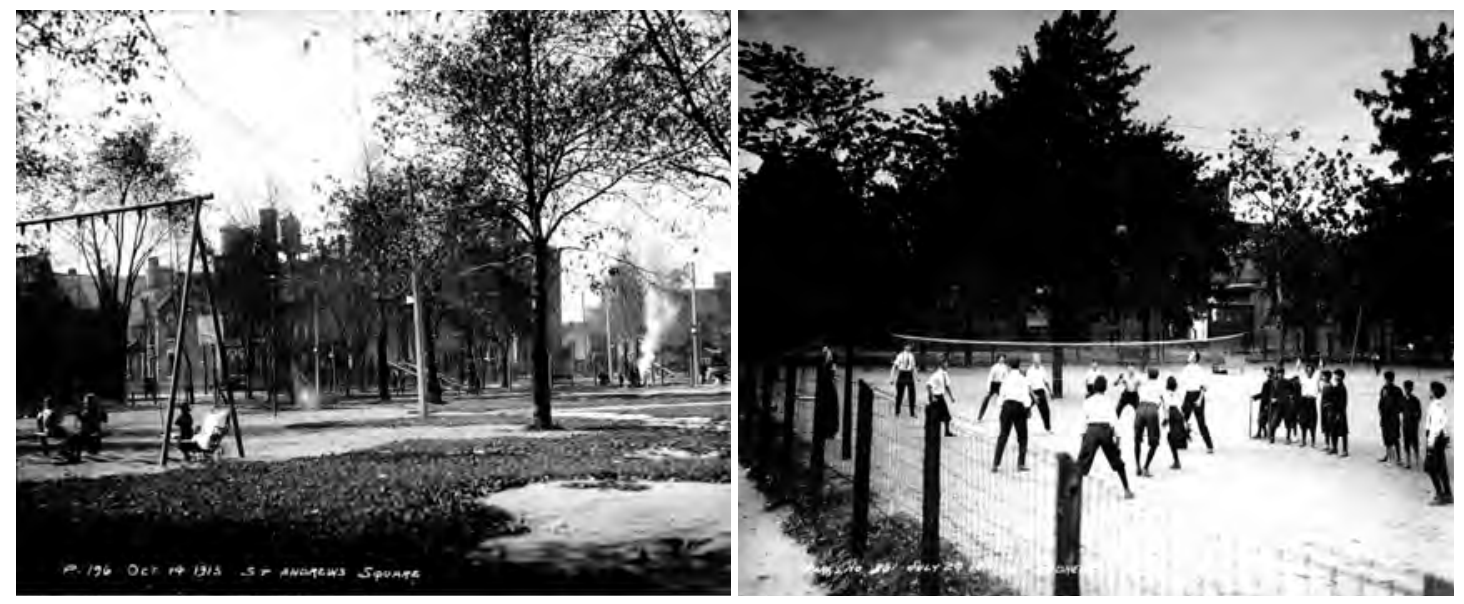

(left) $\quad$ Fig.8.14 St. Andrew's Playground swing set, 1913

(right) Fig.8.15 St. Andrew's Playground volleyball, 1914
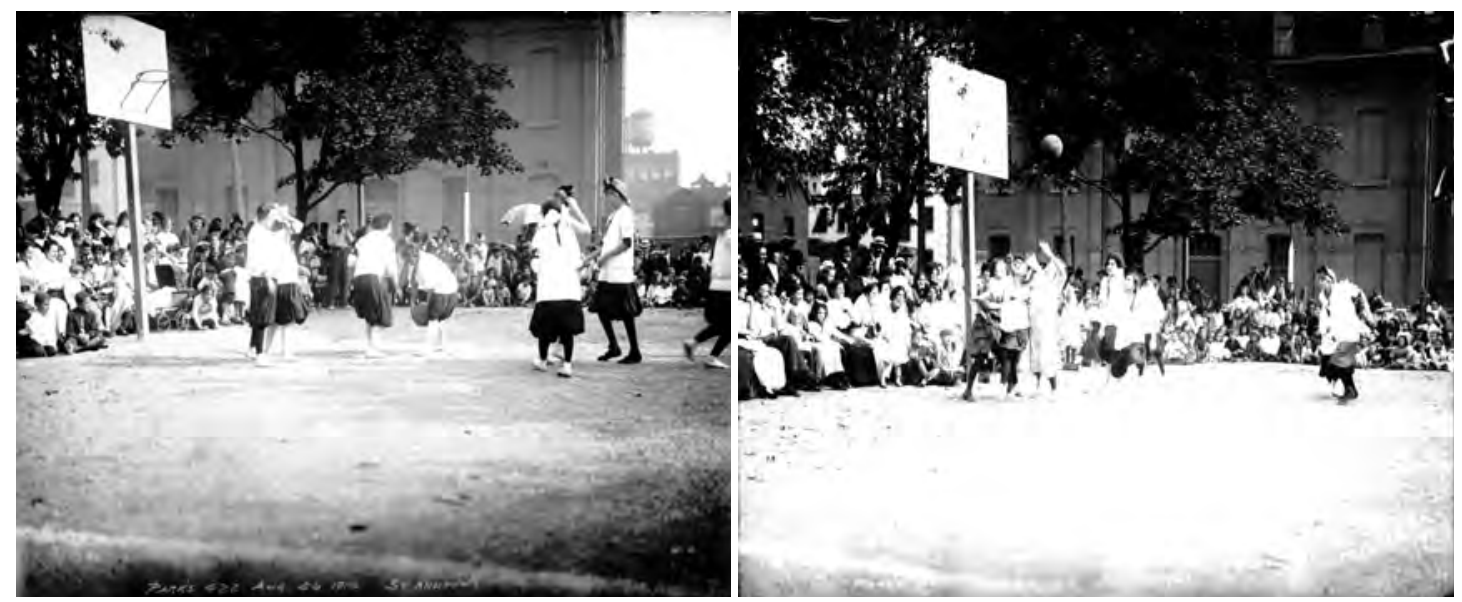

(left) Fig.8.16 St. Andrew's Playground basketball, 1914

(right) Fig.8.17 St. Andrew's Playground basketball, 1914

(opposite)

Fig. $\quad$ 8.13 St. Andrew's playground map, 1924 

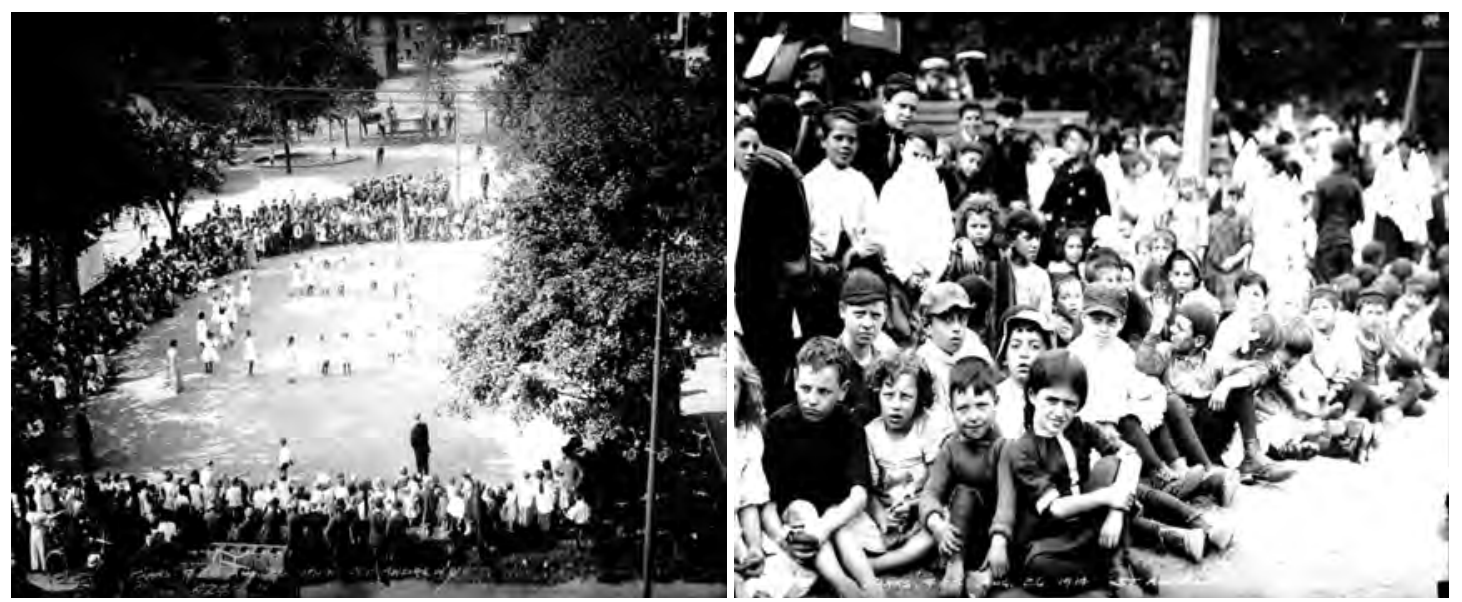

(left) Fig.8.18 St. Andrew's Playground dancing, 1914

(right) Fig.8.19 St. Andrew's Playground children, 1914
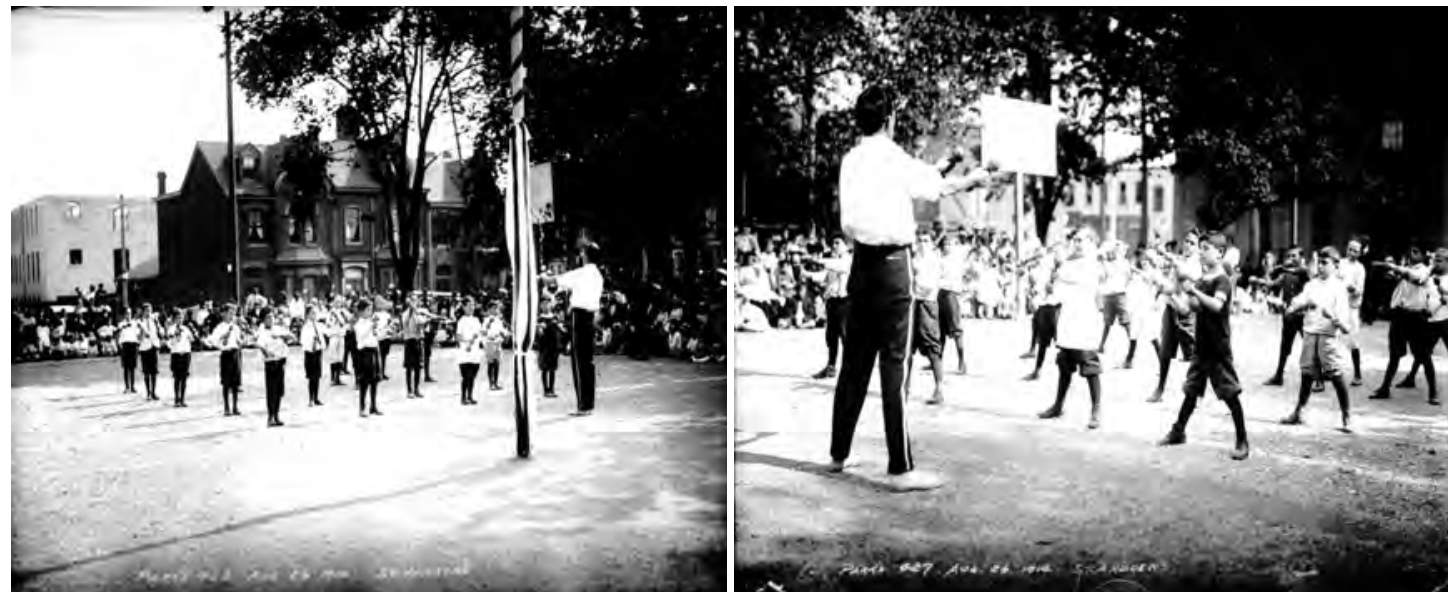

(left) Fig.8.20 St. Andrew's Playground exercises, 1914

(right) Fig.8.21 St. Andrew's Playground exercises, 1914 

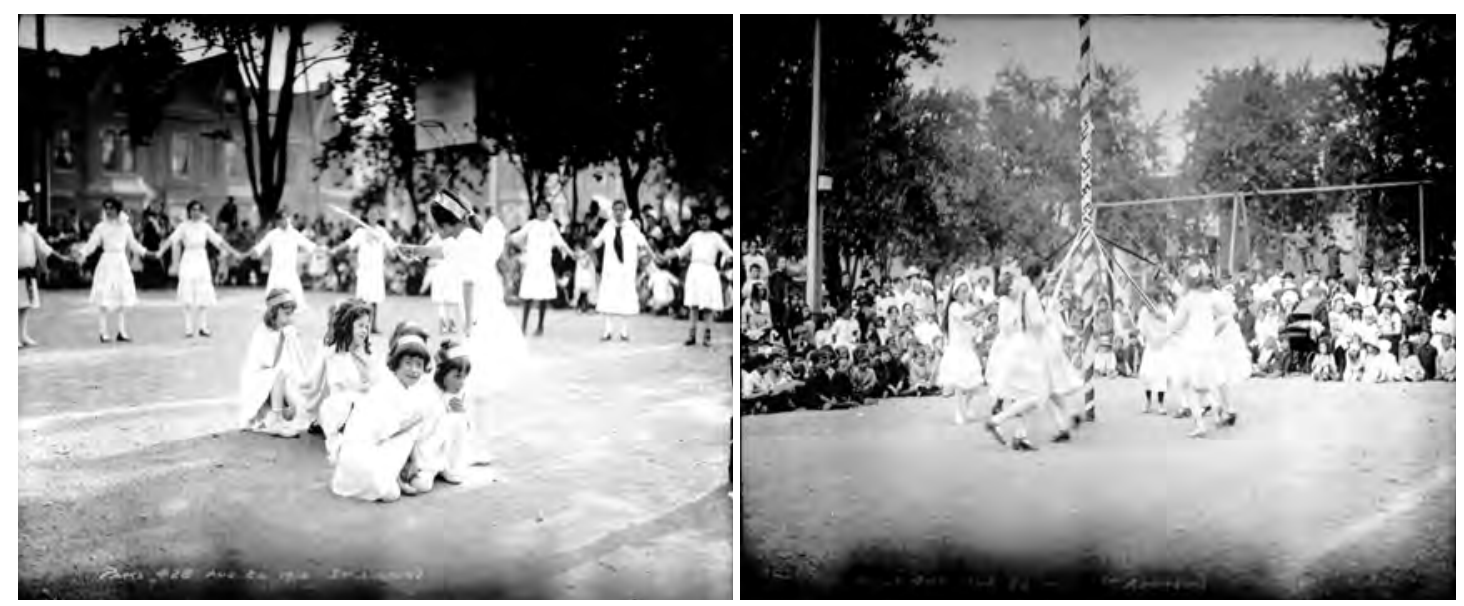

(left) Fig.8.22 St. Andrew's Playground games, 1914

(right) Fig.8.23 St. Andrew's Playground Maypole dancing, 1914
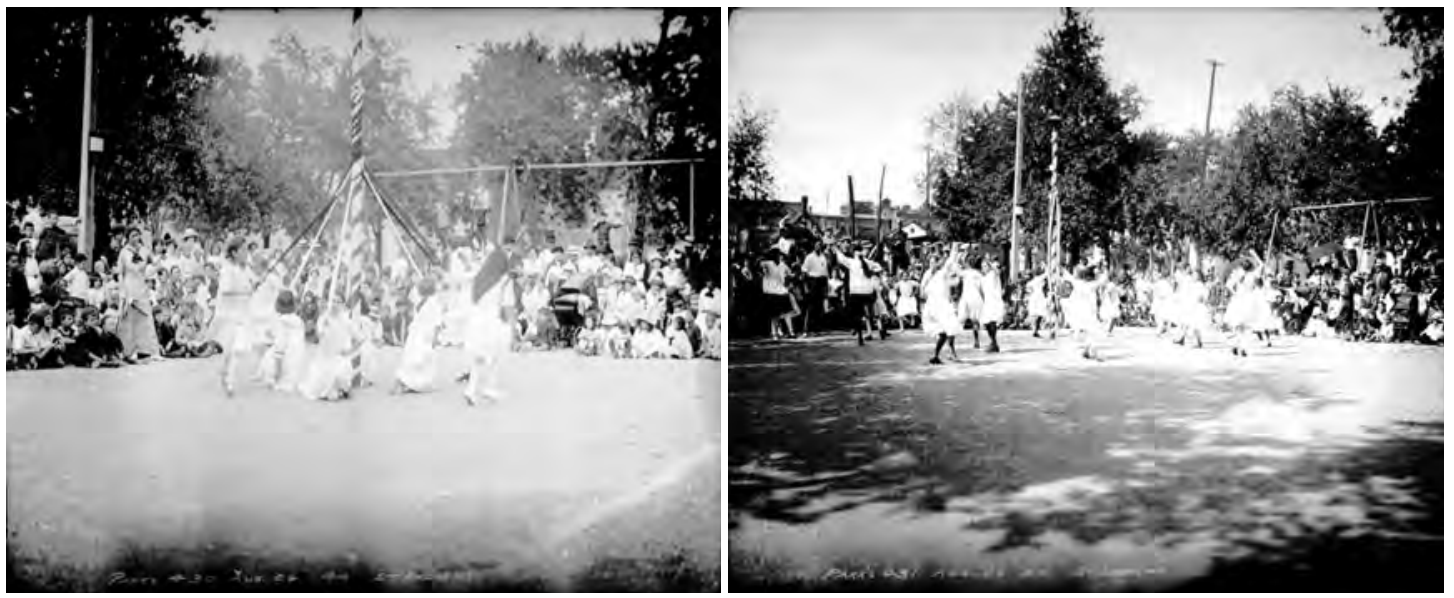

(left) Fig.8.24 St. Andrew's Playground Maypole dancing, 1914

(right) Fig.8.25 St.Andrew's Playground Maypole dancing, 1914 

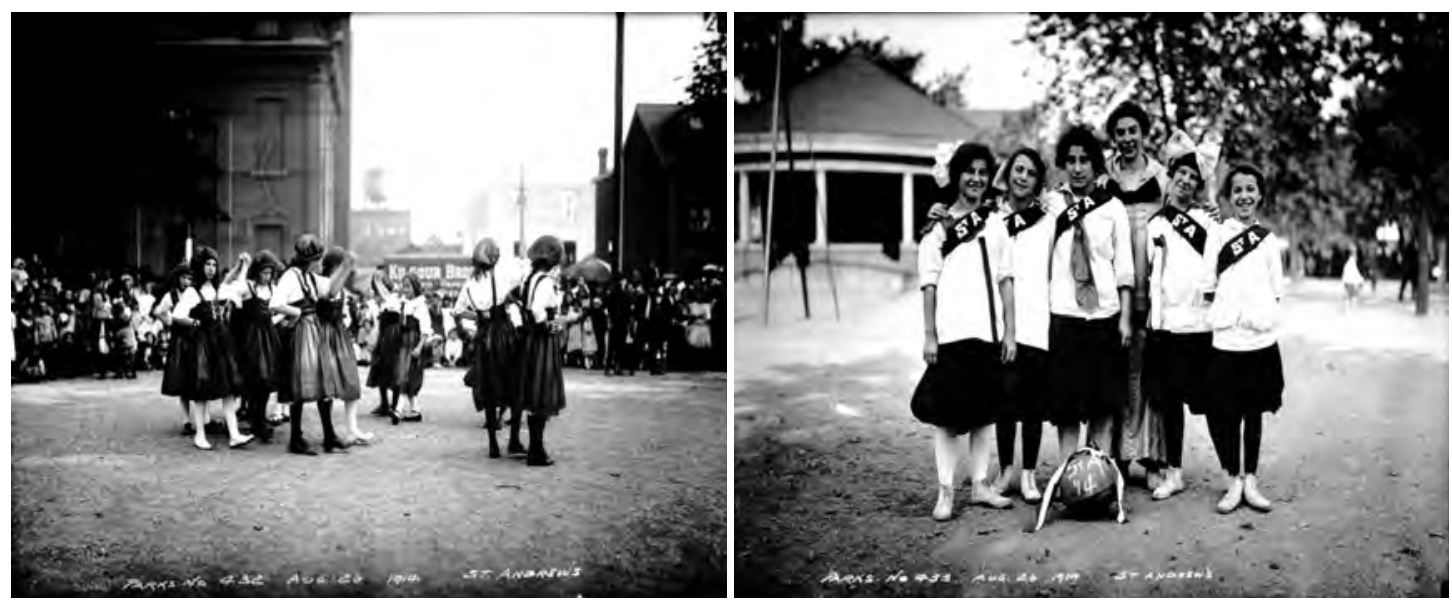

(left) Fig.8.26 St. Andrew's Playground folk dancing, 1914

(right) Fig.8.27 St. Andrew's Playground team, 1914

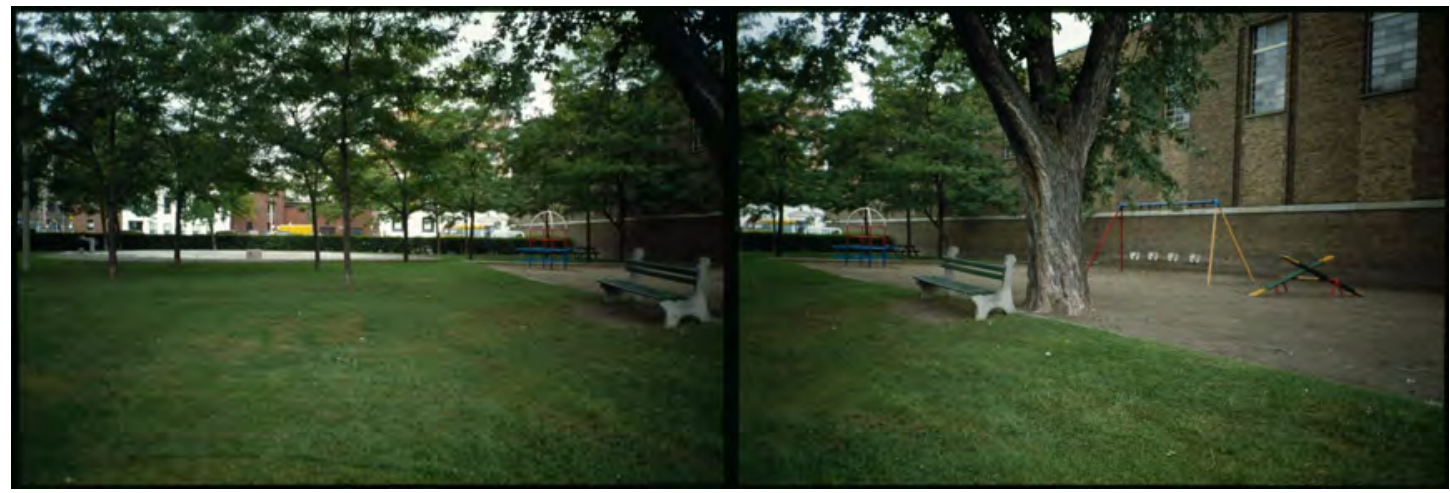

(left) Fig.8.28 Playground in St. Andrew's Park looking west, 1991

(right) Fig.8.29 Playground in St. Andrew's Park, 1991

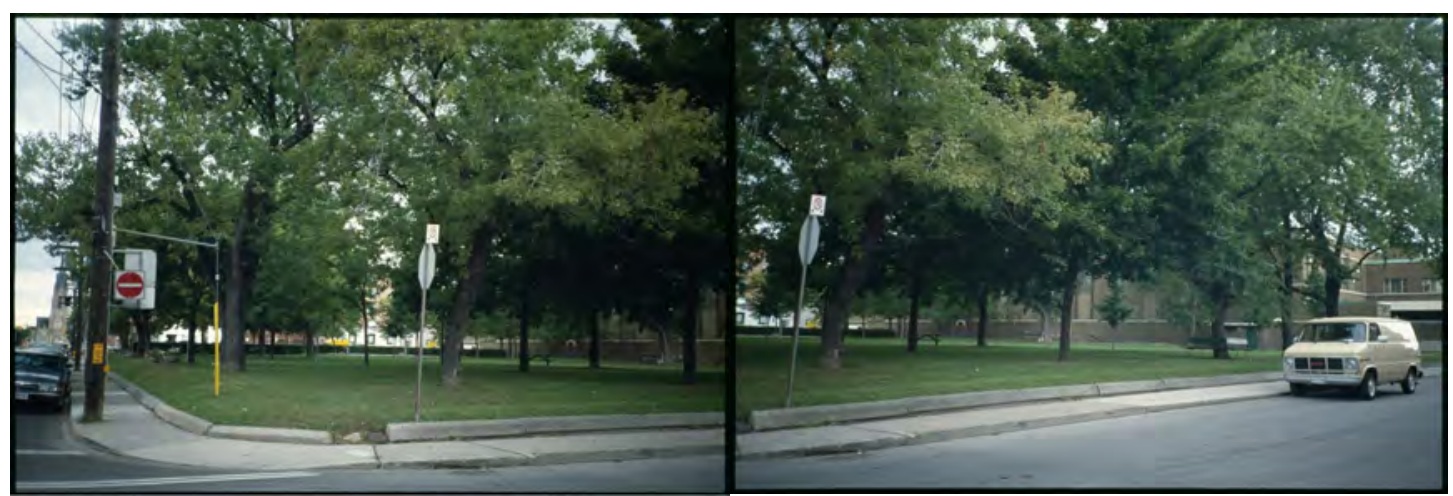

(left) Fig.8.30 St. Andrew's Park looking north-west, 1991

(right) Fig.8.31 St. Andrew's Park looking north-west, 1991 


\section{Appendix D}

\section{Waterworks Drawing Set (1932) \& Archival Photographs}

(drawing set)

Fig.8.32 Waterworks Building - sheet \# 1 Basement and Foundation Plan, 1932, J.J.. Woolnough

Fig.8.33 Waterworks Building - sheet \# 2 First Floor Plan, 1932, J.J. Woolnough

Fig.8.34 Waterworks Building - sheet \# 3 Second Floor Plan, 1932, J.J. Woolnough

Fig.8.35 Waterworks Building - sheet \# 4 Third and Roof Plan, 1932, J.J. Woolnough

Fig.8.36 Waterworks Building - sheet \# 5 Richmond Street Elevations, Brant Street Elevation, Sections DD to JJ, 1932, J.J. Woolnough

Fig.8.37 Waterworks Building - sheet \# 6 North Elevation of Garage, South Elevation of Courtyard, Sections KK to MM, Section O0, 1932, J.J. Woolnough

Fig.8.38 Waterworks Building - sheet \# 7 South Elevation, Maud Street Elevation, Gates Details, 1932, J.J. Woolnough

Fig.8.39 Waterworks Building - sheet \# 8 Office Building Basement, First, Second, and Third Floor Plans, 1932, J.J. Woolnough

Fig.8.40 Waterworks Building - sheet \# 9 Office Building North, South and West Elevations, Sections AA to CC, Stair Detail, Vestibule Detail, 1932, J.J. Woolnough

Fig.8.41 Waterworks Building - sheet \# 10 Office Building Detail at Front Entrance, 1932, J.J. Woolnough

Fig.8.42 Waterworks Building - sheet \# 11 Detail at Pattern Storage Entrance/ Driveway Entrance, Details of steel rolling doors/ partitions and shower/ toilet partitions, 1932, J.J. Woolnough

Fig.8.43 Waterworks Building - sheet \# 12 Water Services and Drainage Plan, 1932, J.J. Woolnough

Fig.8.44 Waterworks Building - sheet \# 70 Basement and Foundation Heating Plan, 1932, J.J. Woolnough

Fig.8.45 Waterworks Building - sheet \# 71 First Floor Heating Plan, 1932, J.J. Woolnough

Fig.8.46 Waterworks Building - sheet \# 72 Second Floor Heating Plan, 1932, J.J. Woolnough

Fig.8.47 Waterworks Building - sheet \# 73 Third Floor and Roof Heating Plan, 1932, J.J. Woolnough

Fig.8.48 Waterworks Building - sheet \# 78 Third Floor and Roof Electrical Plan, 1932, J.J. Woolnough 


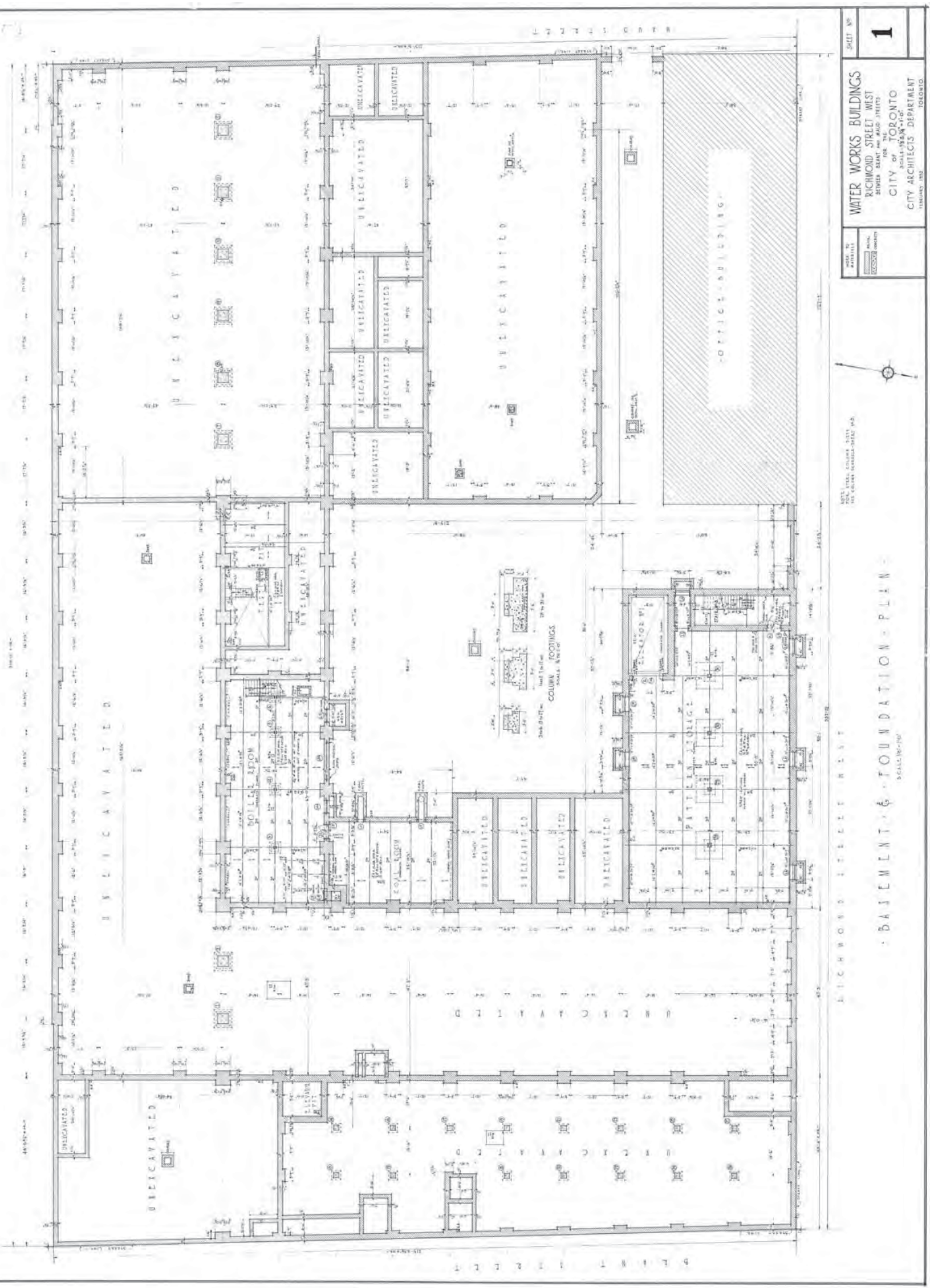




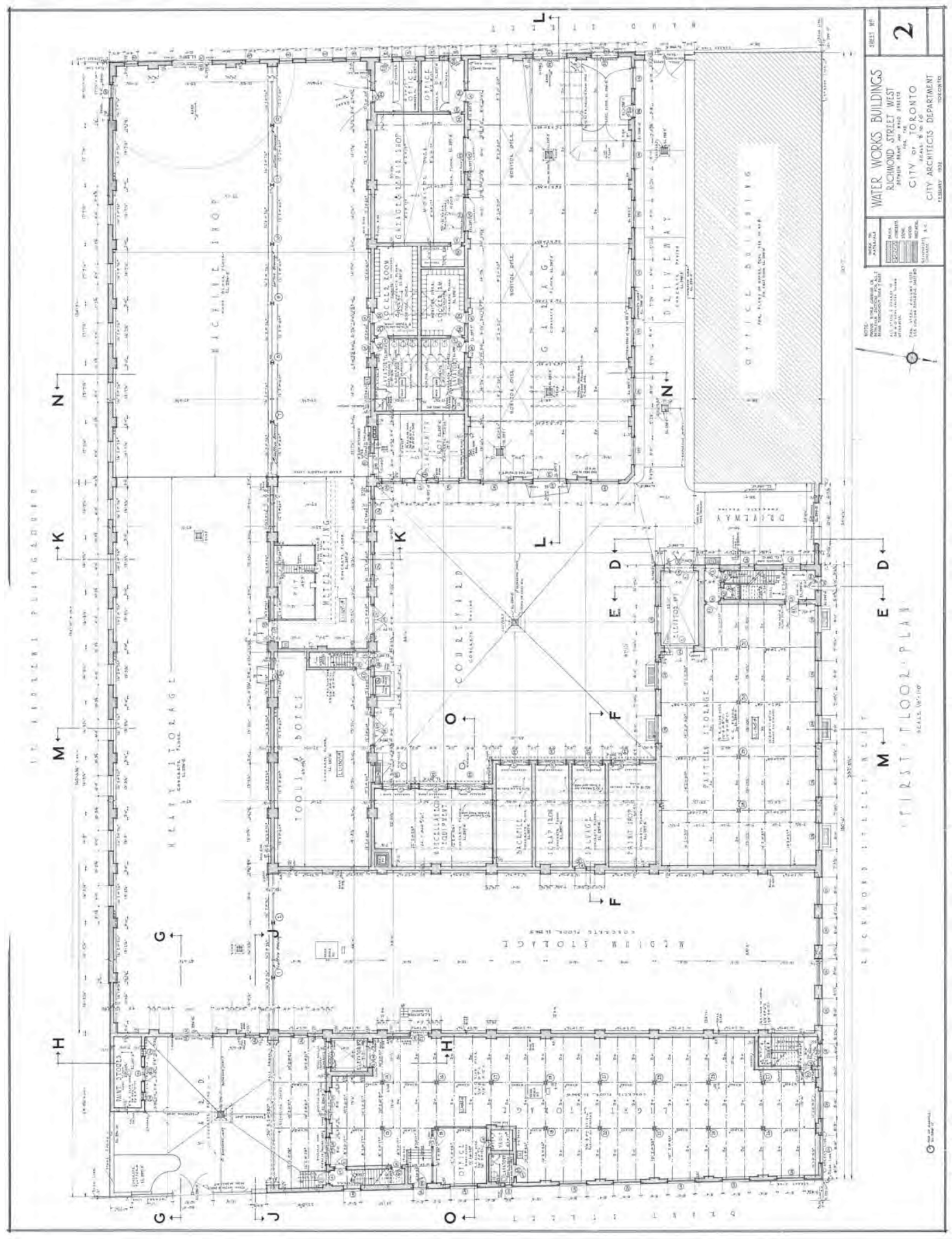




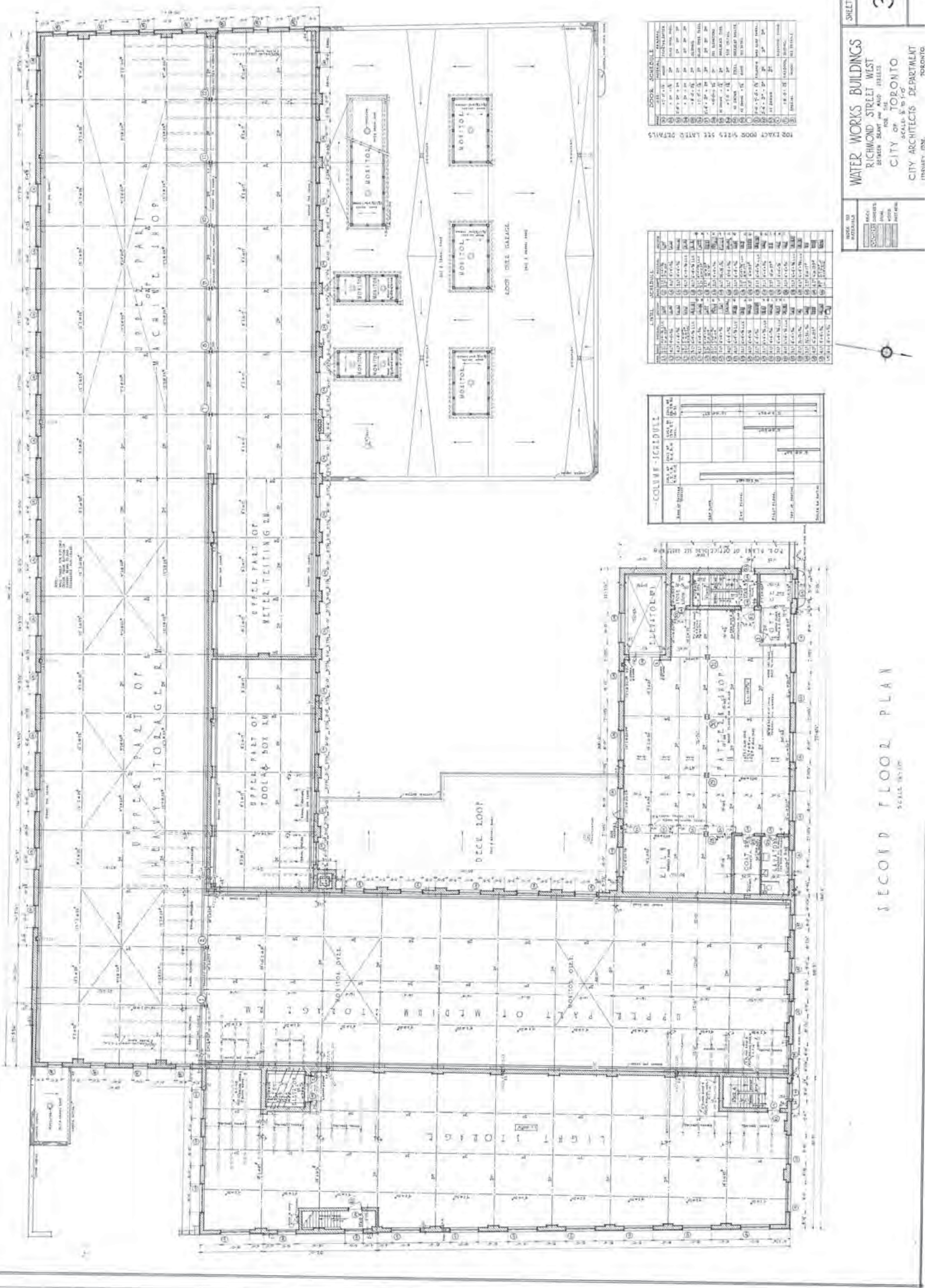




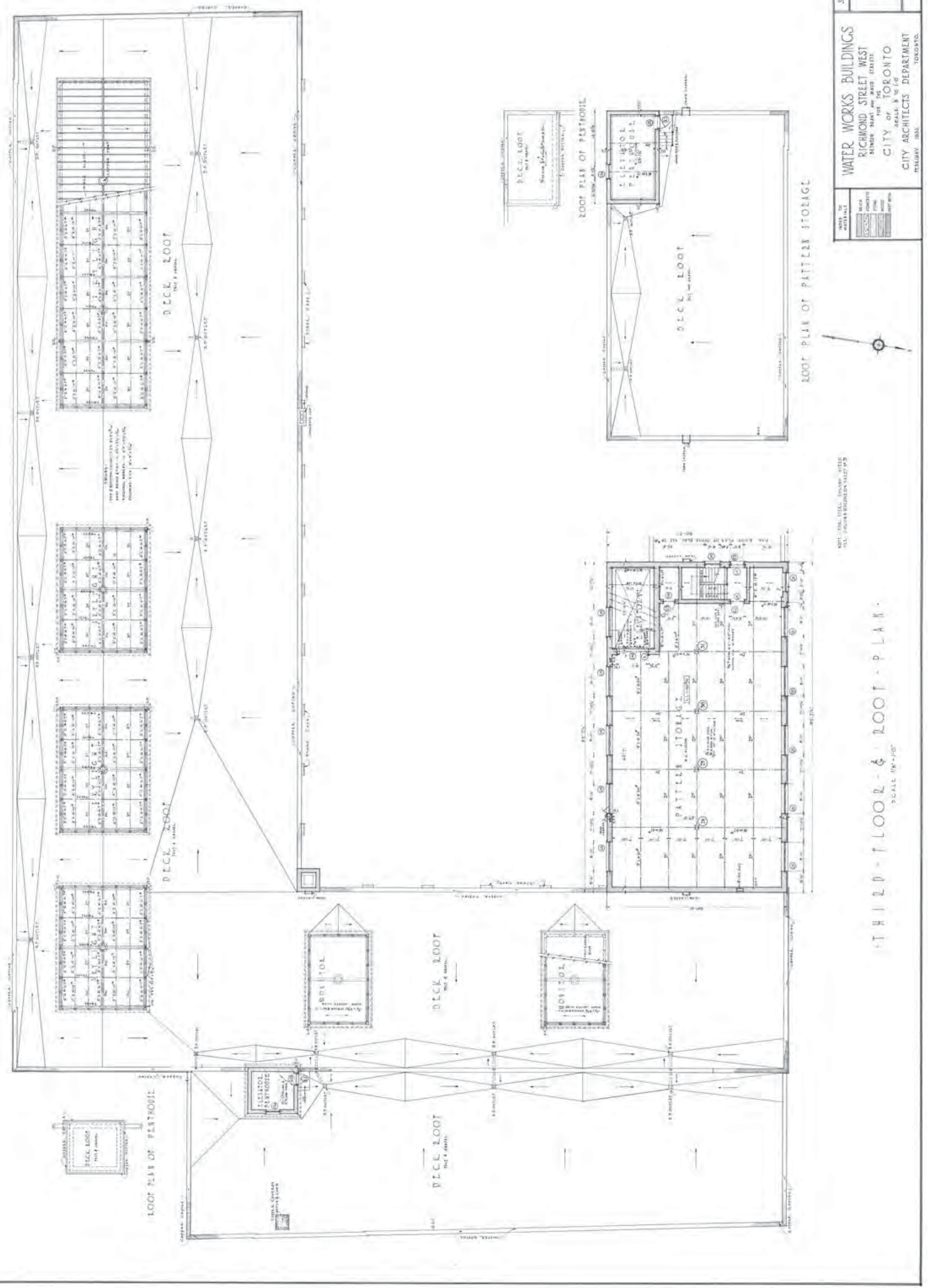




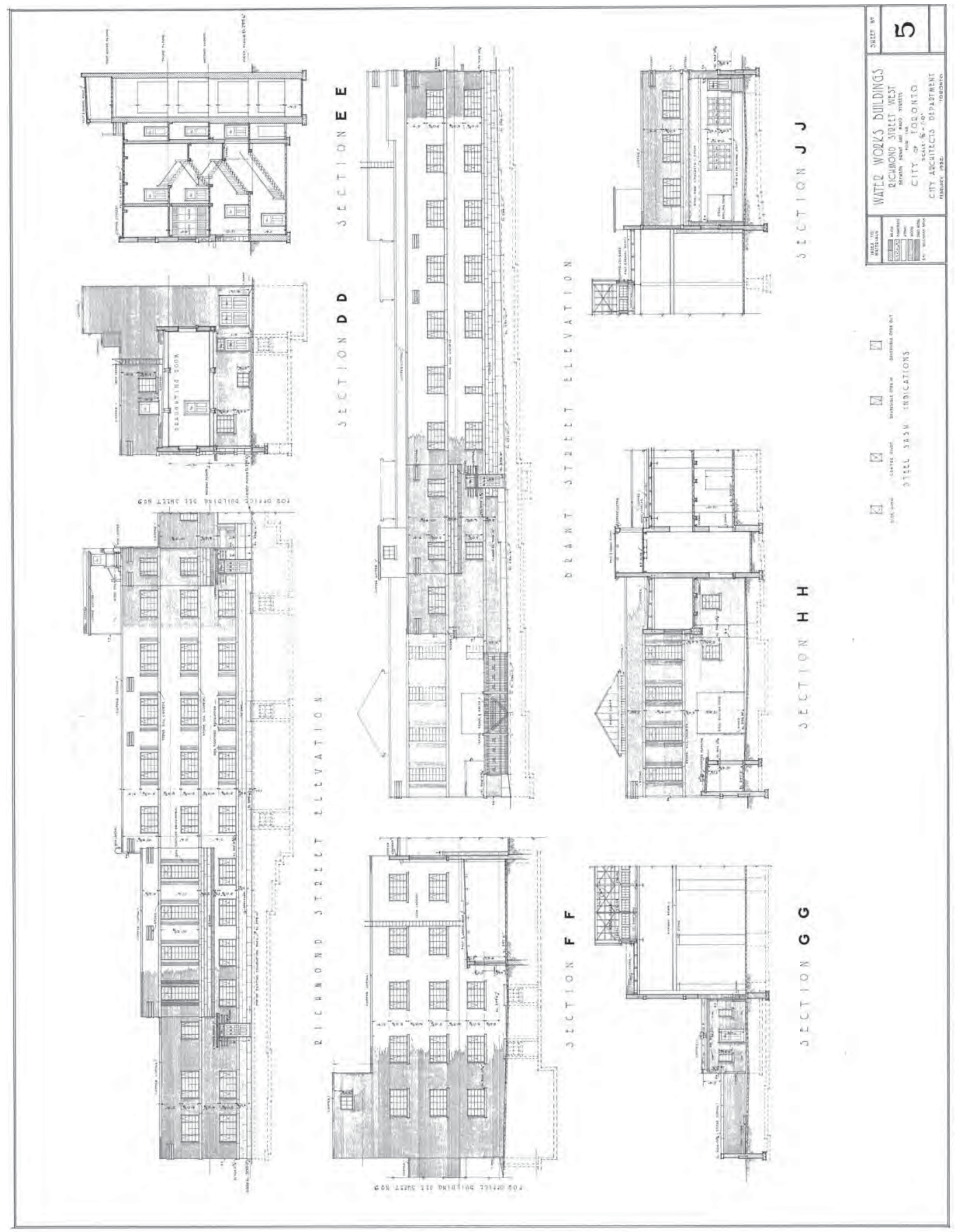




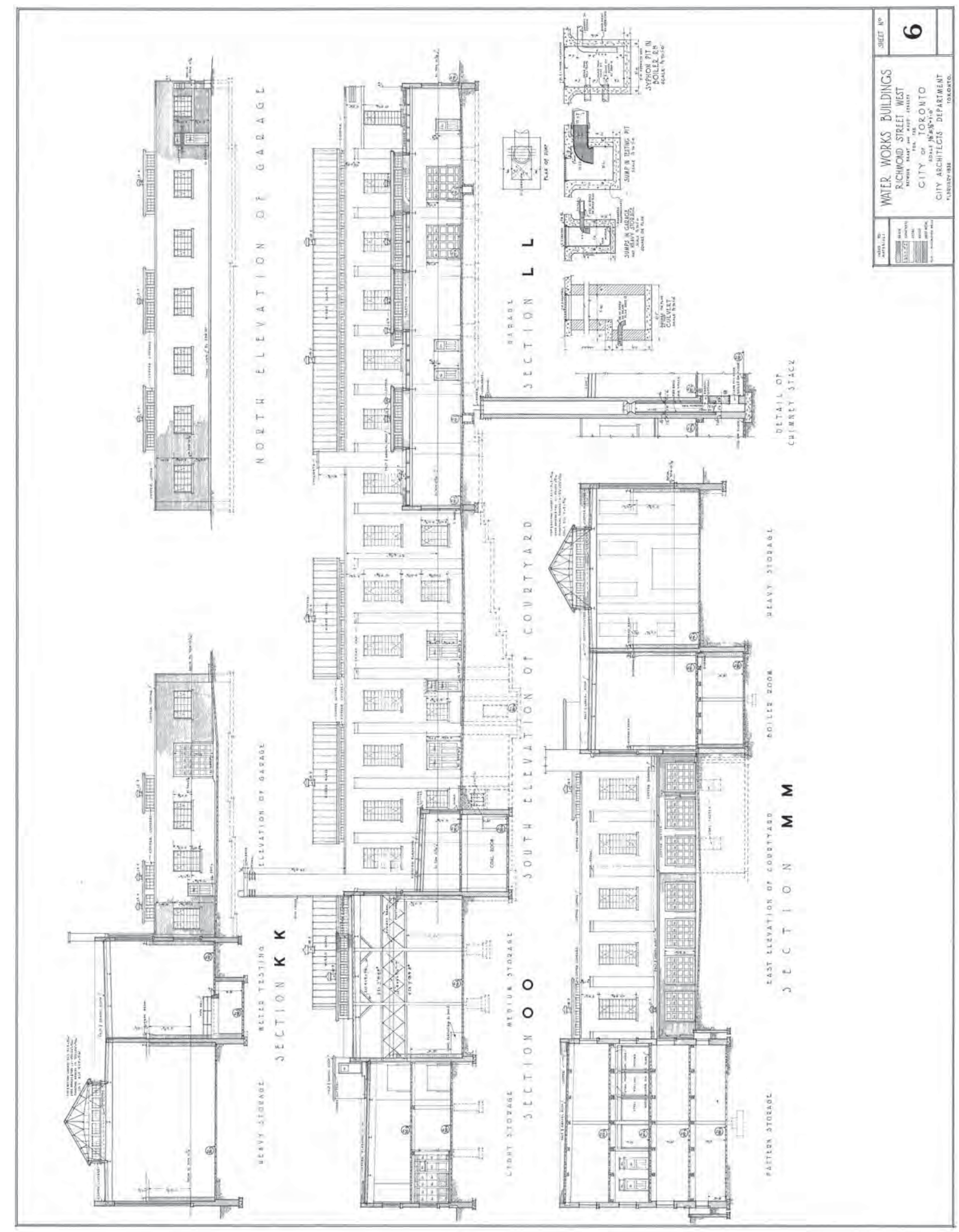



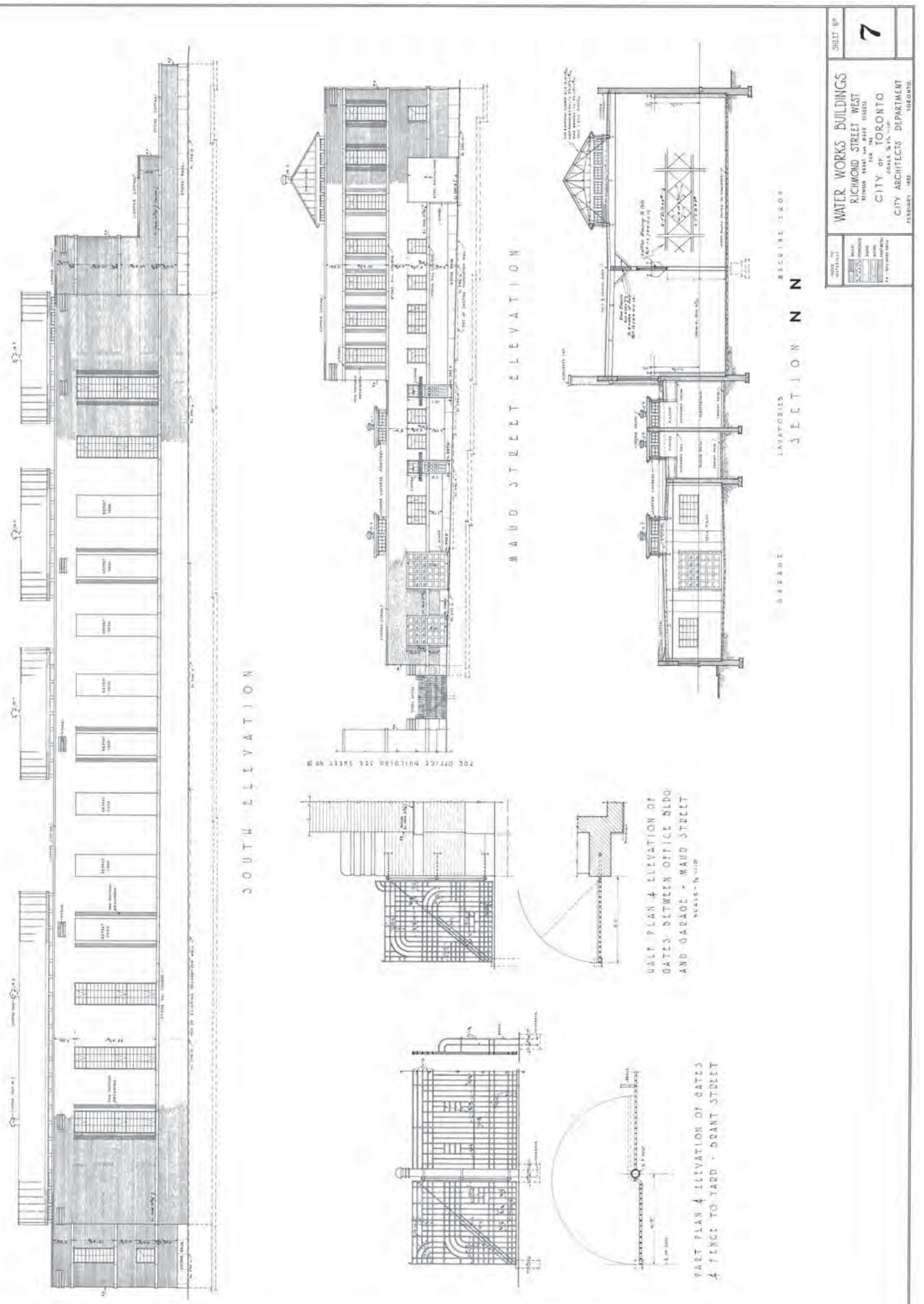


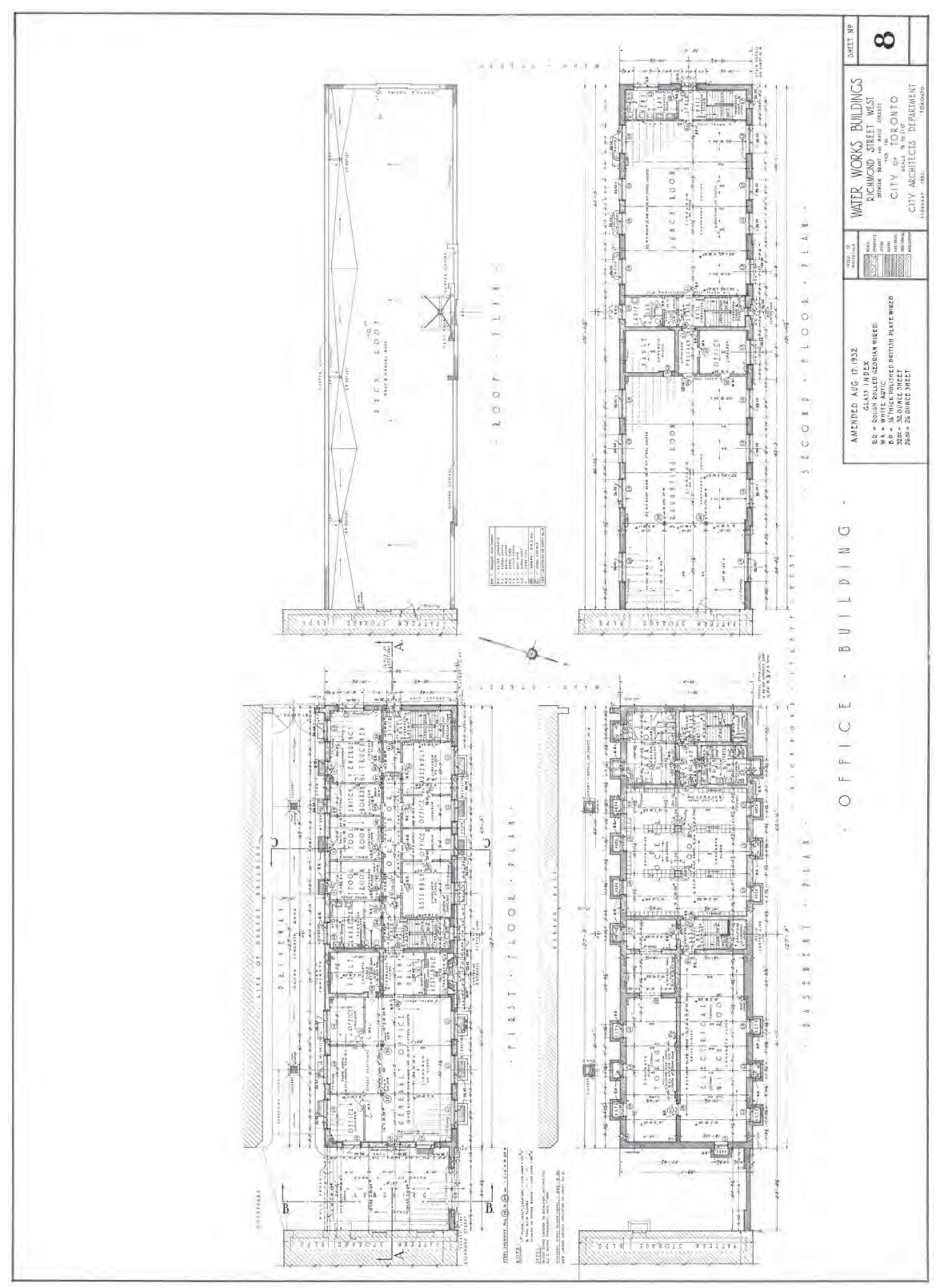




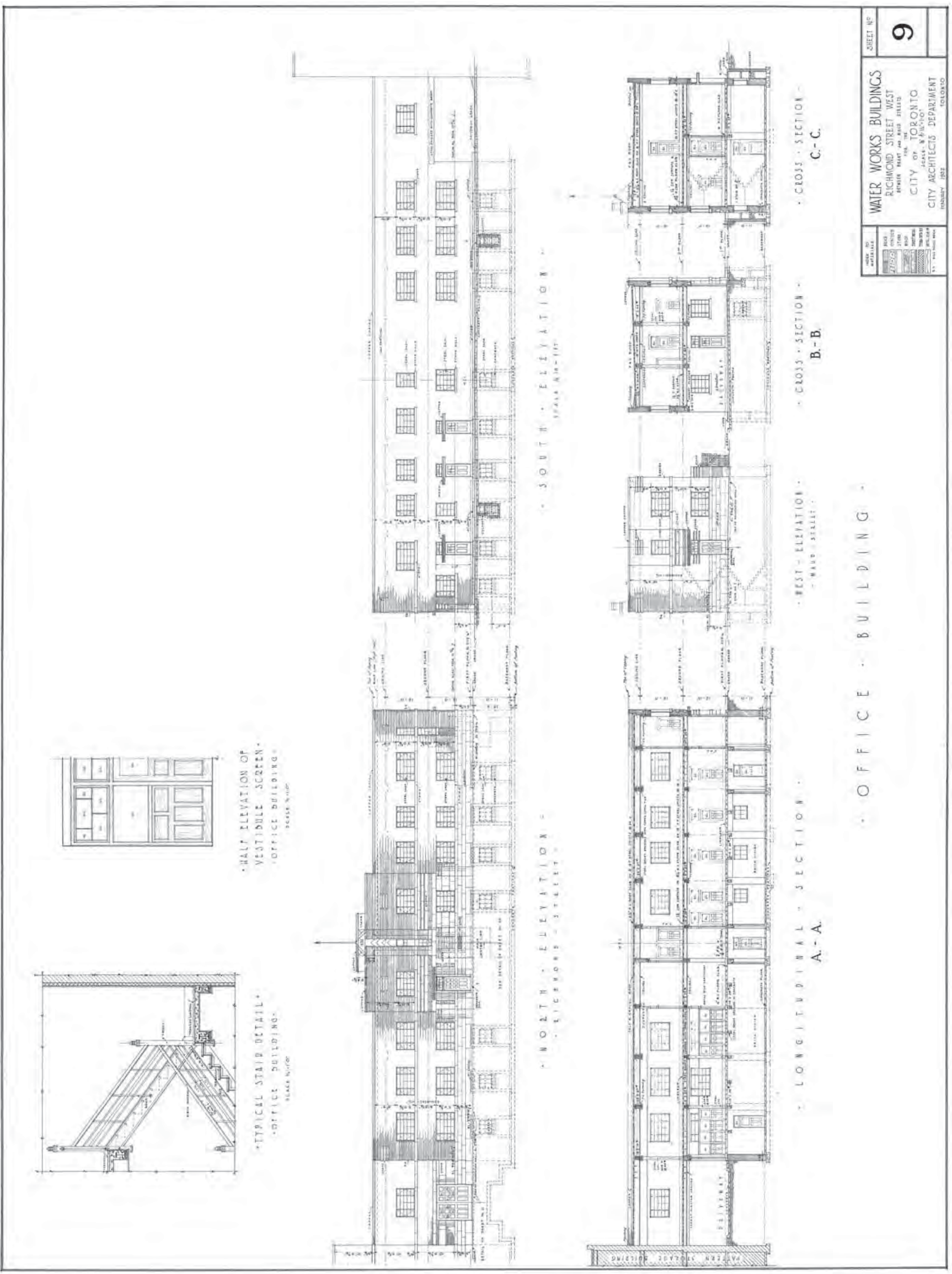




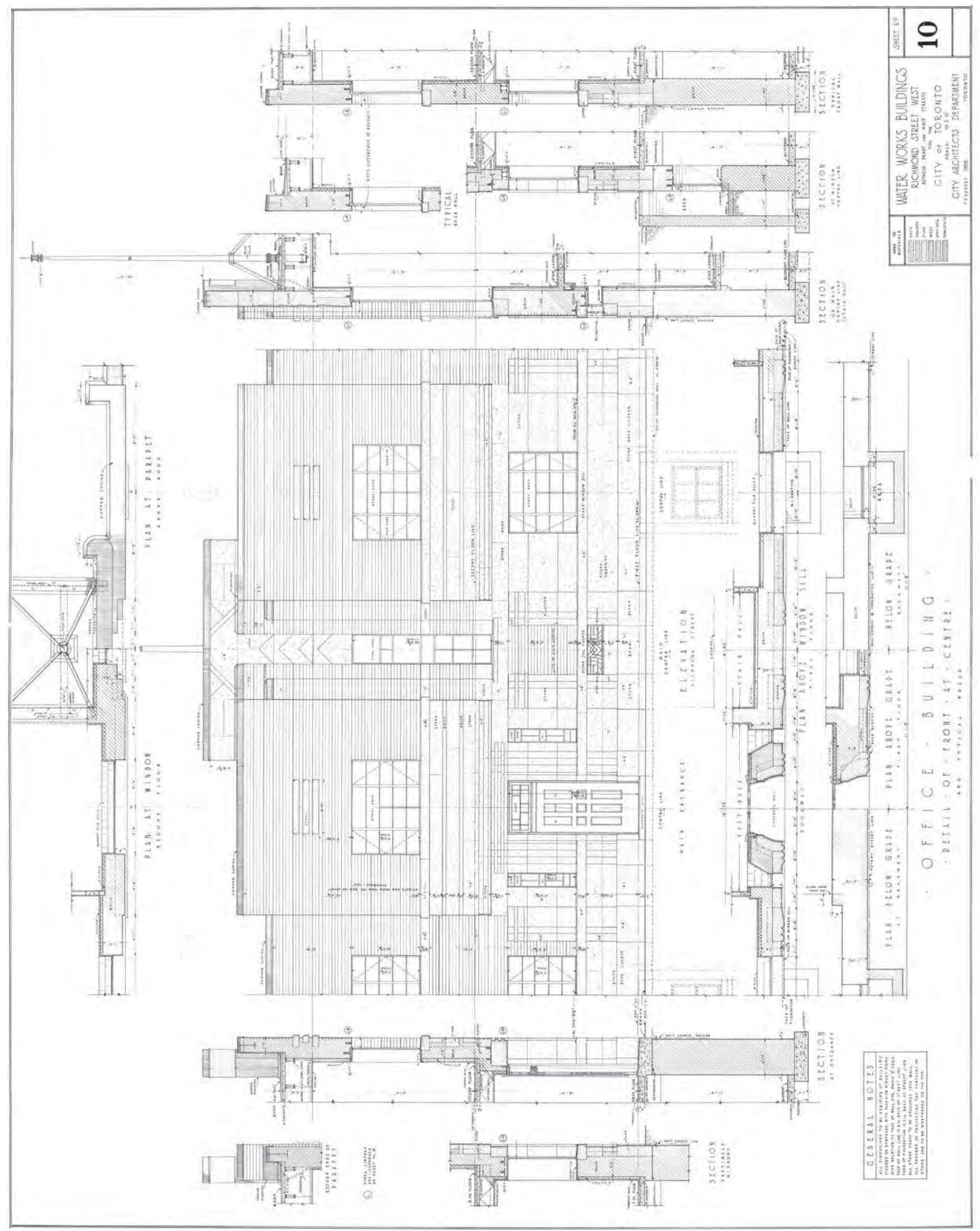




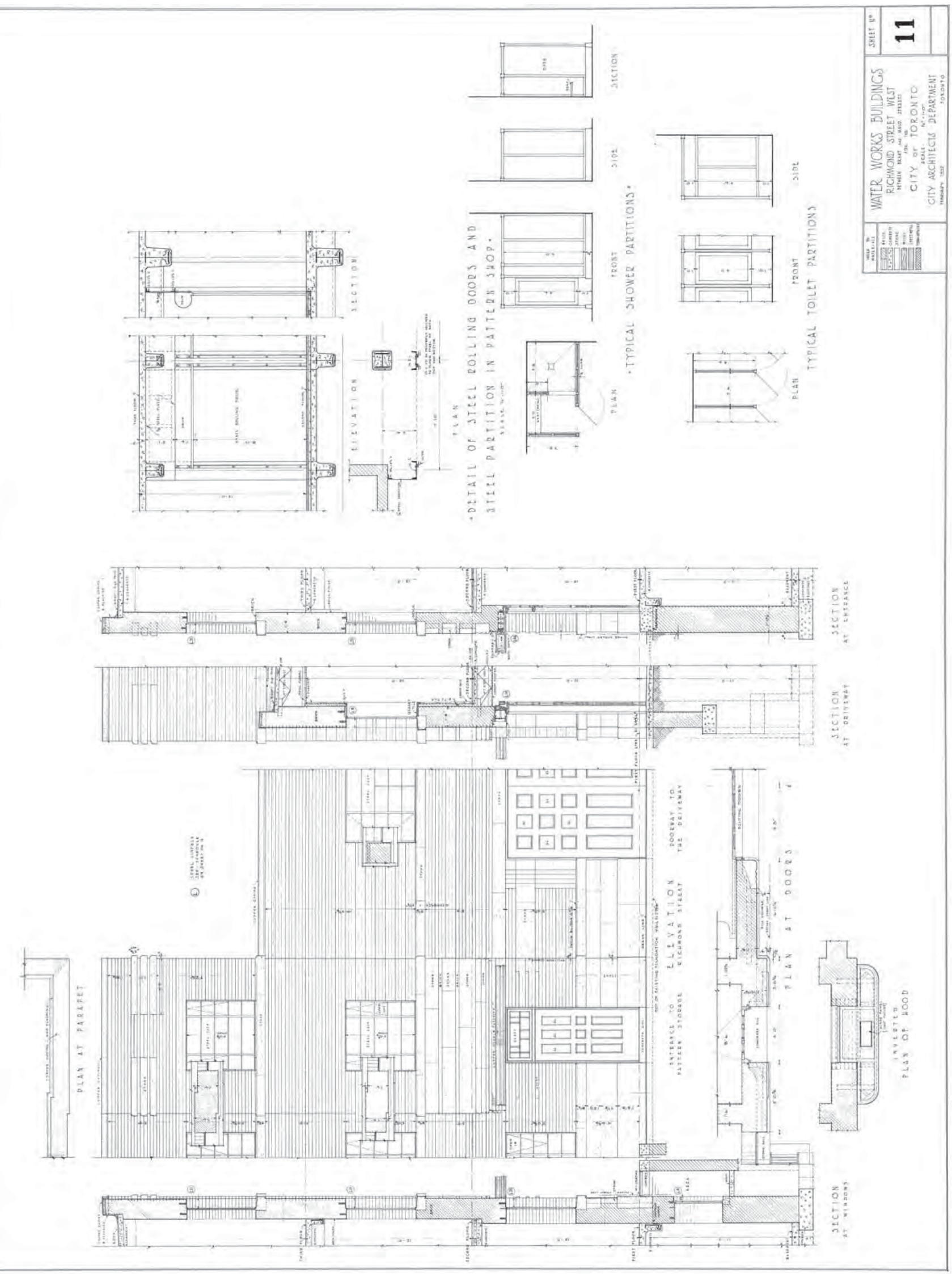




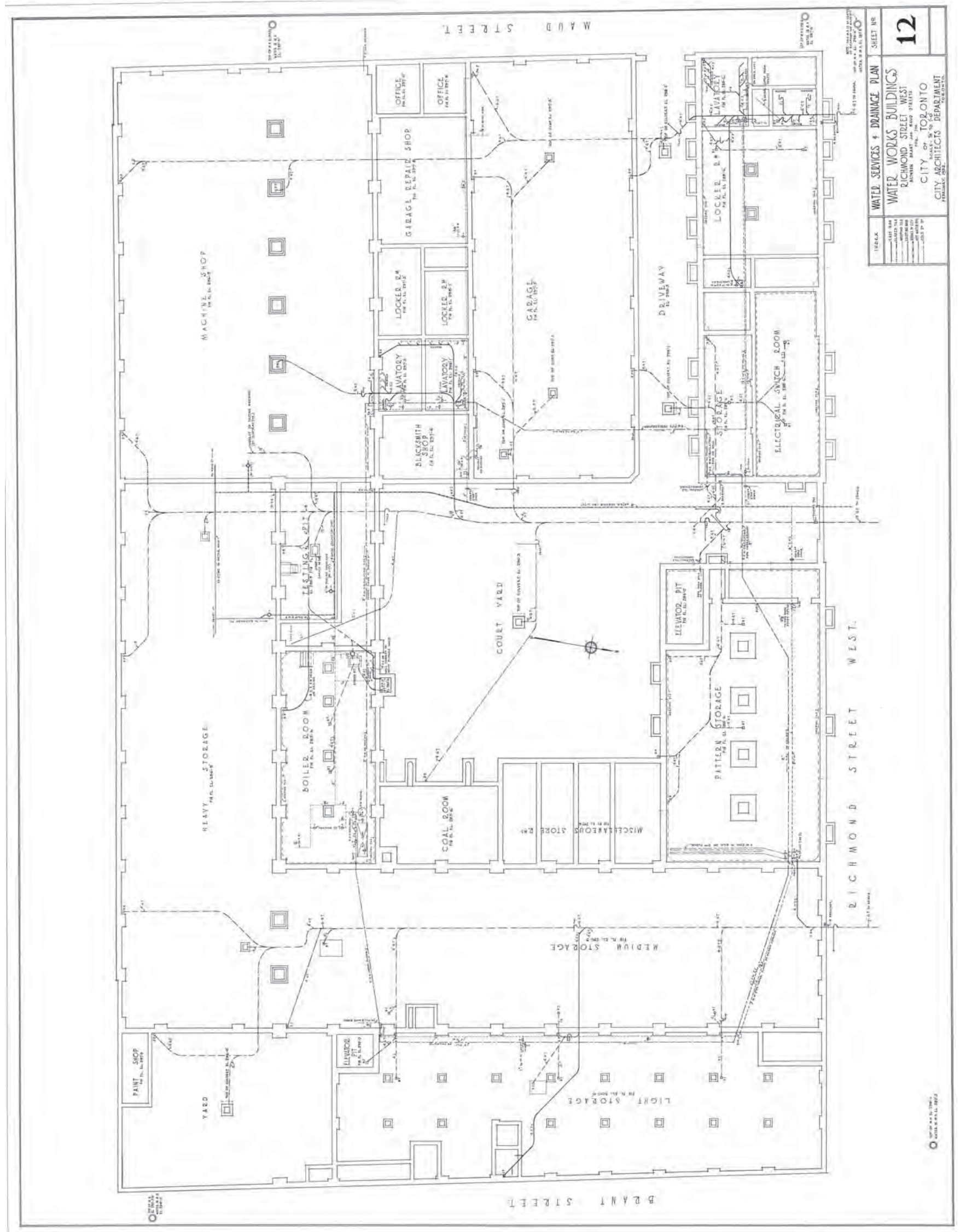




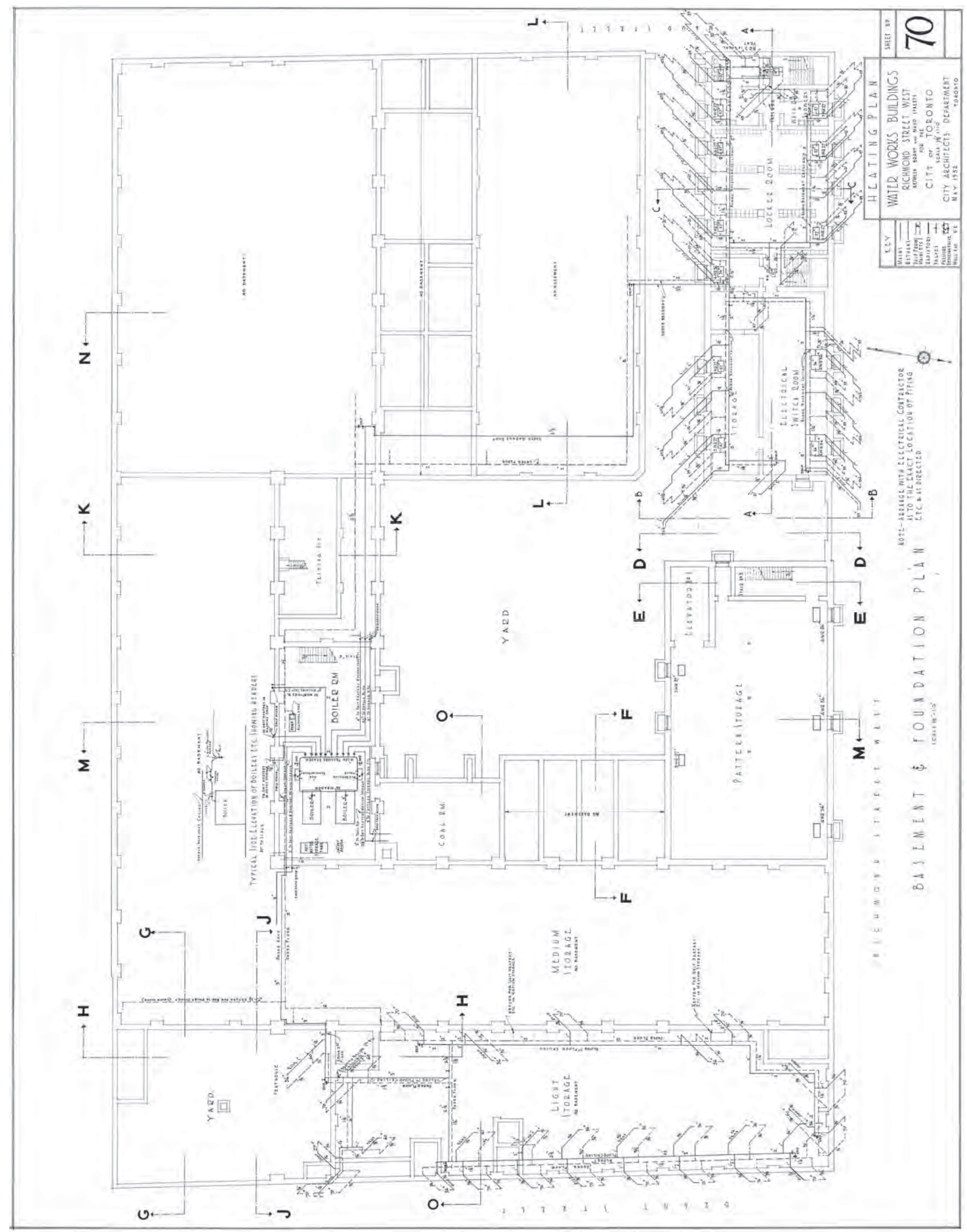




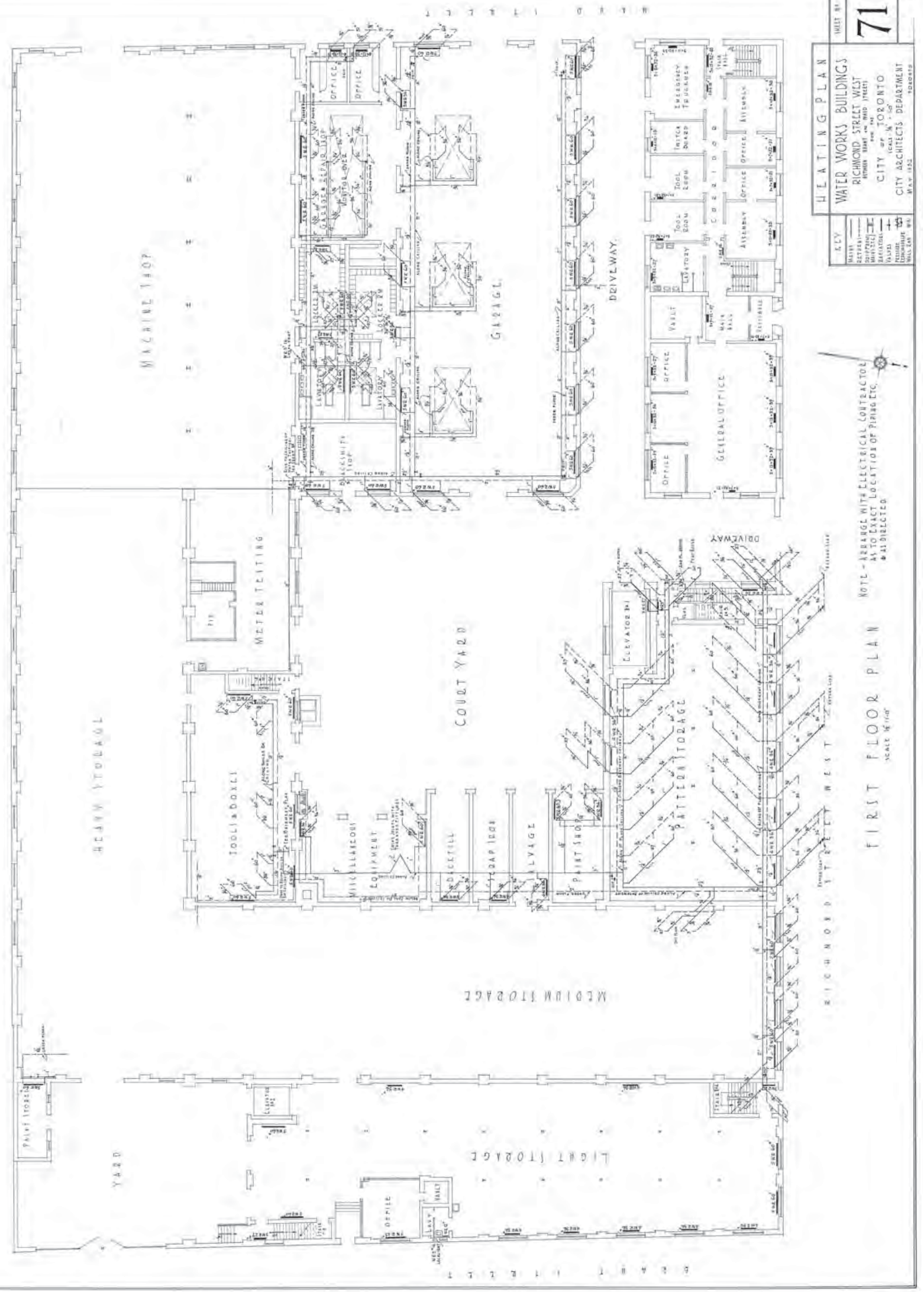




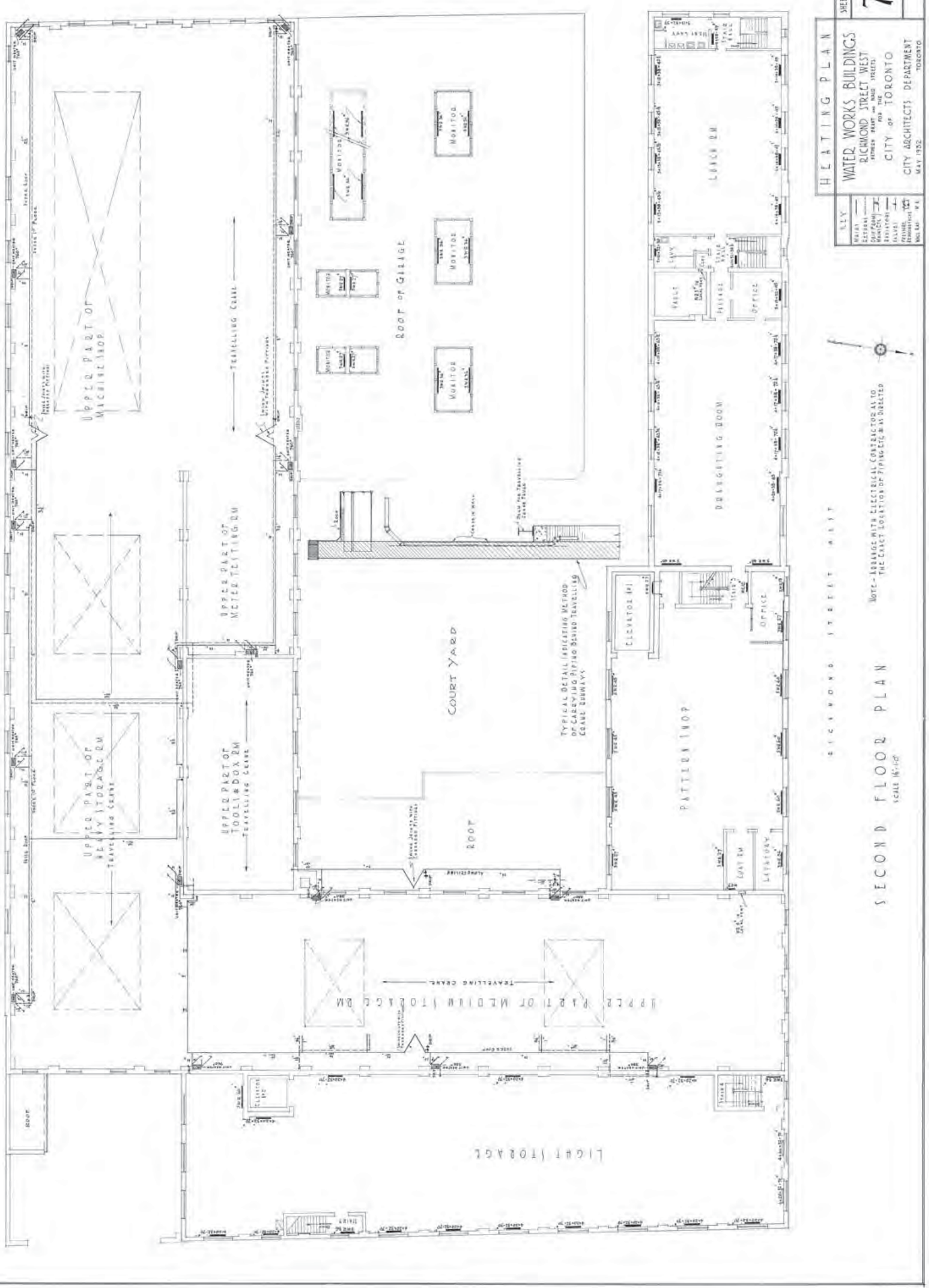




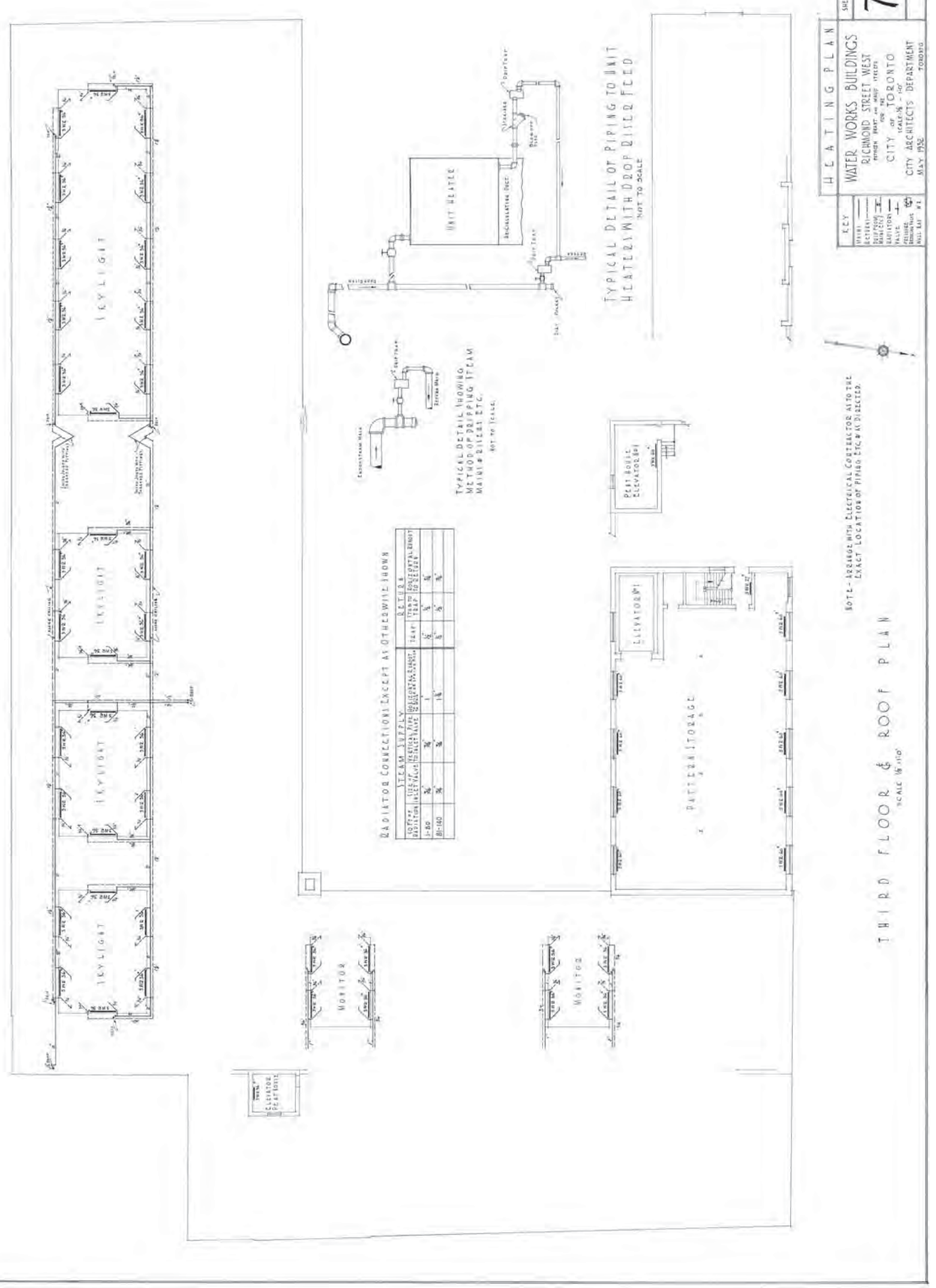




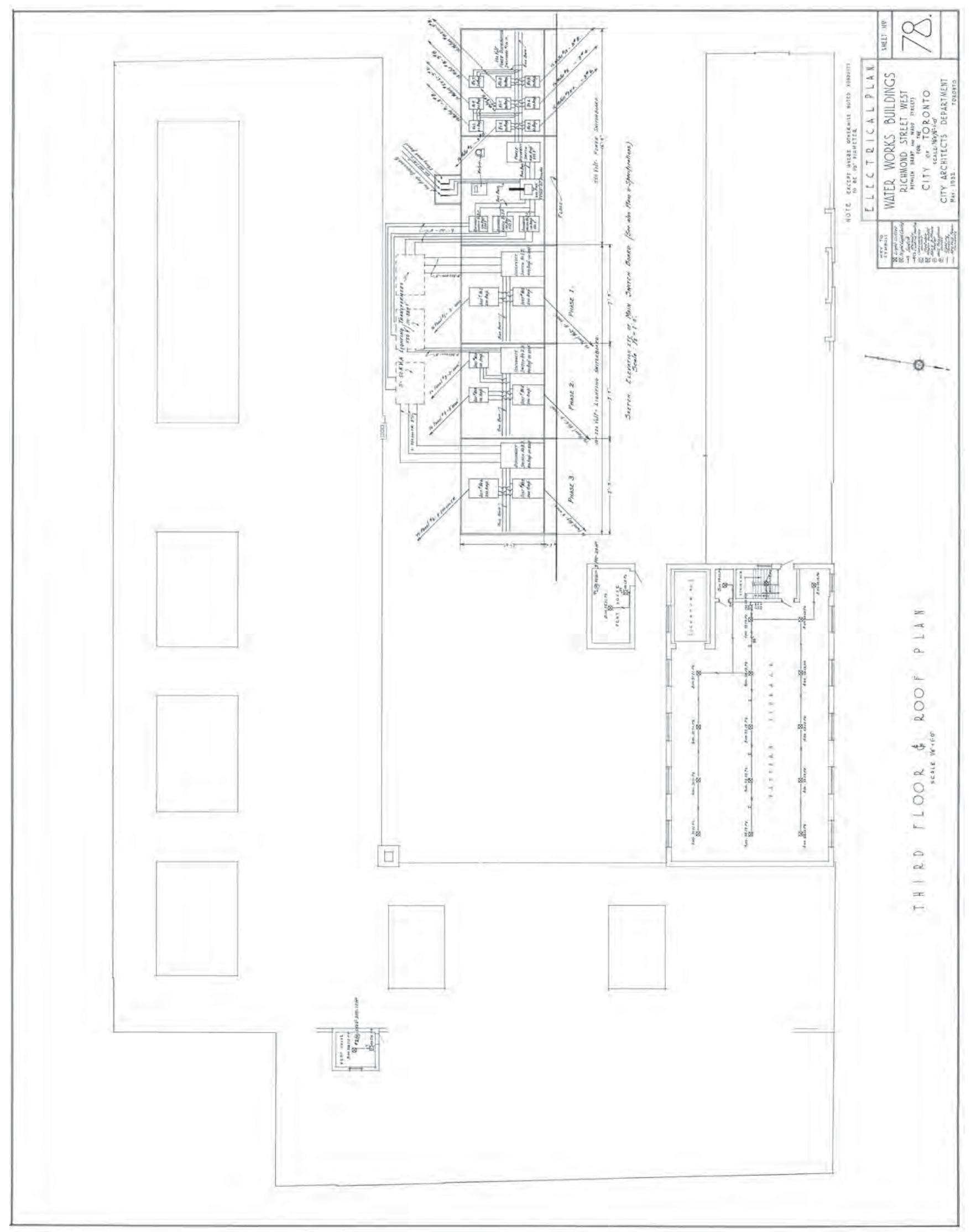




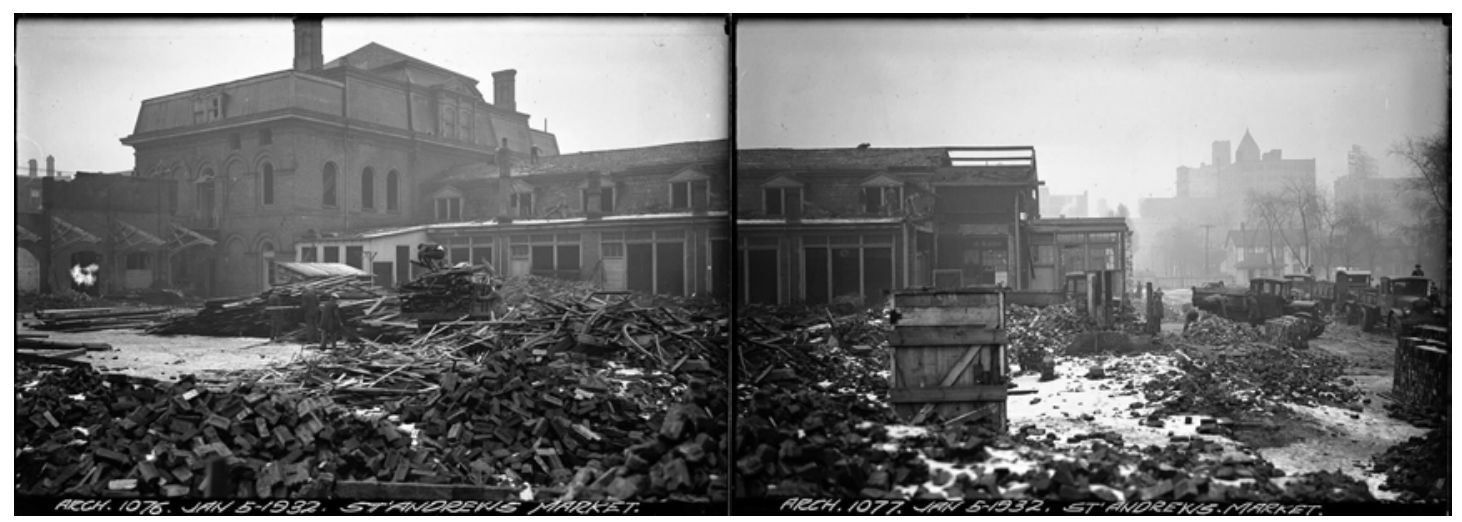

(left) Fig.8.49 St.Andrew's Market demolition, 1932

(left) Fig.8.50 St. Andrew's Market demolition, 1932

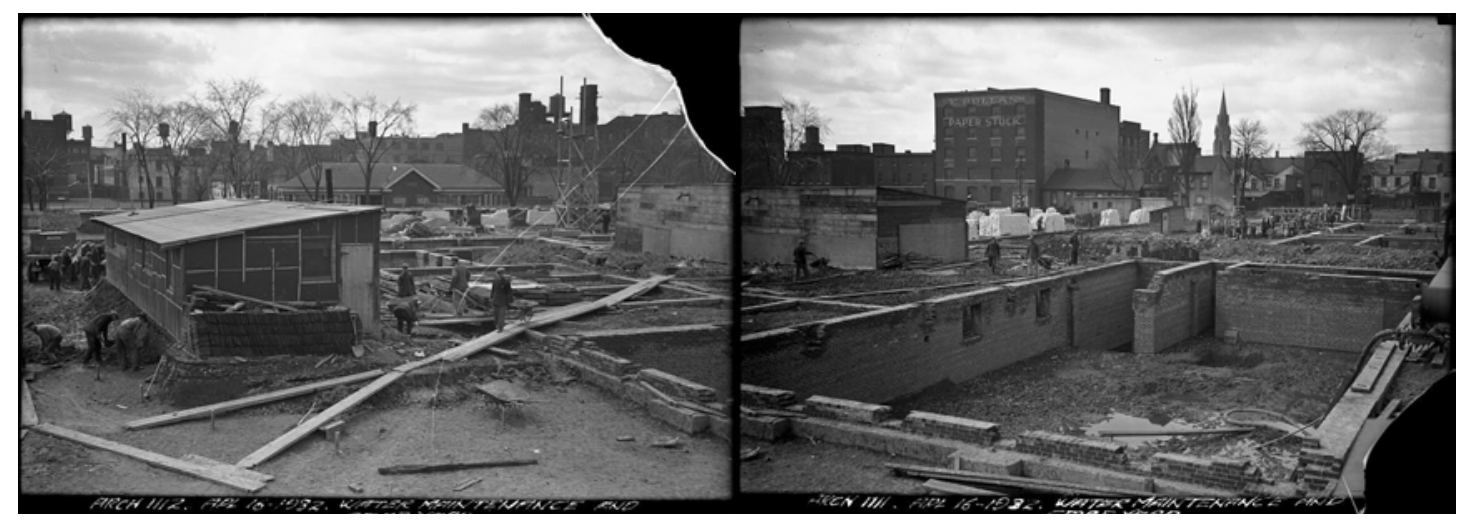

(left) Fig.8.51 Waterworks construction, 1932

(left) Fig.8.52 Waterworks construction, 1932

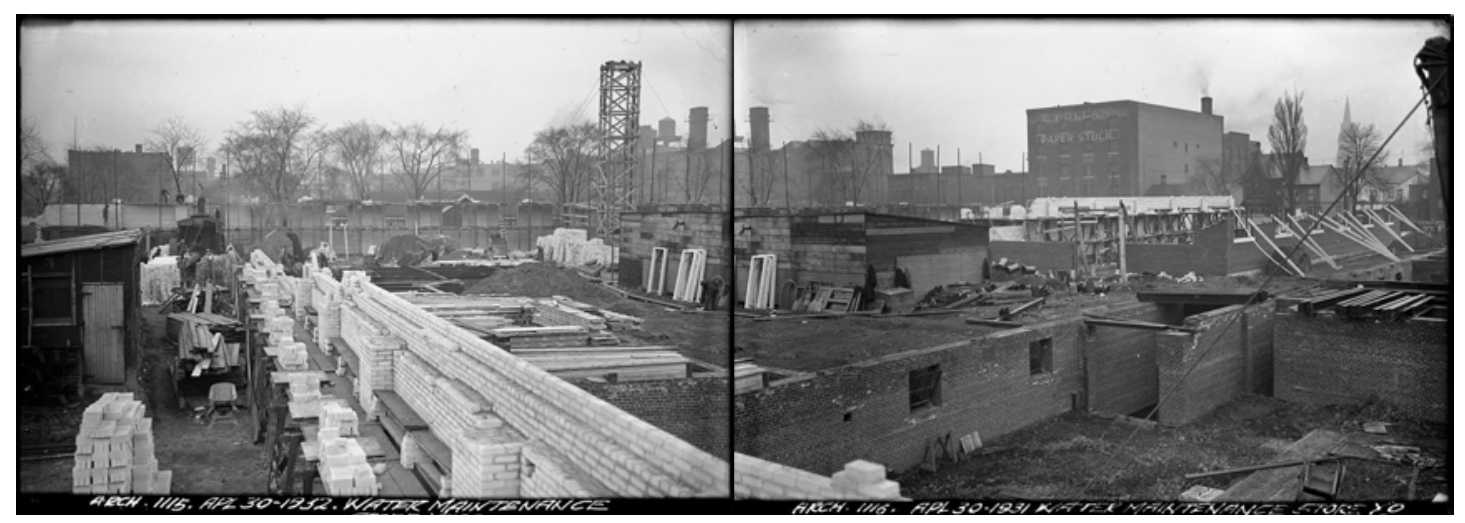

(left) Fig.8.53 Waterworks construction, 1932

(right) Fig.8.54 Waterworks construction, 1932 


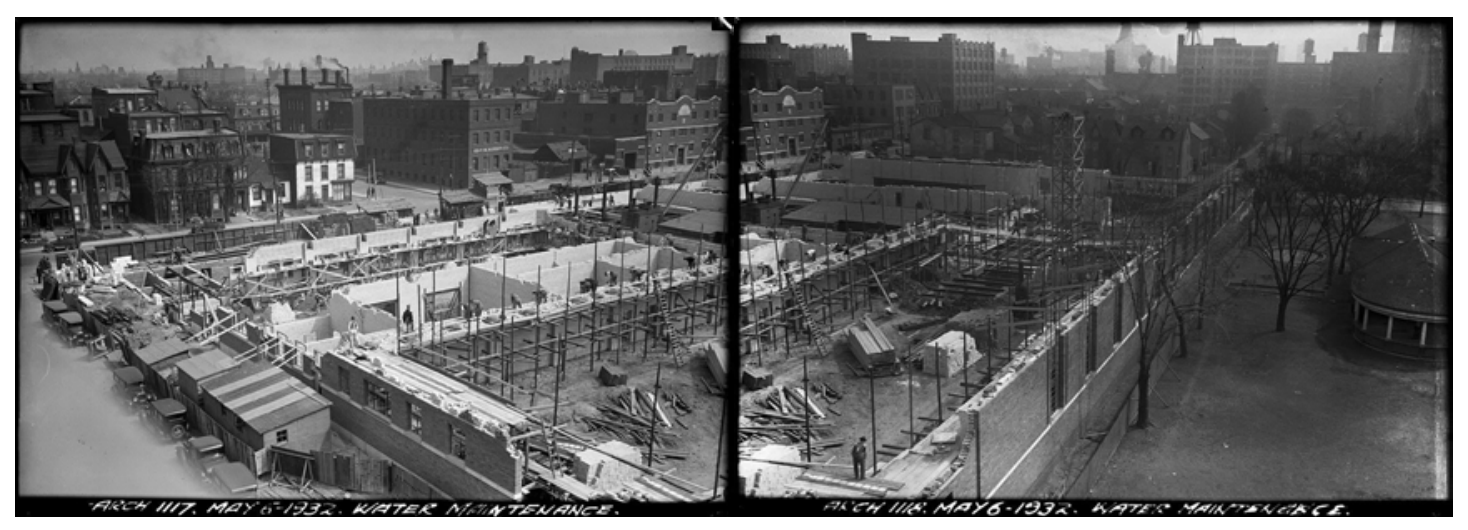

(left) Fig.8.55 Waterworks construction, 1932

(right) Fig.8.56 Waterworks construction, 1932

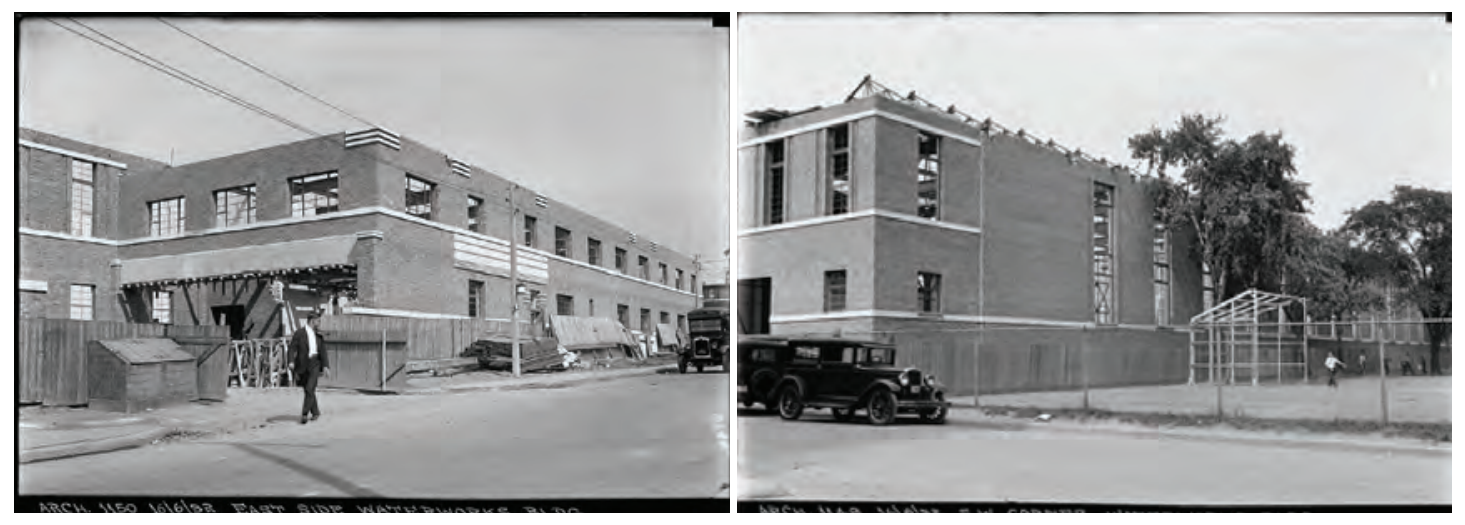

(left) Fig.8.57 Waterworks construction, south-east corner, 1932

(right) Fig.8.58 Waterworks construction, south-west corner, 1932
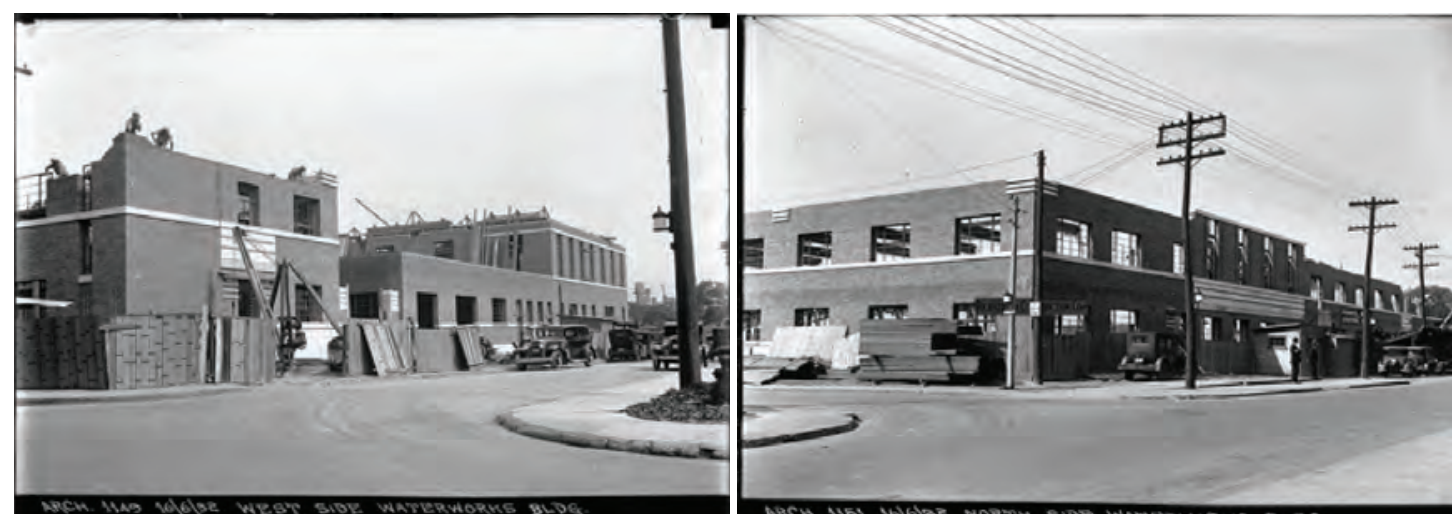

(left) Fig.8.59 Waterworks construction, north-west corner, 1932

(right) Fig.8.60 Waterworks construction, north-east corner, 1932 

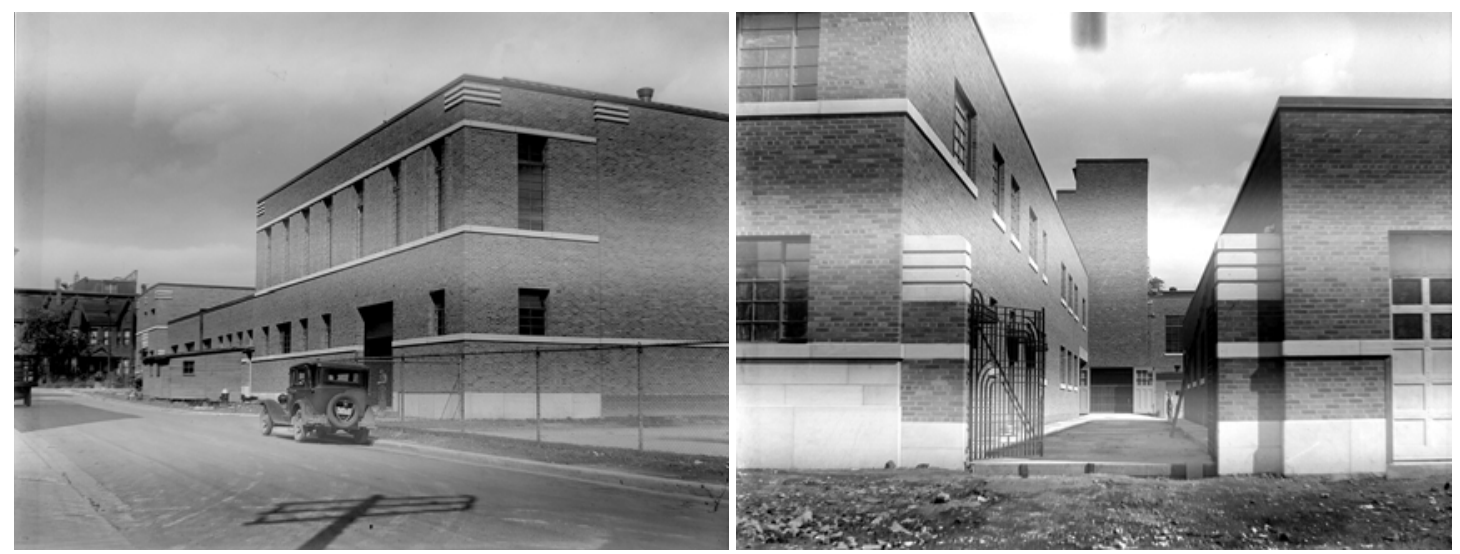

(left) Figure 8.61

Waterworks - south-west corner, 1932

(right) Figure 8.62

Waterworks - looking down driveway at Maud, 1932
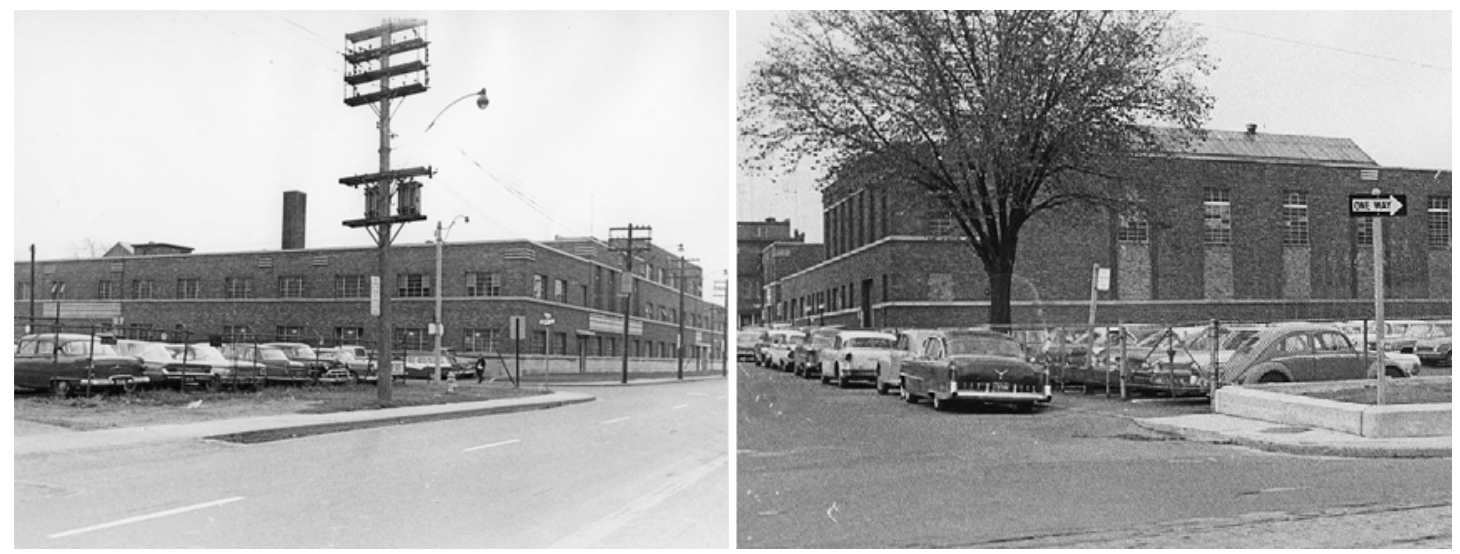

(left) Fig.8.63 Waterworks - looking west from Richmond Street West, 195-

(right) Fig.8.64 Waterworks - looking north from Adelaide Street West, 195-

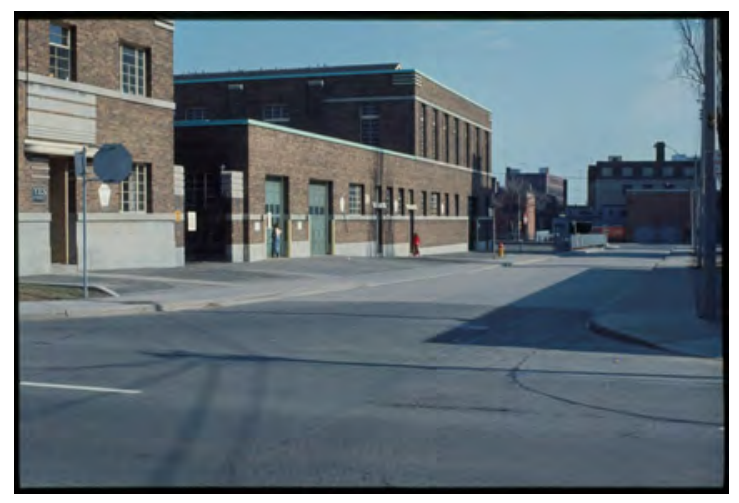

Fig.8.65 Waterworks - looking south from corner of Richmond Street West and Maud Street, between 1975 and 1983 


\section{Appendix E}

Waterworks \& St. Andrew's Park Photographs (2017)
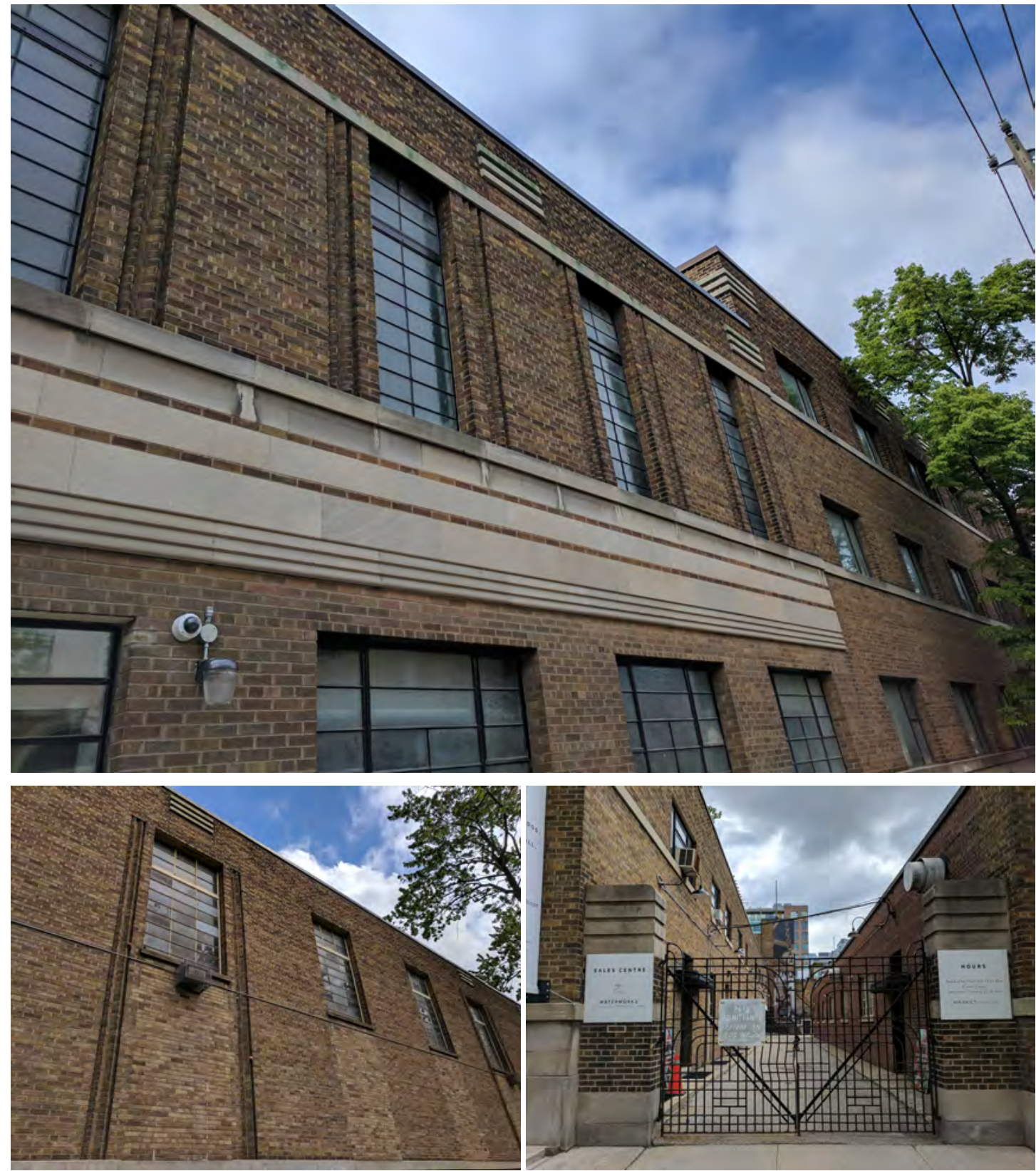

(top) Fig.8.66 Waterworks Richmond Street elevation close-up

(left) Fig.8.67 Waterworks St. Andrew's Park elevation close-up

(right) Fig.8.68 Waterworks Maud Street driveway gate 

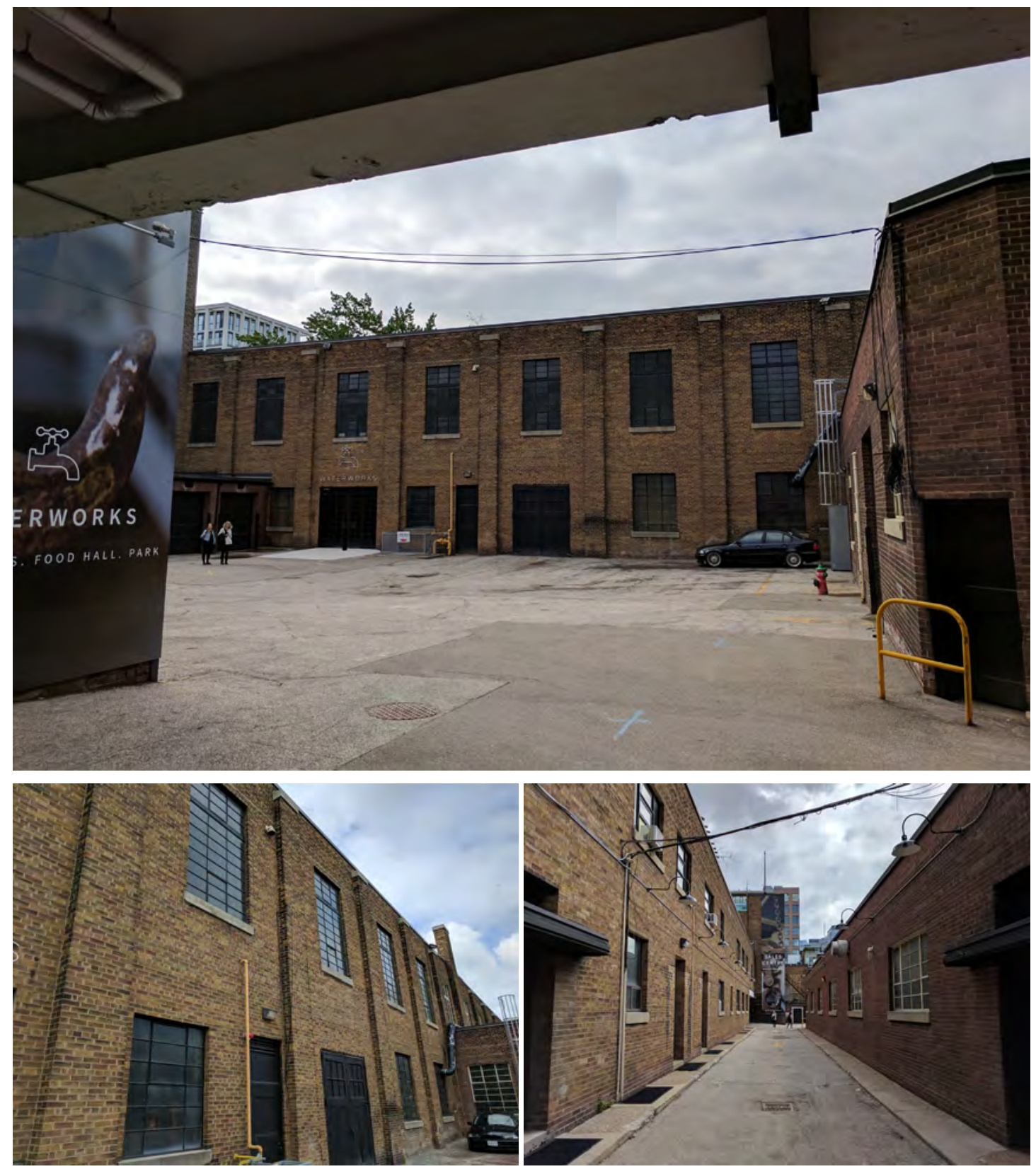

(top) Fig.8.69 Waterworks view of courtyard from Richmond Street driveway

(left) Fig.8.70 Waterworks south hall north facade close-up

(right) Fig.8.71 Waterworks Maud Street driveway 

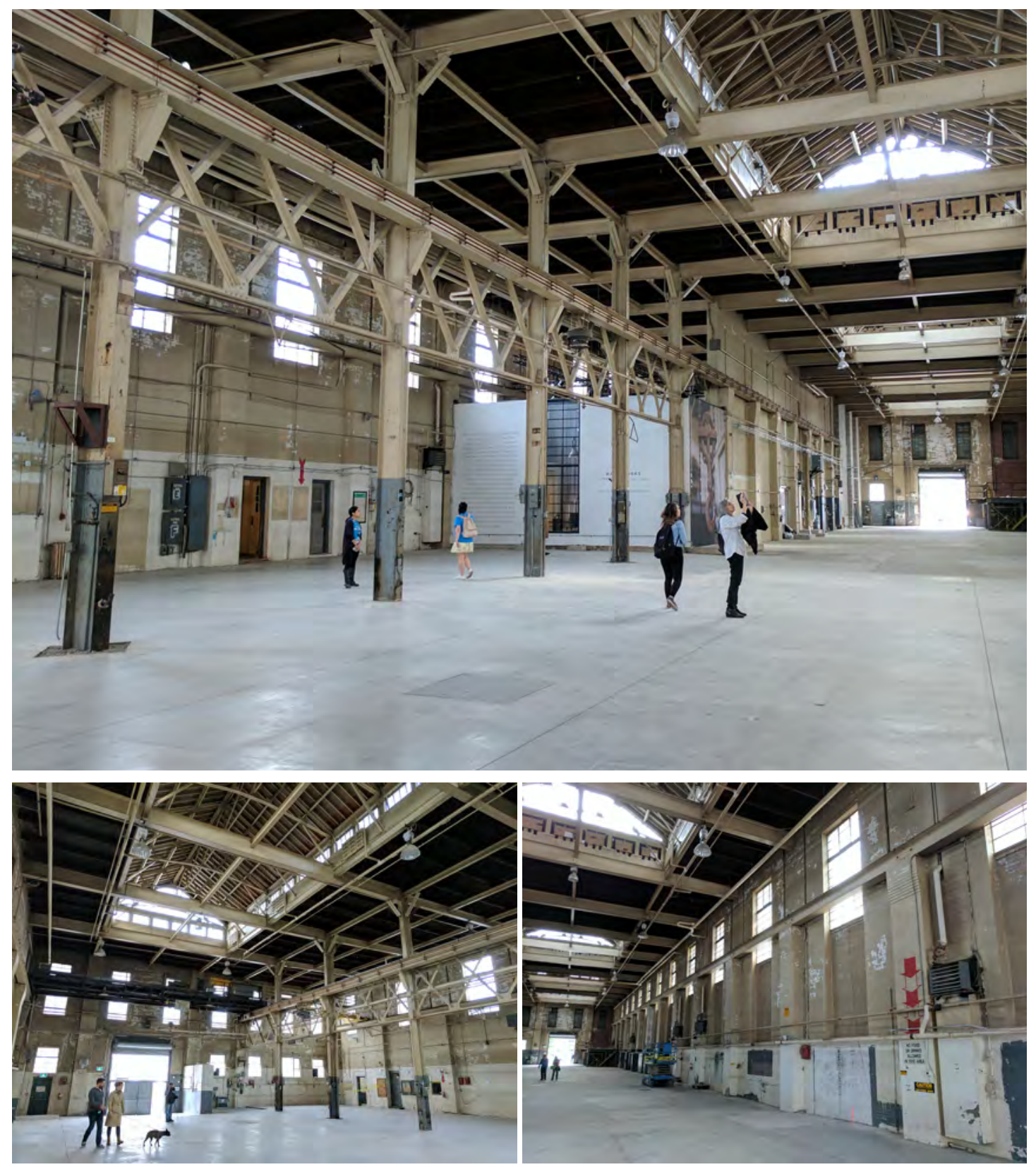

(top) Fig.8.72 Waterworks south hall looking east

(left) Fig.8.73 Waterworks south hall looking west

(right) Fig.8.74 Waterworks south hall looking east 

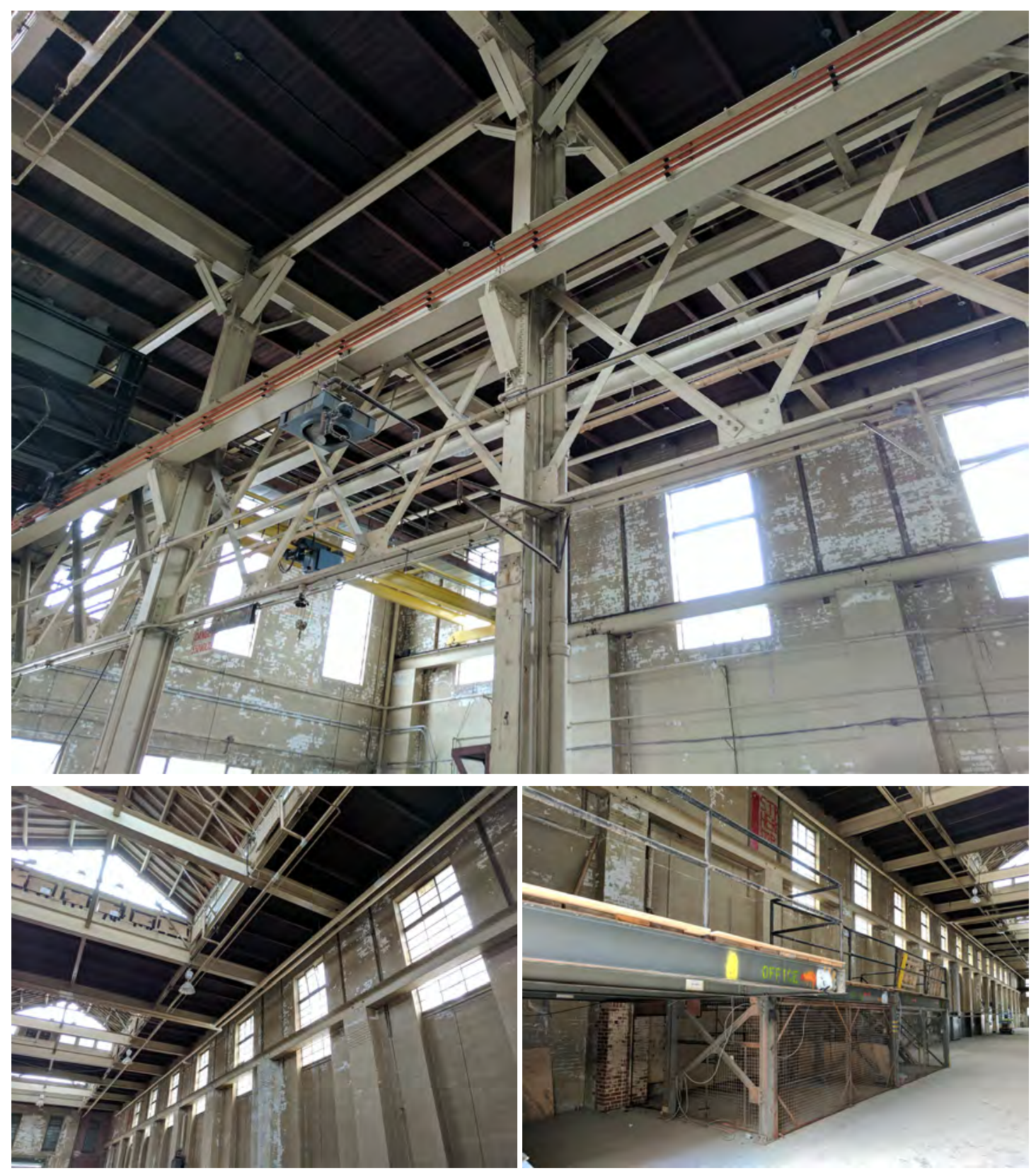

(top) Fig.8.75 Waterworks south hall latticework bracing close-up

(left) Fig.8.76 Waterworks south hall looking south-east

(right) Fig.8.77 Waterworks south hall looking south-west 

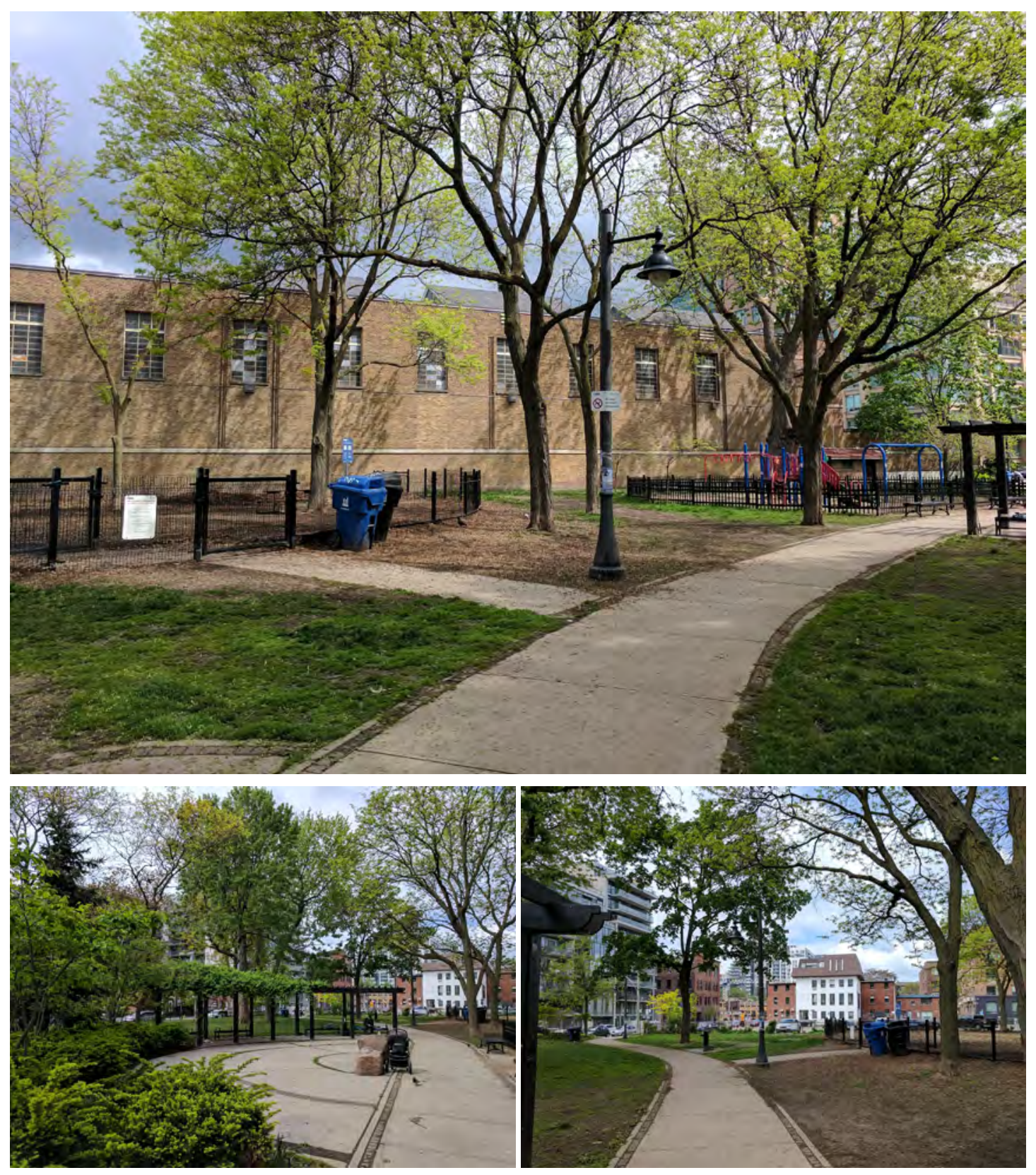

(top) Fig.8.78 St. Andrew's Park looking north-east

(left) Fig.8.79 St. Andrew's Park sheltered seating area

(right) Fig.8.80 St. Andrew's Park looking south-west 

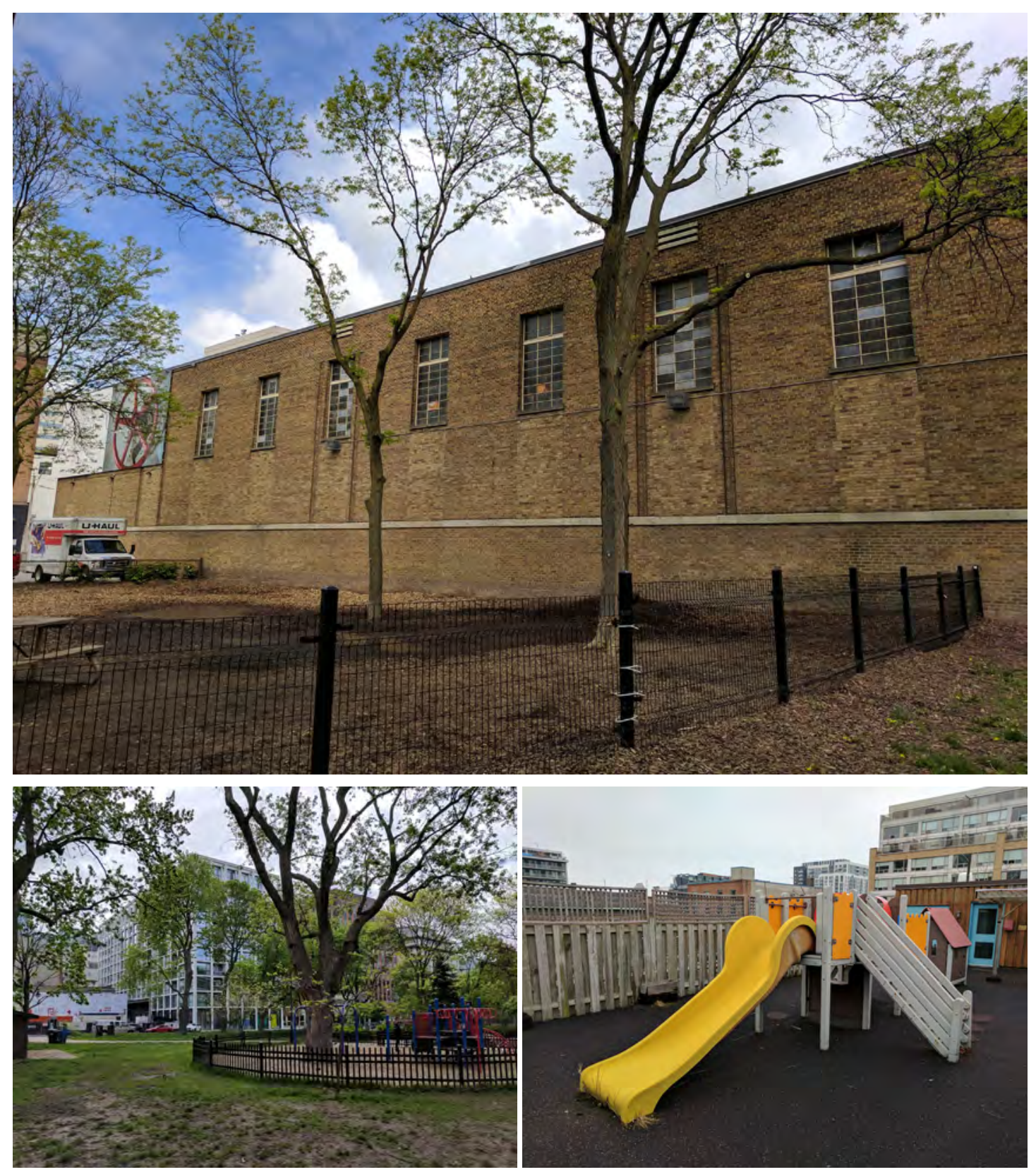

(top) Fig.8.81 St. Andrew's park off-leash dog area

(left) Fig.8.82 St. Andrew's Park children's play equipment

(right) Fig.8.83 Waterworks office building rooftop playground 


\section{Appendix $\mathrm{F}$}

Site 2.0 Design Project Process work, Models
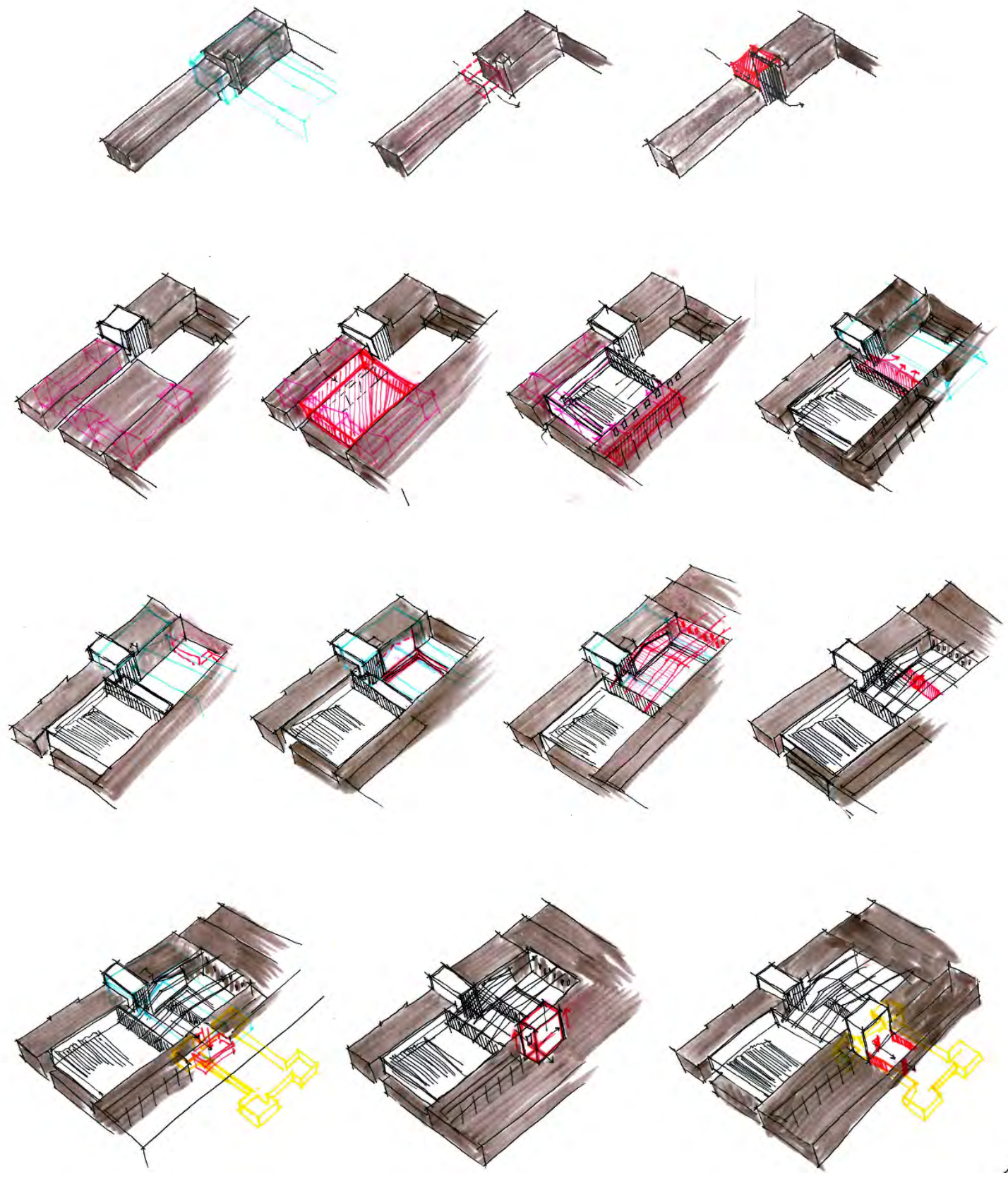

Fig.8.84 Process sketches 

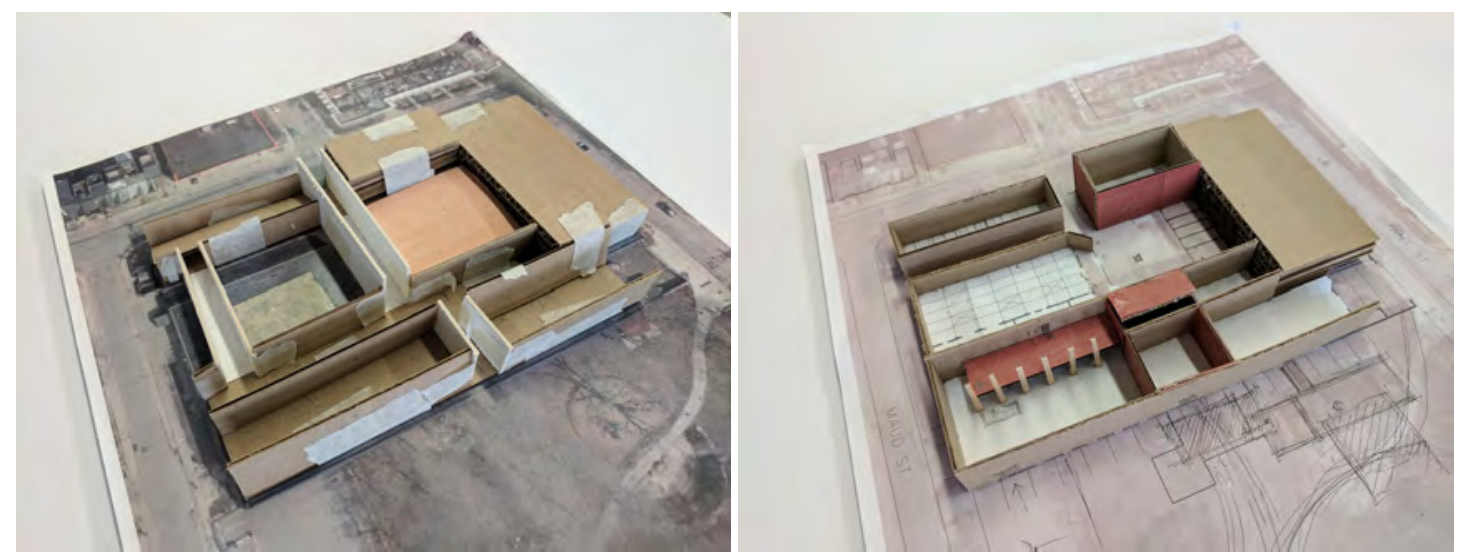

(left) Fig.8.85 Early process model

(right) Fig.8.86 Early process model

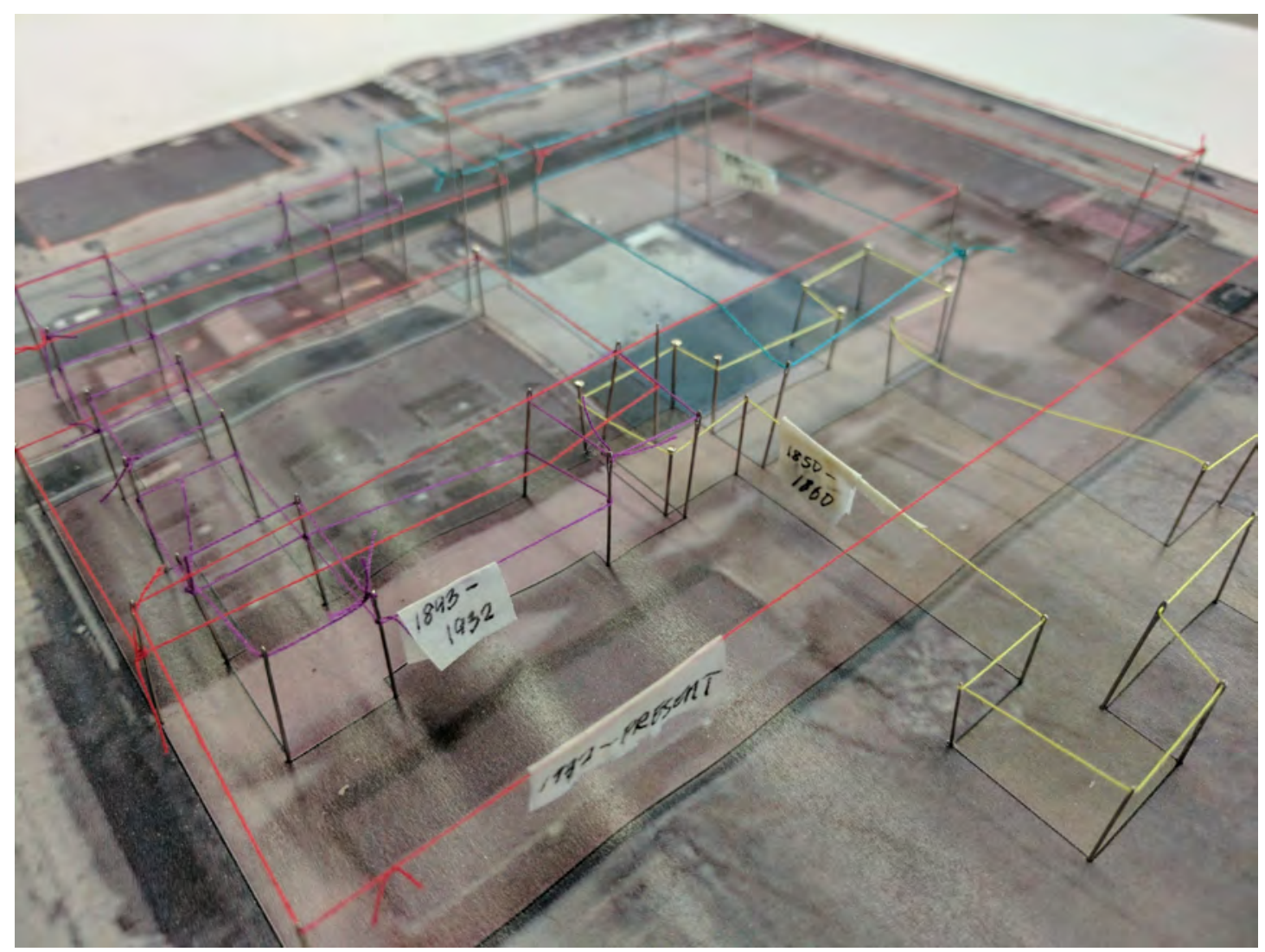

Fig.8.87 Overlap of all forms all buildings on the site using string 

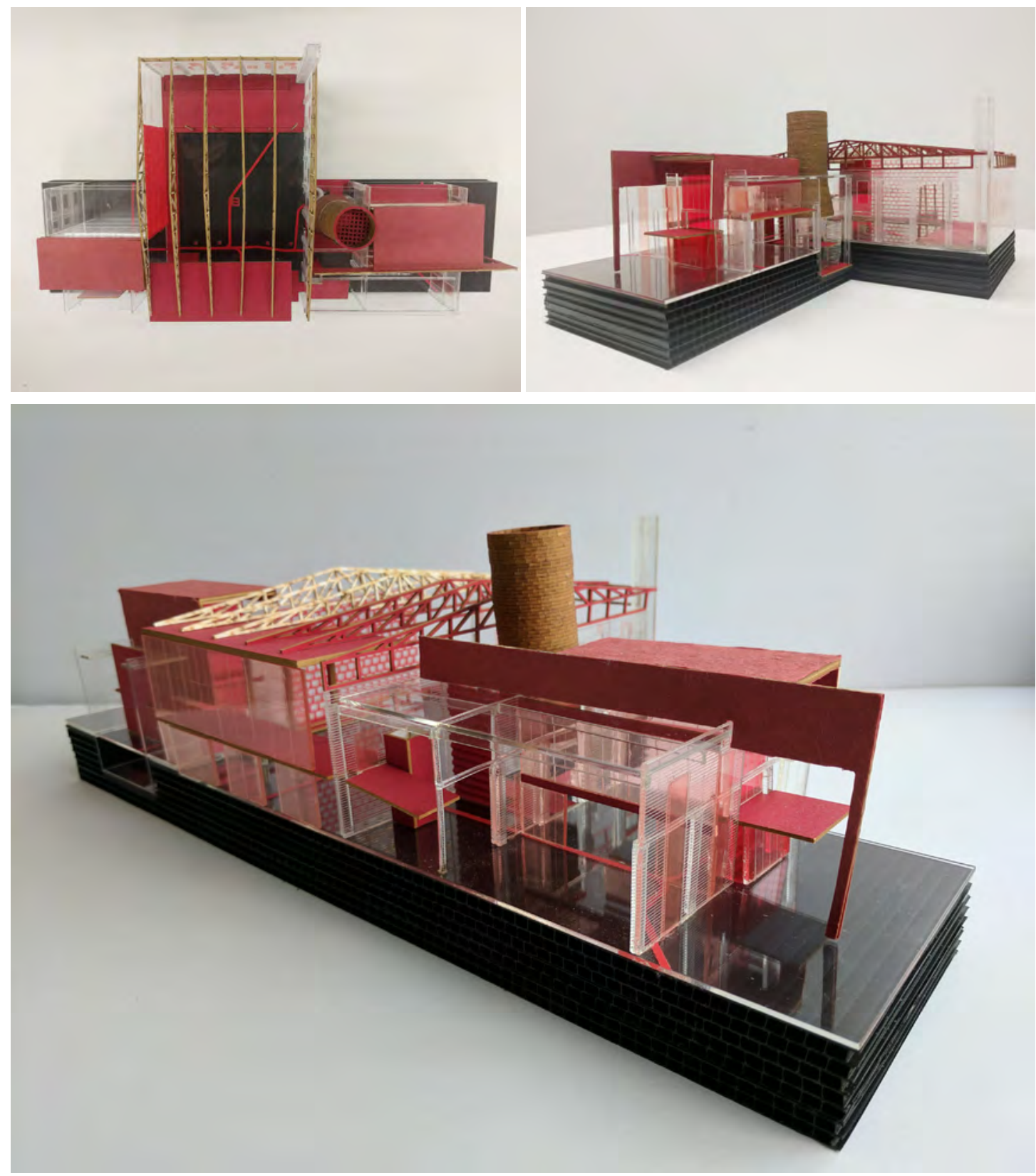

Fig.8.88 Sectional model of axial connection (red indicates new), scale 1:200 

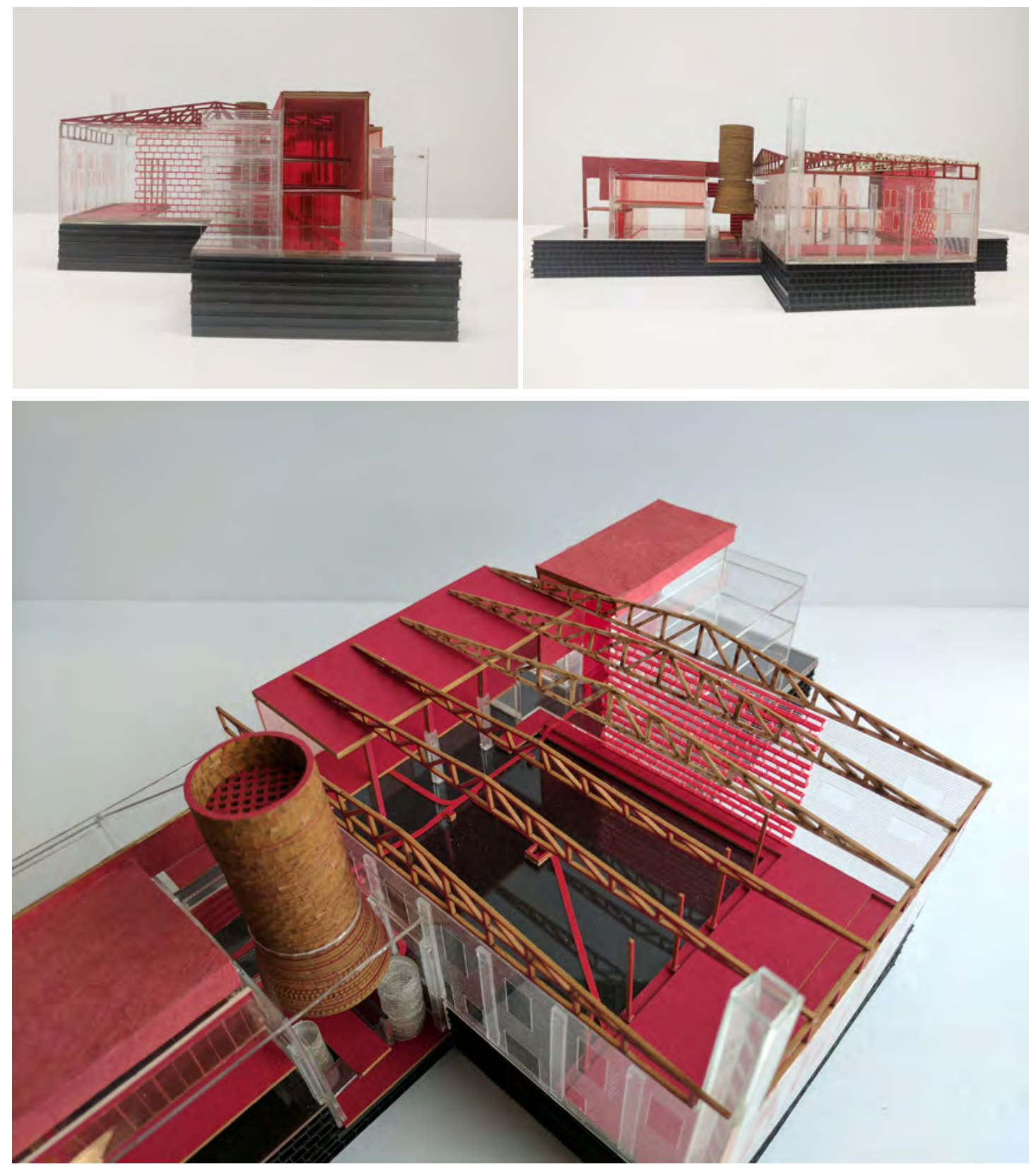

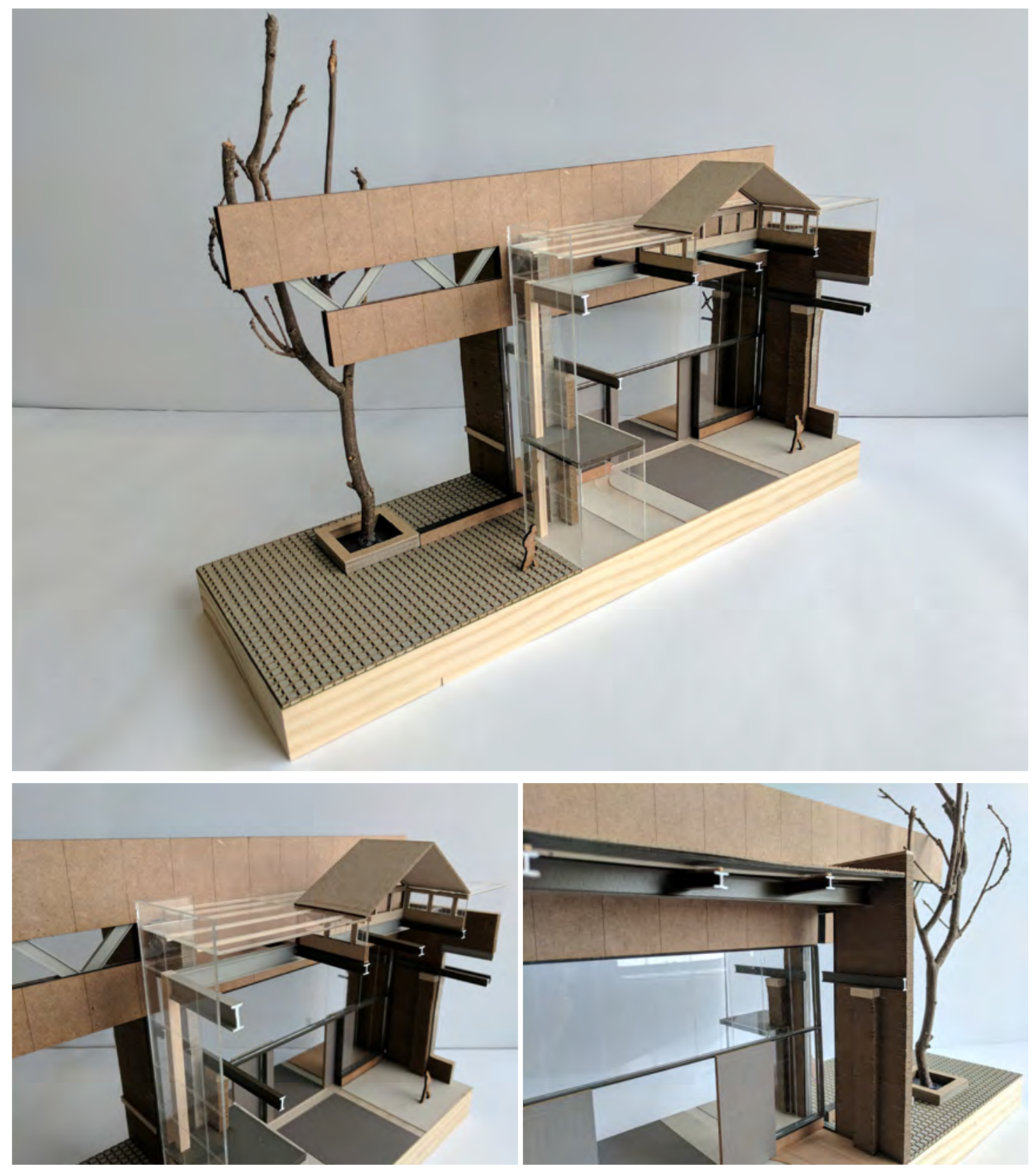

Fig.8.89 Sectional model of St. Andrew's Park entrance and lobby area, scale 1:50 

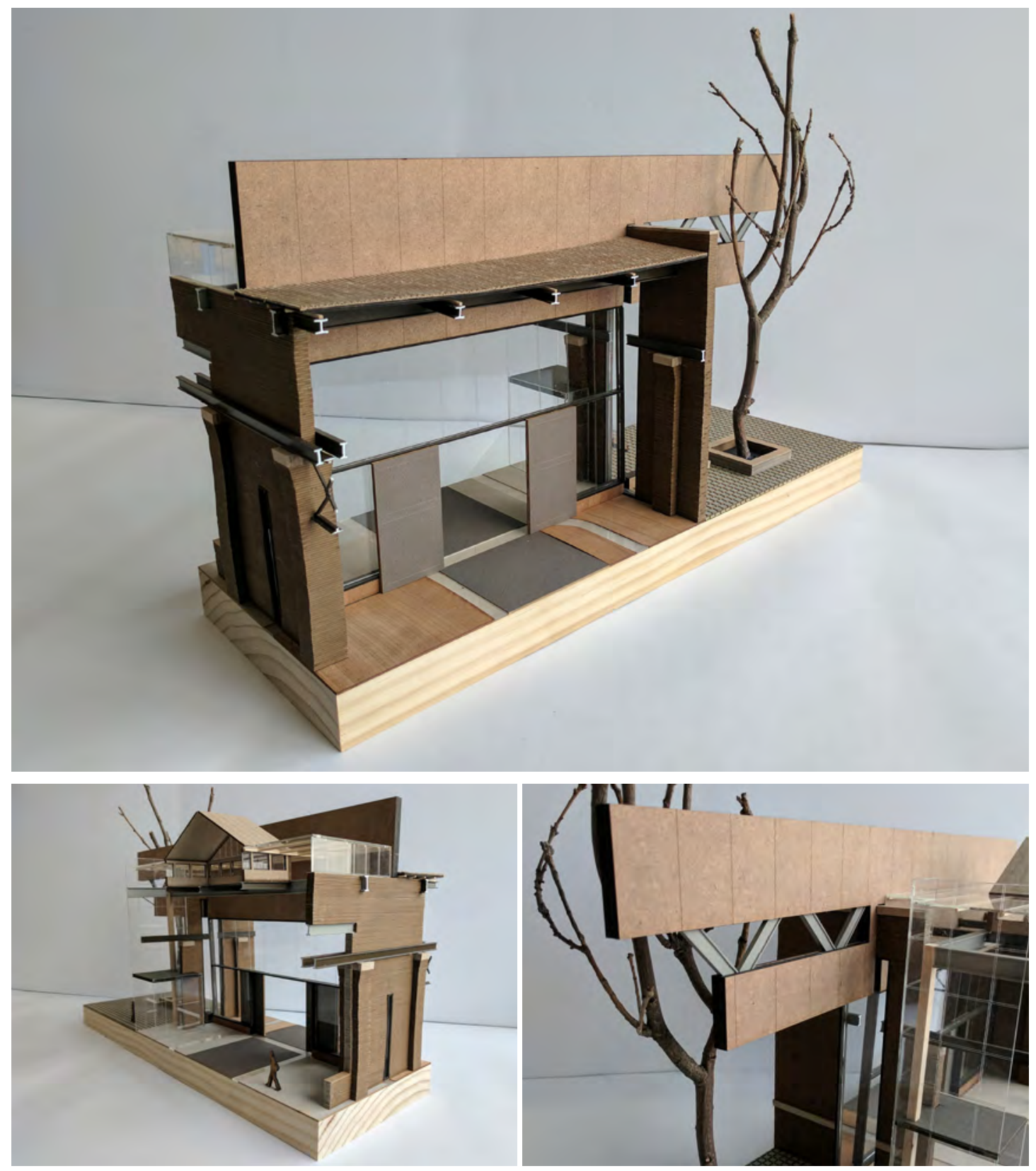


\section{Bibliography}

Brader, M. (2015, June 25). A Brief History of Transit in Toronto - Transit Toronto - Content. Retrieved April 15, 2017, from http://transit.toronto.on.ca/spare/0012.shtml

Bari, O. (2017, July 15). Three Principles of Architecture as Revealed by Italo Calvino's "Invisible Cities." Retrieved September 2, 2017, from http://www.archdaily.com/875409/three-principles-ofarchitecture-as-revealed-by-italo-calvinos-invisible-cities

Barrie, T., \& Bermudez, J. (2016). Architecture, Culture, and Spirituality. Routledge.

Bastéa, E. (Ed.). (2004). Memory and architecture. Albuquerque: University of New Mexico Press.

Bateman, C. (2016, December 9). The rise and fall and rise of St. Lawrence Hall. Retrieved April 15, 2017, from http://spacing.ca/toronto/2016/12/09/rise-fall-st-lawrence-hall/

Birksted, J. (2012). Landscapes of Memory and Experience. Taylor \& Francis.

Boles. (n.d.). Toronto Railway Historical Association. Retrieved April 15, 2017, from http://www.trha.ca/history. $\mathrm{html}$

Calabi, D. (2004). The market and the city: square, street and architecturein early modern Europe. Aldershot ; Burlington, VT: Ashgate.

Calvino, I. (1974). Invisible cities. New York, N.Y: Harcourt, Brace, Jovanovich.

City of Toronto. (2012). Staff Report: Intention to Designate under Part IV, Section 29 of the Ontario Heritage Act and Authority for a Heritage Easement Agreement - 497 Richmond Street West. Retrieved from http://www.toronto.ca/legdocs/mmis/2012/te/bgrd/backgroundfile-46666.pdf

Condello, A., \& Lehmann, S. (2016). Sustainable Lina: Lina Bo Bardi's Adaptive Reuse Projects. Springer.

Corkin Gallery. (2010, May 1). Retrieved May 16, 2017, from https://www.canadianarchitect.com/features corkin-gallery/

Crinson, M. (2005). Urban memory. Routledge.

Davey, P. (2011, July 5). "Zumthor"s Diocesan Museum shows clearly and movingly the continuity of Christian faith'. Retrieved April 5, 2017, from https://www.architectural-review.com/buildings/zumthorsdiocesan-museum-shows-clearly-and-movingly-the-continuity-of-christian-faith/8616966.article 
De Quincey, T. (1890). The Collected Writings of Thomas De Quincey: Tales and prose phantasies. A. and C. Black.

Dillon, S. (2005). Reinscribing De Quincey's palimpsest: the significance of the palimpsest in contemporary literary and cultural studies. Textual Practice, 19(3), 243-263. https://doi. org/10.1080/09502360500196227

Durkheim, É., \& Fields, K. E. (1995). The elementary forms of religious life. New York : London: Free.

Eisenman, P. (2004). Eisenman inside out: selected writings, 1963-1988. New Haven, CT: Yale University Press.

ERA Architects. (2016). The Waterworks Building: 505 Richmond Street West Heritage Impact Assessment.

Etherington, R. (2008, May 22). Caixa Forum - Herzog \& de Meuron. Retrieved May 16, 2017, from http://www arcspace.com/features/herzog--de-meuron/caixa-forum/

Freud, S. (1930). Civilization and its discontents. (T. Dufresne, Ed., G. C. Richter, Trans.). Broadview Press.

GDNA. (n.d.). About. Retrieved September 3, 2017, from http://www.gdnatoronto.org/about.html

Gladstone, B. Dark, dangerous police station in St. Andrew's Market, 1907. (2012, August 1). Retrieved April 15, 2017, from http://www.billgladstone.ca/?p=8170

Goffi, F. (2016). Time Matter(s): Invention and Re-Imagination in Built Conservation. Taylor and Francis.

Gordon, K. (2009, June 3). Farmers' market rises again | Toronto Star. Retrieved March 11, 2017, from https:// www.thestar.com/life/2009/06/03/farmers_market_rises_again.html

Halbwachs, M. (1992). On collective memory. Chicago: University of Chicago Press.

Hertzberger, H. (1991). Lessons for students in architecture. Uitgeverij 010 Publishers.

Konody, P. (2013, April 21). From the Observer archive, 21 April 1912: Venice sees its Campanile reborn. Retrieved September 2, 2017, from https://www.theguardian.com/news/2013/apr/21/observerarchive-venice-campanile-rebuilt

Lima, Z. R. M. de A. (2013). Lina Bo Bardi. Yale University Press.

Lynch, K. (1972). What time is this place? Cambridge, Mass: MIT Press.

Lyndon, D. (2009). The Place of Memory. In M. Treib (Ed.), Spatial recall: Memory in Architecture and Landscape. New York; London: Routledge.

Marot, S. (2003). Sub-urbanism and the art of memory (Vol. 8). Architectural Association. 
Marullo, F. (2011, September 10). Underground Observatories: on Marot's Palympsestuos Ithaca. Retrieved September 2, 2017, from http://thecityasaproject.org/2011/09/underground-observatories-onmarots-palympsestuos-ithaca/

Nora, P. (1989). Between Memory and History: Les Lieux de Mémoire. Representations, (26), 7-24. https://doi org/10.2307/2928520

Nora, P., \& Kritzman, L. D. (1996). Realms of Memory: Conflicts and divisions. Columbia University Press.

Palassio, C., \& Wilcox, A. (2009). The Edible City. Coach House Books.

Pallasmaa, J. (2009). Space, Place, Memory, and Imagination: The Temporal Dimension of Existential Space. In M. Treib (Ed.), Spatial recall: Memory in Architecture and Landscape. New York ; London: Routledge.

Robertson, J. R. (1974, 1896). Landmarks of Toronto; a collection of historical sketches of the old town of York from 1792 until 1833 and of Toronto from 1834 to 1895 - Scholars Portal Books. Retrieved January 10, 2017, from http://books2.scholarsportal.info.ezproxy.lib.ryerson.ca/viewdoc.html?id=/ ebooks/oca5/38/landmarkstoronto02robeuoft

Rossi, A. (1982). The Architecture of the City. (D. Y. Ghirardo \& J. Ockman, Trans.). MIT Press.

Rowe, C., \& Slutzky, R. (1963). Transparency: Literal and Phenomenal. Perspecta, 8, 45-54. https://doi org/10.2307/1566901

Schultz, A.-C. (2014). Carlo Scarpa: layers (Third, revised edition). Stuttgart: Edition Axel Menges.

Serageldin, I., Shluger, E., \& Martin-Brown, J. (2001). Historic Cities and Sacred Sites: Cultural Roots for Urban Futures. World Bank Publications.

Sharr, A. (2012). Reading Architecture and Culture: Researching Buildings, Spaces and Documents. Routledge.

Holtorf, C. (2002, May 5). Sites of Memory. Retrieved November 27, 2016, from https://tspace.library.utoronto. $\mathrm{ca} / \mathrm{citd} /$ holtorf/2.6.html

Skinner, J. (2016, October 3). Eva's Phoenix rises again in Toronto with opening of new Brant Street youth residence. Retrieved September 5, 2017, from https://www.insidetoronto.com/news-story/6886394 eva-s-phoenix-rises-again-in-toronto-with-opening-of-new-brant-street-youth-residence/

Taylor, D. (2010). The Villages Within: An Irreverent History of Toronto and a Respectful Guide to the St. Andrew's Market, the Kings West District, the Kensington Market, and Queen Street West. iUniverse.

Taylor, D. (2015, September 28). Plans for Waterworks Building at 505 Richmond Street West. Retrieved January 26, 2017, from https://tayloronhistory.com/tag/waterworks-buildings-toroonto/

Verheij, R. (2015). Palimpsest in Architecture, Six Personal Observations. Delft University of Technology. 
Williams, R. J. (2009). Brazil: Modern Architectures in History. Reaktion Books.

Yates, F. A. (1966). The art of memory. Chicago: University of Chicago Press.

Yu, S. (2016, November 17). Waterworks condo project taps a well of possibilities. Retrieved March 20, 2017, from http://www.theglobeandmail.com/real-estate/toronto/waterworks-condo-project-taps-a-wellof-possibilities/article32871421/

Zeballos, C. (2012, April 24). Peter Zumthor: Kolumba Museum, Cologne. Retrieved December 1, 2016, from http://architecturalmoleskine.blogspot.com/2012/04/peter-zumthor-kolumba-museum-cologne. $\mathrm{html}$

\section{Works Consulted}

Bartonoli, Paolo. 2006. Memory in Language: Walter Benjamin and Giuseppe Ungaretti in Literature and Aesthetics. 145-16

Bailey, G. (2007). Time perspectives, palimpsests and the archaeology of time. Journal of

Boyer, M. C. (1994). The city of collective memory: its historical imagery and architectural entertainments. Cambridge, Mass: MIT Press.

Claessens, F. (2006). Reinventing Architectural Monumentality. OASE 71 Urban Formation and Collective Spaces, (71).

Eisenman, P., Bédard, J.-F., Balfour, A., \& Canadian Centre for Architecture (Eds.). (1994). Cities of artificial excavation: the work of Peter Eisenman, 1978-1988. Montréal : New York: Canadian Centre for Architecture ; Rizzoli International.

Huyssen, A. (2003). Present pasts: urban palimpsests and the politics of memory. Stanford, Calif: Stanford University Press.

Kähler, G. (2014). On Old Foundations: Building in a historical context - von Gerkan, Marg and Partners Architects. (V. Marg, Ed.). Munich ; Hamburg: Dölling Und Galitz Verlag.

Lowenthal, D. (1985). The past is a foreign country. Cambridge, [England]: Cambridge University Press.

Murphy, R. (1991). Carlo Scarpa and the Castelvecchio. London ; Boston: Architectural Press.

Wigley, M. (1999). The architectural cult of synchronisation. The Journal of Architecture, 4(4), 409-435. http://doi.org/10.1080/136023699373783 http://journals2.scholarsportal.info.ezproxy.lib.ryerson.ca/details/13602365/v04i0004/409_tacos. $\mathrm{xml}$ 
